\title{
The Moral Fibre: Hemp-Based Building Industry Supplied by Sustainable Permaculture Communities
}

\author{
by \\ Lysander C. Zimmerman
}

A thesis submitted to the Faculty of Graduate and Postdoctoral Affairs in Partial fulfillment of the requirements for the degree of

\author{
Master of Architecture \\ in
}

Architecture

Carleton University

Ottawa, Ontario

(C) 2016, Lysander C. Zimmerman 


\section{ABSTRACT}

In our world of globalized capitalism, the threats to vital ecosystems worldwide are innumerable. Unchecked urbanism, irresponsible industrial agriculture, deforestation, unethical logging practices, petrochemical hegemony, freshwater pollution, air pollution, automobile dependency, centralized economics and indifference towards viable alternatives are just a few of the most alarming human actions that continue to imperil the ecological health of our Earth.

Despite the spread in environmental movements and the proliferation of recent scientific studies on anthropogenic ecological degradation, weak environmental policies remain the norm for the majority of world nations, cities and municipalities. Alternative models, practices, technologies and energies continue to occupy the fringes of our society. Yet, many such efforts to improve the relationship between humans and Nature offer real potential for reversing the present destructive dynamic and are still relatively unknown and ignored. One prime example is the holistic approach to agriculture, community, ecology and economics referred to as permaculture.

In this thesis, urban community planning, agroecology and architecture are united in a detailed proposal to repurpose 260 hectares of Ottawa's 375-hectare Central Experimental Farm as an urban-suburban model for highly-sustainable residential and 
agricultural projects. The title of this envisioned project is, The Ottawa Permaculture Initiative (OPI).

By imagining an economically-decentralized and eco-centric farming community that infiltrates a typical metropolitan environment, a subversive vision of a functioning alternative to our present urban paradigm is presented. Planned and designed to incorporate some of the most ecologically-sound agricultural techniques (as opposed to traditional monoculture and chemical-based industrial agriculture), the main yield crop would likewise be one of the most versatile and sustainable plants known today: industrial hemp (Cannabis sativa). The primary intended use for this crop would be twofold: provide high-grade organic plant fibres for research and development into novel building materials-structural biocomposites to replace wood and petrochemical-based plasticsas well as to supply existing hemp-based building product markets. 


\section{ACKNOWLEDGEMENTS}

First and foremost, I would like to express my profound gratitude to my advisor, Dr. Federica Goffi, for her constant encouragement, insight, open mind, direction, continued patience, and, above all, her devotion to her students-someone who embodies all of the qualities of a true academic and mentor. The project may not have been possible without her supervision.

At the Azrieli School of Architecture, I would like to give my thanks to professors Manuel Baez and Larry Hately, whose comprehensive Building Technology courses and equally distinct approaches to the field helped galvanize my continued interest in architectural engineering and the building sciences. For his rare intellect, Dr. Claudio Sgarbi deserves my sincerest thanks for rekindling my interest in philosophy and stimulating my understanding that architecture can be equally driven by theoretical consciousness as it is by applied intellect. To Professor Yvan Cazabon, my first formal teacher of the craft, I give thanks for introducing me to architectural representation and the critical-iterative design process. In the administration, I would like to thank Director Jill Stoner for her help and encouragement; to the graduate coordinator, Ewa Mroz, I offer my appreciation for always having an open door to offer her administrative aid and support, even at her busiest hours. To my friend and colleague, Meria Faidi, I would like to

extend my gratitude for her encouragement, advice and support when it was most needed over the course of my degree. I would also like to thank the external examiner, Linda 
Dicaire, for introducing me to the concept of cultural landscapes, which has enriched my understanding of heritage values.

Lastly, I would like to thank the British Café, in Aylmer, Quebec, for providing the ideal atmosphere for study and design, and its staff for tolerating my near-constant presence over the past year and a half, where several of my projects were started and completed-including this thesis. 


\section{DEDICATION}

This project is dedicated firstly to Nature, the universal teacher, healer and lifeprovider, in all her wonders, mysteries and beauty, who gives humanity our home, sustenance, spirituality and reason for existence. A steadfast devotion to giving back to Nature should forever be our collective purpose as a species.

Secondly, I dedicate this to two of permaculture's forefathers, Bill Mollison and Toby Hemenway, whose recent losses on September $26^{\text {th }}$ and December $20^{\text {th }}$ of 2016 , respectively, demonstrated the essential importance of keeping this dream alive, of spreading their message of hope and practical wisdom to the world. In particular, the pioneering work of Mollison stands as the most comprehensive and profound individual contribution to the permaculture movement. His work will be conveyed as long as agroecology bears fruit.

Most importantly, this thesis is dedicated to the Standing Rock Lakota Sioux and their fellow Water Protectors, for placing their bodies and lives on the line to staunchly oppose the Dakota Access Oil Pipeline and the general threat of callous corporate indifference to the Earth's life-support systems. My solidarity also extends to social justice, anti-war and environmental activists everywhere; in particular, to indigenous defenders of Nature across the world, whose combined selfless resistance efforts-in spite of facing 
centuries of oppression, repression and extermination campaigns-should stand as an example to all humanity.

Lastly, I dedicate this work to my father, Arthur, and my departed mother, Monique, to both of whom I owe everything from my love for the natural world, to my appreciation of knowledge and culture, to my quest for philosophical consciousness; most of all, from whom I inherited the spirit of resistance, empathy and Universal Love. Moreover, without my father's continued support and encouragement, this project would not exist. I am eternally grateful to both for always placing my education and struggles above all else in their lives. And wherever your spirit now roams, Mother, I hope these words somehow reach you. 
«Si deve parlare di lotta per una nuova cultura, cioè per una nuova vita morale che non può non essere intimamente legata a una nuova intuizione della vita, fino a che essa diventi un nuovo modo di sentire e di vedere la realtà... "

"We must speak of the struggle for a new culture, that is, for a new moral life which cannot fail to be intimately linked to a new intuition of life, until it becomes a new way of feeling and seeing reality..."

- Antonio Gramsci - 


\section{TABLE OF CONTENTS}

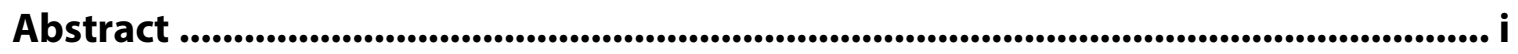

Acknowledgements ........................................................................................................... iii

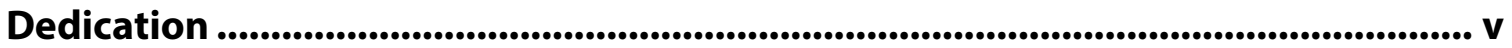

List of Figures .............................................................................................................................................. xiii

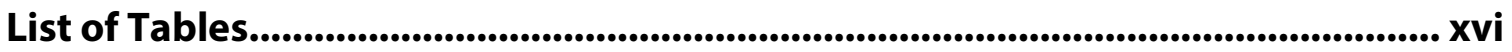

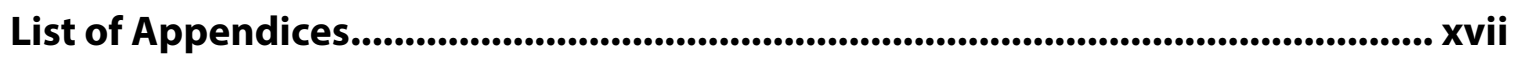

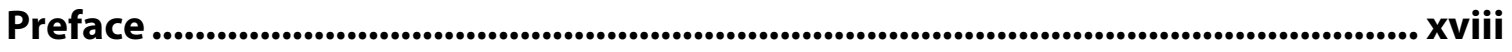

1. Chapter: Urban and Suburban Permaculture .................................... 1

1.1. Principles and Philosophy........................................................................ 2

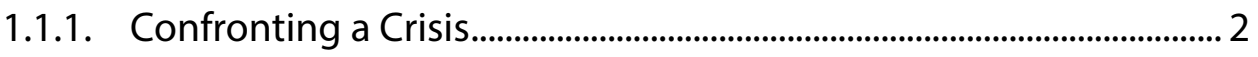

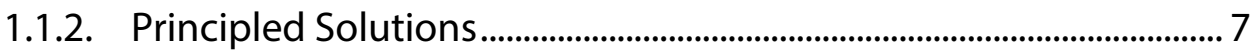

1.1.2.1. Ethics, Principles and Insights .................................................... 7

1.1.2.2. Indigenous Inspiration ....................................................................... 16

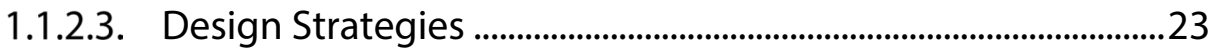

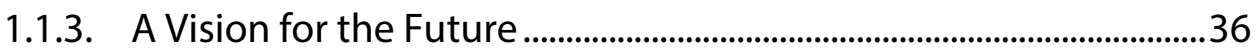

1.1.3.1. Urban Permaculture and Ecovillages................................................36

1.1.3.2. The Ottawa Permaculture Initiative ................................................42

2. Chapter: Sustainable Yield Crops: Cannabis as Moral Fibre............ 48 
2.1. Building Products

2.1.1. Hemp-Lime Biocomposites

2.1.2. Insulation Materials

2.1.3. Structural Building Materials and HFRPs

2.1.4. Hemp-Reinforced Structural Concrete

2.2. Nutraceutical and Holistic Medicine .63

2.3. Legalization Trends

2.4. Bioremediation (Phytoremediation) 67

2.5. Cannabis and Permaculture. 69

3. Chapter: Ottawa's Central Experimental Farm ............................. 71

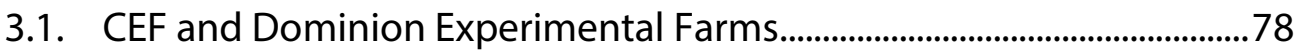

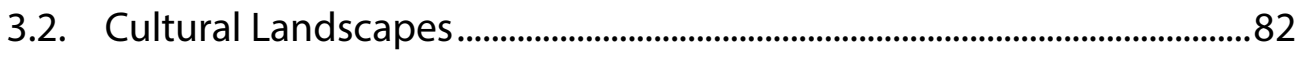

3.2.1. The Central Experimental Farm National Historic Site Management Plan 82

3.2.1.1. Associative Landscapes .83

3.2.1.2. HSMP Recommendations .86

3.2.2. Disturbance and Succession: A [R]evolved Cultural Landscape.87

3.2.2.1. Shared landscapes: OPI and CEF's HSMP .87

3.2.2.1.1. Mutual Objectives. 88 
3.2.2.2.1. Conflicting Value Systems . .92

3.2.2.3. Criticism of the HSMP for CEF 100

3.2.2.3.1. Rectilinear Fragmentation 100

3.2.2.3.2. Forgotten Landscapes 103

3.3. Site Analysis.

3.3.1. Site Geography 113

3.3.2. Land Use Patterns 116

3.3.2.1. Zoning 116

3.3.2.2. Surrounding Land Use Areas

3.3.3. Climate and Natural Forces.

3.3.3.1. Microclimate 124

3.3.4. Site Ecology, Geology and Agronomy. 126

4. Chapter: Planning the Ottawa Permaculture Initiative . 134

4.1. Praxis Diagram: New Directions for the CEF 134

4.1.1. Urban Ecosystem 140

4.1.1.1. Reforestation 141

4.1.1.1.1. Zone Buffering . 142

4.1.1.1.2. Wildlife Habitat 143 
4.1.1.1.3. Forest Gardening \& Alley Cropping ...

4.1.1.2. Infrastructure

4.1.1.2.1. Constructed Water Features

4.1.1.2.2. Stormwater Management

4.1.1.2.3. Wastewater Management

4.1.1.2.4. Building Placement

4.1.1.2.5. Solar Energy Harvesting.

4.1.1.3. Sustainable Sustenance: Crops and Market Gardens. 159

4.1.1.4. Intercropping Industrial Hemp and Medical Marijuana ..... 163

4.1.2. Human Habitat and Activity 165

4.1.2.1. Communal and Quasi-Atomic Communities 165

4.1.2.2. Practice and Education 169

4.1.2.3. Eco-Tourism 170

5. Chapter: Permatecture: Permaculture Meets Architecture 171

5.1. Design Considerations 171

5.1.1. Natural Daylighting, Sun Path and Building Design 174

5.1.2. Earth-Integrated and Crop-Integrated Architecture 179

5.1.3. Rainwater Harvesting 182

5.1.4. Envelope Systems and Materials ...... 183 
5.1.4.1. Transforming Dual-Skin Façade.

5.1.4.2. Engineered Glue-Laminated Lumber.

5.1.4.3. Reinforced Concrete 188

5.1.4.4. Stabilized, Reinforced and Insulated Rammed Earth 189

5.1.4.5. Stainless Steel Roofing 194

5.2. Community Complex Plans.. 196

5.2.1. Community Space 199

5.2.1.1. Community Kitchens 204

5.2.1.2. Drum Circles 205

5.2.1.3. Needs-Based Space Allocation 206

5.2.2. Indoor Winter Gardens 207

5.2.3. Residential Units 209

5.3. Single-Family Residential: Earth-Sheltered Berm Housing 215

Discussion and Conclusions

Final Thoughts 230

References... 232

Appendices 248 


\section{LIST OF FIGURES}

Figure 1: Permaculture wheel used for zoning analysis and planning.

Figure 2: Logo for the Ottawa Permaculture Initiative.

Figure 3: Transverse and longitudinal sections showing components of cannabis stem..... 50

Figure 4: Google Earth aerial view of propsed OPI site and reserved area for CEF. 73

Figure 5: Google Earth aerial perspective of proposed OPI site, looking north. .73

Figure 6: Surrounding area - Dow's Lake, Rideau Canal, Arboretum and Carleton University. 74

Figure 7: Surrounding area - relation to downtown core 74

Figure 8: Surrounding area - relation to Rideau Waterway system and the Ottawa River.............................75

Figure 9: On Morningside Lane, looking east towards Prince of Wales Dr. and Carleton University............75

Figure 10: View from Cow Lane, near Ash Lane, looking northwest toward NCC Scenic Driveway.............76

Figure 11: View from Morningside Lane, near Cow Lane, looking northwest toward Fisher Ave. ................76

Figure 12: View from Cow Lane, looking towards the Canada Agriculture and Food Museum at CEF........77

Figure 13: Map of CEF (provided by Agriculture and Agri-Food Canada).................................................77

Figure 14: photograph of metal plaque at the corner of Maple Dr. and NCC Scenic Driveway..................... 80

Figure 15: Average temperature and precipitation graphs for on-site weather station (CDA) ....................119

Figure 16: Average wind speeds, directions and temperatures for CDA from 02/2012 to 12/2016 [113]....121

Figure 17: Seasonal wind direction distribution percentage for CDA from 02/2012 to 12/2016. 122

Figure 18: Summer versus winter storm patterns for Ontario and Eastern Canada...................................123

Figure 19: Approximate seasonal sun paths over OPI site; site depicted in "seasonal colours". .124

Figure 20: Topographical contours of the CEF and immediate surrounds.

Figure 21: 3D drainage simulation; from Google Earth topography data................................................133

Figure 22: Praxis Drawing (Master Plan) of the Ottawa Permaculture Initiative (OPI)...............................138

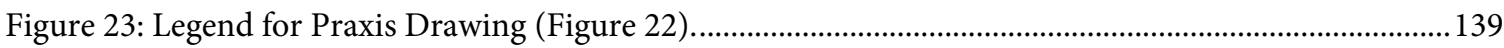


Figure 24: Perspective of Community Complex's south-facing side.

Figure 25: Walk above communal kitchen (under construction) 177

Figure 26: Glulam 'Giant Oak Tree' in Winter Gardens (under construction). 177

Figure 27: View of entrances to units in communal kitchen and on mezzanine... 178

Figure 28: "Eye-shaped" atrium roof under construction....... 178

Figure 29: Perspective of the Community Complex’s north-facing “quasi berm-sheltered” construction.. 180

Figure 30: Top view of north side (or rear) of Community Complex. 181

Figure 31: STCBS applied to parabolic compound curvature; shutters in open position. 185

Figure 32: STCBS applied to parabolic compound curvature; shutters in closed position. 186

Figure 33: Plan for Level 1 of the Community Complex.

Figure 34: Plan for Level 2 of the Community Complex. 201

Figure 35: Plan for Level 3 of the Community Complex. 202

Figure 36: Plan for Winter Garden Modules and Communal Kitchens. 203

Figure 37: East-west section (from right to left). 211

Figure 38: North-south section (from right to left).

Figure 39: Model large family dwelling unit; total living space is $165 \mathrm{~m}^{2}\left(1776 \mathrm{ft}^{2}\right)$.

Figure 40: Model small bachelor/student dwelling unit. 214

Figure 41: Solar-Thermal Control Barrier System (STCBS@), preliminary design. 249

Figure 42: 'DETAIL A' (from Figure 41 ) - STCBS@ in both open and closed positions. 250

Figure 43: SCTBS@ close up detail of insulated louver. 251

Figure 44: STCBS@ in winter operation with peak solar gain; partial glare control (open louvers).............252

Figure 45: STCBS@ in winter operation for extreme cold outside; total glare control (louvers closed).......253

Figure 46: STCBS@ in summer operation, stack effect cooling; total glare control (louvers closed) 254

Figure 47: STCBS@ applied to dual-skin glazed facade and dual-skin glazed roof concept. 255 
Figure 48: 'DETAILS A, B, \& C' from Figure 46.

Figure 49: A 'typical' application of STCBS@ in a high-performance dual-skin envelope system................257

Figure 50: STCBS insulated louver system (cavity components) shown without glazing skins....................258

Figure 51: STCBS $\odot$ mechanical components and 'typical' IGU-fixing system..........................................258

Figure 52: STCBS $\odot$ with original dual-skin ventilated roof and wall envelope system................................259

Figure 53: STCBS $\odot$ limitations discussion and system perspective. ............................................................260 


\section{LIST OF TABLES}

Table 1: Temperature averages for the years 1981-2010, taken at CDA......................................................120

Table 2: Precipitation averages for the years 1981-2010, taken at CDA.........................................................121 


\section{LIST OF APPENDICES}

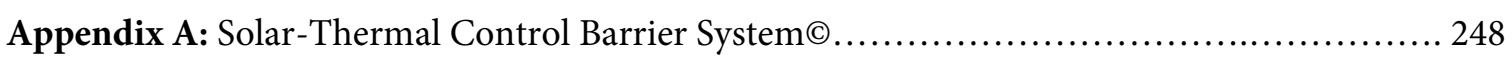




\section{PREFACE}

We are Nature. We are from Nature; when we die, we return to Nature. Yet, it has become our nature to attack, devastate, take from, discard into, and forsake the very nature that brought us into being, that must sustain our being. Philosopher Jean-Paul Sartre wrote that, "once cast into the world", man "is responsible for everything he does" ${ }^{1}$. And if human beings are at once condemned to freedom-free to choose how we relate to each other and to Nature-and condemned to confront this freedom in a world largely pre-determined by our historical reality, then why do we continually choose to condemn ourselves and our world to this mechanism of destruction? Why do we not choose a path of liberation over serialization, harmony over dissonance, mutualism over parasitism, equality over class stratification and cooperative participation over alienation? Have we allowed ourselves to become so alienated in civilization and outside of Nature, that our survival in this universe is fundamentally threatened by our action upon the world? Have we become hostile aliens in our own world?

When Karl Marx wrote that, "man is alienated from his species-life ... that each man is alienated from others, and that each of the others is likewise alienated from human life" 2 , could he foresee the eventual and pervasive consolidation of this social estrangement in

\footnotetext{
${ }^{1}$ From Existentialism Is a Humanism by Jean-Paul Sartre [204].

${ }^{2}$ From Economic and Philosophical Manuscripts of 1844 by Karl Marx [205].
} 
both the superstructure and infrastructures of the "postmodern" capitalist world? Over the course of the century and a half that followed his contribution to political philosophy, we find the manifestation of this condition in nearly every aspect of human activity. The atomization and stratification of society is reflected in our built environment. Our mode of existence has been overtaken by the external forces of alienation, from our daily work activities in capitalism to the singular and unitized dwelling spaces that shelter and separate us from the natural world. We have been conditioned to demand private property and personal luxuries at the expense of a cooperative and mutual responsibility to each other, to our species as a whole and to its only true source of life: Nature.

If Marx's statement is correct, that "in the type of life activity resides the whole character of a species, its species-character"', then what is to be said of the human race at this particular moment in history? To question the notion of "progress" is to question the core of what we have become as a species. And it would appear that our relationship to the environment is now parasitical, at best; one may even argue that we have become the universal predator, with everything, even the world we inhabit, as our prey. Our hunting grounds know no bounds within the vast confines of Earth. We have built ourselves a gigantic machine-a rolling abattoir-and it traverses the continents slaughtering anything in its path, scouring the land, transforming natural earth elements into fuel and raw

\footnotetext{
${ }^{3}$ From Economic and Philosophical Manuscripts of 1844 by Karl Marx [205].
} 
materials for our urbanized world; behind this psychopathic machine undulates the wake of perpetual growth. The machine is hungry and it must be fed incessantly, to provide for its continual and nonsensical self-replication.

For the sake of financial empires and unmitigated "progress", we have let nothing stand in our way as we raze and burn some of the most diverse and rare ecologies on Earth. The rainforests, as an example-teeming with life, concealing secrets unknown, medicinal cures, unique species of flora and fauna-are treated like mere objects of humanity's monetary interests and governmental policies. What may have taken thousands, perhaps hundreds of thousands of years (or more) to evolve and diversify, are callously and savagely attacked by the machinery of capitalism, to feed the gluttonous global markets. This cataclysmic policy has been given the euphemistic name of "globalization", and sold to the world as an inevitable stage in the evolution of our species; a process, we are told, is to be welcomed with open arms or, at the very least, to be accepted passively as our fate, for better or for worse.

As our built world expands with logarithmic intensity-like an uncontrollable force of Nature yet, paradoxically, in opposition to Nature-we are evermore duped by the reflection of our god-like image in our awe-inspiring towers of glass and steel. Creative insight has been supplanted by an unquenchable egoism and maniacal individualism. We have forgotten our past and forsaken our future, while we allow our present to be hijacked by a fanatical globalized economic policy intended to entrench the control of an elite few 
and further alienate the will of our species-being. Has the architect become a simple instrument of this financial power? Has the vain quest for personal glory become architecture's principal raison d'être, laying waste to the artist's greater responsibility, reducing that spirit of creation to a mere commodity to be bought and sold on the global markets? Has architecture renounced its species-responsibility? If this is the general condition, then how can responsible architects engage their freedom and sense of responsibility to correct the wrongs of the past and present generations, so that generations of the future will still have a world to live in and, most importantly, to live for?

As humanity moves forward and confronts the coming crises of the $21^{\text {st }}$ Centuryour collective future-will the response simply involve a blind application of "sustainable technologies" within the current system, without any fundamental change? Can new technology itself-perhaps a main culprit in the making of this era of uncertainty-be applied in the same reckless manner without producing more of the same disastrous consequences? Can it truly be our only saviour? Or do we also have to look to the past for guidance and wisdom?

One of the greatest crimes in recorded History was the destruction wrought by European settlers on the native populations of the Americas. For thousands of years, these great cultures existed in near-perfect harmony with their natural environments. They taught a deep respect to all things, for they saw the life in all matter that constitutes the 
Earth. And for these so-called "savage" and "godless" ways our ancestral settlers and their ruthless armies did their utmost to wipe them from the face of the world, disregarding their words of wisdom, warnings and gestures of peace. In doing so, two great crimes against humanity were committed: first, the genocide and cultural decimation, then the dismissal of their way of life, which could have perhaps shown the displaced savages of the "old countries" a surefire way of creating harmony with their natural surroundings. The second great crime, of course, was against Nature and, unknowingly, against their very own future generations.

Of course, we North Americans are the offspring of these great crimes and it is no wonder why this era finds itself at the cusp of a great turning point. Our choices will determine whether we are accomplices or the bastard children of a savage legacy, free to remake ourselves in this realm of possibility we call Time. Perhaps the reclaiming of our humanity will require that we look back and begin to heed the warnings of the longtime dead. To progress, sometimes we need to digress, even retrogress, so that our path forward is elucidated by the grievous errors of our past. Sartre called this the regressive-progressive 
method, which involves embracing the dialectic between past, present and future, to comprehend how history is perpetually totalized in the moment of the present. ${ }^{4}$

When we do look to the past, we find that the success of those multifaceted native tribes-some agrarian, some hunter-gatherer-was derived from their understanding of symbiotic relationships within their habitats. They learned, over the course of an untold number of eras, the secrets of Nature with its predator-prey and symbiotic relationships. This deep understanding of ecosystems formed the basis of their spirituality, their oral traditions, their social interrelations and most importantly, their daily lives.

The present day's attempt to revive and reapply many of these principles is called "permaculture".

${ }^{4}$ This concept was first introduced in, Search for a Method, published separately as the introduction to Critique of Dialectical Reason (1960). While possessing many layers of complexity developed in great detail in the latter work, here it is applied in its basic form:

"This means that we must never yield to simplifications based wholly on techniques or consider social conditions to be conditioned by techniques and tools in a context peculiar to themselves alone. Aside from the fact that traditions and history...intervene at the same level of work and needs, there exist other material conditions... which reciprocally condition techniques and the real level of life....The point is to subordinate nothing a priori.... On these terms nobody can any longer criticize the Marxist interpretation as being incompletely "determining"; it is sufficient in fact that the regressive-progressive method take into account at the same time the circularity of the material conditions and the mutual conditioning of the human relations established on that basis....In this prospective form, with its absence of theoretical foundation and the precision of its auxiliary method-research tests, statistics, etc. - sociology, a temporary moment of the historical totalization, discovers new mediations between concrete men and the material conditions of their life, between human relations and the relations of production, between persons and classes (or some totally different grouping)" [206]. 


\section{CHAPTER: URBAN AND SUBURBAN PERMACULTURE}

"Permaculture is revolution disguised as organic gardening." - Mark Feingold ${ }^{5}$

Permaculture is a system of ethics, principles and design processes based on the ecology of living systems that draws on both traditional and scientific knowledge to reintegrate human society back into Nature. The ethical model includes a recognition of the dialectical relationship of humans to the earth and to each other. As such, it can be argued that it is inherently anti-capitalist and tends towards a more communal and socialistic application of sustainability principles, which recognizes that individual needs are universal throughout our species and cannot be separated from the natural processes of the physical world.

As a system that can be applied to many physical or social systems, it is theoretically highly scalable, although not intended nor suitable for commercial profiteering operations. In agriculture, it can be practiced as a single rural- or urban-residential garden, or can be implemented as a holistic organic farming practice. In design, it can be used to plan an individual property or an entire community. As a movement, it has the potential to become a working alternative economic model based on barter or ethical monetary trade. Master planning an envisioned permaculture community thus becomes an act of dissent, a

\footnotetext{
${ }^{5}$ Mark Feingold quoted in Do It Yourself: A Handbook for Changing the World [207].
} 
promotion of models for better living, in an age so badly in need of an escape plan-a way out of the highly-centralized global market system and a prospect for a better world.

\subsection{PRINCIPLES AND PHILOSOPHY}

\subsubsection{CONFronting A CrisIS}

We are living in a utopian moment. The majority of humans are already being negatively affected by a number of coupled social and environmental crises. These conditions are created in large part by hegemony of thought and practice that ontologically separates humans from nature, rationalizes the externalization of the social and environmental costs of production and consumption, justifies extreme inequality, and sees solutions only in a continuation of the same systems that generated the problems in the first place. Together, these and other problems constitute a crisis that demands imaginative responses and viable alternatives [1].

As defined by its originators and pioneers, Bill Mollison and David Holmgren, the

term, "permaculture", refers to "an integrated, evolving system of perennial or selfperpetuating plant and animal species useful to man...a complete agricultural ecosystem." [2] It is a self-sustaining method of agroecology intended for nearly any climactic zone, which promotes a working and viable alternative to the current environmentallydevastating agribusiness model. However, as an alternative, it emphasizes a philosophy of holistic change, rather than futile attempts to recuperate a fundamentally-flawed and illfated corporate agronomic system. Indeed, the intent to "improve extant agricultural 
practices" worldwide is clearly affirmed by Mollison and Holmgren in the introductory comments to Permaculture One. But this improvement takes the form of a new lifestyle, "where regional self-sufficiency is more important than cash cropping for export, or monoculture for commercial gain" [2].

This renewed agroecological approach to living, one that espouses a rejection of current large-scale agricultural practices, is perhaps self-explanatory to some; however, many will wonder why such a radical change would be desirable in our age of science and high-technology. Yet, even a cursory examination of the evidence against high-tech industrial agribusiness reveals that such a drastic change is no longer simply desirable; evidently, it has become imminently critical.

As the world's population continues to rise, it is reported that per capita food production is actually in decline. Between 1960 and 2007, the number given by the United Nations Food and Agriculture Organization (FAO) has decreased by over half, from 0.5 to 0.23 hectares of farmland per person. Add to that the U.S. Census Bureau's prediction that Earth's total population will reach 9.5 billion by 2050, along with the Intergovernmental Panel on Climate Change (IPCC) forecast for the Earth's average temperature rising by 1.8 to 4.0 degrees Celsius by 2100 [3], and the origin of a worldwide crisis begins to emerge.

Food security for both developing and developed nations will thus be negatively impacted. The long-term effect of climate change and climate instability on crops is 
expected to result in yield declines, increased weed and pest damage, increased prices for staple food harvests, decreased revenues for agricultural communities and an estimated 20 percent increase in child malnutrition by 2050 [3]. This scenario merely describes the direct impact on human systems, while associated ecosystem decline is feared to compound the problem.

To make matters even worse, present-day agricultural practices create a plethora of ecological pressures that alone pose veritable threats to biodiversity. Because of monoculture-based growing, combined with rapidly-increasing urban populations that rely almost exclusively on rural food production, Earth's forests and other sensitive natural habitats are declining at scales inverse to population growth. As a point of clarification, the United Nations reports that as of 2007, the total number of world urbanites exceeded rural inhabitants for the first time in history. By contrast, in 1950, when the world's population totalled only 2.5 billion, over two-thirds ( 1.75 billion people) lived in rural areas. This trend is forecasted to continue with only one-third of the Earth's projected 9.5-billion population (3.1 billion people) living rurally by 2050 [4]. To put these numbers in perspective, one must consider the fact that almost 40 percent of the continental natural world has already been transformed into agricultural land. By 2100, commercial agriculture will have consumed approximately 60 percent of Earth's land area [3], leaving only 40 percent to divide between natural habitat and human settlement. And for that 60 percent lost to agriculture, there is a further loss of area biodiversity due to ecosystem simplification, 
resulting in a reduction in "ecosystem services". Ecosystem services are, as the term implies, services provided by ecosystems that benefit larger ecologies, including human habitations and, ironically, agricultural practices. These include water cycles, water purification processes, pollination, topsoil preservation, nutrient cycles, nitrogen fixation and atmospheric carbon sequestration [3]. When these essential natural cycles are imperiled, not only are ecosystems put at risk of collapse, but so is human food production.

How modern agriculture destroys natural ecosystems is no mystery. To begin with, vast land areas are stripped of almost all their natural organisms, planted with single-variety crops (now often genetically-modified strains), fed with chemically-derived fertilizers, sprayed with toxic herbicides, pesticides and fungicides, worked over by massive soilcompacting diesel-powered machines and often irrigated by artificially-diverted natural watercourses.

Each and every one of these deleterious practices poses a host of alarming concerns. When combined as a system, they unite to produce serious threats to the environment: pollution of watersheds, watercourses, large waterbodies and groundwater; food contamination from antibiotics, pesticides and chemical fertilizers; food-chain toxicity in natural habitats; air pollution from greenhouse gases, ozone-depleting chemicals, ammonia, etc.; exhaustion of natural resources; topsoil destruction, compaction and erosion through mechanical disturbance; and the killing of beneficial organisms that aerate soils, compost organic matter (earthworms), transform soil elements into bioavailable 
nutrients (symbiotic microorganisms), pollinate flowering plants (bees and other pollinators) and many additional constituent members of healthy ecosystems [3]. It is important to add that this list is by no means comprehensive. The negative impact of energy-intensive farming reaches well beyond the farmland and its immediate surrounds.

The vicious circle is complete once genetically-modified crops are added to the equation, for not only do they attempt to simplify the problem and erroneously reduce it to perceived genetic weakness in natural plant varieties, but can be linked to the destruction of crucial soil microbiota and other organisms [5] [6]. They do so through a number of various direct and indirect mechanisms, but the most alarming is a result of their intended function, as "super-strains" that produce high-yields in inhospitable soils and under adverse conditions, thus allowing reckless agribusiness to continue its practice of mechanized, chemical, industrial monoculture farming, in spite of increasing detriment to the environment. A further concern with GMOs stems from the actual genetic modifications. Aside from the artificial interference with natural evolutionary processes and the creation of organisms with unknown and potentially-disastrous ecological ripple effects, there is mounting evidence that indicates negative health consequences in people who ingest certain genetically-modified foods on a regular basis [7].

In the face of mounting evidence to the contrary, one may still choose to embrace the notion that "urbanism conserves habitat", but when the larger dynamic between standard agricultural practices and current urbanization trends is understood, it becomes 
apparent that nothing could be further from the truth. In just one century, from 1950 to 2050 , the world's population will have risen by 380 percent, with the bulk of that growth being concentrated in urban centres. During that same period, habitat loss to agriculture alone will be somewhere in the vicinity of 7.5 billion hectares ( 50 percent of Earth's total continental land area if we use FAO statistics to estimate), most of which will be used to feed this growth in urban population. Of course, the root cause of uncontrollable population increase is another matter, which is also frequently linked to irresponsible global economic policies that magnify social inequality; but, the core issues of urbanization, as they concern permaculture advocates, revolve mainly around feeding the human world while reclaiming and preserving as much of the Earth's biodiversity as possible.

\subsubsection{PRinCipled SOlUtions}

\subsubsection{Ethics, Principles and Insights}

A single solution to our era of uncertainty and crisis perhaps does not exist. Given the complexity of the human world and its historical relations to the natural world, it appears that a diversity of approaches in all spheres of human activity is required to undo the damage caused by unchecked industrialism, monopoly capitalism and centralized urbanism. However, such a diversity also requires a universalizing and totalizing method for unifying all struggles together into a holistic movement for change. Be they issues of 
environmental justice or social-justice, the common imaginevision that they seek is justice itself.

Because of the rise in environmental movements worldwide, the fight for universal justice is no longer one of anthropocentrism and anthropomorphism. The notion of fairness and equality now extends to the Earth and all its inhabitants, regardless of race, species or element. In the face of the rapid consolidation of elite financial power called, "globalization" or "new world order politics", the world is witnessing the birth of a universal awareness in active opposition to them. And this consciousness is active at many levels of humanity, some knowingly anti-capitalist and some unwittingly so, for any grassroots movement that seeks true sustainability is engaging itself against centralized economic control.

It is not uncommon to read, see or hear the phrase, "capitalism is unsustainable" or some variant, printed in current texts, spray-painted on city walls or repeated aloud in lecture halls and coffee shops alike. In a recent publication, Ecovillages and Capitalism, Ted Baker [8] writes on the confrontation between ecologically-centred communitarian efforts and the "global capitalist reality." With regard to its future survival, he states:

If the logic and requirement of capitalism is perpetual growth, then the obvious conclusion, given a finite planet with limited resources, is that such a system is unsustainable. 
Testing this assumption is as simple as casually investigating the ecological and human consequences of capitalism in its present and arguably its most hegemonic stage, i.e. global monopoly corporatism. Alternative energies continue to be suppressed by "free-market forces", as wars for petroleum dominance decimate the Middle East, bursting oil wells and pipelines threaten water security and ecosystems everywhere they are found. At a certain point, enumeration of every single excess, injustice and calamity becomes redundant. Even apologists for capitalism can no longer hide its inherent flaws and naked evils; yet, as its crisis unfolds at an alarming rate, they continue to cling to the dogma that "advanced technology and free market mechanisms will take care of the more egregious problems" [8]. Although, as it grows-the more technological control it produces and the more it attempts to "self-regulate"-the more it consumes and devastates. It appears that the Marxist deduction was prophetic after all: capitalism sows the seeds of its own destruction.

Indeed, the very ethics and principles of permaculture have also reached this very same conclusion, whether it is stated openly or left unsaid and contained interlineally throughout its ethical foundations. In the preface to his book, Permaculture: Principles and Pathways beyond Sustainability, Holmgren [9] reiterates the spirit of Marx's words when he writes:

The avalanche of evidence and information about the impermanence of almost every aspect of modern society and economy, especially due to looming environmental threats, undermines any sense of certainty about the continuity of everyday life. 
Of course, in the era of globalization, both "modern" socio-economic reality and "everyday life" are overwhelmingly capitalist experiences; it cannot be denied. The average Western citizen is interred in debt, nearly everything has a price-tag, prices are inflated by merchants and corporate retailers, and gas prices are watched as closely as our one-time ancestors followed the migrations of the wild herds. It is thus difficult to read any pretense of "freemarket" ideology into Holmgren's or any other steadfast permaculturalist's ideologies.

When monetized economics are described alongside of permaculture principles, profit and individual financial gain are always relegated to the lowest ambition, if mentioned at all. Instead, fair trade (in its truest form) and barter are encouraged as a means of forming regional self-sufficiency. This concept is often distinguished from other decentralized models, such as individual self-sufficiency, as it recognizes the vital significance of reciprocal cooperation (mutualism) between all members of a society [10]. Knowledge, expertize and services are traded in addition to tools, goods and products, creating a socialistic support network that promotes a regional economy, rather than a globalized and corporatized control network. The chant, "think globally and act locally" replaces the rhetoric of globalized trade.

Permaculture thus upholds its "ethics of diversity", in all aspects of its application from "caring for the Earth" to caring for one another [10]. But as a system of design, it is guided by ethical principles that are equally practical as they are spiritual or philosophical. Since Mollison and Holmgren coined the term and its founding set of seven basic 
characteristics $^{6}$ in 1978 , permaculture has evolved into a vast and complex system of realistic strategies for "permanent" human co-existence with and within Nature. Today, there are generally twelve guiding principles, which are given by Holmgren [9] and repeated here:

1) Observe and interact.

2) Catch and store energy.

3) Obtain a yield.

4) Apply self-regulation and accept feedback.

5) Use and value renewable resources and services.

6) Produce no waste.

7) Design from patterns and details.

8) Integrate rather than segregate.

9) Use small and slow solutions.

6 “1) Small scale land-use patterns are possible; 2) Intensive, rather than extensive land-use patterns; 3 ) Diversity in plant species, varieties, yield, microclimate and habitat; 4) Long-term; an evolutionary process spanning generations; 5) Wild or little-selected species (plant and animal) are integral elements to the system; 6) Integration with agriculture, animal husbandry, extant forest management and animal cropping become possible, and landform engineering has a place; 7) Adjustable to steep, rocky, marshy or marginal lands not suited to other systems." [2] 
10) Use and value diversity.

11) Use edges and value the marginal.

12) Creatively use and respond to change. ${ }^{7}$

When these twelve practical concepts are applied in the real world, as a backyard garden oasis or an intensive organic farmstead, a productive feedback system is established between human activity and ecosystem response. As with wild ecologies, its complexity is built over time, reaching a self-sustaining climax with increased soil fertility, microclimate regulation, earth moisture retention, intricate symbiotic species interrelations and catastrophe-defence mechanisms [2].

It is important to note that the principles are also a product of a feedback system. After several decades of practice at various locations worldwide, the observation of natural ecosystems and their interface with permaculture projects is gradually refining the knowledge base and leading to further awareness and innovation. Bane lists and describes eleven "ecosystem insights" [10] that inform the practical workings and principles of permaculture. What follows is an interpretation of these insights:

\footnotetext{
${ }^{7}$ The description and application of these seemingly-simple 12 principles can form the subject of entire volumes, as with Holmgren's 270-page book, Permaculture Principles \& Pathways [9]. A condensed and welldescribed version of the principles is offered by Bane in the fourth chapter to his Permaculture Handbook (pp.29-40) [10]. For a "case-study" of their real-world application, see Environmental Anthropology Engaging Permaculture, by Veteto and Lockyer (pp.101-104) [211].
} 
1) Open boundaries: an isolated ecosystem does exist in Nature; there is an exchange of nutrients, organisms and elements between all contiguous ecologies.

2) Dynamic adaptability: ecosystems are resilient and always seek a balance within the diversity of species, even after the occurrence of a disastrous change.

3) Stability in complexity: homeostasis is maintained best in large complex systems; ecosystem simplification can lead to a loss of biodiversity, even total collapse.

4) Universal solar energy: most of Earth's energy comes from the sun; carbon cycles are solar-powered and, thus, so are "food chains"; before the negative influence of human industry, urbanism, experimentation and other "civilized" activities, macroclimate was mainly influenced by the sun.

5) Food web systems: the term "food chain" is a misnomer that presupposes hierarchic feeding structures and disregards complex interspecific relationships ${ }^{8}$ (food webs or 'sustenance matrices'). In nature, ecosystem balance relies on healthy predator-prey, browsing and grazing dynamics; population overshoot is created by a food-web

\footnotetext{
${ }^{8}$ Referring to interrelations between different species; also, interspecial.
} 
imbalance, where a habitat's carrying capacity for a given species is undermined by a rapid increase in its population. ${ }^{9}$

6) Waste is food: waste products do not exist in nature; everything is part of the food web. Thermodynamics dictates that energy cannot be created nor destroyed, only converted from one form to another. In ecosystems, this translates into: 'one organism's excrement is another's nourishment'.

7) Living thermodynamics: much of the energy on Earth is stored solar energy (amassed in oceans, forests, soils and organisms, i.e. stored in the chemical bonds of carbonbased compounds). Photosynthesizers are the essential source organisms that harness solar energy and make it bioavailable for complex food webs; without them, life on Earth would end. Deforestation and soil destruction equals a depletion of stored bioavailable energy, meaning that worldwide entropy is increasing.

8) Elemental cycling: all life on Earth consists of only six elements (carbon, hydrogen, nitrogen, oxygen, phosphorus and sulphur), four of which are mainly found as gaseous molecules in our atmosphere. The remaining two, combined with other compounds of the former, are found in mineral compounds in oceans, soils and the earth's crust. These elements circulate throughout an ecosystem as organisms are born, eat, excrete,

\footnotetext{
${ }^{9}$ Studies have found that, because of modern modes of living, human beings have been in a state of population overshoot on Earth for nearly 30 years [10].
} 
die, are in turn consumed and decompose; most cycle relatively locally and are rarely lost to larger circulation currents. Industrial agriculture, deforestation and urbanization cause these disruptions in local life-cycles, resulting in mineral depletion of the food web and a degradation in ecosystem health. Every organism dependent on these vital cycles is thus impacted, including humans.

9) Information pathway redundancy: ecosystems accumulate and transmit genetic information through feedback pathways (species interactivity and symbiotic behaviors, such as pollination, seed dispersal, etc.). The most resilient ecosystems result from multiple pathways and complex feedback systems, providing redundancy should one or more pathways decline or disappear.

10) Species succession and diversification: rainforests represent a climax in biodiversity: the oldest and greatest-complexity ecosystems on Earth. They, and every other diverse ecosystem, are results of succession, a gradual process of increasing ecological complexity beginning with a simple disturbance in the soil. Once disturbed, small weeds grow by uptaking nutrients for photosynthesis and commence a chain of successive growth cycles, species attraction and proliferation that, over longer periods of time, result in the creation of forests.

11) Cooperation versus competition: the examples of cooperation drawn from natural ecosystems far outweigh those of deadly competition. Even predator-prey relationships 
give rise to symbiosis with third-party organisms (scavengers) of all sizes benefiting from the kill, right down to the level of soil bacteria. Examples of habitat sharing, feeding pattern modification, mutualistic behaviours, and territorial adjustment abound in Nature, whereas staunch competition more rare than is commonly believed.

From this synthesis of science, traditional wisdom and lived observation, comes the practical vision of its applications to human systems; to "get ourselves back to the Garden". In recognition of age-old Native-American wisdom, Nature can finally be regarded by European descendants as the universal teacher, after centuries of irrational denial. The question remains: how many are willing to listen to her lessons, before the window of opportunity closes?

\subsubsection{Indigenous Inspiration}

"Upon suffering, beyond suffering:

The Red Nation shall rise again and it shall be a blessing for a sick world; a world filled with broken promises, selfishness and separations; a world longing for light again."

I see a time of Seven Generations when all the colors of mankind will gather under the Sacred Tree of Life and the whole Earth will become one circle again.

In that day, there will be those among the Lakota who will carry knowledge and understanding of unity among all living things and the young white ones will come to those of my people and ask for this wisdom. 
I salute the light within your eyes where the whole Universe dwells. For when you are at that center within you and I am that place within me, we shall be one."

-Crazy Horse, War Leader, Oglala Lakota Sioux ${ }^{10}$

A discussion of permaculture that fails to mention aboriginal influence on the core of its values and practices is either the product of ignorance, oversight or partiality, for the oft-overlooked aboriginal contribution to environmental consciousness cannot be denied. Many of the hardest-fought battles against corporate threats to ecological security have been organized and continue to be fought by Native activists groups, often by whole tribes. In many parts of the world, aboriginal resistance to crimes against the earth has met brutal state repression, including here in North America. Their blockades against deforestation, damming, mining, oil operations and agribusiness on Native lands and near sensitive ecosystems worldwide continue to this very day. A rising trend is occurring, where peoples of all ranks and colour are joining these struggles for treaty rights, human rights and

\footnotetext{
${ }^{10}$ Crazy Horse quoted while smoking the Sacred Pipe with Sitting Bull for the last time, four days before he was murdered by U.S. Army soldiers who bayonetted him during an attempted arrest. He was set up and double-crossed during a supposed peace negotiation [208].
} 
environmental justice. Gradually, the recognition of Native peoples as inherited protectors

of air and water-the ancestral stewards of the land-is being revived. ${ }^{11}$

In general, when one examines the precolonial lives of most Indigenous

Americans, it becomes irrefutably clear that their cultural reality was largely eco-centric.

Humans, as they defined them, were innately tied to the natural order, not outside and above it, as many European ideologues have contended for centuries. Ever thing from their art and emblems, to their shelters and even their given names, revolved around the great circle of life that brought together all known organisms and natural forces. In general, their spirituality, everything took its place, equally, in the divine order of their Creator. When the natural world was described as something outside of Native Man, it was understood that the human bore the unique and great responsibility of maintaining that balance. And

${ }^{11}$ The present ongoing struggle of the Standing Rock Lakota Sioux, and fellow "Water Protectors", against the Dakota Access Pipeline (DAPL), is a prime example of this diverse solidarity movement, bringing together people of all ethnicities and population sectors from across the U.S. and the world to stop the dangerous oil pipeline's construction. The scandalous route of the pipeline has it passing over unceded Lakota territory, through ancestral burial grounds, sacred sites and beneath the Missouri River just north of their reservation, putting both the river and subterranean aquifer system at serious risk. Together, the aquifer and river provide drinking water for some 18 million people of both Native and non-Native decent.

The protests were met with severely-repressive police action, with the use of tear gas, plastic bullets, beatings, arrests, concussion grenades and water cannons in sub-freezing temperatures causing many injuries and cases of hypothermia. One young women suffered severe trauma after having an arm nearly blown off by a police concussion grenade. After being joined by a contingency of some 4,000 military and navy veterans, the protests were successful in pressuring the Obama administration to order the Army Corps of Engineers to deny the Dakota Access company (Energy Partners, L.P.) the permit to drill under the Missouri River pending a full environmental assessment by the U.S. Environmental Protection Agency (EPA). The victory, albeit temporary (as of December $5^{\text {th }}, 2016$ ), is historic in that the Native struggle created widespread outrage, leading to a broad-spectrum support network that included hundreds of thousands, if not millions of nonNatives across the world. 
they learned this through generation upon generation of careful observation and oral education, what Western academics have often dismissed as simplistic "mythology". Yet, what is now evident is that this holistic wisdom is perhaps best described as the spiritual culmination of thousands of years of lived experience.

One example of their reciprocating relationship with the natural world is given by Mollison and Holmgren [2] when they describe the agrarian activities of Tasmanian and Australian aborigines, who inhabited the region for some 20,000 years before British settlement. The English colonizers erroneously categorized them as primitive "huntergatherers", perhaps a conscious and premeditated strategy for the seizure of their territories $^{12}$, ignoring the telltale signs of plant and tree domestication, wildlife management, controlled burning, animal taming and limited territorial boundaries: signs of early permacultural practice and not boundless nomadism. Of course, the term "permaculture" only applies to them in retrograde, as a description of their permanent agricultural habits, which evolved as their intrinsic state of being. But the signs of this advanced land stewardship were everywhere to be found, which included high mineral content in soils on their most populated areas, microclimate moderation, distinct structured "edges" of vegetative growth (indicating cultivation and "fire regimens"),

\footnotetext{
${ }^{12}$ In Australia, the British used a roman-derived legal concept, terra nullius, under their common law system to deny aborigines their natural territorial rights, giving the English, in their minds, the ownership of the entire continent. The Latin term literally means, "Nobody's land", and remained legally-binding until finally being overturned in 1992 [9].
} 
defined "pockets" of superior soil composition, and discrete symbiotic food-bearing ecologies; all revealing signs of cooperative human intervention and land managementprecisely what modern permaculturalists aspire to in their agrarian initiatives [9].

Roughly 10,000 kilometres from the Australian continent, Native American tribes speak of traditions of land management and agriculture long before the invasion of the Europeans. Indeed, it is a well-known fact that the first settlers would have succumbed to the harsh winters had it not been for the generosity of the Wampanoag tribes, who provided them with a portion of their kills and harvests. In addition to their natural acts of charity, they also taught the Pilgrims more efficient farming techniques and survival strategies that included land navigation, gathering wild edibles and hunting wild game [11]. What is not well-known is their advanced understanding of agricultural efficiency and ecological management, which to them meant simply how to survive while appreciating and caring for their shared home. Similar to the Aborigines of Tasmania and Australia, they practiced fire regimes, arboriculture, agroforestry and symbiotic polyculture, providing improved soil fertility, enhanced crop yields, species regulation, agricultural clearings and hardwood for heating, building and fabrication (tools, weapons, etc.). Both recent studies and the settler historical record together prove that controlled burning and arboriculture were widely practiced throughout the northeastern United States, which corroborate the Native oral histories. Settlers described well-defined forest edges caused by intentional and wellcontrolled fires. These ecological customs had a direct impact on the species composition 
of the forests, promoting the proliferation of oak, hickory and chestnut varieties over other species that were less useful to them. Their methods were effective to the degree that they achieved "primary forest efficiency" near their settlements. In effect, their strategic activities increased local biodiversity and contributed to a balanced food web system: providing deer and other herbivores with managed browsing territory, thereby presenting predators and scavengers with prey and carrion, including herd animals for their tribe [12].

Unlike European agriculture, Indigenous American farming techniques did not involve destructive plowing practices, nor did they limit themselves to monocultures. This made their methods far more efficient and productive over continual growth cycles, season after season, without depleting soils of their vital nutrient, mineral and microbiological compositions. A popular example of their practice of polyculture (mutualistic-symbiotic planting) is the Three Sisters Guild, in which corn, beans and squash are planted together, each species contributing to an overall reciprocal relationship. The corn stalk acts as a vertical support for the climbing bean vines, which fixate nitrogen in the soil; the squash acts as ground cover that retains soil moisture and repels insects with its bristly stems and leaf undersides [10].

It is said that Native American crop varieties included potatoes, beans, corn, peanuts, pumpkins, tomatoes, squash, peppers, nuts, melons, and sunflower seeds [13]; however, more recent study into the agroecology of specific tribes reveals a much richer 
tradition of permaculture-like systems specific to regions and localities. For instance, First Nations' habitat management in British Columbia involved a complex system of farreaching and long-standing practices, as well as very localized and focused activities, which increased yield and quality in both domesticated cultivars and managed wild species. Their methods have been described as "domesticating landscapes" and "perennial agriculture", what may now be rightly called, permaculture [14].

The coastal tribes benefitted from a total of 250 species of plants, which were used for sustenance, heating fuel, buildings, fibre, boats, pigments and adhesives. Of these, they consumed 35 species of roots and 25 varieties of greens, as well as berries and tree bark [15]. They too were erroneously branded as simple "hunter-gatherers" by the settlers, yet had been openly involved in advanced wildlife management and farming techniques such as periodic landscape burning, clearing and weeding, plot bounding, tilling, dissemination, transplanting, pruning and coppicing, selective harvesting, resource monitoring, conservation and many other managing systems [14]. But this way of life effectively ended for the First Nations of B.C. and Canada when the Royal Canadian Mounted Police (RCMP) came for their children [15], kidnapping them under the authority of the 
Government of Canada's nationwide policy of "gradual civilization", and forcing them into the harsh, abusive and often homicidal Church-administrated residential school system. ${ }^{13}$

After centuries of suffering and death delivered by Western colonialism's policy of genocide, the world is perhaps finally learning that it was not the native populations that needed "civilization". On the contrary, the displaced Europeans and their descendants could have received an invaluable education in humility, humanity and harmony from those they chose to instead dehumanize and destroy. Had their choices been influenced by a greater good, rather than by ignorance, greed and supremacy, perhaps today there would be no need to argue the case for permaculture or any other alternative way of life.

\subsubsection{Design Strategies}

Following a discussion on the ethics, principles and historical motivations of permaculture as a movement for change-its fundamental moral implications-the next step is to define it as a practical system. Over the past 40 years since its introduction as a permanent and self-sustaining form of agriculture, its definition has been recycled repeatedly in attempts to reapply it to various social contexts. It may now be correctly

${ }^{13}$ As revealed in the documentary film, Unrepentant, by former United Church minister, Reverend Kevin Annett, many suffered horrendous physical and sexual abuse, even torture and death as severe punishments for merely speaking their traditional languages. Others died of smallpox or simply disappeared into the system, never to be seen again. Annett's work offers evidence that thousands of Indigenous children and adolescents met their demise at the hands of the Canadian federal government, the Roman Catholic Church, the Anglican Church of Canada and the United Church of Canada. The survivors suffered life-long psychological trauma, with many never recovering and falling into mental illness and substance abuse [209] [210]. 
interpreted as an applied unification of ecology, agronomy, sociology and environmental

politics-in other words, as a budding political philosophy. What separates it from more

speculative philosophies is its focus on everyday strategies for re-shaping our material

world into a totalizing ecomorphic system. Thus, intrinsically, it involves design, self-

critique and redesign, as a continual process of the critical dialectic. ${ }^{14}$ But short of digressing

into the complex realm of dialectical materialism and Marxist existentialism, it is important

here to understand it simply as a living system of design that designs for living systems.

The permaculture design process is described somewhat differently by each of its

practitioners and designers; its phases often fall in variable orders depending on the author.

This is conceivably due to the fact that all begin learning their art from a mentor, followed

${ }^{14}$ In his Critique of Dialectical Reason, Sartre creates a distinction between static-dogmatic and continuallyevolving critical applications of Marxism. He defined this opposition as dialectique critique versus dialectique dogmatique and it is well introduced by the following quote from The External Dialectic in Modern Marxism section in the work's introduction [242, p. 26]:

This difficulty has appeared insurmountable to modern Marxists. They have seen only one solution: to ref use to acknowledge thought itself as a dialectical activity, to dissolve it into the universal dialectic, and to eliminate man by dispersing him into the universe. This enables them to substitute Being for Truth. There is no longer knowledge in the strict sense of the term; Being no longer manifests itself in any way whatsoever: it merely evolves according to its own laws. The dialectic of Nature is Nature without men. There is therefore no more need for certainty, for criteria; even the attempt to criticize and establish knowledge becomes useless. Knowledge of whatever form is a relation between man and the world around him, and if man no longer exists this relation disappears.

The source of this unfortunate approach is well known: as Whitehead said, a law begins by being a hypothesis and ends by becoming a fact. When we say that the earth revolves, we no longer feel that we are stating a theory, or that we are relying on a system of knowledge; we feel that we are in the presence of the fact itself, which immediately eliminates us as knowing subjects in order to restore to us our 'nature' as objects of gravitation. For anyone with a realist view of the world, knowledge therefore destroys itself in order to become the world, and this is true not only of philosophy but also of all scientific Knowledge. When dialectical materialism claims to establish a dialectic of Nature it does not present itself as an attempt at an extremely general synthesis of human knowledge, but rather as a mere ordering of the facts. 
by his or her real-world application and reinterpretation of that mentor's teachings. Reinterpreting is the critical act of evaluating one's education in the light of lived experience. As permaculture has yet to become recognized as a formal field of interdisciplinary academic study, it remains a hands-on exchange of knowledge between teacher and pupils. The doctrine of "Each One, Teach One" invokes the timeless spirit of oral tradition and point-of-production education [10]. When combined with theory (ecology, botany, sociology, architecture and engineering), it becomes a veritable expression of holistic schooling. This is perhaps where it succeeds over traditional compartmentalized mass education: theory and practice are treated as a totalizing dynamic. One does not precede the other. The university is the field; the field, the university.

Despite lacking a consensus on the exact succession of design phases, masters of the craft nevertheless agree on its core principles and inspirations, which again are understood dialectically. From these follow the processes of predesign and iterative design. As mentioned above, design is a continually-evolving process, a feedback system that continues in perpetuity, perhaps. Before that process can begin, several preliminary procedures are enacted by the designer. The following is a reduction and interpretation of an extensive catalogue of design strategies, derived from several comprehensive sources [2] [10] [16] [17] [18]. The order in which they are here listed is deduced logically and is based on customary architectural practices: 
1) Observation: The birthplace of a project is the site itself. All analyses, design concepts, infrastructure and future human interactions with the site begin with careful examinations of its existing environment (within and without its boundaries). Before any site analysis is begun, assessments of topography, drainage, wildlife, vegetation, macroclimate, microclimate, melt patterns, lighting environments and sense impressions are made under diverse conditions, at varying times, over time. This involves visiting the site during different seasons, at all hours of the day and night, during both moderate and severe weather events and being accompanied by the client, who can relate more detailed anecdotal and experiential data. If the designer is also the owner, then living on-site for a year or more is ideal. During this time or these visits, maps and diagrams are drawn, a working site plan and diary of notes are kept. Observations are arranged according to analytic categories (see below). The better the designer understands these dynamics, the more informed and streamlined the predesign process will be [10].

2) Research: All through the observation stage, current, recent, archived information and studies on the site, its locale and greater region are gathered from all available sources. This includes internet sources, government agencies (in Canada: ECCC, NRCAN, 
AAFC, GSC, provincial, regional, city or municipal bodies and archives) $)^{15}$, local libraries, colleges and universities, journals, periodicals, past owners, etc. Focus is placed on the official plan (city or regional gov.), maps and information overlays (GIS) ${ }^{16}$, climate data, geology, watersheds, groundwater, soil composition, topographical data, property records, surveys, site land use history, surrounding land use patterns, native/invasive species and the area's history. This information supports the site observations and is crucial to both the analytical and iterative design phases [10].

3) Landform analysis: This process begins with the maps and topographical data $v$ collected and drawn during steps 1) and 2). It also involves an analysis of any outstanding land features, vegetative growth patterns, wildlife corridors or trails, and existing water features.

a) Topography: if both an updated land survey and topographical survey are not already in existence, of which the latter is rare, professional services may be required. ${ }^{17}$ Analysis follows by noting all the highest and lowest points, with all

\footnotetext{
${ }^{15}$ Environment and Climate Change Canada (ECCC); Natural Resources Canada (NRCAN); Agriculture and Agrifood Canada (AAFC); and Geological Survey Canada (GSC). Equivalents in the United States are: the Environmental Protection Agency (EPA); National Oceanic and Atmospheric Administration (NOAA); United States Geological Survey (USGS); Natural Resource Conservation Service (NRCS); and the United States Department of Agriculture (USDA).

${ }^{16}$ Geographic Information Systems (GIS): public databases can be found online or through universities and colleges. Private databases that offer paid services may also exist for a region.

${ }^{17}$ Topographical information from GIS databases and government topographic maps are usually too low in resolution (i.e. the scales are to small) to give accurate pinpoint data on a site.
} 
gradients that lie in between. This information is invaluable for both analysis and schematic planning.

b) Drainage: topographies are then assessed to create an understanding of natural drainage patterns. Crucial in planning for water systems, planting zones, irrigation, stormwater management and building placement.

c) Microclimate zones: identifying existing site thermodynamics is critical for the schematic design phase, as plant and animal biodiversity depend heavily on microclimate [2]. The factors that can affect it are numerous. Depending on their surrounding topography, low spots can pool water and colder air. Being denser, cool air generally flows down along slopes, creating convective currents and atmospheric stratification [10]. Geology can also influence microclimate, with different rock types possessing different thermal properties (thermal mass and blackbody properties like heat capacity, reflectivity, absorptivity and emissivity, etc.). For example, a sloped granite outcropping may create a convective updraft in the afternoon after absorbing and reemitting passive solar energy all morning. Likewise, hydrology directly affects site thermodynamics. Water has a high heat capacity (absorbs and retains heat) and, depending on its stillness, can act as a perfect mirror, reflecting sunlight according to the incidence-reflection angle rule (law of reflection); both these properties, combined with water feature surface area 
and volume, influence localized air temperatures and dynamic energy exchange.

Forested areas, even small thickets, can cause dramatic differences in air temperatures, moderating extremes by cooling daytime air and warming it at night.

d) Soil: localized soil fertilities, topsoil depth and mineral content are affected by geology, topography, drainage patterns, plant/tree growth and wildlife activity, and it is indicated by wild plant distribution among other things. Stormwater run-off causes erosion, bringing nutrient-rich topsoil to lower areas and basins [10], while animal dung from wildlife corridors and habitat also increase soil fertility. Plant indicators can reveal soil condition (depth, composition, fertility, moisture content and retention, etc.) by species, concentration and dispersion patterns.

e) Vegetative growth: beyond soil mineral content, plant variety and distribution are also accurate indicators for many other important site specifics, such as site contamination, past land use patterns, buried building foundations, abandoned graveyards and more [10].

f) Shading: linked mainly to vegetation patterns and landforms, shading is a function of time of day, tree types and their dispersion about the site; it affects planting zones, plant selection and microclimate [16]. 
4) Needs analysis: As an essential step in the analytical process, it begins with assessing the needs of the human inhabitants; the number of people, their age groups, dietary and caloric requirements and social needs are weighed against the site's existing features. Once established, they provide an indication of yield production requirements, both in terms of food staples and bulk quantities, as well as building characteristics (floor areas, essentials and amenities, etc.). This, in turn, gives an idea of what labour requirements and infrastructure projects are to be assessed, planned and designed in the following phases. Furthermore, it establishes the necessary feedback loop in the planning process—specific subsystem requirements reveal overall system needs and vice versa. When most of these needs are addressed in the planning stages, the potential for success in establishing a self-sustaining ecosystem is much higher [10].

5) Zone analysis (human activities): being linked directly to the needs analysis, Mollison refers to this process as, "design by the application of a master pattern" [17]. Depicted graphically as a two-dimensional series of annular rings-much like the cross section of a tree trunk (Figure 1) -its concentric bands represent the inverse relationship of both energy expenditure and human intervention to the physical distance from the main dwelling.

a) Zone 0 - highest intensity: the place of human dwelling, be it home or communal building, all attached structures and immediate outdoor living spaces. This is the 
area of highest intensity human activity, which requires the highest energy expenditure.

b) Zone 1 - high intensity: the areas of constant supervision, intensive fruit and vegetable gardening, involved procedures, and recurrent visitation. Chicken coops, herb gardens, greenhouses and nurseries are best kept here, relatively close to the primary dwelling. This zone is mainly for self-reliant sustenance provision; Mollison asserts that most of a household's food requirements can be met within a 6-metre walk from the home [17], depending on family or commune size, naturally.

c) Zone 2 - moderate intensity: the zone of lower-maintenance gardening, lessfrequent visitation, such as home orchards for household consumption, sharing, charity or local barter system trade. Terraces, raised beds and animal shelters do well here, as well as small ponds, grazing areas for livestock (milk-producers) and foraging for turkeys and water fowl [17].

d) Zone 3 - low-intensity: sections allotted for staple income intercropping fields and alley-cropping orchards, i.e. commercial farm, market crops or higher-level regional barter system crops. Larger aquaculture and irrigation ponds, field buffers (windbreaks and hedgerows) and barns will inhabit this space [10] [17]. 
e) Zone 4 - lowest-intensity: mix of pasture and managed forest that borders on wilderness. Grazing for livestock, wild edible foraging for household, wildlife corridors, largest ponds, constructed wetlands, and woodlots (household fuel or building/woodworking material trees) can all be planned for this zone [10] [17].

f) Zone 5 - zero intensity: remains wild and unmanaged, wilderness preserve land, wildlife habitat, protected wetlands, ecologically-sensitive habitats, coastlines, ridgelines, etc. Humans visit, hike and enjoy, but do not settle or develop this area [10] [17].

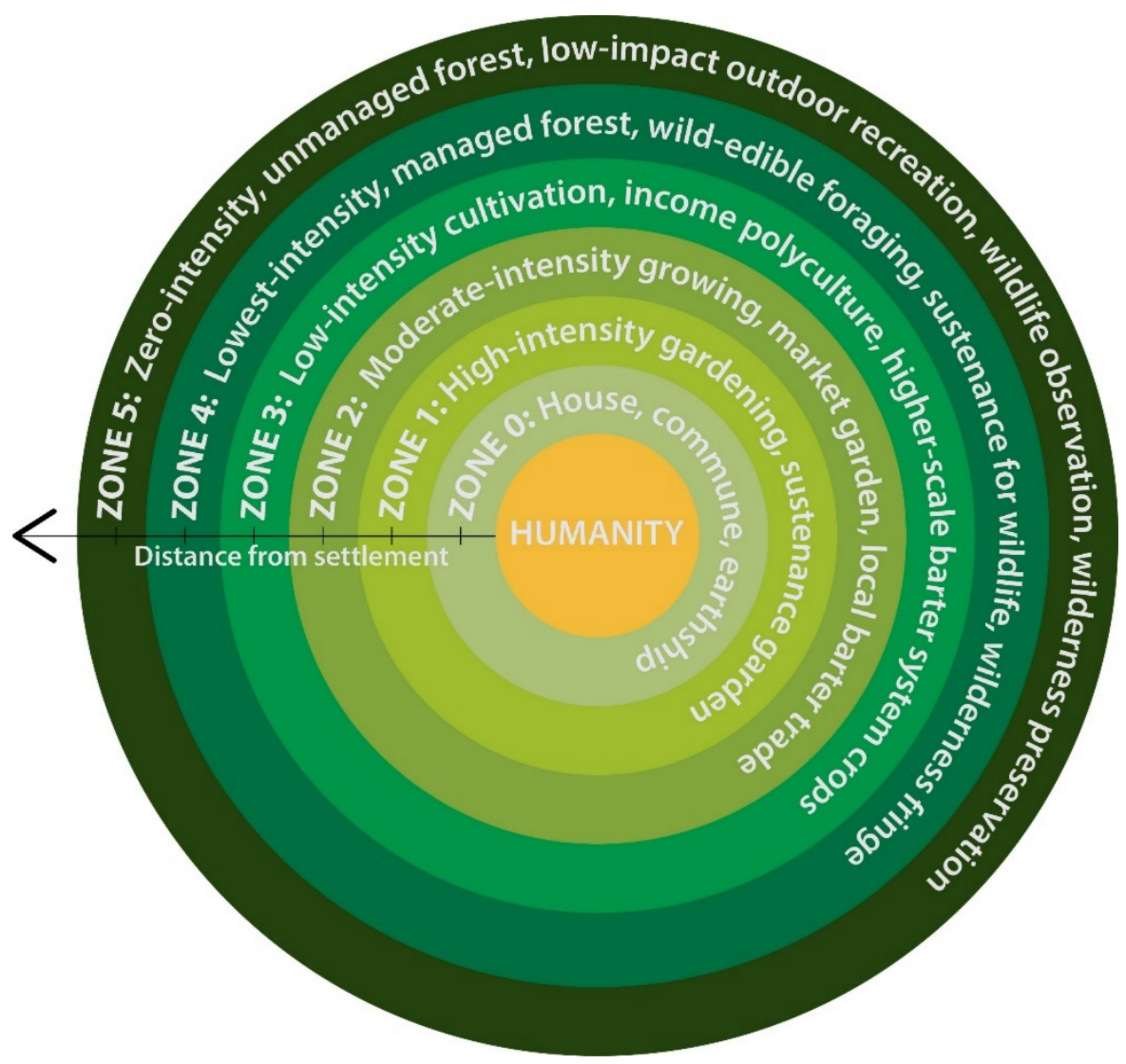

Figure 1: Permaculture wheel used for zoning analysis and planning. 
6) Sector analysis (natural influence): at once a product of the site observations and research, sectors are drawn from the natural forces and energies acting upon the future system. It is often also represented by a series of concentric rings signifying the above zones, which are now carved into something like a pie-chart diagram. The "slices", or sectors, represent the different forces of nature: wildlife corridors, genetic drift, pollution (road salt, noise, artificial light, air and water), vistas/views, seasonal sun paths, wind patterns, wildfire risk, storm patterns and precipitation [10] [17]. In other versions, a single circle represents the site, with the force and energy sectors represented by arrows passing through the centre [10]. In both depictions, the dwelling marks "ground zero", with the outlying site as the circle of constructed ecosystems. The forces of nature act upon all systems within the disc and analysis thereof must consider their use (sun, winds, precipitation and beneficial wildlife) and/or deflection (fire, storms, strong winds, pests and pollution) to maximize systems efficiency and long-term resiliency. Each future site element is then later designed, according to these analytics, to perform two or more functions and maximize returns on initial investments in time, energy, labour and costs [17].

7) Iterative design: sometimes referred to as schematic or incremental design, it is likened by Mollison to standard engineering methods, wherein the design of any system or any system component is an ongoing process of refinement, beginning with a preexisting design [17]. The pre-existing design is itself almost always a redesign or 
revision of another previous design. When a novel prototype is first produced, it also represents the reordering or recombination of existing components. In other words, nothing is invented ex nihilio and perfected instantaneously. Only iterative processes and gradual improvement, usually exacted by different designers over long-periods of time, can produce system efficiency. This is also the process by which knowledge is inherited and advanced: by historical (dialectical) totalization. In terms of permaculture design, where each site is a unique landscape and ecosystem (whether initially flourishing or broken down), the original balance can be seen as the first iteration. The designer begins with an established ecosystem and intervenes to either integrate or rehabilitate. In both cases, the aim of the second iteration-the human settlement as a working prototype-is to seek maximum efficiency within a new equilibrium. And this process continues over years, even decades, until a climax in biodiversity and energyefficiency is achieved, after requiring as many design revisions, or iterations, as necessary until a self-sustaining ecosystem is reestablished.

8) Master planning (working plan): a process of graphically representing the incremental design of a site, along with its gradual implementation and evolution throughout Time. In permaculture, it does not represent the supreme dictates of a designer and/or developer. It is the expression of a long-term commitment to a project, to a lifestyle and, moreover, to their core ideologies. In its initial form, it displays the designer's original intent. Successive iterations build over time, creating an illustrative history of 
the project. As such, it need not remain simply graphical, but can include written observations, instructions, and wisdom gained over decades. Beyond that, the master plan should remain in existence as long as the settlement exists, which means it should transfer from each successive generation to the next, whether as a family heritage or as a developing socio-environmental praxis for a communal eco-village. Thus, it is perhaps best articulated as a praxis diagram, to dispose of any associations to outworn hierarchic constructs.

9) Infrastructure detailing: the essential addenda to the praxis diagram (master plan). They include all detailed designs of systems, subsystems and technological prototypes that participate in the whole-system equilibrium. There are hundreds, or even thousands of examples to draw from; it will suffice to mention a few: swales, irrigation ditches, thermosiphons, constructed wetlands, aquaculture ponds, greywater recycling systems, aquaponics systems, planters, catchment systems, cold frames, solar kilns, etc.

10) Building design: the planning and design of central structures that house residents, guests, animals and indoor systems. All buildings should aim to integrate within the site's greater equilibrium. This is achieved by intentionally utilizing and contributing to site thermodynamics, catchment, drainage and biodiversity. All combined materials should minimize carbon footprint, embodied energy and building energy consumption. Locally-sourced and site-sourced materials usually meet the first two 
criteria. Building energy consumption will depend on a myriad of dynamic factors, including but not exclusive to building placement, envelope detailing, building systems design, site-interaction and passive design.

\subsubsection{A VISION FOR THE FUTURE}

\subsubsection{Urban Permaculture and Ecovillages}

From permaculture a maxim has emerged that can characterize any movement for

positive change: "starting where you are" [19]. Earth is our only known plane of existence, with all it contains interconnected through great cycles of elements and energy. If one major ecology dies off, it could send a destructive wave throughout the whole pond. Therefore, the struggle to safeguard our collective waters against a possible complete loss of biodiversity is, at once, here and everywhere. Everyone's rural Eden is possible, but not everyone can abandon their present urban niche in a mass exodus to the country. With the majority of the world's population now living in cities, many, if not most, would have to stay and fight the battle for new fertile ground in their own backyards.

From its modern beginnings as a model for regenerative eco-agronomics in rural farming areas, permaculture has since been evolved to include peri-urban, suburban and urban residential contexts. The concept of microfarming is now wedded to ecology and sociology, giving rise to a new vision for cities and their subsets. This novel paradigm may be here termed, 'socio-ecomorphism', and defined using the words of sociologist, Randolph 
Haluza-DeLay, as "a place awareness and interrelationship of social and ecological linkages that can be a foundation for increased orientation toward sustainability" [19]. In opposition to the tenuous yet tenacious anthropomorphic paradigm of Western civilization, socio-ecomorphic patterns in urbanity are expressed through networks of sustainability initiatives at the grassroots level, uniting people of diverse socioeconomic strata in their will and action to re-empower the environmental movement. As capitalism continually attempts to co-opt and subvert the grassroots, in vain attempts at maintaining its economic and ideological grip on society, the resiliency of the marginalized continues to spring forth with novel, ingenious and innovative subversions. One such likely seditious concept is the ecovillage.

Within the last two decades, true environmental values have begun to take hold, even if this trend is not reflected in mainstream society and its dominant power structures. Whether the powers that be like it or not, citizens are growing increasingly discontented with their lives within the alienation of urbanized capitalism. Berezan draws attention to this dissatisfaction when describing his urban permaculture students:

Many...have identified a sense of isolation, a dissatisfaction with the anonymity they experience in their neighbourhoods, and a strong desire to live a more vibrant, engaged, and environmentally sensitive community life. Often this has been expressed in the desire to "start and ecovillage," either in a rural area or within the city itself [19]. 
Of course, there are numerous aspects of the current sociopolitical reality that contribute to this impetus. The centralized economy has devolved humanity into a virtual state of fearful infancy, suckling at the bosom of a toxic totalitarian beast. Food is something almost alien to the urbanites who ingest it: it comes from invisible sources and the mechanisms of planting, producing, processing, preserving, packaging, promoting and profiteering are accepted a priori, mainly in willful ignorance. But, with food inflation scaling at unmanageable rates and living wages remaining relatively stagnant, many are beginning to rethink their relation to sustenance, to the system itself. For, with this revival in food consciousness often follows environmental and social consciousness. At some point in this process, permaculture is encountered and consciousness blooms into revelation, then bears the fruit of holistic insight.

Modern ecovillages are hard to define because they have yet to develop a universalizing praxis; they are a diverse collection of "intentional communities"communes, small communities and residential initiatives-devoted to reducing their ecological footprints while developing stronger communal relations otherwise lost upon urban world. In what is referred to as, the "Global North" ${ }^{18}$, they are usually situated in rural or peri-urban areas and populated by individuals fleeing urbanity, drawn together by

\footnotetext{
18 "Global North" is a term employed to refer to a "North-South" divide of the world based on wealth disparity on the global scale, as well as poverty concentrations within individual countries. It is a generalization based on the fact that most of the world's wealth is concentrated in the "northern countries", with their elite aggregating the greatest share and having the most control over globalized financial systems.
} 
their strong will to transcend common discontent [20]. Activist and educator, Jonathan Dawson offers his interpretation:

Private citizens' initiatives; in which the communitarian impulse is of central importance; that are seeking to win back some measure of control over community resources; that have a strong shared values base, often referred to as "spirituality"; and that act as centers of research, demonstration and in most cases training [20].

As a movement, ecovillage success here in North America is limited by factors mainly beyond their own control: skyrocketing land values, mortgage and lending policies, sustainability deficiencies of building codes, increasingly oppressive local land use by-laws and government planning regulations, as well as wider external factors that influence internal group dynamics [8]. With similar initiatives gaining attention in developing nations, ironically, here in the industrialized "democracies", where the world's wealth is concentrated, new ecovillage projects are dwindling in frequency [20]—-being smothered by capitalist "market forces" and the regulations of "civil society". Thus was spawned the idea of a more disseminated network-based form of urban socio-ecomorphism: the "distributed ecovillage" [19].

In the distributed ecovillage model, like-minded eco-conscious urbanites discover one another through neighbourhood and city-wide environmental networks. The networks are comprised of activists, educators and citizens working together to enrich their lives and promote ecological awareness. Permaculture makes this system possible for city- 
dwellers who lack the means of buying expensive properties, dealing with inhospitable municipal governments and financing site-infrastructure projects at eco-village scales. Beginning from where each individual or household is already grounded-in their urban homes-residential yards are transformed into biodiverse ecosystems that provide much of a household's nutrient requirements. "Each one teach one" is applied as every property becomes a classroom and a community centerpiece. Larger community garden initiatives are conducted in higher-density neighbourhoods where backyards are non-existent. Even high-rise balconies are seen as an opportunity for smallest-scale permaculture, sometimes referred to as micro-gardening.

This model does face many challenges, however. Again, by-laws and regulations serve to hinder the proliferation of urban permaculture, making core features like backyard chicken coops illegal in most major cities in Canada, including Ottawa [21] [22]. Grey water systems can also be viewed as a "health hazard" in many municipalities. The present social and structural impediments to distributed ecovillages in North American cities are such that they require integration within the sectors analysis stage of permaculture design. Alongside natural forces like sun and wind, are added traffic, zoning, codes, homeowners' associations, easements, neighbours, passersby, commerce, local customs, pets, crime, arson, bylaw enforcement and police [23]. Neighbourhood and adjacent homeowners aside, the main barriers to urban permaculture take the form of public unawareness and mediocre government commitment to advanced sustainability innovations. 
One potential solution for resolving this conflict between mainstream society and urban permaculturalists can be found in Tomlik's proposal [24], who argues for the integration of a permaculture programme directly into the City of Guelph's official plan. This is achieved by the implementation of "permaculture districts" corresponding with the permaculture zones discussed here in 1.1.2.3. ${ }^{19}$ The zones are then overlaid on the City's current land use map, effectively mapping out a distributed ecovillage within the existing city limits. By bringing the permaculture model directly to a city's official plan, regulations are revised to comply, officials become educated on urban biodiversity and public exposure and acceptance grows congruently. Naturally, the purpose of socio-ecomorphism is to transcend mainstream acceptance and agitate for a diametric reversal in socioenvironmental consciousness: isolated individualist consumers become productive self-reliant urban communitarians.

Certainly, the official permaculture plan and the distributed ecovillage can only form the beginnings of an urban permaculture, the second iteration in a new collective praxis. Achieving a genuinely sustainable city can only be the end result of numerous

\footnotetext{
${ }^{19}$ Permaculture District 1 (PD1) comprises land parcels with direct access to a residence (residential zoning parcel). Permaculture District 2 (PD2) refers to public parcels within higher-density residential areas, where food production (community gardens) would be performed in designated community parks or on public institutional grounds. Permaculture District 3 (PD3) identifies parcels within industrial areas, agricultural areas and larger regional parks. Permaculture District 4 (PD4) is land just abutting the built environment, where prior development was either not possible or not economically-feasible. This includes floodplains, forested parkland and greenbelt zones. Permaculture District 5 (PD5), the outermost ring, includes protected wetlands, waterways, larger floodplains, wildlife corridors and habitat, and any other greenspaces not suited to development [24].
} 
iterations in a continually-progressing multilateral design process. The urban socioecomorphic paradigm will be reached when automobiles no longer choke the circulatory system of the city and most of the pavement is transformed back into greenspace; when squirrels no longer have to dodge vehicles and raccoons no longer have to dig through the garbage; when backyard fences are torn down, reused as herb planters and honeysuckle trellis; when every property joins to form one network of biologically-diverse microfarm gardens and grocery stores only stock that which cannot be grown outside the home; when nobody begs for change in front of the supermarket and not one is forced to experience homelessness or hunger. But in order for such a radical change to take root in our senselessly-urbanized world, the soils need to be fertile once again: the urbanite must experience bioremediation of the mind and soul. And to begin the process, thriving examples need be set; resilient seeds must be sown.

\subsubsection{The Ottawa Permaculture Initiative}

Starting from here, Ottawa (Odawa $)^{20}$ hence became the focus of this design project. The capital city of Canada (Kanata) occupies a region rich in biodiversity. Once maintained

\footnotetext{
${ }^{20}$ The name Ottawa is said to be derived from the Odawa First Nations of the Georgian Bay region of Ontario, who once traded along the Kichi sipi. Odawa means, "traders", and it is theorized that since both tribes spoke similar dialects, the Algonquin version, atawe, is the original source [212]. Kanata is Huron/Iroquois for "village" [213]. Kichi sipi, means "big river" in anishinabemowin, the language of the Algonquin First Nations and several other aboriginal peoples [212]. Kébec is Algonquin for "where the river narrows", referring to the St-Lawrence River (Kaniatarowanenneh, meaning "big waterway" in Iroquois) in the general vicinity of what is now Quebec City [213]. It is important to note that, although today referred to as "Algonquin" peoples, in their native tongue, they refer to themselves as simply, "real people", or anishinabeg [212].
} 
solely by the First Nation peoples, the entire capital region and most of the Ottawa River (Kichi sipi) watershed reside in unceded Algonquin territory. An estimated 75,000 square kilometres of Ontario's mostly dense mixed forest stretching west-east from North Bay to Hawkesbury [25], including nearly 1.5 times that area in Quebec (Kébec $)^{21}$, comprised their hunting and fishing grounds, trading routes, and communities-what should be rightfully regarded as their land stewardship region. Until the extensive logging executed by French and English settlers, the Ottawa River Valley area was covered in a thick blanket of oldgrowth forests. Today, it is nearly completely gone. Yet, forests in the non-agricultural rural areas of both provinces, especially on the Quebec side of the river, have since grown back. This testifies to the fact that, despite the ravages of settler industry, the area wants to be a forest $^{22}$. And since westernized humans have taken so much from the region's ecology, it is high time to start giving back.

To begin this process, Ottawa would require a network of dedicated activists, academics, educators, students and general permaculturalists who can devote their free time-some even their lives - to campaigning, pressuring and outreach. In Alberta, a

\footnotetext{
${ }^{21}$ Area claimed as Algonquin Nation territory between 1850-1867A.D.; a total land area of approximately 195,772 square kilometres, with 38 percent of that territory in what is now the province of Ontario [104].

${ }^{22}$ In Falk (p.27), he writes, "The area I live in wants to be a forest. ...80 to 90 percent of my home state of Vermont was cleared of its forest only a century and a half ago. Yet without replanting it is nearly entirely reforested today. We are fortunate to live in a place and time where the right combination of moisture consistency across the year and temperature patterns promote the establishment and growth of trees on all surfaces of the landscape except on the steepest cliffs and open water [16]."
} 
precedent and working model for such a burgeoning network already exists: the Edmonton Permaculture Network (EPN). Started by Berezan and a small cohort of guerilla gardeners, EPN has amassed a relatively tight web of distributed ecovillagers (180 members as of 2013) who are dedicated to spreading their vision for urban permaculture [19]. And, as promising as existing models are, enterprises like EPN mark merely the early beginnings of a socioecomorphic revolution. Here in the capital region, aside from a few small local initiatives, Ottawa permaculturalists have yet to publicize such a network, if one even already exists.

The aim of this thesis is thus, first and foremost, to contribute to this revolution: the creation of an imaginary and considerably-sized permaculture ecovillage, in the heart of the Nation's Capital-a "ground zero"-that has the function of spawning an upsurge in similar initiatives everywhere, at different scales. It shall be called, The Ottawa Permaculture Initiative (OPI). Proposed as a decentralized communal living and farming collective, its mission would be to disseminate its 'spores' throughout the city, beginning a distributed ecovillage with the potential of one-day achieving an eco-city. The culmination of such a communitarian movement is a worldwide reversal of the present state of affairs.

Admittedly, the entire premise for OPI speaks of an idealized preliminary bias. However, this is not a scientific study. What the fields of permaculture and architecture share, among many other commonalities and intersections, are their interdisciplinary tendencies. Neither field can be branded as a "science" or an "art"; it is because, each are 
both. This is perhaps what is so enchanting about them. Neither have to hide intent behind the veil of "objectivity"; both are guided by the power of imagination; yet, each can produce objective, verifiable and enduring results. The appeal of combining them into a "permatecture"23 is partially what fueled this imagination. After discovering the beauty, hope and inspiration that agroecology synergizes into a singular pursuit, it was immediately understood what needed to be done. Permaculture has already encountered and assimilated elements of architecture, but it would appear that architecture, strangely, has yet to even discover permaculture. After nearly 40 years of the former overlooking the latter, it is time for a humbling re-acquaintance. Therefore, the second goal of this thesis is to help facilitate this amalgamation.

The third goal is to stimulate yet another "discovery" by the architectural community: cannabis. It is not here assumed that both permaculture and hemp are unknown to architects, but rather it appears that architects have yet to comprehend their collective capacity for 'holistic bioremediation' ${ }^{24}$, and generally turn to energy-efficiency

${ }^{23}$ The concept of "permatecture" is relatively new [238] [239] [240] [241]; here it is employed as a developing dialectical philosophical concept and method here defined as 'socio-ecomorphic holism applied to urban design, community planning and architecture' and not simply as a practical application of basic permacultural principles to architectural design processes.

24 'Holistic bioremediation' here refers to a conceptual (i.e. philosophical) use of the term, "bioremediation", where the 'soil' to be remediated is not literally the ground, but rather the social and environmental landscape taken as a whole. 
improvements in building systems (such as conformity with LEED standards) ${ }^{25}$, within the prevailing urbanist framework. Yet, on the level of building technology alone, hemp is emerging as one of the most versatile natural building products known to humanity-if not the most versatile. When this is understood alongside of its sustainability considerations and soil phytoremediation uses, it becomes apparent that every decade that passes without major advancements in hemp-based trade and technology is lost to deforestation and the petroleum industry (both recognized by ecologists and environmentalists as major contributors to climate instability and loss of biodiversity).

\footnotetext{
${ }^{25}$ For more on the Leadership in Energy and Environmental Design ${ }^{\circledR}$ international programme, please see: http://www.cagbc.org/CAGBC/LEED/CAGBC/Programs/LEED/Going green with LEE.aspx?hkey=54c44 792-442b-450a-a286-4aa710bf5c64.
} 


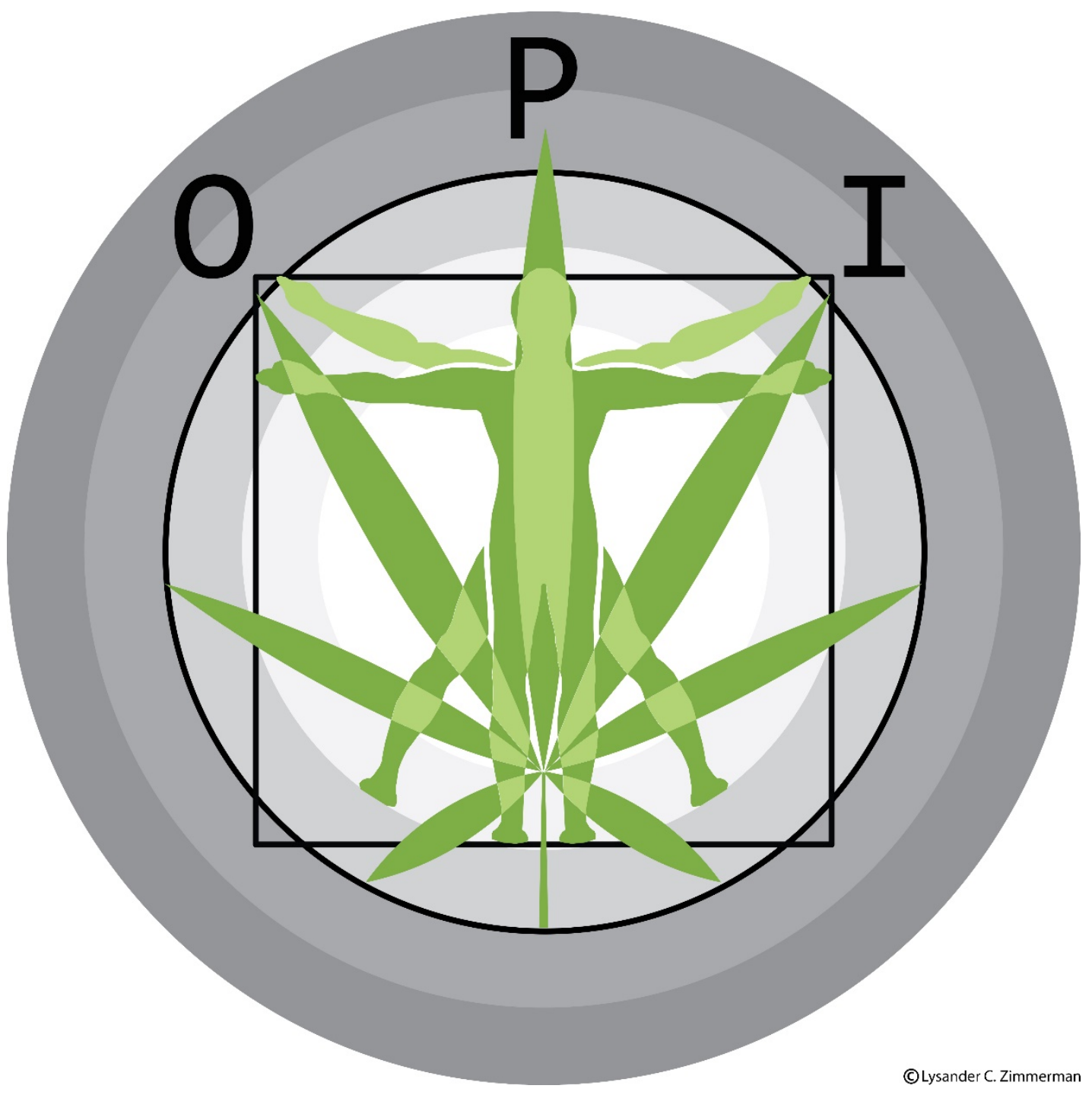

Figure 2: Logo for the Ottawa Permaculture Initiative. 


\section{CHAPTER: SUSTAINABLE YIELD CROPS: CANNABIS AS MORAL FIBRE}

Cannabis is perhaps the most unique, prized and likewise controversial plants in the world [26]. Together, hemp and marijuana varieties form one of the oldest cultivated species on Earth, evidenced to be some of the very first domesticated non-food crops. Believed to have been utilized by Paleolithic humans as early as 30,000 years ago, research suggests that "interaction" between migratory humans and Cannabis indica lead to its introduction in Central Asia and beyond. Eleven-thousand-year-old pollen has been discovered in Central China and its earliest known domestication in East Asia is shown to have taken place at around 6,000 years ago [27]. Here in North America, Indigenous peoples cultivated cannabis (both hemp and marijuana) for generations before the arrival of Europeans. Some tribes speak of sacred strains possessed and cultivated for hundreds of generations, meaning for thousands of years. The commonly-held belief amongst Caucasian Americans that tobacco was the main sacrament of the peace pipe ceremony may be entirely false. Many herbs were used, which varied according to specific tribal entheogenic customs. And Cannabis was certainly one of them [28]. 
Intrinsically bound to the history of agriculture itself, no other known plant possesses the diversity of uses and products that the hemp and marijuana cultivars ${ }^{26}$ offer humanity. At present there are at least 30,000 known products that can be manufactured from only one of the hemp plant's components-its stalk, also known as its stem-which produces two invaluable raw materials. The first is prized bast fibre; the second is the hurd (or shive) [29], which was generally regarded as a "waste" material (Figure 3). Today, there is very little organic waste material left over after hemp processing; modern science is discovering uses hitherto unknown and knowledge of its historical usages is helping to elucidate its future. Furthermore, its vital significance for the permaculture movement is perhaps another discovery waiting to be made. Chemical fertilizer-free, herbicide-free, high-yield, rapid-growing, soil-rejuvenating (phytoremedial), locally-processed: all welldocumented descriptions that position cannabis as the next major participant in the evolution of organic agriculture and sustainable industry.

\footnotetext{
${ }^{26}$ Cannabis nomenclature (taxonomy), in brief, as follows. A member of a relatively small plant family: Cannabaceae. Cannabis L. is its genus, which is one among 11 genera in the same family. There are 3 subspecies within the genus: Cannabis sativa L., Cannabis indica and Cannabis ruderalis. Hemp is classified as a cultivar of C. sativa L. It is interesting to note that there is recent doubt thrown into the classification and nomenclature of the three subspecies. See "A Question of Rank: Using DNA Barcodes to Classify Cannabis sativa and Cannabis indica", by John M. McPartland and Geoffrey W. Guy, a paper they presented at the $24^{\text {th }}$ Annual Symposium of the International Cannabinoid Society in Baveno, Italy, in 2014 [224] [225].
} 


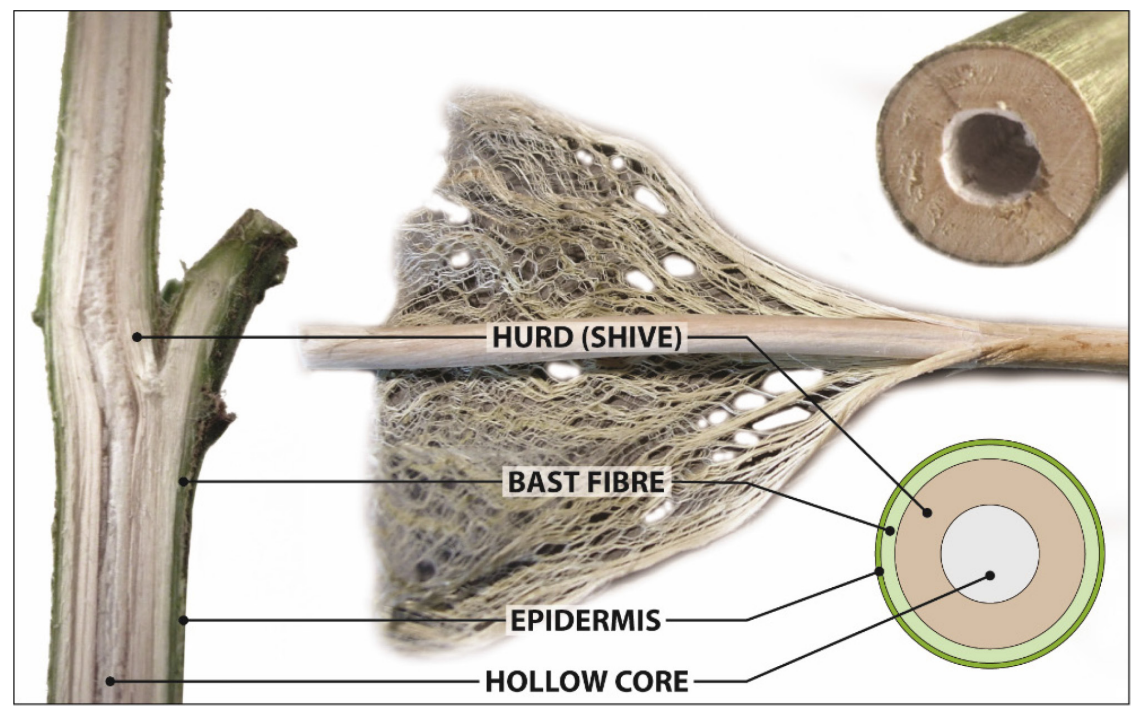

Figure 3: Transverse and longitudinal sections showing components of cannabis stem.

As a sustainable raw material, it is possible that cannabis knows no equal. Even wood cannot compare. Both are renewable natural products, but each species has its own radically different set of characteristics, which include growth cycles, ecological functions, physical attributes and geographic-climactic distributions. To begin with, cannabis is a fastgrowing annual with a wider geographical distribution than any other crop (to 60 degrees' latitude north and to the southernmost tip of Chile) [27]. Its typical growth cycle has it reaching maturity in 8-12 weeks (60-90 days). This means that it is capable at least one crop per year anywhere within its distribution area, and up to three crops per year in some tropical locations [30].

Typical softwood lumber trees require on average 30 to 50 years of growth before reaching maturity, sometimes even longer depending on the species and climate [31]. In that time, diverse forest ecosystems can be established, making every harvest a catastrophic 
event for dependent organisms. This type of human intervention, referred to a clearcutting, is likened to "natural wildfires", ignoring the fundamental differences between their frequencies, distribution and effects on local ecologies [32] [33] [34] [35] [36] [37] [38] [39]. Cannabis, on the other hand, is a born yield crop by comparison. Its average life-cycle makes all strains and cultivars nearly exclusively annuals-it is meant to grow rapidly, go to seed, die off and be regrown again the following growing season, even in tropical and subtropical regions [40]. Trees, on the other hand, are woody perennials that can survive for hundreds, even thousands of years depending on the species. They are evolved to thrive and play their vital role in forest habitats. Beyond growth cycles, cannabis does very well in high-density planting arrangements and can produce up to four times the amount of industrial raw material than a typical softwood tree species [41]. Add to that the fact that old growth forests continue to be razed for lumber and standard agricultural land, especially in rainforest regions, making deforestation operations a significant contributor to ecosystem simplification and the reduction of ecosystem services.

\subsection{BUILDING PRODUCTS}

The two raw materials extracted from hemp stems are both composed of lignocellulosic fibres. The outer stock forms $20-40$ percent of the stem (by weight) and is mainly comprised of cellulose (57-77 percent); while its woody inner hurd makes up 60-80 percent of the stem and has higher contents of hemicellulose and lignin (18-24 and 21-24 
percent, respectively) [42]. The high-quality cellulose fibre is what has been traditionally prized for the production of rope, textiles and paper. Today it is also being applied as reinforcing fibres in structural biocomposites, as natural lightweight replacements for glass fibres and synthetic polymers [26].

While still generally considered by industry as the "least valuable" component of the hemp plant, the wood-like hurd has been gaining recent interest from the scientific community, especially for applications in the building industry as a useful material with its own set of specific properties. These include physical properties in the following categories: thermal, mechanical, acoustic, aseptic (anti-microbial), density, moisture sorption and others. Economically and environmentally, its benefits are low-cost production, short turnaround, biodegradability, and general sustainability [42].

It is interesting to note that hemp hurd properties originally thought of as "weaknesses", such as high sorption and low-density, are now being discovered to produce desirable results in specific building components that benefit from enhanced hydric management characteristics. To begin with, its highly-porous and low-density structure can play a significant role in moisture vapour transport (MVP), thereby regulating the interior atmospheric moisture of inhabited spaces. These same physical properties also increase its thermal performance over glass or polymer reinforcing fibres. Combined, these are referred to as hemp's hygrothermal characteristics, or its hygroscopic properties, which 
can contribute directly to building envelope performance, occupant comfort and energy efficiency when used as a construction material.

It is thus encouraging to see that further research into its expanded role in the building industry is creating growing interest in cannabis products. Architects and engineers are beginning to take notice as environmental consciousness, in general, expands worldwide. Recent precedents demonstrate how an entire low-rise building can be constructed out of upwards of 90 percent hemp products, or more [43]. In Europe, use of hemp in building construction is gaining ground, with hundreds of buildings in France making use of hemp-lime composites [44]. Four of the main construction material classes used in such buildings, including their brief characterizations and associated products, are here listed below.

\subsubsection{HEMP-LIME BIOCOMPOSITES}

Hemp-lime composite (HLC) materials generally make use of the "waste products" of hemp processing, the inner hurds (shives), by combining them with construction lime binders to create a type of lightweight insulating hemp concrete (often referred to as hempcrete). While not suited for high-performance structural applicationssuperstructures, bridges or other high-stress/high-load applications-hempcrete materials are ideal for low/medium rise construction and can replace a variety of less sustainable 
products. While new research is being conducted into improving its physical performance, this technology has reportedly been in use for centuries [44].

Recent applications of hempcrete employ it as a cavity filler material in staggered stud framed walls as replacements for higher embodied-energy/embodied-carbon materials like fibreglass batt and plastic foam insulations. Generally having superior mechanical properties to plastic foams, the addition of HLC to properly anchored and fastened stud walls could significantly improve their structural performance under dynamic loading conditions. Indeed it has been shown that its increased tensile strength provides 10 times more racking resistance than a diagonally-braced wood stud ("composite") wall system [45]. To compare, typical compressive strengths of polystyrene, polyisocyanurate and polyurethane foams used in structural applications (such as structural insulating panels, or SIPs) range from 0.07 to $0.17 \mathrm{MPa}$ (10 to $25 \mathrm{psi}),{ }^{27}$ whereas HLC with hydrated lime binders ranges from $0.23 \mathrm{MPa}$ to $0.83 \mathrm{MPa}$ ( 30 to $120 \mathrm{psi})$. Those HLCs with magnesium oxide cement binders ranging from 1.37 to $2.73 \mathrm{MPa}$ (250 to 400 psi) [44].

Despite having generally satisfactory tensile and compressive strengths, the thermal resistance of HLCs is only slightly better than that of insulating concrete building materials

\footnotetext{
${ }^{27}$ High-load variants of extruded polystyrene (XPS) are available from some companies like Dow and OwensCorning with compressive strengths in the $0.28,0.42$ and $0.69 \mathrm{MPa}(40,60$ and $100 \mathrm{psi})$ ranges [214], but at enormous costs to builders, contractors and clients. They are therefore limited to specialty applications and generally not suitable for standard residential or commercial construction budgets.
} 
like autoclaved aerated concrete (AAC) [44]. However, other studies publish more favourable results and place it in the range of 3.5 RSI (R 20) for a 300 millimetre wall and 6.9 RSI (R 40) for a 600 millimetre wall, ${ }^{28}$ which is also the thickness range recommended to achieve a desirable thermal lag effect (from thermal mass). Based on RSI values alone, it would seem that HLCs provide only mediocre thermal performance when compared to other insulation materials. For example, to achieve the same RSI value as 300 millimetres of HLC in the lowest performing plastic foam insulations (expanded polystyrene, or EPS), a thickness of only 100 millimetres is required.

Although it would appear that HLC is an unexceptional thermal insulator, it must be understood that due to their ultra-low densities, plastic foams have negligible thermal mass. In terms of indoor humidity control, they are only capable of acting as moisture vapour barriers, providing little to no hygrothermal dynamics. Hemp-limes produce a phenomenon called hysteresis, which in simple terms amounts to a hydric lag between adsorption and desorption, making it an "excellent hydric regulator" in wall cavities [46]. What makes this "phenomenon" even more interesting is the fact that HLC is airtight (acts as an air barrier) yet still has a high MVP. Furthermore, it provides decent thermal lag performance compared to standard insulation materials due to a combination of its specific heat capacity and density. For climates regions such as Ontario's, Berardi's study [45]

${ }^{28}$ Based on conversions from conductivity values given in Sinka (2015) [215]. 
concludes that HLC combined with pressure-equalized rain screen composite wall assemblies would provide the best performance.

\subsubsection{INSULATION MATERIALS}

In addition to using hemp shives for hempcrete and other HLCs, hurds are used as non-toxic loose-fill insulations in composite stud wall cavities. This application is known to exist but is less prevalent and lower-performing than hemp fibre blanket (batt) insulation. Again, the term prevalence is here applied loosely since it is a relatively rare product in the North America, requiring special order that is dependent upon an extremely short supply. As of 2016, no major retailer in Canada or the U.S. stocks hemp batts. Even in Europe, as of 2009, where hemp building products are gradually becoming standardized, insufficient supply is blamed for holding back its market growth [47].

Thermal properties of hemp fibre batt insulation are similar to most blanket insulations, generally ranking higher than standard-density glass and mineral wool (or rock wool) fibres. With an average accepted RSI of 0.62 for a 25 -millimetre thickness (R 3.5 per inch) [47], this puts it slightly below higher-density rock fibre and fibreglass batt products (for example, Roxul ${ }^{\bullet}$ and Owens Corning ${ }^{\circledR}$, who both claim RSI 0.77 per $25 \mathrm{~mm}$ or R 4.4 per inch) [48] [49].

Being a naked and cured plant fibre, fire-retardant treatments like low-toxicity boric acid salts (borates) are required to lower its combustibility. This is perhaps where it 
lags behind fireproof mineral and rock fibres like Roxul ${ }^{\bullet}$. Where it surpasses other standard anthropogenic fibres is in its hygrothermal properties. Like hemp-herd lime composites, hemp batt insulation is moisture vapor permeable and produces a moisture hysteresis by quickly absorbing sudden moisture increases in wall cavities, then gradually releasing it over a longer period of time. One manufacturer, Black Mountain Natural Insulation, claims that, being a hygroscopic material, its NatuHemp $p^{\circledR}$ product can absorb up to 20 percent of its weight in water before suffering from a loss in thermal performance [50]. This is significant since fibreglass batt is known to rapidly lose thermal resistivity as moisture builds up in wall cavities. Roxul ${ }^{\circ}$, on the other hand, has always maintained that its hydrophobic rock fibre sustains its "long term" resistivity, providing third-party test results of only 0.08 percent water sorption at 97 percent relative humidity to support their claims [51]. However, they have yet to publish numbers for R-Value loss under these conditions, is claimed to be negligible.

Ultimately, what truly makes hemp fibre superior to other fibres is that it is beyond carbon neutral; it actually sequesters atmospheric carbon dioxide $\left(\mathrm{CO}_{2}\right)$ in its structural molecules (biomass) during metabolic processes, as well as converts $\mathrm{CO}_{2}$ to $\mathrm{O}_{2}$ (atmospheric oxygen) during photosynthesis. This would make organic hemp products carbon negative-most certainly if produced through agroecological farming practices. Additionally, being a product of sustainable agriculture rather than energy-intensive 
industrial processes, hemp fibre insulation contains much less embodied energy than both fibreglass and rock fibre.

\subsubsection{StRUCtURAL BUILDING MATERIALS AND HFRPS}

Thermoplastic composites made from polymer matrices like polypropylene reinforced with lignocellulosic hemp fibres are now being used increasingly in the automobile industry. These composites belong to a class of materials called hemp fibre reinforced polymers (HFRP) or simply hemp fibre composites (HFC). Lightweight combined with tensile and fire-resistant properties make them ideal for automobile bodies and interior paneling [52]. Research is also being carried out on the use of composite materials that employ hemp fibre for reinforcing thermoset resins such as epoxies and polyesters, as natural replacements for energy and carbon intensive glass and carbon fibres [53]. There are in fact so many HFRP composites presently being researched that an entire chapter could be devoted to them. The ones mentioned here represent a limited crosssection of the field, ones that exhibit potential as future building materials.

Medium-density fibreboard (MDF) and oriented strand board (OSB) products made from hemp shives with both urea-formaldehyde and phenol-formaldehyde, as well as natural binders produced from hemp oils, have been developed. Some are even commercially available, although their distribution is still very limited [54] [55]. Physical and mechanical properties of these quasi-isotropic composite laminates have been tested to 
be at least comparable to wood composites [56] and in some cases upwards of 250 percent stronger and 300 percent more elastic [57] [58] [59]. These results evidence its suitability for structural sheathing applications, a multitude of other uses (furniture, cabinetry, paneling, etc.) and its high probability of eventually replacing wood as a sustainable structural material.

Other similar materials like tri-laminate (triple-layer) particleboards made with a core layer of lignocellulosic hemp particles and woodchips (in a 50:50 ratio) with a standard urea-formaldehyde (UF) or melamine-urea-formaldehyde (MUF) binder resins have also been produced. Lightweight single-layer particleboards made from hemp and petrochemically-derived polymeric methylene diphenyl diisocyanate ( $\mathrm{p}$-MDI) resin were created for interior applications such as paneling and cabinetry [52]. However, the ultimate goal of natural composites is to provide a natural source for both binder (matrix) material and reinforcing fibres, thereby eliminating the industry's dependence petrochemicals and other toxic compounds. With this goal in mind, studies are being carried out on MDF and high-density fibreboards (HDF) that combine hemp fibres with renewable binders derived, for example, from derivations of rape, starch, rye and polylactic acid (PLA) [52].

One exciting prospect for building materials-perhaps even a breakthrough for hemp construction-are novel sandwich panels produced from hemp bast linen fabrics with a core of hemp-reinforced bio-polyurethane (Bio-PU), making them almost entirely naturally-derived. Incredibly, the lightweight composite is roughly half the density of 
wood-based OSB and particleboard (40 to 60 percent lower), while having 30 to 50 percent higher flexural strength, respectively. They are also more than 50 percent more pliable, which amounts to greater impact resistance and less brittleness. Up to now, hemppolyurethane biocomposites have relied on either fully-synthetic polyurethane (PU) or 30 to 50 percent bio-based polyol with 50 to 70 percent "fossil-based" isocyanate matrices. Fischer et al. employed a hemp-reinforced polyurethane material based on upwards of 80 percent polyols from soya, rapeseed or sunflower oil, with the remainder being petro-based isocyanate. In addition to increased mechanical properties, Bio-PU exhibits low moisture absorption-3 to 4 percent water uptake after being completely submerged for 2 monthsmaking it suitable for exterior, automotive and marine applications. This process is completely reversible by leaving it to dry at room temperature for merely 2 weeks. By comparison, OSB, particle board and MDF would be rendered useless by similar underwater conditions, as they exhibit water sorption in the range of 88 to 136 percent by mass [60]. Therefore, potential future uses of hemp fibre reinforced bio-polyurethane ('HFRBPU') extend into many industry sectors, including and especially the building sector: sooner or later, OSB, MDF, plywood and particleboards could all be replaced by 'hyper-sustainable' hemp sandwich panels or something similar.

This development reveals broader possibilities for structural hemp biocomposites. Research still needs to be conducted into HFRBPU for more serious structural applications. Its low flexural modulus compared to OSB and its yet unknown compressive and shear 
strengths means that further studies and advancements need to take place before it could be considered as a viable alternative to structural composite lumber (SCL) in framing applications. SCL products that are made of OSB-like wood chips, such as laminated strand lumber (LSL), could potentially use oriented hemp hurds and natural binders to produce similar standards. Once more is understood about HFRBPU, similar developments could lead to layered structural materials and possibly replace laminated veneer lumber (LVL) products.

\subsubsection{Hemp-Reinforced Structural ConCrete}

Another promising use of hemp for the building industry that architects and engineers should be aware of is currently in development: hemp-reinforced structural concrete. While not a true hemp-based biocomposite, the use of lignocellulosic hemp fibres to reinforce structural concrete and lower coarse aggregate percentage in construction mixes is presently being investigated. Fibres generally employed for this function, as well as to impart particular physical properties, are anthropogenic fibres like glass, steel and synthetics such as polypropelene. Natural agricultural fibres are beginning to gain ground in the construction industry with and have been used in slab-on-grade, airport slabs/runways, concrete pavements, tunneling and shotcrete applications [61]. The sustainability objective of these materials is to reduce the amount of coarse natural aggregates sourced from quarries, which are becoming increasingly destructive to 
environmental landscapes. In terms of their combined physical and environmental properties, natural fibre reinforcements like hemp can improve structural performance (reduce bulk amounts of material for loadbearing applications and conserve natural resources), provide better thermal performance (increase energy efficiency in buildings) and contribute to agricultural economies. Results of some studies reported coarse aggregate reductions between 20 to 30 percent by volume, with only between 0.5 to 1 percent additions of hemp fibre [61] [62]. Physical performance tests showed a decrease in compressive strength but an increase in flexural strength (meaning its more ductile and less brittle), making the resulting concrete behave similarly to glass- or steel-reinforced concretes [61]. In this application, if standardized worldwide, hemp fibre reinforcements for concrete could result in significant decreases in coarse aggregate demand, thus lowering environmental pressures on quarried areas.

One of the primary missions of the Ottawa Permaculture Initiative (OPI) would be to further such research into hemp-reinforced structural biocomposites by providing hemp to public materials research facilities and universities. Agroecology research at OPI would correspond with materials engineering development by advancing ecological hemp farming and producing high-quality raw materials for use in studies. 


\subsection{NUTRACEUTICAL AND HOLISTIC MEDICINE}

In addition to the myriad of industrial applications, both hemp and marijuana families possess many nutritional and medicinal uses. The flowers produce dozens of cannabinoid variants (organic compounds), well over a hundred terpenes (fragrant oils), two-dozen flavonoids (pigments) and two-dozen fatty-acids (oil components) which together synergize in various configurations (depending on the strain and cultivar) and give cannabis its unique nutritive, therapeutic and pharmacological properties. The term nutraceutical is used to describe the combined benefits of medicinal foods such as cannabis. Indeed, the food value of its seeds alone should be of particular interest to permaculturalists: by weight, they contain 20-25 percent protein, 20-30 percent carbohydrates and 10-15 percent insoluble fibre, with most of the remainder in the form of fats (oils) [29].

While there is still a great debate raging in the field of medicine concerning the widespread use of medical marijuana, evidence that its medical benefits outweigh any associated risks is persuading governments everywhere to adopt policies of decriminalization, if not wholesale legalization. Some of the known health benefits of cannabis include treatments for both physical and mental illnesses, migraine headaches [63], cancers [64], multiple sclerosis (MS), epilepsy, nervous disorders, affective disorders [65], movement disorders, chronic pain [66], anxiety, depression [67], weight loss, 
HIV/AIDS [68], and a growing catalogue of other diseases and conditions being researched by physicians and medical scientists worldwide. For example, in an ongoing online survey of some 60 peer-reviewed studies examining 16 different diseases, syndromes and disorders, ${ }^{29}$ a total of 41 studies had favourable conclusions towards medical cannabis (68.3 percent), 14 were indecisive or unclear (23.3 percent) and only 5 concluded against the benefits of its medical use ( 8.3 percent) [69]. While this is by no means conclusive evidence that cannabis products are cures for any of the conditions, it does confirm the growing body of studies that favour its medical use. It is interesting to note that many studies with "indecisive" or inconclusive results include the statement "further study is needed" in the concluding remarks.

One interesting fact that may reveal the reasons behind cannabis' effectiveness in treating various illnesses and neurodegenerative diseases is the discovery of the mammalian endocannabinoid system (ECS). Throughout the human body and the brain itself, are cellular membrane receptors-cannabinoid receptors, $\mathrm{CB}_{1}$ (found on nervous system cells) and $\mathrm{CB}_{2}$ (found on immune cells)—and a "complex apparatus" that synthesizes and degrades molecules in a continual process of "pro-homeostatic" regulation [70]. Research has shown that the ECS also performs neuro-protective functions (protects

\footnotetext{
29 ALS, bipolar disorder, cancer, general medical use, glaucoma, HIV/AIDS, Huntington's disease, IBD/Crohn's, MS, nausea, pain, Parkinson's disease, PTSD, psychosis/schizophrenia, rheumatoid arthritis, and Tourette's syndrome.
} 
nervous system cells), contributes to neurogenesis (brain cell and neuron production) [67] and that disorders like MS, Huntington's, Parkinson's and Alzheimer's may a result from ECS hypofunction or dysregulation [70]. Treatment of such neurodegenerative diseases with cannabis products and cannabinoid extracts is a growing trend, with patients generally finding the results beneficial [65].

Thus, it would seem that humans and other mammals are genetically hardwired to make regular use of the beneficial cannabinoids found in hemp, marijuana and a few other known species of flora that contain phytocannabinoids (plant cannabinoids). The amount of research being carried out on ECS regulation with medical cannabis alone is telling. Beyond nervous disorders, affective disorders and neurodegenerative diseases, treatments for dozens of health conditions are being studied and weighed against its controversial and often debated list of side-effects. Even a superficial read-through of the journal titles and abstracts reveals how enormous the topic of medical marijuana has become.

\subsection{LEGALIZATION TRENDS}

In December of last year (2016), the Canadian federal government released the findings of its Task Force on Cannabis Legalization and Regulation [71], conducted by the federal government under Liberal Prime Minister, Justin Trudeau. Their final report made several recommendations surrounding its legalization and regulation. This marks a step towards it eventual acceptance as not only a therapeutic substance, but also a controlled 
recreational substance in the same category as alcohol. As of January 2017, it still remains illegal to produce, traffic, carry and consume without a medical prescription but it would appear that this is soon to change.

In many other Western countries, it still remains illegal, yet either decriminalized and relegated to a minor infraction for personal use and possession or illegal and left up to local authorities to determine enforcement. In the United States, cannabis occupies a strange dual status of being federally illegal and classified as a "schedule I controlled substance" along with heroin, cocaine and other highly-addictive narcotics [72]; while it is legal for medical use in 23 states and the District of Columbia (more than half the country) and legalized for recreational use in Colorado, Washington, Alaska, Oregon and the District of Columbia [73]. This means that any citizen, regardless of the State's law, can still be arrested, prosecuted and imprisoned by federal agencies. Even with trends to decriminalize and legalize increasing in many countries around the world, it still remains illegal in nearly every country. It would seem that there is a lot of work to be done before humanity and cannabis are again reunited. After all, their estrangement is really an inconsiderable and irrational interlude following a 30,000-year-old fellowship.

Nonetheless, Canada is moving towards this reunion and permaculture collectives could see the legal option of obtaining cultivation licenses within a year of this publication. Indeed, the wording of the Taskforce's final report [71] speaks on behalf of this possible future: 
Use licensing and production controls to encourage a diverse, competitive market that also includes small producers.

This encouraging development offers the prospect for ecovillages to create their own funding for long-term agroecological settlements and initiatives. Paying for land, infrastructure, construction and upkeep may soon not be as impossible as it now seems, with revenues earned from organic cultivation of both medical and recreational marijuana strains. Again the Government's report seems to be opening this window of opportunity:

Promote environmental stewardship by implementing measures such as permitting outdoor production, with appropriate security measures.

It is therefore now logical and "acceptable" to include this option in the plans for OPI. The main production crops would thus consist of Cannabis sativa (hemp), Cannabis sativa (marijuana) and Cannabis indica (marijuana), with a variety of strains and cultivars to provide for agronomical research, medical research, and materials research, as well as supply to both licensed medical dispensaries and recreational "storefronts" (as per the report and coming legislation).

\subsection{BIOREMEDIATION (PHYTOREMEDIATION)}

To add yet another benefit to the list that cannabis holds for permaculture settlements is perhaps one that will prove to be of the utmost importance in the coming years and decades. With soil pollution of all forms being created by industry and urbanity- 
including road salts, agricultural fertilizers, biocides, heavy metals, oil and petrochemicals, aromatic compounds and even radioisotopes-a crop that has the potential to uptake contaminants and accumulate them in its biomass is arguably priceless. If this plant could also remain unaffected by the pollutants it uptakes, all while producing a relatively safe industrial raw material, it would perhaps be called a "miracle worker". This plant exists and it is still illegal to grow in most countries on Earth. Of course, safety concerns from hemp fibres grown in polluted soils depends on the type and level of contamination, but where heavy metals (e.g. lead, copper, zinc and cadmium) are concerned, they are accumulated in the flowers, roots, stems, seeds, leaves and fibre, in a decreasing order of concentrations. The actual bast fibre has the least contaminant count [74]. This means that plant biomass may "lock in" much of the metals, and still allow for the use of its bast fiber in certain industrial materials, clothing excepted. It is assumed that shives (inner stem) are referred to simply as "stems" in Angelova et al. [74], and thus would need to be evaluated for use in building materials considering that they contained 2-3 times the heavy metal content of the fibres.

Studies show that hemp growth and photosynthesis are not affected by cadmiumpolluted soils, making it an excellent candidate for their phytoremediation [75]. Plants that perform this function efficiently are referred to as hyperaccumulators. It has been shown that hemp can grow on soil contaminated with 2,4-dinitrotoluene (2,4-DNT), a member of a class of toxic and carcinogenic aromatic compounds used in the production of military 
explosives, polyurethane foams and other industries [76]. Even deadly radioactive isotopes like cesium-137 can by phytoremediated with hemp, making it an effective accumulator and remediator of some of the most polluted lands. This potential was discovered when the Soviet government used it in Chernobyl to help clean up radioactive soils and ponds [77].

\subsection{CANNABIS AND PERMACULTURE}

As topic of study in itself, cannabis and its value for humanity is as extensive as the subject of permaculture. Together, hemp and marijuana represent the physical embodiment of diversity. Encoded in its genome is the Tree of Life-an example for and a potential means for contributing to the rebalance of Earth's natural homeostasis. Yet, despite its ancient history and seemingly infinite catalogue of uses, it still remains one of the most vilified and debated species of flora on Earth. Fortunately, positive data and findings are amassing, irrational attitudes are reversing and senseless legal barriers are beginning to dissolve. The tide seems to be turning as both medical and recreational marijuana gradually become decriminalized and legalized around the world. Likewise, hemp products are being discovered by industries and consumers alike. The era of hempbased architecture is on the horizon. Architects everywhere need to exercise their just duties to help hasten its arrival. As trends in materials science, medical sciences and agronomy would have it, cannabis should be a staple crop in every permaculture 
settlement. It has become not only an ethical issue, but a fundamental moral obligation: humanity must fight for the liberation of this species-a revival of this moral fibre-because this particular struggle is profoundly bound to universal emancipation; for it has become apparent that all life on Earth is being held hostage and sacrificed off incrementally in the name of centralized wealth, control and power. 


\section{CHAPTER: OTTAWA'S CENTRAL EXPERIMENTAL FARM}

Being an experimental readaptation of largely-abandoned agricultural practices and marginalized economic archetypes, a working example of a self-sustaining permaculture community operating within Ottawa's city limits should require a carefully chosen landscape. Concerning the city of Ottawa and its surrounding region, an urban permaculture project would either have to locate itself within the outlying greenbelt (in the urban fringe, in close proximity to both sprawling suburban development and existing undeveloped lands; or within the city itself (on isolated and fragmented greenspace). In keeping with objective of this thesis-namely, to infiltrate, expose and subvert the prevailing urban paradigm-it was determined that the latter scenario is a more deliberate and influential statement of strategy. For the chosen intentional ecovillage model, acting as a sizeable nucleus for distributed ecovillage diffusion throughout the urban core, there were very few options.

Despite its inherent cultural associations and potentially major challenges, which will be discussed at length in section 3.2, the Central Experimental Farm (CEF) fields stand out as a potential prototype for an urban permaculture settlement (Figure 4 - Figure 12). Other options would require the appropriation of existing parkland or established urban woodland, thereby defeating the purpose of OPI's dissentient and recuperative mission. These other greenspaces, including backyards, would be reserved for the greater project of 
citywide agroecological dissemination. Furthermore, the present state of the CEF fields stand out as a model for standard agricultural practices: ${ }^{30}$ they are almost completely devoid of wooded thickets, hedgerows or windbreaks; they are directly exposed to urban contaminants, with no apparent natural systems of purification or buffering other than sacrificial field plots $^{31}$; they possesses no water features beyond the neighboring Arboretum; they do not incorporate any microclimate moderating components; in short, they are an exhibition of monoculture and ecosystem simplification. The plan for OPI is thus one of rehabilitation and enhancement for CEF-a rehabilitation of not only its

${ }^{30}$ Without accusing CEF and AAFC of wholesale rejection of permaculture and organic agroecology, it should be noted that CEF is conducting research into genetically-modified crops and animals [83], which represents the antithesis to permacultural practices (see 1.1.1).

${ }^{31}$ As an example of the existing condition of some of the soils, a recent news article quoting an AAFC spokesperson has revealed that 5 hectares of CEF are contaminated with road salts and are now "unusable for scientific research anyway" [108]. It should be noted that the use of the word "anyway" refers to the controversial plans to build a 24-hectare expansion of the Ottawa Hospital (Civic Campus) in this area of CEF [216], thereby ignoring any possibility for bioremediation or soil rejuvenation. It would appear that near-sighted and narrow-minded local politics are encroaching on, not only the historical value of the site, but a valuable plot of potential urban greenspace. If the principles of permaculture were interjected in this debate, the argument could well be made that this contamination presents a research opportunity for AAFC to study the loss and revival of farmland due to automobile-associated pollution, something desperately needed for both urban and rural contexts. This holds true especially due to the fact that AAFC has not proposed a possible solution for reversing contamination on CEF property and it could be concluded that AAFC does not yet possess such a strategy nor the will to develop one. Yet, it only seems logical that a federal government body charged with the management of the Nation's agricultural lands would be very interested in such an opportunity and staunchly-opposed to giving up this land for purposes other than scientific research. 
landscape but, more importantly, an enhancement of its role in the larger circle of life.

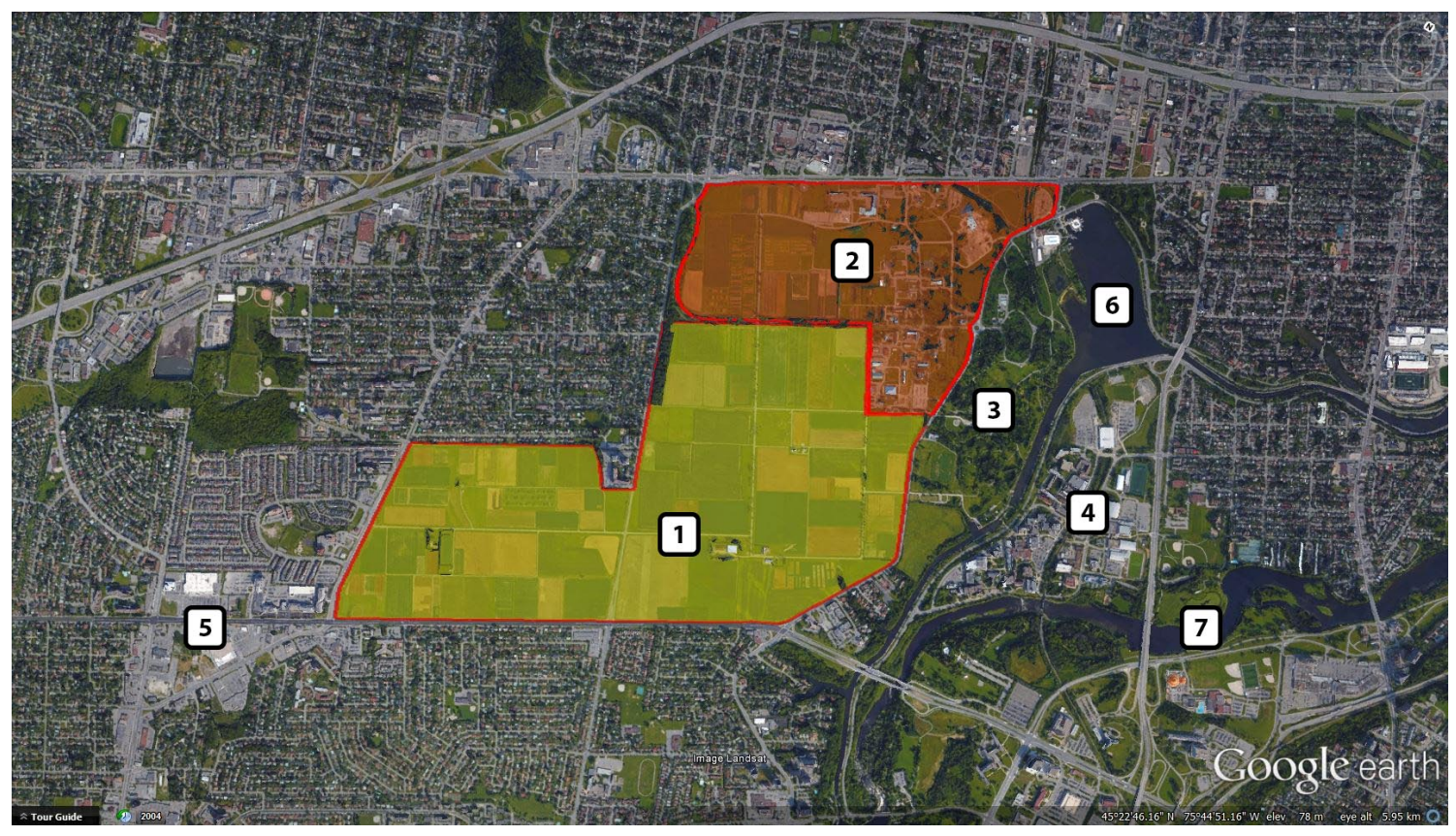

Figure 4: Google Earth aerial view; yellow area is proposed site for OPI and orange area reserved for CEF; no.1proposed OPI site, 2- reserved for CEF, 3-Arboretum, 4- Carleton University, 5- Laurentian Place (shopping), 6-Dow's Lake \& Rideau Canal, and 7-Rideau River.

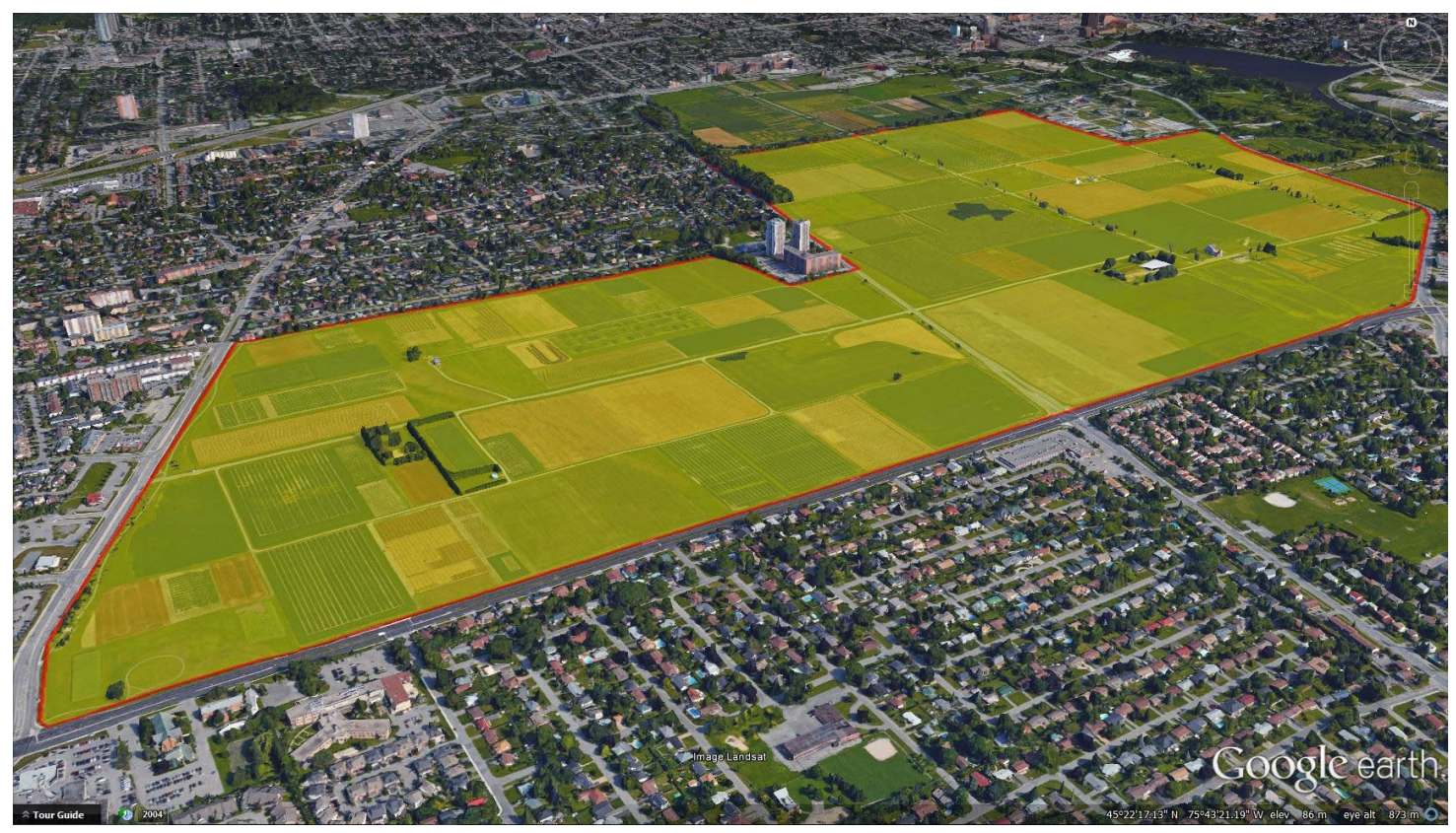

Figure 5: Google Earth aerial perspective of proposed OPI site, looking north. 


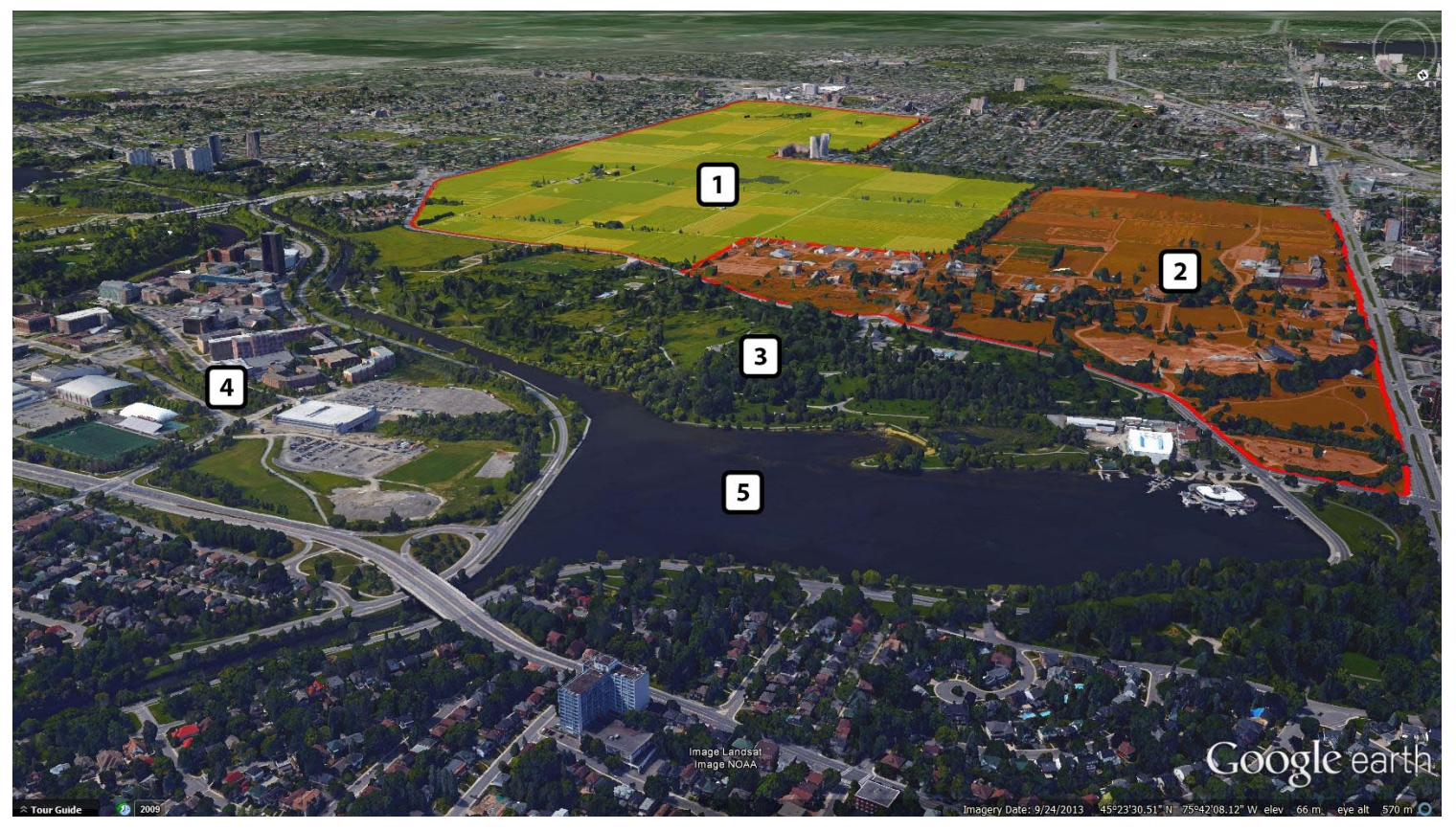

Figure 6: Surrounding area - Dow's Lake, Rideau Canal, Arboretum and Carleton University; ; no.1-proposed OPI site, 2- reserved for CEF, 3-Arboretum, 4- Carleton University, and 5-Dow's Lake \& Rideau Canal.

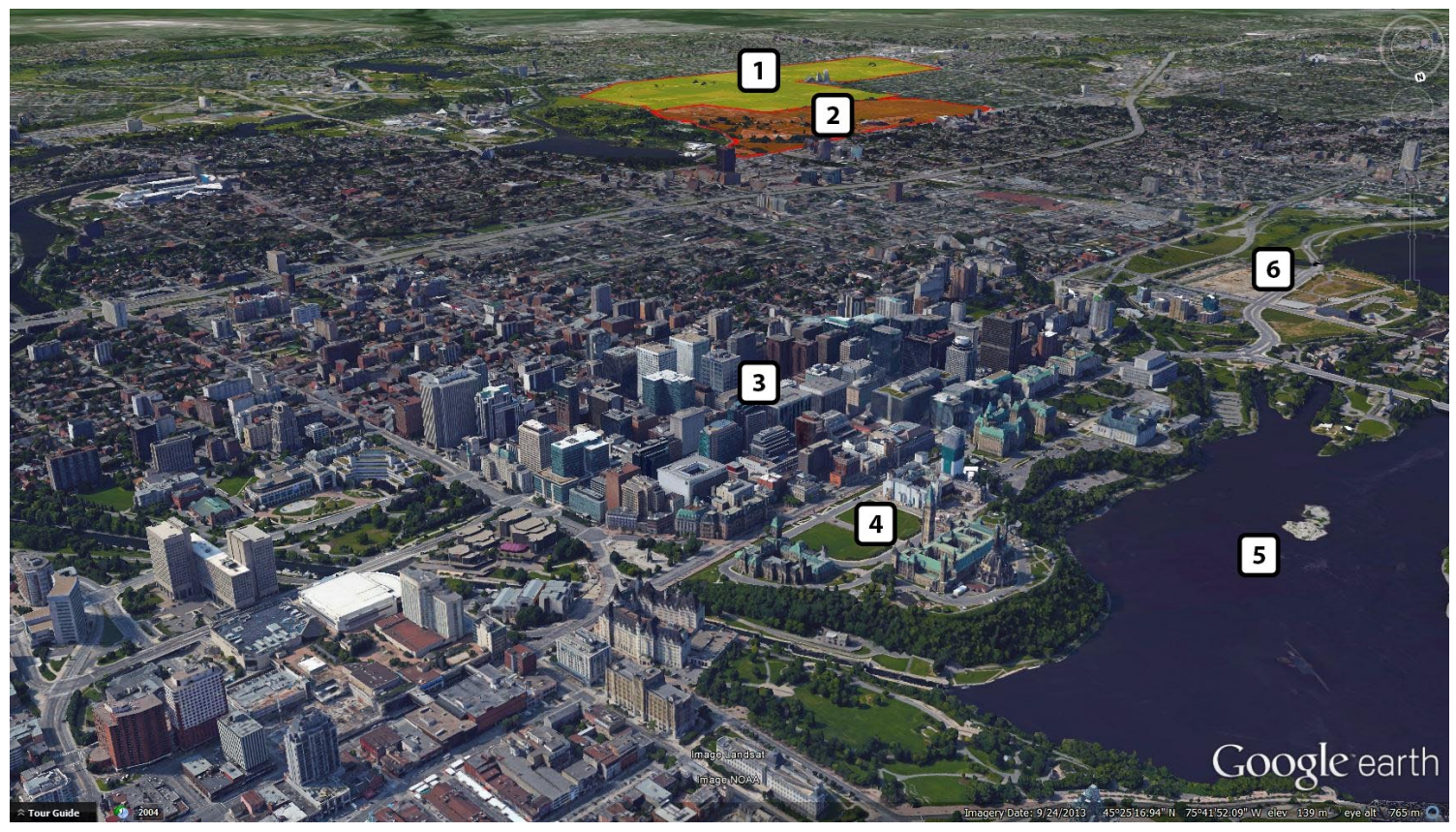

Figure 7: Surrounding area - relation to downtown core; no.1- proposed OPI site, 2- reserved for CEF, 3downtown Ottawa, 4- Parliament Hill, 5- Ottawa River and 7- LeBreton Flats. 


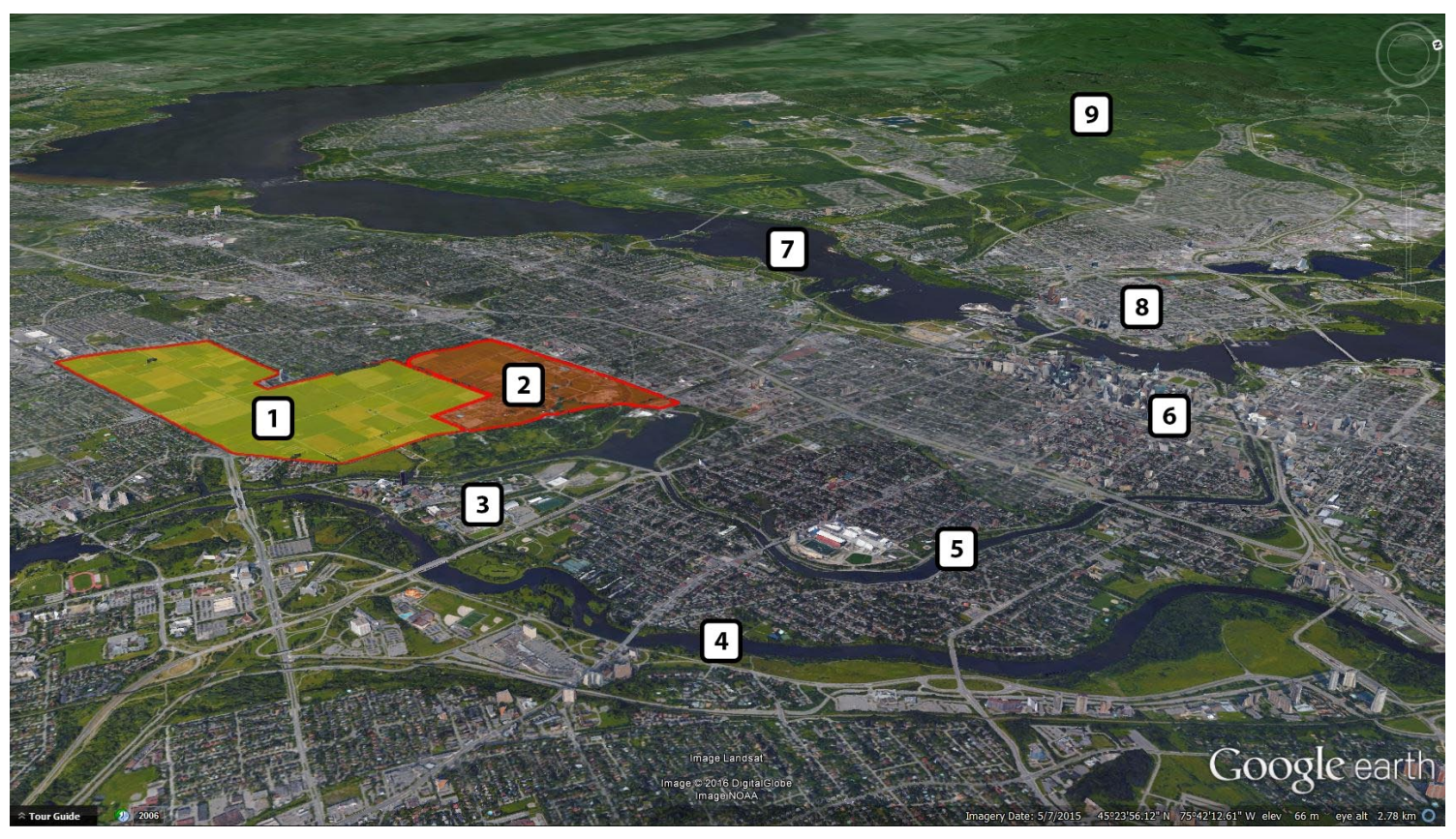

Figure 8: Surrounding area - relation to Rideau Waterway system and the Ottawa River; no.1-proposed OPI site, 2- reserved for CEF, 3-Carleton University, 4- Rideau River, 5- Rideau Canal, 6- Downtown Ottawa, 7Ottawa River, 8- Downtown Hull and 9- Gatineau Park.

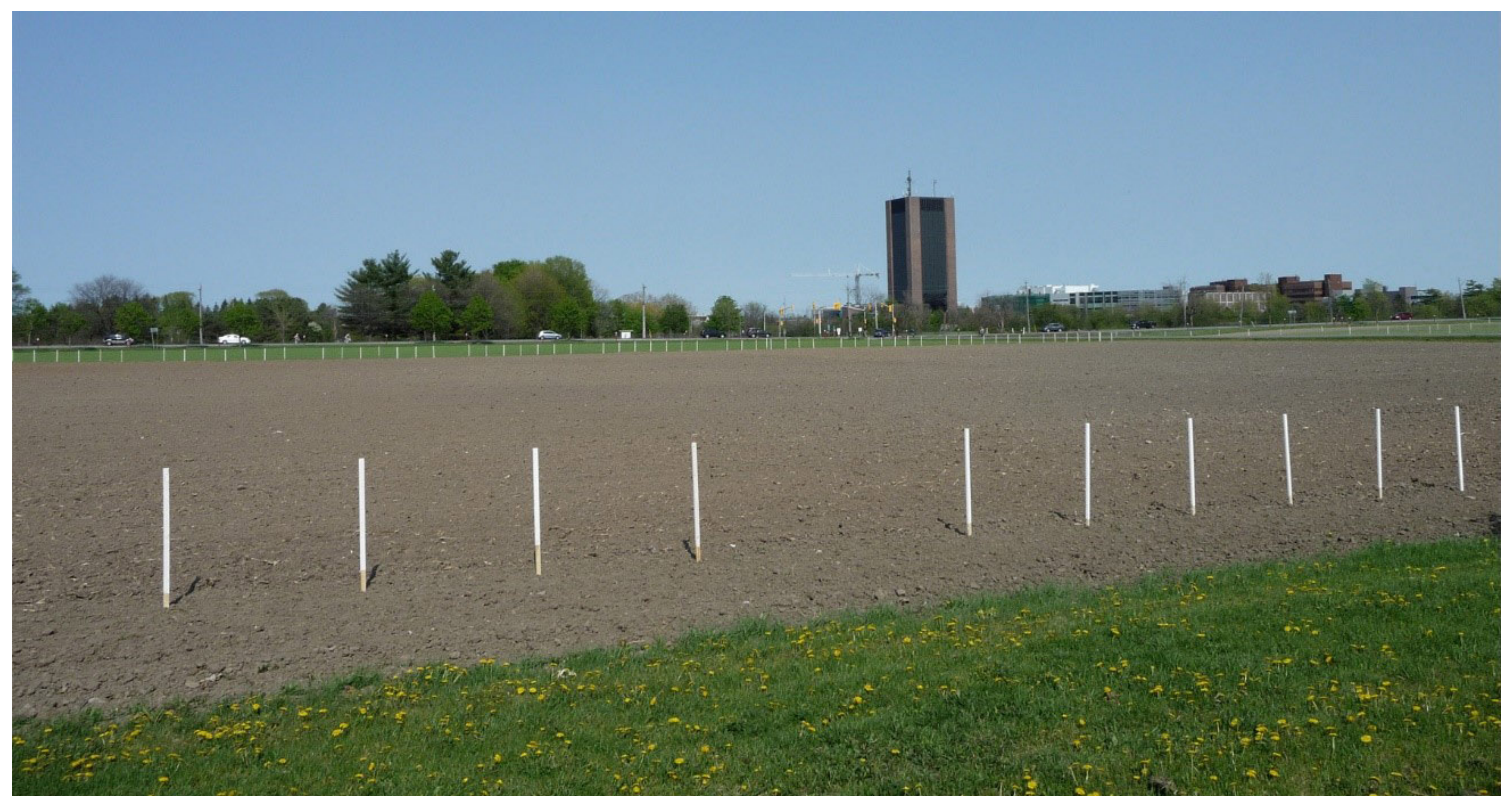

Figure 9: On Morningside Lane, looking east towards Prince of Wales Dr. and Carleton University. 


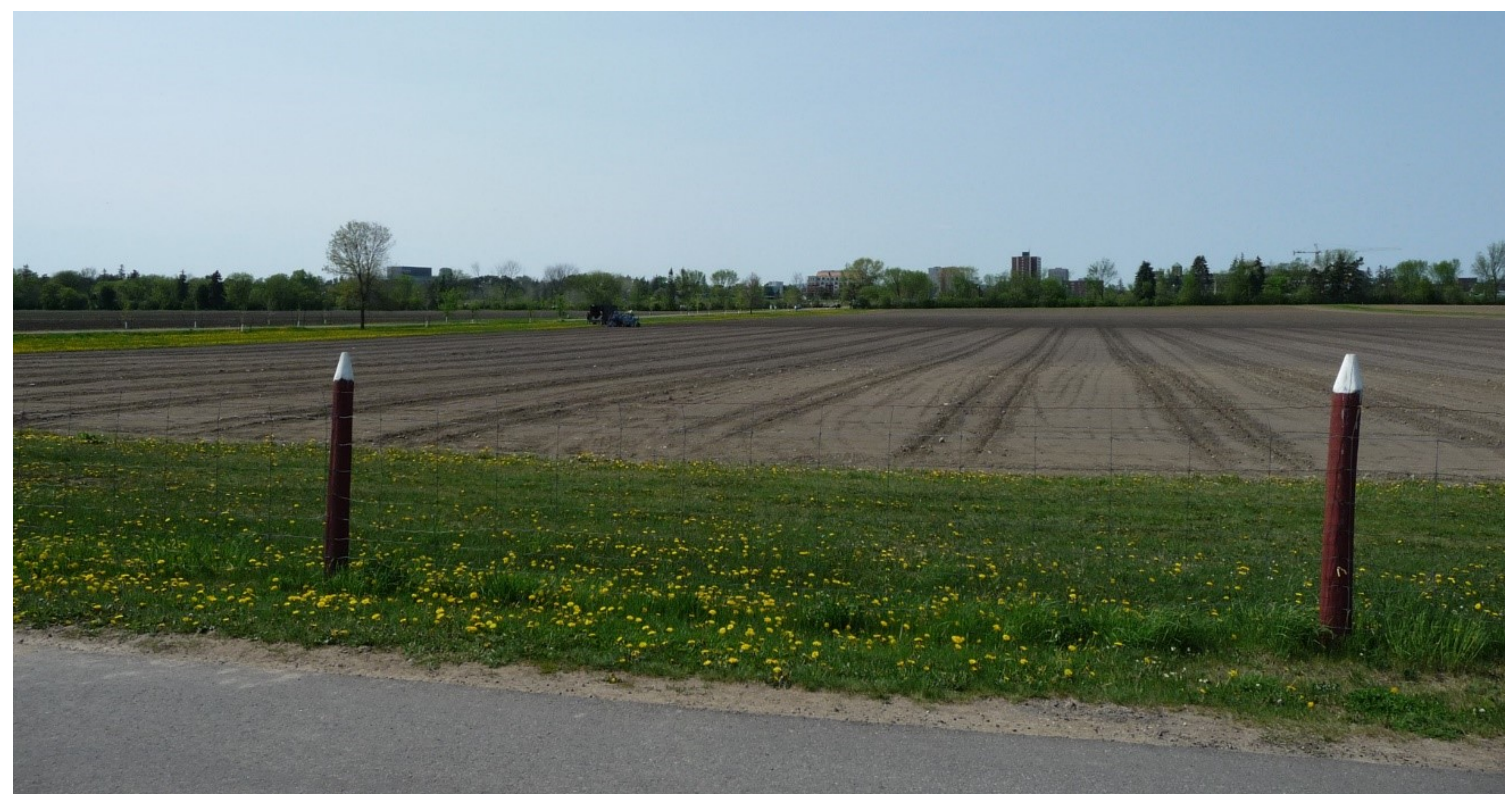

Figure 10: View from Cow Lane, near Ash Lane, looking northwest toward NCC Scenic Driveway.

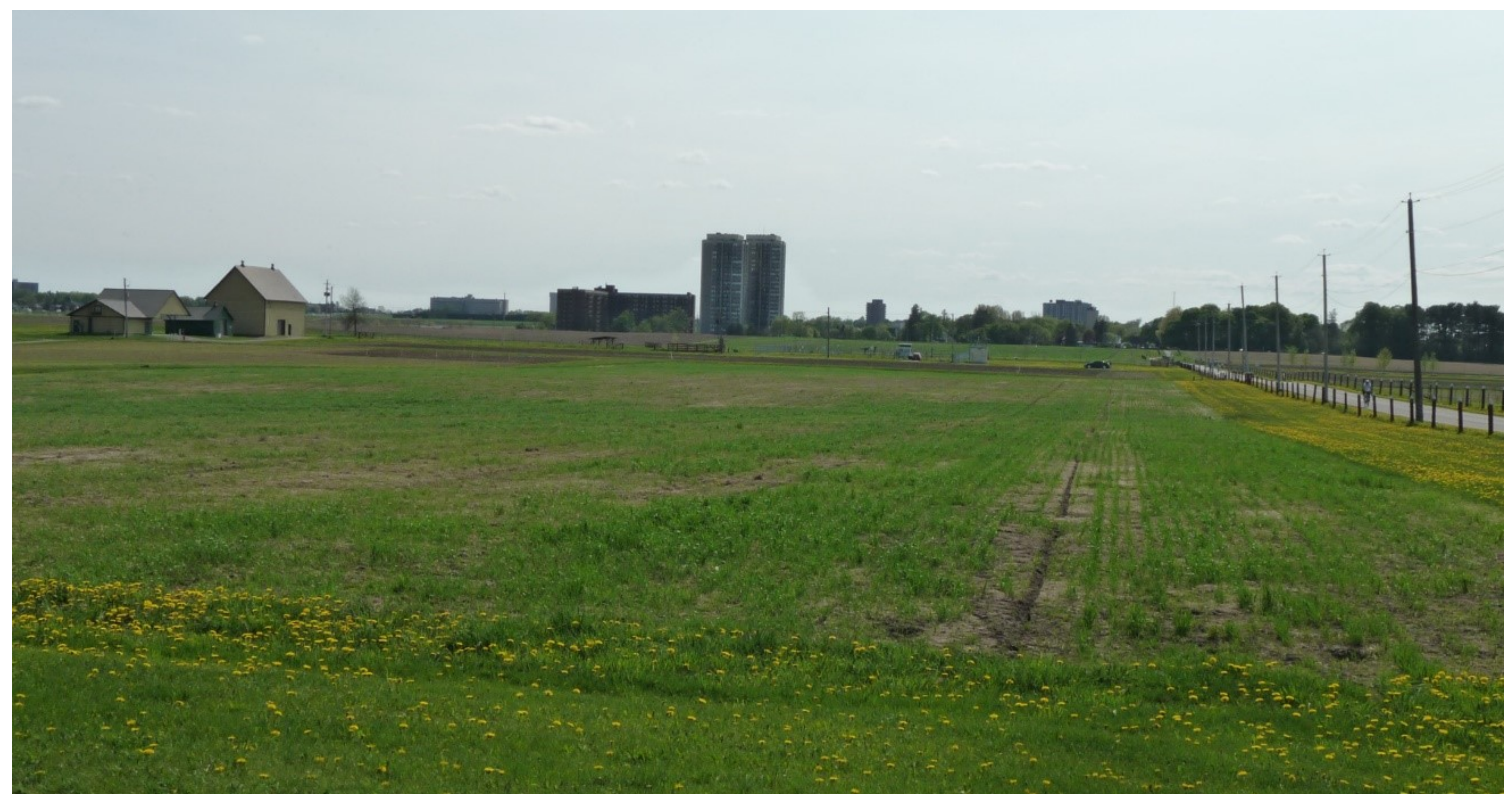

Figure 11: View from Morningside Lane, near Cow Lane, looking northwest toward Fisher Ave. 


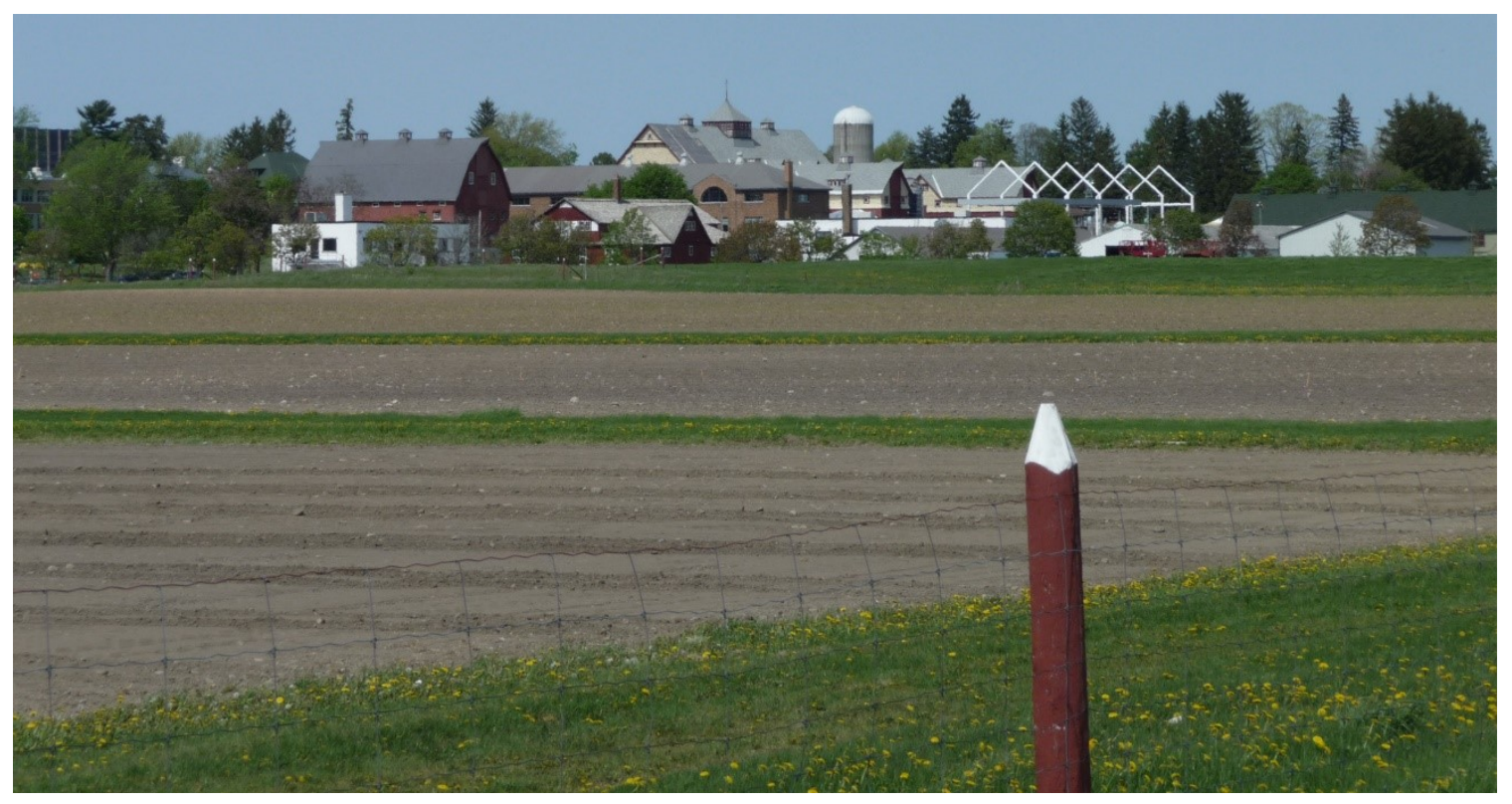

Figure 12: View from Cow Lane, looking towards the Canada Agriculture and Food Museum at CEF.

Central Experimental Farm Site Map Carte de la ferme expérimentale centrale Legend/Légende
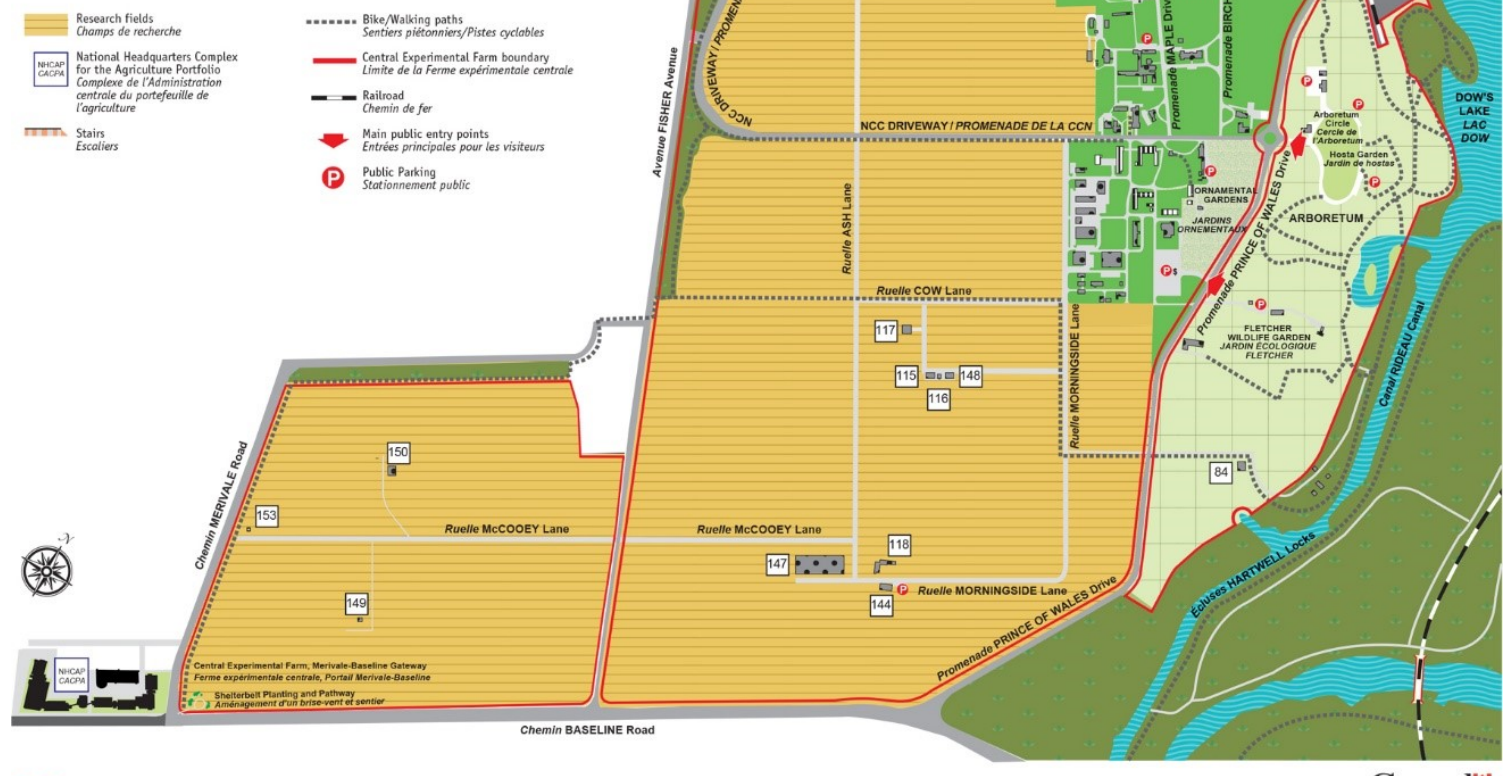

Figure 13: Map of CEF (provided by Agriculture and Agri-Food Canada). 


\subsection{CEF AND DOMINION EXPERIMENTAL FARMS}

The CEF was created in 1886 after the federal Department of Agriculture (now Agriculture and Agri-Food Canada) created its Experimental Farms Branch with the intent of linking together rural agriculture and intellectual institutions and organizations, in a wider project of improving farming settlements in the Canadian northwest and other regions [78]. To study this broader initiative, the federal government appointed pharmacist, natural scientist and horticulturalist, Sir William Saunders. Before his appointment as director of the Dominion Experimental Farms (DEF) system in 1886, Saunders was president of both the Entomological Society (1875-1886) and the Fruit Growers' Association (1873-1886) [79].

Having worked together while still the provincial commissioner of agriculture and public works of Ontario, Conservative John Carling used his influence as the newlyappointed federal minister of agriculture to lobby for Saunders' nationwide scientific farm project. Initially, five experimental farms were established by Saunders under the DEF banner, the first being the Central Experimental Farm in Ottawa, followed by four in other provinces: Nova Scotia (Nappan), Manitoba (Brandon), Saskatchewan (Indian Head) and British Columbia (Agassiz). Saunders held his position as Director of the DEF system until 1911, when he retired at the age of 78 . Later, the DEF system added seven more locations across the country, from Alberta to Prince Edward Island [79]. By 1930, the system 
managed a total of 32 agricultural farms, stations and substations all over Canada, including stations in some of the severest growing climates such as the Yukon, North West Territories and northern Alberta [80].

The role of the farm system was to study nearly every aspect of period agricultural practices in relation to Canada's harsh climate, which included animal breeding (husbandry), dairy farming, cereal culturing, field crops, grasses, forage plants, fruit trees, vegetables, fertilizers, pests and plant diseases, seed production, forestry and the general application of science to agriculture [78] [79]. This involved the chemistry of fertilization and pest mitigation, as well as horticultural practices like cross-fertilization, hybridization and grafting. While under Saunders' directions, DEF published information for farmers, created many new varieties of fruit trees and developed new strains of grain, all while establishing itself as a supplier of seeds and cuttings [79]. The farms fibre division even studied the cultivation of cannabis in the Canadian climate. The results of the hemp study conducted at CEF were reported to be "so promising" that development of the Canadian hemp industry was pledged [80]. This promise was abandoned, unfortunately, with the politics of prohibition that followed during the 1930s, with hemp research in Canada not resuming again until 1994, and its legalization as a licence-controlled agricultural crop finally legislated federally in 1998 [81].

The model for the CEF was imported from England by Saunders, along with its specific notions of the ideal farmstead and landscape, and indeed it typifies the classical 
European paradigm of rectilinear compartmentalization that separates human settlement from large monocultured farm fields, and both from natural ecosystems (Figure 14). The model for the central area (main building complex) is described as "loosely based on English garden landscape tradition associated with public parks and grand country estates". Of course, at that time, the farm's location was far more rural than urban, occupying the fringes of the city. By as early as the mid-1930s, that had changed. The expanding city limits were beginning to encroach on the site's pastoral origins. [78]

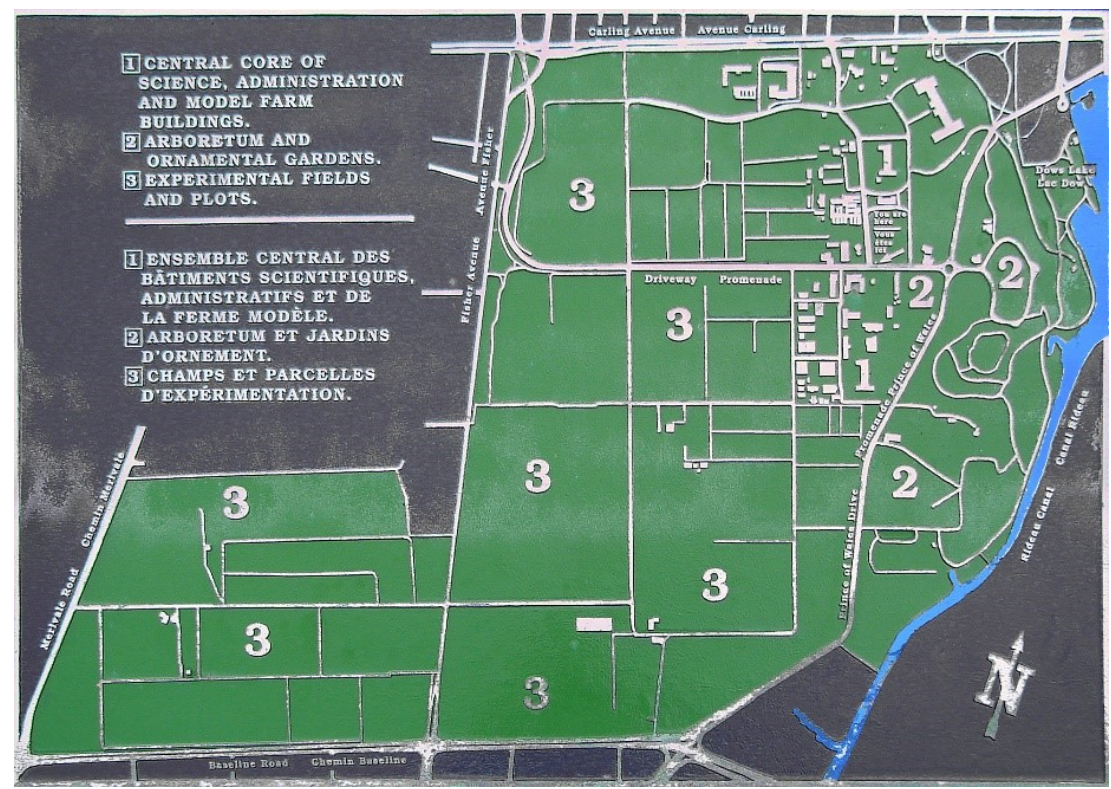

Figure 14: photograph of metal plaque at the corner of Maple Dr. and NCC Scenic Driveway [82].

Since its beginnings in 1886, CEF's mission has not changed much; however, some structural adjustments led to modifications in function, which were followed by further transformations in form: buildings were demolished, new ones were erected and, it would appear, trees were targeted. In 1960, forestry research on the farm ceased and its animal 
research facility was moved to Ottawa's greenbelt. During the period leading up to these changes, a "scenic driveway system" was constructed that lead to the removal of much of the farm's remaining trees and, although these paved roads were completed in the mid1940s, their impact on the landscape is still very much noticeable today. In addition to the area-wide loss of greenspace to urban expansion, followed by its silvicidal "modernization", the farm's timber population suffered another assault when disease terminated a large number of mature elm trees. In retrospect, this should not have come as a surprise, for it has been shown that a decline in species resiliency is a direct result of ecosystem simplification. By the 1960s these lessons either continued to be overlooked or had been forgotten: the last band of remaining forest along Carling Avenue was razed [78].

Today CEF still operates under the supervision of Agriculture and Agri-Food Canada, which in 1886 was named simply, the Department of Agriculture. The farm now includes the Canadian Museum of Agriculture (created in 1983) and in 1998 it was designated a National Historic Site by the Federal Government. The fields and buildings are still used for agricultural research, although it now seems that its scientific endeavours have merged with the interests of corporate biotechnology-unfortunately, it appears that 
much of the CEF research in horticulture and livestock breeding now involves transgenic species [83] [84] [85] [86]. ${ }^{32}$

\subsection{CULTURAL LANDSCAPES}

\subsubsection{The Central Experimental Farm National Historic Site Management Plan}

After being designated a National Historic Site in 1998, public consultations were held to help devise a future management plan for the CEF. Three initiatives resulted from the public consultations. The most current initiative forms body of a report and administration plan that was drafted by AAFC and is published on their website: the Central Experimental Farm National Historic Site Management Plan referred to here simply as, the Historic Site Management Plan (HSMP) [78]. The purpose of the plan was to develop a framework for the protection of the CEF as a National Historic Site with a recognized cultural landscape with heritage value for the National Capital, the entire nation and its agricultural history [87].

${ }^{32}$ It is worrying that AAFC's Ottawa Research and Development Centre at CEF claims, in successive statements, to be at once committed to "genetic enhancement" of crops and "biodiversity of vascular plant, fungi and bacteria, and invertebrates" [219], since genetically-modified organisms (GMOs) pose a series of potential threats to both ecosystems and human health. Some studies prove that GMOs have toxic effects on mammalian body systems [220], while others show that GMO strains are now mixing genetically with naturally-evolved strains [221] [222] [223]. Yet, without knowing the potential ramifications of this budding science, the vast majority of North Americans are unwittingly eating GMO food every day, and a majority of farmers are releasing these mystery genomes into the natural environment at every crop rotation. 


\subsubsection{Associative Landscapes}

The UNESCO (United Nations Educational, Scientific and Cultural Organization) definition of a "cultural landscape" is given in HSMP and then divided into three subcategories, which the author(s) argue can all be applied to the CEF at different stages in its historical development [88]. The broader definition begins as description of the connection between "mental landscapes" and physical landscapes, where a place or area holds collective psychological value for a group, culture or nation. It is a historical relationship that exists between a cultural group and a site, landscape or region, and can have different meanings and associations for various peoples with traditional connections to it [88]. The HSMP separates the CEF's history into three phases marked by relevant turning points, each associated with a generalized form of cultural landscape.

The first is a "designed cultural landscape", beginning with the founding of the CEF in 1886 , when an "imagined landscape" was applied to a physical landscape, thereby transforming it into a tangible anthropogenic reality. The design of the CEF's physical space was an application of $19^{\text {th }}$-Century scientific rationalism-described as a Victorian and Edwardian value system - that created an ordered, rectilinear compartmentalization of the land into its research fields and three overarching recognized zones: an entry zone, a core zone, and a support zone [89]. The entry zone was defined by a "picturesque character" and comprised the bulk of the farm's "soft landscape", which included the 
Arboretum, the Ornamental Gardens and the grounds of the original residential and institutional buildings. The core zone, included a mix of "hard" and "soft" landscapes, where the prominent architecture, roads and research buildings were located. The fields form the relatively unchanged support zone of the CEF, which is named presumably due to its function as outdoor support for the farm's scientific research pursuits. With respect to these support fields, this early phase is described by the HSMP as having "very little of the picturesque landscape left" [88], with only the wooded drives and the forest belt along Fisher near Carling remaining to communicate the image of a scenic farm environment. The picturesque qualities were confined mainly to the first two zones.

In 1936, the Director's residence was demolished to make way for the Saunder's Building. This initiated a series of gradual reforms to the landscape and gave rise to what the HSMP refers to as its second phase, as an evolved cultural landscape. With this type, the primary designed landscape is subjected to various changes and adaptation, over time, resulting in an evolution of its physical and cultural realities, while still retaining a fundamental link to its original purpose. For the CEF, this involved changes to both its physical form and practical function. Between 1936 and its centennial anniversary in 1986, the scientific pursuits moved indoors into greenhouses and laboratories, with a more theoretical research concentration replacing its original empiricism [88]. During this transformation, the direct link to public involvement on the farm was severed, resulting in the CEF's institutional identity becoming more abstract, functional and less picturesque. 
This period also marked the loss of several treed shelterbelts, thus creating a more exposed physical landscape, with less emphasis on its initial character as an idyllic farmstead and its research fields relegated mainly to research support roles [88].

Its third and final phase as an associative cultural landscape began with the CEF's centennial celebrations, which initiated a revival of its public relations initiatives. This celebratory commencement lead to the formation of more intangible cultural associations, where the "imagined landscape" began to reestablish itself as public historical awareness. Discussions about the farm's future led to renewed interest in its role as a public research institution, with various cultural associations revealing what is now considered as its overall heritage value [88]. This culminated in its designation as a National Historic Site in 1998, which has brought the cultural landscape back almost full circle to a reconsideration of the CEF's designed landscape. When the HSMP report was written, a strong emphasis on preserving its $19^{\text {th }}$-Century character was being stressed, all while recognizing the importance of its continued scientific evolution. A dual narrative thus surrounds its associative landscape: one is the story of a post-colonial national heritage site with specific aesthetic, natural and cultural resources, the other is the profile of an active agricultural research institution with scientific value for national and international agronomics. 


\subsubsection{HSMP Recommendations}

After weighing the options for CEF's future mission against the backdrop of the specific challenges faced by each of its "layered cultural landscapes" and their particular associations, the HSMP recommended that a research agenda be adopted, planned and implemented [90]. Because its scientific function has remained intact since its creation, it was perceived that this is the best method of safeguarding the "central heritage identity of the site" [90]. The two rejected options (multiple identity and "Museum-without-Walls") would have either kept the farm essentially as it was in 2013 (factionalized but with greater clarification and coordination) or increased the role of the Agriculture Museum in the farm's management (with a greater cultural and public interpretive function in the community). In both those scenarios, scientific research at CEF would have continued but not as a single unifying objective. This choice reflects perhaps a will for policymakers to return CEF to it roots, as a continuum with its original $19^{\text {th }}$-Century model, now in a $21^{\text {st }}$ Century scientific context. What remains unclear, however, is what this means exactly for CEF's new research initiatives. Many statements are made in HSMP regarding the research option's objectives, management guidelines and design criteria, however, with regard to what type of research will be conducted to meet said objectives, very little is developed and much is left open to interpretation and speculation. Perhaps these specifics were to be included in a follow-up report, although no such document is currently readily available on the AAFC website. 
Rather than list all of AAFC's recommendations separately, it will suffice here to draw parallels and to highlight divergences between the objectives of OPI and the current directions of the CEF, which are detailed and authorized in the HSMP report. What follows in 3.2.2.1.1 and 3.2.2.2.1 are two lists that correspond to these mutual objectives and conflicts in values, the former making the case for the CEF as the chosen site for OPI, the latter exposing barriers to its real-world implementation.

\subsubsection{Disturbance AND Succession: A [R] eVolved Cultural Landscape}

The transformation of CEF's physical landscape proposed in this project would be major, and would result in a significant modification of its cultural landscape. However, the intentions of this transformation would not be to deny existing cultural associations, but to instead create a disturbance that would initiate a succession in both its cultural and ecological landscapes. If ever considered as a real project, the objectives of OPI would thus represent a deliberate evolution in the biological diversity and cultural diversity of the CEF, which, through an envisioned initiation of a distributed ecovillage movement, could potentially result in a socio-ecomorphic enhancement of both the National Capital's cultural landscape and Canada's wider agricultural pursuits.

\subsubsection{Shared landscapes: OPI and CEF's HSMP}

To be certain, the historic site management of the CEF itself could be a potential barricade to the establishment of an experimental agroecological settlement in the area now 
referred to as its research support zone. Nevertheless, careful study of the Central Experimental Farm National Historic Site Management Plan's online report reveals parallel goals and objectives that should not be ignored. Such parallels may or may not justify the radical transformation of its research landscape in a real-world scenario, and this would remain to be determined by a plurality of both Canadian and First Nations voices. In a democracy, such decisions should not be left to policymakers and "stakeholders" alone, as the most valuable patrons of such a significant place as the CEF are the future members of this nation. Absent a widespread public understanding of the benefits that permaculture holds for our world, the debate between decentralized ecological agriculture and corporate biotechnological agribusiness could remain skewed in favour of an environmentallydestructive status quo.

\subsection{Mutual Objectives}

The following list will paraphrase or quote the HSMP in bold italicized typeface, followed by the corresponding statement on OPI's shared objectives, in regular typeface.

\section{1) HSMP pledges to continue agricultural research, with research becoming a renewed} central role. The core mission of OPI is to advance research into perennial agriculture (permaculture) and hyper-sustainable polycultures (hemp and symbiotic food crops), and to further research into renewable building products. OPI is a research-oriented farming collective, hence an experimental farm in its own right, with the potential for strengthening the "research identity" of the CEF. Furthermore, OPI would be 
committed to opposing the loss of CEF acreage to any development contrary to its original function as an agricultural research facility and ecological landscape, including the opposition to the expansion of the Ottawa Hospital's Civic Campus.

2) HSMP stresses the value of heritage and associated historical cultural landscapes. The plans for OPI do not aim to destroy the CEF's cultural heritage; the changes proposed in the Praxis Diagram fall under the definition of an evolved cultural landscape, whose "mental and physical geographies" [88] still hold a direct and strong association to the farm's original purpose as a centre for agricultural advancement. The intent is to add additional layers of complexity to the present cultural landscape, which can enhance its meaning for the past, present and, most importantly, the future of Canadian agronomics.

3) CEF Stands as a monument to agricultural history in Canada, which maintains and conserves many architectural resources and historical buildings, such as the Canadian Agriculture and Food Museum, the Dominion Observatory, the Saunders Building, its heritage Main Barns and several more that have become an integral part of Ottawa's post-colonial heritage landscape. For these reasons, the plans for OPI do not encroach upon the core and entrance zones of the farm. Every single building of heritage value and historical significance would remain untouched.

4) HSMP recommends openness, flexibility and adaptability in the CEF research pursuits. If this is indeed true of their present programmes, then the addition of innovative sustainable organic farming practices should not be seen as a potential infringement, but as an exciting opportunity for scientific advancement.

5) The management plan stresses CEF's commitment to public education. Permaculture is based on socially-mutualistic relationships where education is not only seen as a reciprocal responsibility, but is welcomed as an intrinsic purpose of its craft. OPI would dedicate a substantial portion of its shared resources to public education. 
6) HSMP recognizes the significance of scientific research combined with practical verification. Permaculture can be aptly described as an empirical applied science based on natural ecological relationships. While it has yet to be treated as a "true" natural science, it is devoted to a continual (i.e. perennial) learning process, which amalgamates verified practices, scientific knowledge, experiential data and oral tradition into a totalizing system. Now is perhaps an ideal time for the agricultural sciences begin paying it notice.

7) The CEF is to remain committed to sustainability initiatives and maintaining the site as a public greenspace. The Praxis Diagram for OPI could be regarded as an enhanced sustainability initiative that repositions the CEF as an augmented urban greenspace, a reforested zone and urban cool island, with many benefits for both Ottawa's human and natural systems.

8) HSMP pledges research programmes that integrate urban/rural sustainability and ecology, contribute to public consciousness of urban agriculture possibilities and maintain CEF's identity as "farm within a city" [89]. Permaculture and all forms of agroecology offer promising frameworks for holistic environmental remediation, waste recycling and food production in both rural and urban environments. The development of an experimental agro-ecovillage within a city would take this pledge to the next level in terms of its sustainability commitments.

9) Scientific research that contributes to agricultural initiatives and support of farmers throughout Canada. With the numerous environmental harms caused by energyintensive agriculture, including the gradual decrease in soil fertility and crop yields, the development of a national permaculture strategy for both individuals and farmers, could benefit not only agricultural communities, but the country as a whole. OPI would give $\mathrm{CEF}$ and AAFC the opportunity to research these strategies within an urban environment, where the particular challenges to agroecology could foster novel 
permaculture techniques and contribute to scientific advancement in the field sustainable agriculture.

10) The CEF is to maintain an important role in the function of AAFC. The HSMP revealed in one fleeting mention that there are voices of change emerging from within the various government bodies that now share the CEF; perhaps from even within the AAFC itself. This mention was framed as unnamed persons and institutions that would like to see AAFC embarking on new research pursuits into "sustainable cities, ecological agriculture and the connections between the two" [91]. Presumably, this refers to agroecology and urban permaculture, yet it is mentioned simply in passing without discussing its future role in $21^{\text {st }}$-Century agronomics and how the HSMP recommendations could allow for such future changes.

11) The AAFC commits government to reforestation of urban environments, studying the relationship between agricultural and natural ecosystems and creating a context for urban agriculture. The proposed changes to the CEF under OPI, with its significant reforestation scheme, would provide AAFC, NRCAN and other agencies with a model environment for studying urban reforestation and landscape renewal.

12) Brings together private initiatives like AAFC, the Ottawa Field-Naturalists' Club and the Ottawa Chapter of Landscape Ontario to "encourage restoration of natural habitats in urban and rural settings" [92]. Permaculture is not only reformative, but regenerative and rehabilitating. The overarching goal of OPI is to create a model foodproducing ecosystem that feeds not only human settlements, but contributes to biodiversity and sustains natural wildlife within urban, peri-urban and rural landscapes.

13) The CEF brings together federal agricultural and parks agencies like AAFC, the Canadian Agricultural Food Research Council (AFRC), the Canadian Dairy Commission (CDC), Natural Resources Canada (NRCAN), the National Capital 


\section{Commission (NCC) and Parks Canada, each with its own policy/planning priorities,}

in a common vision of sustaining CEF's scientific and cultural significance. The proposal for OPI does intend to affect these intragovernmental relationships and would certainly include them in its research. One would hope that AAFC, AFRC and CDC would be very interested in OPI's agroecology, cannabis, aquaculture, polycultures and animal-plant symbiosis research; while NRCAN would be attracted by OPI's agroforestry, natural industrial fibres and oils for biocomposites research; while the NCC and Parks Canada would be moved by the prospect of revitalizing a complex foodbearing ecosystem that would also double as an enhanced urban greenspace.

\subsubsection{Barriers to Cultural [R]evolution}

\subsection{Conflicting Value Systems}

The obstacles likely to be confronted in a real-world realization of a project like OPI at the Central Experimental Farm would be many; however, funding issues aside, the HSMP reveals that these barriers are mainly socio-political and values-based, not physical. What is interesting to note is that, overall, the stated environmental sustainability values are directly in line with OPI's, as well as with many of the scientific ideals. What makes OPI seem like such an opposing scheme lies mainly in CEF's specific agronomic model and, most notably, in its recognized cultural identity. In the list that follows, the bold italicized typeface represents a potential challenge or barrier, followed by either a rebuttal or critical agreement, in regular typeface. 


\section{1) The addition of a residential complex to a purely scientific research landscape may be}

deemed contrary to existing zoning bylaws and could require amendments to Ottawa's Official Plan. This would pose a potential conflict with the City; however, considering that the CEF's core zone once included the superintendent's manor and at least four other residences for senior staff, it could be argued that the rehousing of permanent and transient research staff (OPI's main residents) would mark a revival of the original picturesque "rural village" quality of the farm, although within a novel aesthetic context. To state the obvious, there are several historical precedents for such an amendment of the site's current zoning.

2) Perceived insensitivity to the current cultural landscape. In consideration of the HSMP's "cultural landscape approach to land management" [87], it is necessary to reiterate the fact that OPI's mission remains highly congruent with this approach. The intent is to enhance and evolve the cultural landscape, all while retaining those pivotal associations that give the farm its heritage value (all of its heritage buildings, its scientific research, its farm-within-a-city and picturesque village qualities). With its cultural landscape now considered as associative in the HSMP, it is demonstrated that the farm's changes throughout time have severed many of the physical associations with the 19thCentury site. The OPI project would go beyond returning it to its original picturesque landscape: ecovillage settlement, reforestation, bioremediation, ecosystem modelling and intensive agroecology would revive a portion of its precolonial associations, thereby 
overlaying yet another associative cultural landscape through the implementation of a new designed landscape, in the process of creating a new evolving landscape. Of course, this in itself would be a point of contention for those who wish to freeze its "ordered functionalism" in time. However, the HSMP leaves this option open for discussion when it describes the CEF as a "dynamic context of a cultural landscape based on evolving relationships between land, community and science" [93].

3) Perceived challenge to current agricultural research. This is true. Permaculture represents a challenge to most current scientific, agronomic, economic, ecologic and sociologic research pursuits. Its approach to all of the aforementioned involves their reunification under the historical and universal guidance of philosophy. This sadlyforgotten paradigm originates from a time when knowledge itself was still holistic and not yet carved into segregated rectilinear compartments: monocultures of the mind. As such, it challenges research to once again interpret the world as totalizations, the dynamic totalities that give Nature its awe-inspiring order-in-complexity. Again, the goal of OPI is not to negate this present compartmentalized research, but to expand, enhance, diversify and progress it—beyond its fragmented rectilinear order-as a means of confronting the emerging onslaught of global-scale environmental crises that are, at once, presented to human civilization by civilization. If this approach would represent yet another barrier to a sizeable urban ecovillage at the CEF, then it is admitted and to be expected. Such a barrier should remain unchallenged. 
4) Perceived disinterest in AAFC's climate research. Not mentioned in HSMP, but of vital importance to the research pursuits at the CEF, is the farm's present research being conducted on climate change and agricultural soils [94]. AAFC scientists, including, E. G. Gregobich, are presently investigating soil temperatures, as well as nitrogen and carbon cycles in soils and how they are all influenced by climate change [95]. Add to this many other studies into the problems associated with modern agriculture and the CEF must be recognized as an important contributor to international sustainability science [96]. This mention should perhaps have been included in the above section on mutual objectives; however, seeing that present climate research is already underway at CEF, OPI's proposed reordering of the landscape could be interpreted as an undervaluing and a suggested termination of their current efforts. This would not be the case, as the research intended for the experimental ecovillage could work in perfect congruence with AAFC's studies by expanding them into the realm of universal solutions. These new studies would take existing scientific knowledge, combine it with time-honoured practical understanding and apply them to new sustainable methods of agriculture. The methods would then be studied in the context of anthropogenic factors-such as climate instability, deforestation and pollution-to assess yields, symbiotic species dynamics, soil health and remediation, water purification, microclimate, biodiversity, sociological implications and many other patterns and associations. However, if the main goals of the existing studies are simply to provide more evidence of anthropogenic climate 
change and devise small-scale singular responses to the particular problems caused by climate change, then OPI's holism could again be seen as confrontational. But confrontational is perhaps a fitting description for the project, since the goal here is to confront the major problems of our age and to do so first by questioning and subverting mainstream definitions of "progress" and "growth". Confronting institutional policies, uncovering reactionary undercurrents, raising eyebrows and offending egos are the least of humanity's present concerns.

\section{5) Perceived indifference to 19th-Century architectural heritage (architectural} resources). No buildings of recognized architectural significance would be demolished or repurposed. To begin with, the OPI's buildings are not planned for either the entry or core zones and, therefore, do not disharmonize with their Victorian aesthetics. It is not denied that the proposed community complex for OPI does not adhere to the design guidelines of the HSMP, but this is indeed intentional. Permaculture is diversity. Observance of "the Empire's" [93] outworn aesthetic should be reserved for a particular mentality, one that should have little to no voice in the design of contemporary communities that embrace the ethics of diversity. With centuries of oppression, environmental ruin, cultural genocide, racism and third-world impoverishment under its belt, it would appear that "the Empire" has already said too much. It is time that the voiceless are heard throughout the cultural landscape; it is time that their drumbeats again fill the air and their teachings resonate the eardrums of our children. In this spirit, 
the community complexes of OPI would aim to pay homage to the First Peoples of this great landscape we now call "Canada". First Nations groups and elders would be invited to play a key role in the final planning, design and daily functioning of the initiative. If this approach anyway appears incongruent with the cultural heritage of the site, then perhaps proponents of AAFC's historic site management plan could benefit from a careful reread UNESCO's writings and recommendations on indigenous cultural landscapes, which this international organization recognizes as the universal and underlying cultural landscapes of many of the world's heritage sites [97]. Although it is only identified at regional and national levels, the historic site of the CEF, as will be shown below, can claim no exception.

\section{6) Perceived encroachment on the heritage value of the CEF transportation resources.}

With the road system through the research fields remaining intact since its construction, the severance and potential rerouting of Ash Lane proposed in the OPI Praxis Diagram could be seen as a devaluation of the CEF's scenic road system. Furthermore, the traffic barriers that eliminate automobile access to the proposed OPI site would face certain opposition from many of the institutional bodies that presently operate on site-perhaps even from Ottawa and neighbourhood citizens. However, the sustainability concerns associated with automobile dependence in large urban areas are gradually causing a shift in attitudes towards North American car culture. City planners are now realizing that congestion and its associated pollution can only be combatted by alternative 
transportation systems. Walking, cycling and public transit plans are increasingly integrating into official plans via the application of "smart growth principles". Walkable communities are becoming the norm for city planners and it is with these core environmental principles in mind that the OPI plans were modelled as a "car-free community". When CEF's paved driveway system was constructed in the 1940s, automobile dependency was not seen as a deleterious pattern; it was perhaps even welcomed as a perceived technological evolution in modern urbanism. These attitudes are now shown to create numerous problems in cities, especially in an era of climate instability caused largely by anthropogenic greenhouse gas emissions. Therefore, it is difficult to imagine that CEF-linked government agencies would be against sustainability initiatives on the farm that could encourage greener behaviours (walking and cycling) in both its visitors and surrounding area inhabitants. After all, aside from Ash Lane, the farm driveways would remain in operation but limited to maintenance crews, research vehicles and disabled individuals with accessibility limitations. Additionally, several walking/cycling paths in an around the proposed Community Complex would enhance the walkability and cyclist-friendliness of the site by creating diagonal path systems linking Fisher Ave. to Prince of Wales and the NCC Driveway to Morningside Lane (Figure x, Nos. 2, 9 and 14), with several other pathways created in and around the intercropping fields and campground (Figure x, Nos. 4-7 and 11). 
7) Interpreted violation of CEF's identified historic landscape resources and a perceived dismissal of HSMP's support zone landscape design guidelines. The drastic change from Victorian-era rectilinear field compartmentalization to one based on permaculture design considerations would certainly be met with strong opposition. The HSMP considers the landscape as a "key to its cultural value", with the 19th-Century vision of its original founders important to the maintenance of the farm's "utility and beauty as interrelated measures of agricultural success." The largest zone on CEF, the "support" fields, has remained the most unchanged over the past 130 years and still reflects the original agricultural concepts espoused in 1886. This area is where the bulk of the field research has taken place since the establishment of the farm. The transformation of this zone from one of traditional compartmentalized monocultured farming to one of permaculture ecosystem modelling is recognized to be a drastic change that would meet significant resistance from all levels of government, including the AAFC and affiliated scientists. This too is well-understood, but at the risk of seeming repetitive, it can be argued that there exist apparent flaws in the HSMP's value system, beginning with its 19th-Century view of field research and its one-sided interpretation of cultural landscapes. 


\subsubsection{Criticism of the HSMP for CEF}

\subsection{Rectilinear Fragmentation}

It is realized that the purpose of the HSMP was simply to devise an overall scheme for the future direction of the farm and not to mandate its research pursuits; however, it should also be understood that the study of permaculture-like agroecology cannot be done in traditional monoculture compartments, that it is a holistic system that requires a reordering of the landscape to mimic natural patterns of biodiversity. As such, freezing the CEF research fields into their original $19^{\text {th }}$-Century ordered compartments equates to locking the research itself into a traditional tract that will essentially preclude serious future investigations into advanced forms of agroecology and agroforestry. Nevertheless, what is promising within the HSMP is its stated openness to new forms of research, which may require adjustments in the landscape:

The dynamic quality is the research activity itself, the ongoing use of this landscape to promote agricultural research and disseminate information. The static quality is those architectural and landscape elements that carry within them the record of this landscape over time. Some of the static elements will need to evolve in order to sustain the dynamic elements, but this has to happen in a balanced, healthy way in order to keep alive the various overlapping values of the site [90].

With its inherent contradictions aside, when this statement is weighed alongside of the revelation that certain individuals or entities involved with CEF's research are requesting "strategic decisions regarding ... [the] furthering of research into sustainable cities, 
ecological agriculture and the connections between the two", a greater contradiction begins to surface. The landscape elements that HSMP recommends remain "static" are precisely those that would otherwise enable said urban agroecological pursuits. What can be concluded from these statements is that, implicitly, they recognize the impossibility of an inert landscape whose stated function is to further agricultural research, since it is the research agenda that should ultimately determine the shape of the landscape and not simply its heritage designation. Indeed, its very dynamics cannot be removed from CEF's historical context:

Despite the designation, it is not a static site; it is a dynamic one, and this dynamic quality is in fact part of its history and its value. The requirement in terms of management planning is to sustain the underlying, cohesive qualities of the site at a broad level, while allowing significant evolution of individual components and programs at a local level [88].

This statement is reinforced later in the text when these "static" cultural elements are left open for modification or transformation through an evolutionary process dedicated first and foremost to scientific research:

The dynamic qualities of the cultural landscape would thrive in a renewed commitment to a research identity. The more static cultural resources could be caught up in an evolving model of site development, but careful review and assessment of proposed changes could provide protection where appropriate. The treatment of natural resources would depend on the overall research agenda [98]. 
Thus, it would appear that there exists some apprehension or confusion regarding CEF's research future and its correlation with the somewhat ambiguous notion of its "associative cultural landscape". The very idea of labelling certain associations as "static" within an overall dynamic environment serves to heighten the paradox. But instead of conceding to the impossibility of stasis within a rapidly-changing world, the HSMP then devised its design guidelines in such a manner as to preclude any changes to the landscape, in spite of its earlier statements on site dynamics. The support zone, it is stated, is defined by its "ordered" and "rectilinear grid", which "unifies" its landscape, and is to remain as such with mainly its crops and research allowed to change over time. Nevertheless, the contradictions of the HSMP lend themselves well to further debate and interpretation.

For certain, CEF and OPI presently represent two opposing agronomic models; one is already accepted and in practice, while the proposed could potentially be highly controversial. But controversy does not always generate a negative outcome and, often, it is required in order to stimulate debate, initiate progress and to break free from static paradigms. It is accurate to refer to the CEF, as it now stands, as an inert entity? Not at all, but it is the HSMP itself that recommends a duality between static and dynamic cultural resources and unfortunately it has deemed the research fields as static. It has done so implicitly by referring to their compartmentalization as an "intricate quilt" that should retain its "overall landscape character". Yet it is precisely this rectilinear model that results in intentional linear fragmentation of ecosystems and, in ecology, it is regarded as a 
negative human intervention on a natural landscape [99]. Thus, it can be argued that the landscape character of modern agriculture itself, with its ordered compartments of monocultures, is a major factor in the prevention of complex farmland biodiversity. If AAFC truly has voices lobbying for agroecology, then one would hope that its current direction is open to change. Taken as a whole, the HSMP's conflicting statements should be welcomed as an opportunity to make such revolutionary proposals as OPI, even if they still occupy an imaginary realm.

\subsection{Forgotten Landscapes}

Perhaps the most substantial criticism of the HSMP is centred on its cultural landscape assumptions, which appear to involve a major oversight. For a report on planning guidelines said to be based on a "cultural landscape approach to management"a 153-page report that makes 112 uses of the term-and cites UNESCO for its definitions, it is perplexing that not one mention is made to the oldest known and most ecologicallycentred cultural landscapes of the entire Kichi Sipi Valley: at least eight thousand years of First Nations' (i.e. the Algonquin peoples) heritage. The Central Experimental Farm is without a doubt seated on unceded Algonquin territory, yet AAFC does not officially recognize it as such: no statements are readily available on their website or recorded on internet search databases (as of January, 2017). Yet, in June of 2011, its closest educational institutional neighbour, Carleton University, released an official statement approved by its 
senate acknowledging its location on "the traditional, unceded territories of the Algonquin nation" [100]. It would appear that the Federal Government is also well aware of the relation of the Royal Proclamation of $1763^{33}$ to the Central Experimental Farm lands, since the Ottawa Civic Hospital Central Campus project—which has been granted permission to appropriate 20 hectares of the $\mathrm{CEF}$-requires legal consultations with the Algonquin First Nation before its final approval [101]. But, somehow, during the final year of United Nations' declared First International Decade of the World's Indigenous People (1995-2004) [102], AAFC released its Central Experimental Farm National Historic Site Management Plan [103] without making one mention of the 8,000-year-old cultural landscape of the Algonquin peoples. The only reference to an indigenous peoples' cultural landscape is in passing, alongside of tourist and mining communities, as a references to particular examples of associative landscapes:

A wilderness site can be an example of an associative cultural landscape. To a local aboriginal community, it may be a sacred site because of cultural patterns that use this landscape for rites of passage and for communal celebrations that are specific to the place [88].

While honest in its content, the statement undermines the fact that associative landscapes for indigenous peoples often include the entire land stewardship region that once

\footnotetext{
${ }^{33}$ The Royal Proclamation of King George III of England was "intended" to protect native rights to "all unceded, unsold land", to First Nations' groups in the British colonies, including the Algonquin peoples of the Upper and Lower Canadas. Today, it is still "recognized" under Section 25 of the Charter of Rights and Freedoms [25].
} 
encompassed their precolonial territories. For the Algonquians, this included some 200,000 unbroken square kilometres, as late as 1867, in Ontario and Quebec [104]—only nine years prior to the founding of CEF. Just how vast their territories were prior to European settlement is knowledge lost to the "stories told by the victors" (i.e. the histories recounted by Eurocentrists and colonialists).

With UNESCO providing the HSMP with its definitions of "cultural landscapes", it is difficult to understand how an indigenous narrative was not included along with discussions on the site's history and it associative landscapes. The overall outlook of this management plan report would seem to have agriculture and human settlement in the Ottawa River Valley beginning solely with the European colonies. Despite the rich indigenous history of the area, UNESCO's frequent published references to aboriginal land stewardship, indigenous contributions to World Heritage Site protection, traditional knowledge bases and native ecological management appear to have escaped the HSMP authors' notice. Indeed, in the preface to UNESCO's World Heritage Paper No. 26 on cultural landscapes [105], Director Francesco Bandarin accredits the protection of world heritage sites to the work of "local communities and indigenous people", whose "daily work and lives maintain these sites, often through their own protection measures, not by official legal provisions." References to indigenous peoples and communities abound in this and many other UNESCO documents, specifically in reference to their connections to ecosystems, biodiversity and land stewardship. In the section on "engaging and supporting 
communities" [105, p. 106], indigenous peoples are described as "the traditional custodians of the cultural values which are expressed in the landscape". This is not to insinuate that local descendants of settlers cannot perform some of these same functions in contributing to experiential awareness, being motivated by their particular cultural associations, or that all individuals of native descent still hold true to their traditional values; however, it draws attention to the fact that the strongest associative connections are most often those of indigenous peoples. This is due to the fact that First Nations cultures are undeniably rooted in the ecosystems they have managed and protected for thousands of years.

In another UNESCO publication on world heritage-a report on the Proposed World Heritage Indigenous Peoples Council of Experts (WHIPCOE) that was published in 2001, three years in advance of the HSMP_concern was raised regarding the absence of aboriginal voices in the creation of "laws, policies and plans" that would protect their "holistic knowledge, traditions and cultural values" [97]. The document provides a summary of the recommendations made to the World Heritage Committee concerning the formation of WHIPCOE and reminds states contracted under the World Heritage Convention of their "extensive obligations" towards the protection of indigenous populations, their natural heritage and cultural landscapes. Members from Canada were part of the process, as this country is signatory to the conventions. Most notable with regard to CEF and its HSMP is perhaps the following affirmation: 
AFFIRMS the view of indigenous peoples as the traditional owners and guardians of lands and waters, including biota thereon and therein, who remain forever the repositories, proprietors and custodians of their holistic knowledge, traditions and cultural values, which apply to all their ancestral lands especially those within or comprising sites now designated as World Heritage areas [97].

These words do not simply apply to World Heritage sites, but also "cultural landscapes" and "mixed cultural/natural" areas that are to be identified, protected and conserved, "even where properties are not included on the World Heritage List" [97]. If these definitions somehow fail to apply to the CEF, then the authors of its HSMP failed to communicate those mysterious qualities that separate it from all other national and international heritage sites. One may argue that its particular commitment to the agricultural sciences give CEF its specific value to the landscape. This is not to be denied; however, science, in itself and by itself, does not necessarily represent the pinnacle of human systems of knowledge. There are many who would point to oral traditions, inherited practice and native empiricism to highlight the specific deficiencies in Western scientific methods.

One document that shares this point of view deserves particular mention for a discussion on indigenous knowledge and its assistance with the study of ecology. Authored jointly by UNESCO and the Intergovernmental Platform on Biodiversity and Ecosystems (IPBES), it is titled, The Contribution of Indigenous and Local Knowledge Systems to IPBES: Building Synergies with Science. The first part of the document is a report on an IPBES Expert meeting that offers several case studies of these working local and aboriginal 
knowledge bases; the second presents an approach for IPBES scientists working with native peoples to further their understanding of complex ecologies and create new approaches to reversing the widespread damage caused by industrialism and urbanism. From the first paragraph of its introduction, the central importance of comprehensive (i.e. holistic) approaches to scientific inquiry is stressed in an age of environmental uncertainty:

Biodiversity is inextricably intertwined with the well-being of people and of Planet Earth. Across the globe, people are in constant interaction with the biological components of their environment, and through this interaction they nurture sophisticated sets of knowledge and practice, which include both science and indigenous \& local knowledge (ILK). In the face of unprecedented declines in biodiversity over past decades, it has become increasingly apparent that synergies must be built among knowledge systems in order to provide policy-makers and science practitioners with the best available knowledge to decide what urgent action must be taken to halt the rapidly accelerating degradation and loss of the biodiversity and ecosystem services that underpin sustainability, as well as resilience in the face of global change [106].

It would thus appear that science is facing both external and internal crises; the first being the unmitigated depredations of perpetual growth, which is perpetually enabled by science; the second being the realization that it alone cannot provide all the answers and solutions to the dilemmas it has blindly helped to create:

In the face of the global biodiversity crisis and its emerging challenges and unknowns, it is essential that decision-makers and practitioners base policies and actions on the best available knowledge. The bio-physical and social sciences contribute significantly to our collective understanding of earth systems, social systems and their interactions. However, there has been a growing awareness that scientific knowledge alone is 
inadequate for addressing the erosion and degradation of biodiversity and ecosystem services. In particular, the knowledge of indigenous peoples and local communities often referred to as local, indigenous or traditional knowledge - is increasingly recognized as a source of vital importance [106, p. 65].

What is being argued here is far from a negation of the present research being conducted on the CEF fields. Science is beginning to expand its horizons in or order to face the building storms looming on humanity's collective horizons. The CEF and the nation as a whole could benefit tremendously from holistic agroecological schemes such as the OPI. This imagined proposal should not be interpreted as an affront to the AAFC, its scientists and other bodies associated with the farm. As UNESCO and various international scientific bodies such as the IPES call for the recognition and incorporation of indigenous knowledge systems within the present action frameworks against climate change, ecosystem failure, species extinction and environmental insecurity, scientists everywhere should be heeding their call and opening their minds. Moreover, governments need to begin opening their wallets to pledge funding for such alternative initiatives instead of continuing down the reckless path of petrochemical extraction, waterbody imperilment, deforestation and unmitigated urbanism. Yet, what Canadians continue to witness is persistent resistance to calls for drastic change, with increased blame and responsibility for climate inaction being placed on taxpayers in the form of new "carbon taxes".

This resistance is likely what would keep OPI in the "realm of speculation"; however, the question should be raised: should the designation of a heritage site equate to 
an agricultural paradigm remaining frozen in time? It should perhaps be reiterated that the recommended option of the HSMP was one of agricultural research, in rejection of the Museum-without-Walls scenario. If science is curtailed by $19^{\text {th }}$-Century notions of itself, then what is its purpose to a humanity facing a $21^{\text {st }}$ Century reality? When scientific research from worldwide sources is now proving how detrimental this paradigm is for the world's ecosystems and ecosystem services, then is it not time to begin searching for alternatives? The role of science is not to support industry and cater to its near-sighted profiteering. Science is intended to advance all of humankind. When science uncovers a fundamental flaw in human systems, it must act to correct that flaw, regardless of how fundamental, enduring and omnipresent said flaw may seem, and no "official plan" should be allowed to stand in the way of environmental progress. Unfortunately, this is not how the world presently functions: conservation is too often confused with "conservatism", instead of progressive radical change. As a proposal for making such drastic transformations to the CEF, the Ottawa Permaculture Initiative would also be a project devoted to the most important form of conservation in this era of climate instability: environmental conservation.

Is CEF still the desired location? Yes, because the stated goal of this thesis is to subvert, via permacultural disturbance, post-colonial agronomic and socio-economic paradigms. CEF stands as an archetype for $19^{\text {th }}$ and $20^{\text {th }}$-Century agricultural practices and a change in its direction for the future-one that demonstrates a continuity in the 
advancement of Canadian and international agronomics-could help accelerate humanity's progression towards agroecology and veritable sustainability. Why Canadians and their government would rather freeze its fields in time, as an immutable designed cultural landscape representing obsolete notions of hierarchic "scientific order", rather than enhance their potential for sustainable agricultural research as an evolved cultural landscape representing biodiversity and ecological complexity, is a direction that should be questioned. Inherently, this thesis poses these questions, all while offering an imagined alternative scenario based on the principles, ethics and philosophies of permaculture.

\subsection{SITE ANALYSIS}

The Central Experimental Farm is located in Ottawa's inner suburbs, on the border of the inner urban core, in the Civic Hospital/Central Park neighbourhood (Figure 4 Figure 6). It is an irregularly-shaped property divided in two by an arterial road (Fisher Avenue). Excluding its arboretum on the eastern side of the farm, its total area is about 375 hectares (925 acres) $)^{34}$ and is also surrounded by arterial roads: Carling Avenue to the north, Prince of Wales Drive to the east, Baseline Road to the south and Merivale Road to the west

\footnotetext{
${ }^{34}$ Accurate survey information was not available; property reports obtained online from GeoOttawa (http://maps.ottawa.ca/GeoOttawa/) appear to include the arboretum bordering the farm along its eastern side, for a grand total of $405.75 \mathrm{ha}$. This conflicts with area measurements done with their provided measuring tools when the arboretum is included (approx. 425 ha.). The numbers given above in the main text coincide with the map tools, which yield a total property area of $375 \mathrm{ha}$. (not including the arboretum).
} 
[107]. The farm's geographical centre (land area centroid) lies at approximately at $45^{\circ} 22^{\prime} 52.8^{\prime \prime} \mathrm{N}, 75^{\circ} 43^{\prime} 1.2^{\prime \prime} \mathrm{W} .^{35}$

The site for the Ottawa Permaculture Initiative will not encompass the entire CEF. The farm will be divided along the National Capital Commission Driveway, from its intersection with Fisher Ave. through to Morningside Lane, then divided by Morningside until the southernmost laneway (immediately following the building cluster), then along that laneway to its intersection with Prince of Wales Dr. All existing government research buildings in the north corner will remain and presumably participate in agronomic research in conjunction with OPI permaculturalists. In addition to the research buildings, 48 hectares of existing research fields along Carling Ave. will remain and be recommended for the study of urban pollution and organic soil remediation, as at least 5 of those hectares are now deemed "unusable" due to road salt pollution [108]. This leaves OPI with approximately 255 to 260 hectares of existing CEF fields for its ecovillage settlement.

With site observations and descriptions in permaculture design phases generally requiring lengthy and involved procedures (see 1.1.2.3), often completed over long periods of time under all possible climatic conditions, a similar undertaking is beyond the capacity of this study. To simplify the site description, its information will be broken down into categories and enumerated in the subsections below. The following observations and data

\footnotetext{
${ }^{35}$ Calculated with Rhinoceros ${ }^{\circledast}$ Version 5 SR12 using imported topography data from Google ${ }^{T M}$ Earth Pro.
} 
represent a condensed site study process, with more discussion on the site reserved for the design discussion in Chapter 2.

\subsubsection{Site GEOGRAPHY}

The numbered list that follows reveals the site's situation in the human world. Some of the features may overlap with the sections that follow, however, they are here grouped together as part of the existing human system of the city and its relation to the site. A few of the following area features correspond to selected numbered features on the area maps and three-dimensional aerial images from Google Earth (see Figure 4 to Figure 8, pp. 7375).

1) Geographical centre: $45^{\circ} 22^{\prime} 38^{\prime \prime} \mathrm{N}, 75^{\circ} 43^{\prime} 4 " \mathrm{~W}$ (OPI site)

2) Distances to downtown core: walking/cycling $(6.6 \mathrm{~km})$ and driving $(7.2 \mathrm{~km})$.

3) Neighbourhood: Civic Hospital/Central Park

4) Area: Inner suburbs

5) City: Ottawa

6) Municipality: Ottawa (single-tier)

7) Greater region: Eastern Ontario 
8) Province: Ontario

9) Watersheds: Ottawa River (major) and Ottawa Central (minor)

10) Surrounding watercourses (shortest distance; straight-line) ${ }^{36}$ : Rideau Canal $(1.2 \mathrm{~km})$, Rideau River (1.3 km), Ottawa River $(3.5 \mathrm{~km})$, Gatineau River $(8.6 \mathrm{~km})$.

11) Surrounding watercourses (shortest distance; walking/biking): Rideau Canal (1.5 km), Rideau River (1.8 km), Ottawa River (4.3 km), Gatineau River (14.4 km).

12) Surrounding water bodies (shortest distance, straight-line; water area): Dow's Lake (2.0 km; 24 ha.) and Mooney’s Bay (1.7 km; 40 ha.).

13) Surrounding water bodies (shortest distance; walking/biking): Dow's Lake (2.5 km) and Mooney’s Bay $(3.0 \mathrm{~km})$.

14) Official Greenbelt (shortest distance; straight-line): Woodroffe Ave. \& West Hunt Club Rd. $(6.0 \mathrm{~km})$.

15) Official Greenbelt (shortest distance; walking/biking): Woodroffe Ave. \& West Hunt Club Rd. (7.4 km).

\footnotetext{
${ }^{36}$ All approximate distances for the numbered list running throughout Section 1.3.2 are walking/cycling distances (unless otherwise noted) from OPI's site geographical centre. Distances were taken from Google Earth and Google Maps (http://maps.google.com/).
} 
16) Key parks and recreation areas: Arboretum \& Fletcher Wildlife Garden (1.6 km), Vincent Massey Park (2.5 km), Carlington Park (2.8 km), Hampton Park (2.9 km), Hog's Back $(3.0 \mathrm{~km})$, Brewer Park $(3.1 \mathrm{~km})$, Mooney's Bay park/outdoorathletics/beach (3.6 km), Remic Rapids (5.7 km), Bate Island (5.7 km), Kitchissippi Lookout/Westboro Beach (5.8) and Gatineau Park (8.8 km to southernmost tip; Hull, QC).

17) Nearest wilderness area: Gatineau Park; nearest entry point for unrestricted wildlife area and corridor; near Boulevard Saint-Raymond and Chemin Pink, in Gatineau, QC $(12.5 \mathrm{~km})$.

18) Nearest universities and/or colleges: Carleton University (2.2 km), Algonquin College $(6.2 \mathrm{~km})$ and University of Ottawa $(8.4 \mathrm{~km})$.

19) Nearest hospital: Ottawa Hospital Civic Campus / Civic Hospital (2.2 km).

20) Nearest airport and train stations: Carleton O-Train (2.2 km), Carling O-Train Station (3.4 km), Ottawa International Airport $(9.0 \mathrm{~km})$, Ottawa VIA Rail Station $(10.9 \mathrm{~km})$ and Fallowfield VIA Rail Station $(11.2 \mathrm{~km})$.

21) Key shopping areas: Westgate Centre $(2.6 \mathrm{~km})$, Laurentian Place $(2.9 \mathrm{~km})$, Borden Farm (3.9 km), Billings Bridge (4.9 km), College Square (5.0 km), Westboro (5.0 km), 
Carlingwood Mall (5.6 km), W. Hunt Club Rd. \& Merivale Rd. (5.7 km), Rideau Centre (7.3 km), Trainyards $(8.4 \mathrm{~km})$, and St. Laurent Centre $(9.7 \mathrm{~km})$.

22) Key entertainment and dining areas: Little Italy $(4.4 \mathrm{~km})$, the Glebe $(4.9 \mathrm{~km})$, Lansdowne Park (4.9 km), Westboro $(5.0 \mathrm{~km})$, Elgin St. $(6.5 \mathrm{~km})$, Promenade du Portage (6.8 km; Hull, QC), and Byward Market $(7.9 \mathrm{~km})$.

23) Arts and culture: Canadian Museum of Nature (5.9 km), Parliament Hill (7.0 km), National Arts Centre (7.0 km), Canadian Museum of History (7.3 km; Hull QC) and the National Gallery of Canada $(8.0 \mathrm{~km})$.

\subsubsection{LAND Use Patterns}

\subsubsection{Zoning}

The CEF is zoned under a section of the zoning bylaw specific to itself: L3-Central Experimental Farm Zone [109]. It is designated as a special agricultural research area with limited land uses. As CEF has scientific, cultural and historical significance to both the City and the Country, the by-law is intended to protect the CEF from any development that contravenes its original purpose. OPI will continue in this mission, all while giving CEF a new progressive and sustainable direction for the future and enhancing its original intent. Present zoning restrictions are almost precisely in line with OPI's master plan, with the exception of only one obstacle: there is no mention of residential uses, of course. Included 
land uses are agricultural, community gardens, environmental preserves, education areas, experimental farm offices, an agricultural museum, parks, and a research centre limited to agricultural research. For an ecovillage settlement, a specific amendment would have to be included in the by-law text to allow for 'a permanent experimental residential complex and home cluster, both limited in size and function to combined sociological, ecological, and agricultural research.'

\subsubsection{Surrounding Land Use Areas}

Being classified as an "inner suburban" zone, the areas surrounding the OPI site are mainly mixed-density residential, with mostly single-family residences to the south of Baseline Rd. Mixed in with the residences are commercial properties, mainly to service the surrounding population. This land use is true for the bordering western and southern areas, with the exception of the land at the southwest corner, opposite Merivale Road, where Agriculture and Agri-food Canada (AAFC) has its office buildings. To the north is the Ottawa Hospital's Civic Campus and the Royal Ottawa Mental Health Centre, with various private medical buildings, residences and other limited commercial uses lining Carling Ave. To the north of Carling are more single-family residential inner suburbs. To the east of the site, in between the Rideau Canal and the CEF, are the Arboretum and Fletcher Wildlife Garden, which are divided between "open space" and "environmental protection zone" classifications. 


\subsubsection{Climate and Natural Forces}

One of the most important site analyses to carry out is that for climate and sectors. It is perhaps the most difficult as it requires months of study, observation and research in order to gain a working understanding of the land. A similar study has not yet been carried out for this thesis, however, the data and observations that follow represent the initial study required for any real permaculture design project. Included below is a list of the preliminary factors that led to the master planning and design of OPI.

1) Geographical climate zone: North Temperate Zone

2) Climate classification (Köppen-Geiger): Dfb; Humid Continental Climate, which is characterized by a high degree of seasonal temperature variation, from severe winters to very warm humid summers. Another defining characteristic is the lack of a dry season [110]. Figure 15 demonstrates how well Ottawa's historical climate data generally conforms to its classification. However, with growing climate instability it is becoming more common that temperatures vary between $65 \mathrm{deg}$. C or more in a single year (+35 deg. C in July or August to lower than -30 deg. C in January). By 2040, graphs like these are predicted to appear quite differently. 

OTTAWA CDA

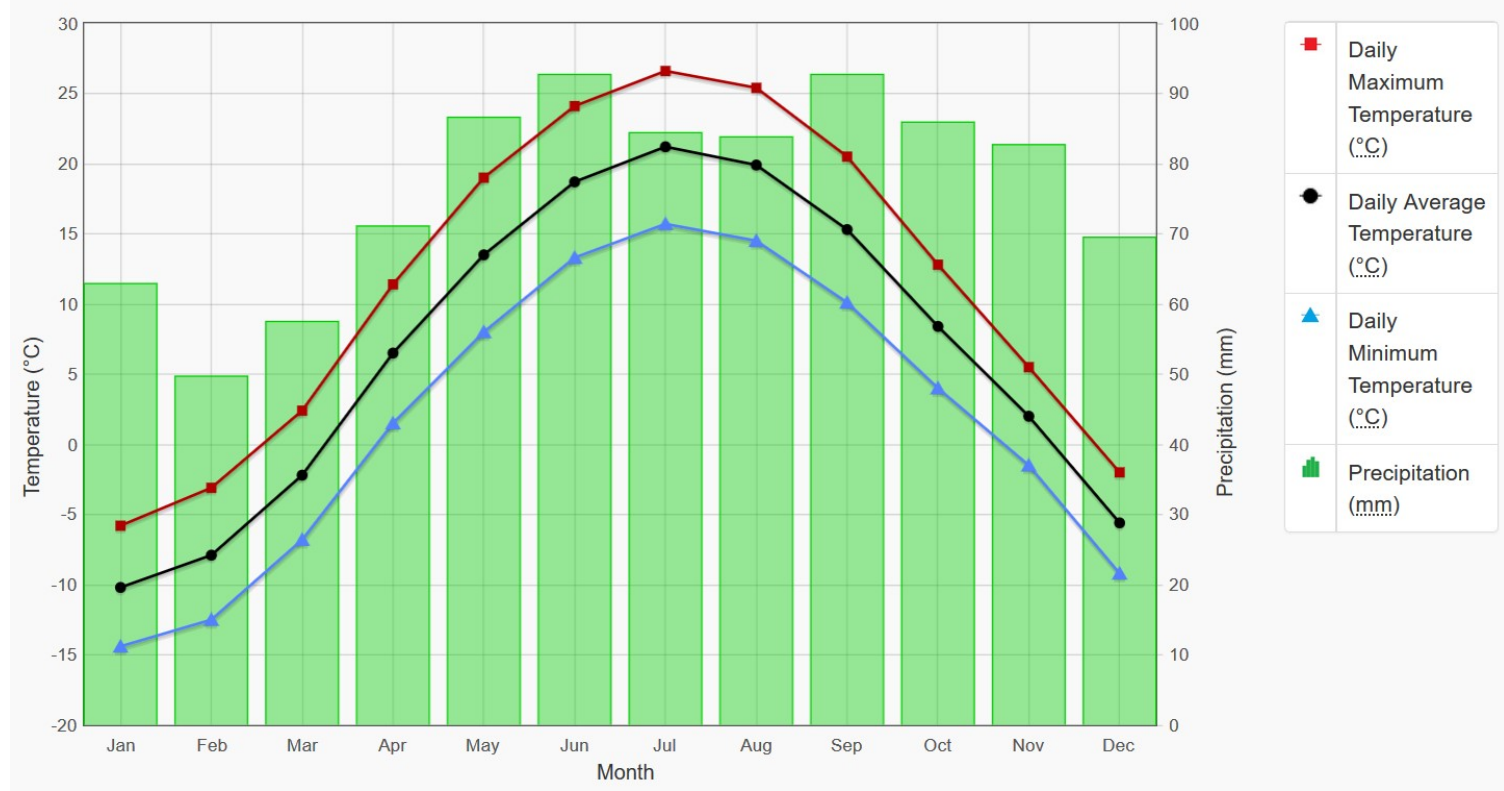

Figure 15: Average temperature and precipitation graphs for on-site weather station (CDA) at CEF [111]. ${ }^{37}$

3) Temperatures: see Table 1 and Figure 15.

4) Plant hardiness zone: $\mathbf{5 b} / \mathbf{5 5}$; average extreme minimum temperature of -26.1 to -23.3

(see 1.3.2.4-14 for description) [112].

${ }^{37}$ Ottawa CDA weather data station $\left(45^{\circ} 22^{\prime} 57^{\prime \prime} \mathrm{N}, 75^{\circ} 42^{\prime} 51^{\prime \prime} \mathrm{W}\right)$ is located on the Central Experimental Farm, only $650 \mathrm{~m}$ from OPI's geographical centre. 
Table 1: Temperature averages for the years 1981-2010, taken at CDA [111].

\begin{tabular}{|c|c|c|c|c|c|c|c|c|c|c|c|c|c|c|}
\hline & Jan & Feb & Mar & Apr & May & Jun & ! & Aug & Sep & Oct & Nov & Dec & Year & Code \\
\hline Daily Average $\left({ }^{\circ} \mathrm{C}\right)$ & -10.2 & -7.9 & -2.2 & 6.5 & 13.5 & 18.7 & 21.2 & 19.9 & 15.3 & 8.4 & 2.0 & -5.6 & 6.6 & $\underline{A}$ \\
\hline $\begin{array}{l}\text { Standard } \\
\text { Deviation }\end{array}$ & 3.4 & 2.5 & 2.2 & 1.6 & 1.7 & 1.3 & 1.1 & 1.3 & 1.5 & 1.3 & 1.8 & 3.3 & 0.9 & $\underline{A}$ \\
\hline $\begin{array}{l}\text { Daily Maximum } \\
\left({ }^{\circ} \mathrm{C}\right)\end{array}$ & -5.8 & -3.1 & 2.4 & 11.4 & 19.0 & 24.1 & 26.6 & 25.4 & 20.5 & 12.8 & 5.5 & -2.0 & 11.4 & $\underline{A}$ \\
\hline $\begin{array}{l}\text { Daily Minimum } \\
\left({ }^{\circ} \mathrm{C}\right)\end{array}$ & -14.4 & -12.5 & -6.8 & 1.5 & 8.0 & 13.3 & 15.7 & 14.5 & 10.1 & 4.0 & -1.5 & -9.2 & 1.9 & $\underline{A}$ \\
\hline $\begin{array}{l}\text { Extreme Maximum } \\
\left({ }^{\circ} \mathrm{C}\right)\end{array}$ & 11.8 & 12.2 & 25.6 & 31.2 & 35.0 & 36.7 & 37.8 & 37.8 & 36.7 & 29.4 & 23.3 & 16.1 & & \\
\hline Date (yyyy/dd) & $\begin{array}{r}2005 / \\
13\end{array}$ & $\begin{array}{r}1953 / \\
21\end{array}$ & $\begin{array}{r}1945 / \\
28\end{array}$ & $\begin{array}{r}1990 / \\
27\end{array}$ & $\begin{array}{r}1921 / \\
21\end{array}$ & $\begin{array}{r}1921 / \\
22\end{array}$ & $\begin{array}{r}1913 / \\
04\end{array}$ & $\begin{array}{r}1917 / \\
01\end{array}$ & $\begin{array}{r}1931 / \\
11\end{array}$ & $\begin{array}{r}1891 / \\
03\end{array}$ & $\begin{array}{r}1961 / \\
03\end{array}$ & $\begin{array}{r}1951 / \\
07\end{array}$ & & \\
\hline $\begin{array}{l}\text { Extreme Minimum } \\
\left({ }^{\circ} \mathrm{C}\right)\end{array}$ & -37.8 & -38.3 & -36.7 & -20.6 & -7.2 & 0.0 & 3.3 & 1.7 & -4.4 & -12.8 & -23.9 & -38.9 & & \\
\hline Date (yyyy/dd) & $\begin{array}{r}1925 / \\
19\end{array}$ & $\begin{array}{r}1934 / \\
17\end{array}$ & $\begin{array}{r}1938 / \\
04\end{array}$ & $\begin{array}{r}1923 / \\
01\end{array}$ & $\begin{array}{r}1902 / \\
10\end{array}$ & $\begin{array}{r}1910 / \\
04\end{array}$ & $\begin{array}{r}1942 / \\
10\end{array}$ & $\begin{array}{r}1934 / \\
30\end{array}$ & $\begin{array}{r}1947 / \\
28\end{array}$ & $\begin{array}{r}1933 / \\
26\end{array}$ & $\begin{array}{r}1925 / \\
30\end{array}$ & $\begin{array}{r}1933 / \\
29\end{array}$ & & \\
\hline
\end{tabular}

5) Precipitation: see Table 2. 
Table 2: Precipitation averages for the years 1981-2010, taken at CDA [111].

\begin{tabular}{|c|c|c|c|c|c|c|c|c|c|c|c|c|c|c|}
\hline \multicolumn{15}{|c|}{ Precipitation } \\
\hline & Jan & Feb & Mar & Apr & May & Jun & !يبي ي & Augg & Sep & Oct & Nooy & Dec & Year & Code \\
\hline Rainfall (mm) & 23.0 & 17.9 & 28.8 & 63.2 & 86.6 & 92.7 & 84.4 & 83.8 & 92.7 & 83.1 & 67.5 & 31.9 & 755.5 & $\underline{A}$ \\
\hline Snowfall $(\mathrm{cm})$ & 44.3 & 34.7 & 29.1 & 7.2 & 0.0 & 0.0 & 0.0 & 0.0 & 0.0 & 2.9 & 16.0 & 41.3 & 175.4 & $\underline{A}$ \\
\hline Precipitation (mm) & 62.9 & 49.7 & 57.5 & 71.1 & 86.6 & 92.7 & 84.4 & 83.8 & 92.7 & 85.9 & 82.7 & 69.5 & 919.5 & $\underline{A}$ \\
\hline $\begin{array}{l}\text { Average Snow Depth } \\
\text { (cm) }\end{array}$ & 17 & 22 & 17 & 1 & 0 & 0 & 0 & 0 & 0 & 0 & 1 & 8 & 6 & $\underline{\mathrm{C}}$ \\
\hline $\begin{array}{l}\text { Median Snow Depth } \\
(\mathrm{cm})\end{array}$ & 18 & 22 & 17 & 0 & 0 & 0 & 0 & 0 & 0 & 0 & 1 & 8 & 5 & $\underline{\mathrm{C}}$ \\
\hline $\begin{array}{l}\text { Snow Depth at } \\
\text { Month-end }(\mathrm{cm})\end{array}$ & 21 & 22 & 5 & 0 & 0 & 0 & 0 & 0 & 0 & 0 & 3 & 13 & 5 & $\underline{A}$ \\
\hline $\begin{array}{l}\text { Extreme Daily Rainfall } \\
(\mathrm{mm})\end{array}$ & 40.1 & 38.4 & 41.8 & 48.3 & 75.9 & 77.5 & 74.2 & 90.4 & 108.6 & 58.4 & 49.0 & 73.2 & & \\
\hline \multirow[t]{2}{*}{ Date (yyyy/dd) } & $1995 /$ & $1997 /$ & $1980 /$ & $1956 /$ & $1916 /$ & $1946 /$ & 1899/ & $1943 /$ & 2004/ & $1995 /$ & $1907 /$ & $1933 /$ & & \\
\hline & 15 & 21 & 21 & 15 & 17 & 17 & 11 & 23 & 09 & 05 & 07 & 31 & & \\
\hline $\begin{array}{l}\text { Extreme Daily Snowfall } \\
\text { (cm) }\end{array}$ & 55.9 & 45.7 & 48.3 & 33.0 & 19.1 & 0.0 & 0.0 & 0.0 & 0.0 & 21.6 & 53.3 & 37.6 & & \\
\hline \multirow[t]{2}{*}{ Date (yyyy/dd) } & $1894 I$ & $1895 /$ & $1947 /$ & $1970 /$ & $1907 /$ & $1890 /$ & $1890 /$ & $1890 /$ & $1890 /$ & $1933 /$ & $1912 /$ & 1973/ & & \\
\hline & 29 & 08 & 02 & 02 & 04 & 01 & 01 & 01 & 01 & 24 & 25 & 20 & & \\
\hline $\begin{array}{l}\text { Extreme Daily } \\
\text { Precipitation }(\mathrm{mm})\end{array}$ & 55.9 & 45.7 & 48.8 & 48.3 & 75.9 & 77.5 & 74.2 & 90.4 & 108.6 & 58.4 & 53.3 & 73.2 & & \\
\hline \multirow[t]{2}{*}{ Date (yyyy/dd) } & $1894 /$ & $1895 /$ & $1962 /$ & $1956 /$ & $1916 /$ & $1946 /$ & 1899/ & $1943 /$ & $2004 /$ & $1995 /$ & $1912 /$ & $1933 /$ & & \\
\hline & 29 & 08 & 12 & 15 & 17 & 17 & 11 & 23 & 09 & 05 & 25 & 31 & & \\
\hline $\begin{array}{l}\text { Extreme Snow Depth } \\
\text { (cm) }\end{array}$ & 53 & 97 & 89 & 66 & 8 & 0 & 0 & 0 & 0 & 18 & 30 & 51 & & \\
\hline \multirow[t]{2}{*}{ Date (yyyy/dd) } & $1971 /$ & $1971 /$ & $1971 /$ & $1971 /$ & $1963 /$ & $1961 /$ & $1961 /$ & $1961 /$ & $1961 /$ & $1997 /$ & $1995 /$ & $1970 /$ & & \\
\hline & 30 & 24 & 12 & 01 & 11 & 01 & 01 & 01 & 01 & 27 & 28 & 25 & & \\
\hline
\end{tabular}

\section{6) Wind Patterns: see Figure $\mathbf{1 6}$ and Figure 17.}

\begin{tabular}{|c|c|c|c|c|c|c|c|c|c|c|c|c|c|}
\hline \multirow[t]{2}{*}{ Month of year } & Jan & Feb & Mar & Apr & May & Jun & Jul & Aug & Sep & Oct & Nov & Dec & Year \\
\hline & 01 & 02 & 03 & 04 & 05 & 06 & 07 & 08 & 09 & 10 & 11 & 12 & $1-12$ \\
\hline Dominant wind direction & 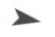 & 4 & 4 & $\downarrow$ & 4 & $\lambda$ & 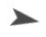 & $>$ & 4 & 4 & - & 4 & $>$ \\
\hline \multicolumn{14}{|l|}{ Wind probability >= 4 Beaufort $(\%)$} \\
\hline & 21 & 24 & 19 & 31 & 20 & 14 & 9 & 6 & 8 & 18 & 20 & 15 & 17 \\
\hline \multicolumn{14}{|l|}{ Average Wind speed (kts) } \\
\hline & 7 & 8 & 8 & 9 & 8 & 7 & 7 & 6 & 6 & 7 & 7 & 7 & 7 \\
\hline Average air temp. $\left({ }^{\circ} \mathrm{C}\right)$ & -10 & -9 & -2 & 6 & 16 & 19 & 23 & 21 & 17 & 10 & 3 & -3 & 7 \\
\hline
\end{tabular}

Figure 16: Average wind speeds, directions and temperatures for CDA from 02/2012 to 12/2016 [113]. 

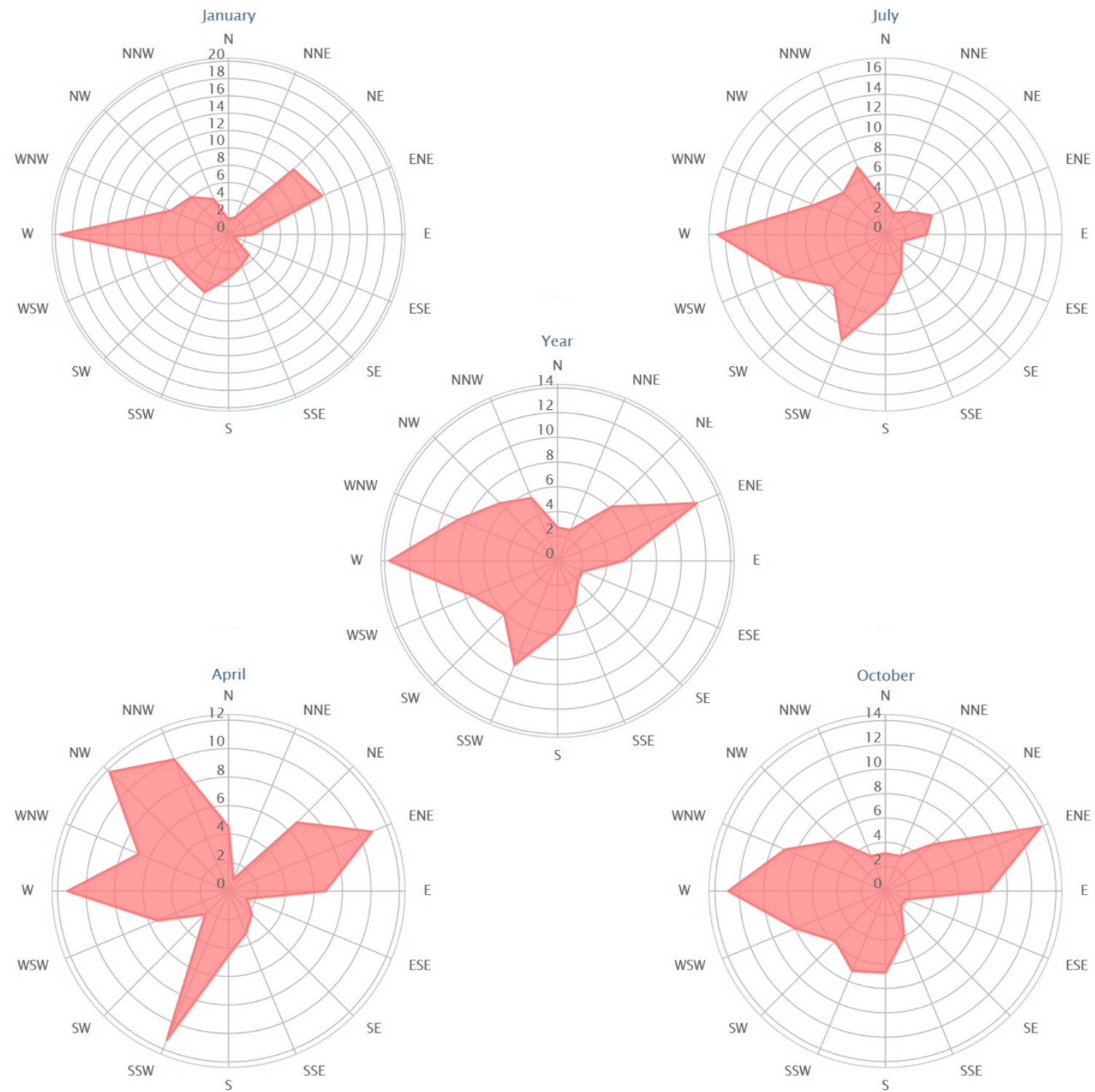

Figure 17: Seasonal wind direction distribution percentage for CDA from 02/2012 to 12/2016. Concentric rings represent magnitude of directional \%; yearly average graph in centre [113].

7) Storm patterns: see Figure 18. 

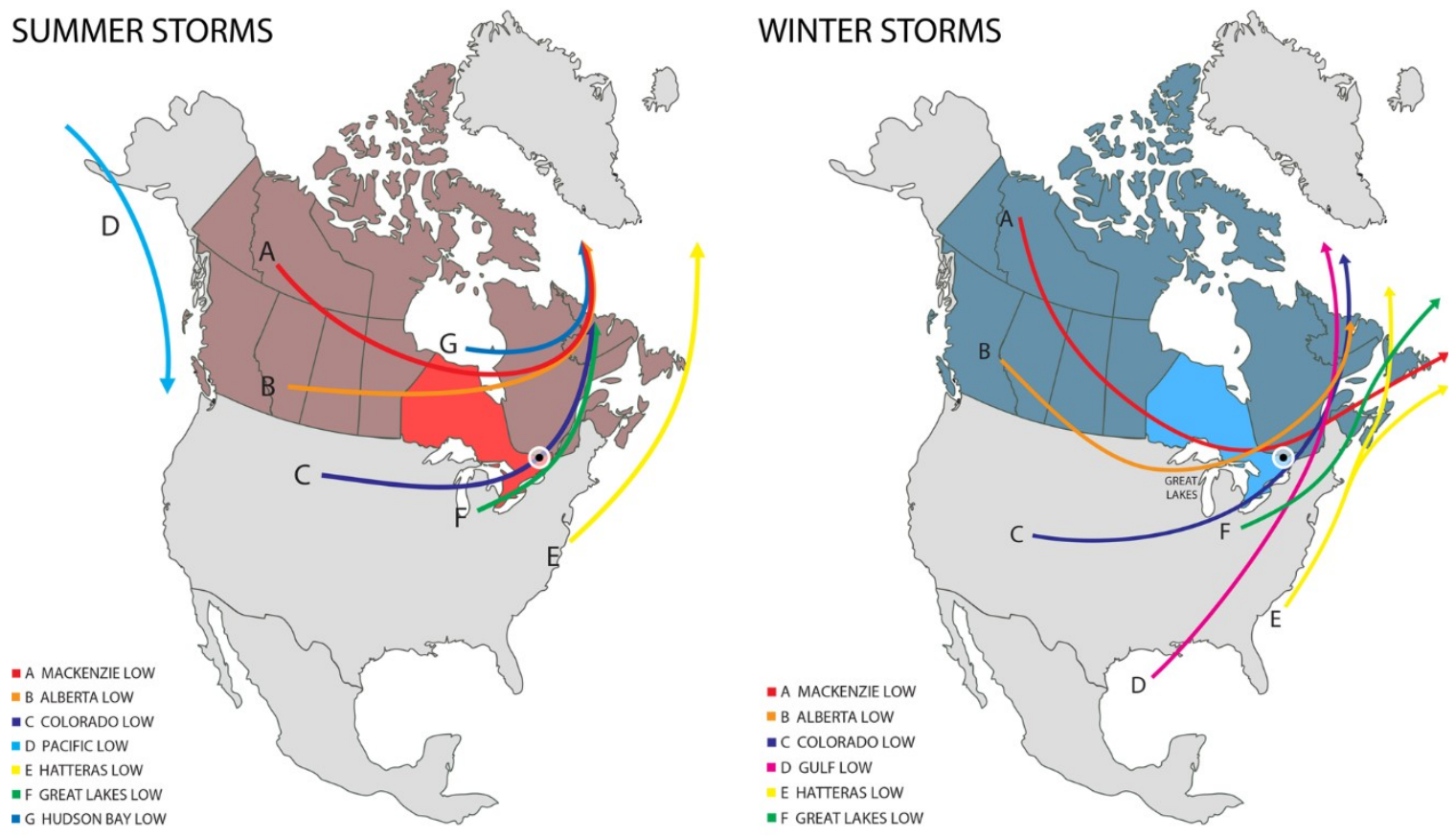

Figure 18: Summer versus winter storm patterns for Ontario and Eastern Canada [114].

8) Sun paths and angles: sun paths across the OPI site are shown provided in Figure 19. 

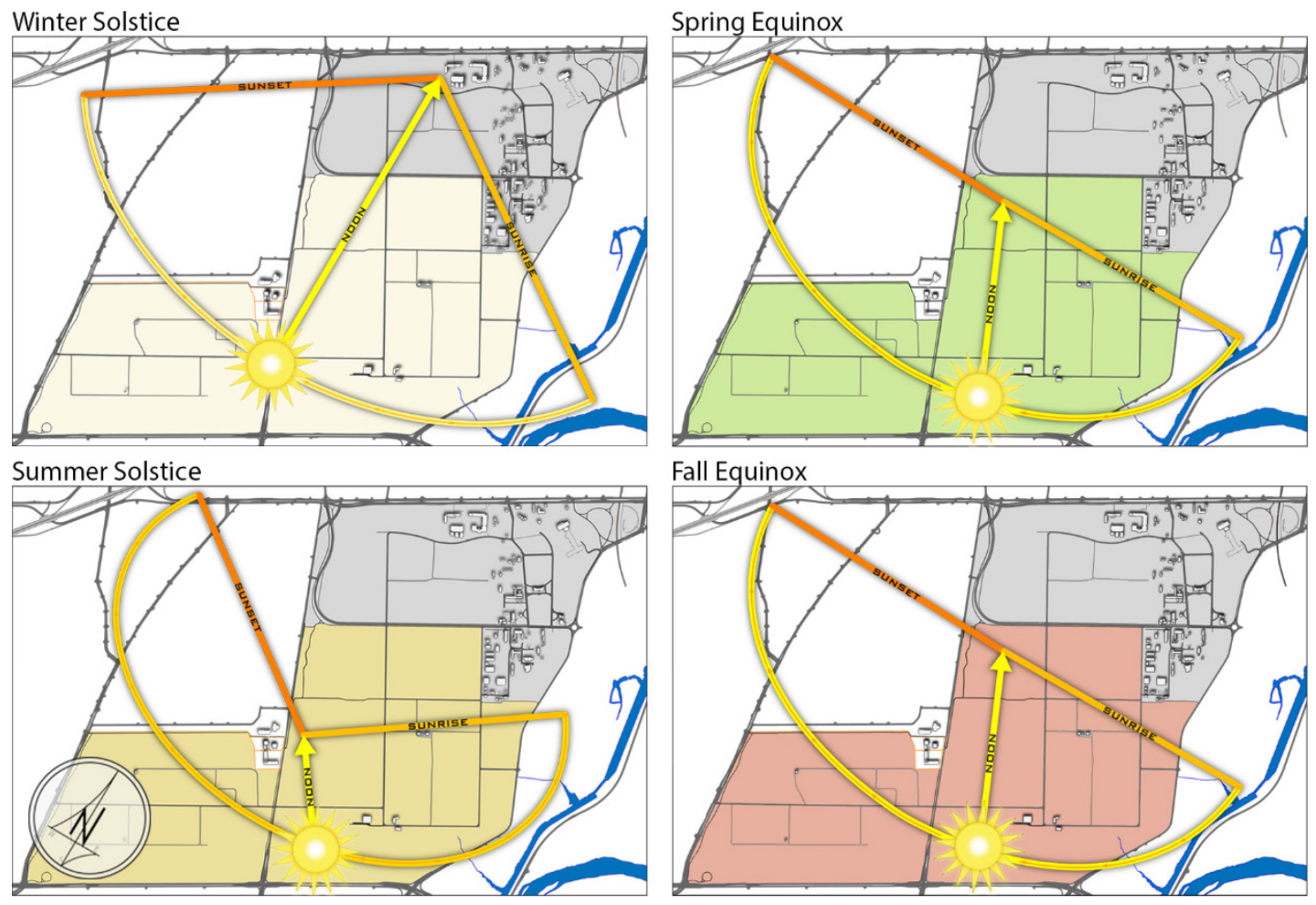

Figure 19: Approximate seasonal sun paths over OPI site; site depicted in "seasonal colours".

\subsubsection{Microclimate}

Assessing existing microclimate indicators for the OPI site is not a simple task.

Being a pocket of greenspace in the middle of an inner suburban area, complex dynamics between surrounding land use patterns, existing natural surrounds, all interact with macroclimatic models to produce a complex scenario. An accurate assessment could only be performed by combining climate data, real-time satellite thermal data, computer 
modelling and statistical analysis, which were not possibilities for this study ${ }^{38}$. In fact, urban heat island (UHI) effect and mitigation thereof are currently the subjects of many studies. It will perhaps suffice here to simply mention potential and known microclimate indicators, since it is shown that the only cure for UHI is the maximization of urban greenspace and water features-natural ecosystem rejuvenation-and permaculture is conceivably the best existing strategy.

1) Site features: the OPI site is very large (about $2,600,000 \mathrm{~m}^{2}$, approx. $3 \mathrm{~km}$ diagonally between extreme corners and a total perimeter of around $8 \mathrm{~km}$ ). Only about 15 of those 260 ha. provide any shade or shelter, which includes trees, a couple of hedge rows and a few buildings. Thus, it suffices to conclude that, aside from green crop cover during the growing season, and perhaps subsurface geological composition, there are no visible sources of microclimate within the site itself. Taken as a whole, however, it may suffice to call the entire CEF and its Arboretum an "urban cool island" (UCI), which means that it plays a larger role in moderating surrounding UHI effects. Once established as an intentionally-designed ecosystem, this moderation potential will only be increased. Studies show that greenspace is not enough to increase UCI effect: parkland must be properly planned and designed to

\footnotetext{
${ }^{38}$ An example study used a "temperature-emissivity separation (TES) algorithm" to retrieve land surface temperature (LST) data from the TIRS (Thermal Infrared Sensor) from the Landsat Thematic Mapper (TM) to study heat-island effect in Yzad, Iran [218]. Landsat is a remote-sensing satellite project between the USGS, NASA and the Landsat Project [217].
} 
have a significant effect on UHI intensity [115]. In other words, a CEF-like greenspace alone is not enough.

2) Surrounding UHI contributors: nearby commercial plazas (Laurentian Place, Skyline, Merivale Rd. shops, etc.); institutions, office complexes and their parking lots (e.g. AAFC, Carleton University, etc.); sparsely-treed residential clusters; dark rooftops and residential rooftops; and all roads, traffic activity and automobile exhaust gases (Highway 417, Baseline Rd., Carling Rd., etc.).

3) Surrounding UCI indicators: gardens (Arboretum and Fletcher Wildlife Gardens) and open greenspaces (Carlington Park, Vincent Massey Park, Hog’s Back, Mooney's Bay Park, etc.); canals and river systems (Rideau Canal/River and Ottawa River); water bodies (Dow's Lake and Mooney's Bay).

\subsubsection{Site ECology, Geology AND Agronomy}

The following list assesses all three categories of site characteristics that pertain to the natural terrestrial systems. The data and observations work together to situate the site in terms of larger ecological systems and cycles: thinking globally. Seeing the world, its constituent regions and localities in terms of eco-totalities and environmental regions, rather than politico-cultural divisions. This information also contains site details that help 
to zero in on the original ecology of the site. The goal is to begin to see the dialectic between the local and the global, to understand not only how one should apply this information in the design, but also how the project synergizes with larger natural systems and cycles.

1) Biogeographic realm: Nearctic.

2) Terrestrial bioregion: Core of Laurentia.

3) Ocean drainage: Atlantic Ocean.

4) Floristic kingdom: Boreal or Holarctic (Holarctis).

5) Floristic region: North American Atlantic.

6) Floristic province: Appalachian.

7) Forest region (national): Great Lakes-St. Lawrence.

8) Biome (forest type): temperate broadleaf and mixed forest.

9) Ecoregion (provincial): 6E (Lake Simcoe-Rideau) [116]; encompasses 6.3 million ha. (6.4\% of Ontario). Most densely human populated ecoregion. See MNR (2009) for detailed description.

10) Landform (physiographic) region: Canadian Shield. 
11) Subsurface geology: Late Ordovician (Ottawa Formation - Black River and Trenton Groups; mainly limestone with some lower dolomitic limestone layers and interbedded with sandstone shale) [117] [118] [119].

12) Surfical geology: mostly mottled clay and glacial till, with some sandy areas (highterrace alluvium); clay is eroded marine clay and sea bottom marine clay deposits, till is from glacial deposits [118] [120].

13) Aquifer (groundwater): there are at least 13 drilled wells on site, plus several more about the other areas of CEF property. ${ }^{39}$ The highest flowrate on the OPI site is from Borehole

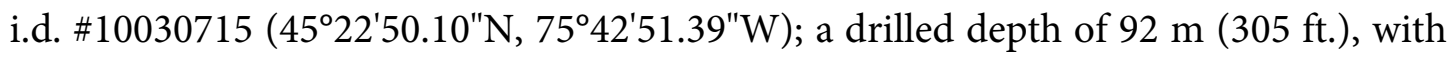
recommended minimum well depth of $60 \mathrm{ft}$.; water type is fresh, with a flowrate of 68 $\mathrm{L} / \mathrm{min}$ (15 gal/min) [121]. This is not the highest groundwater flowrate at CEF, as it increases dramatically in the northernmost CEF wells.

14) Plant hardiness zone/index: $5 \mathrm{~b} / 55$; average extreme minimum temperature of -26.1 to -23.3 (see 1.3.2.3 above for more climate data); used to establish plant species that are recommended for cultivation in an area. The NRCAN interactive plant hardiness

\footnotetext{
39 Well data obtained from Google ${ }^{\mathrm{TM}}$ Earth $\mathrm{KMZ}$ file downloaded from Ontario Groundwater (http://ontariogroundwater.com/).
} 
database lists 1712 full range species and 1190 core range species for Ottawa [122]. It is important to note that Cannabis sativa $\mathrm{L}$. is included.

\section{5) Topography:}

a) General: overall a gently-sloping plot of land, gradually graded towards the Rideau Canal. Most intense slope area occurs in the southwest corner, where it drops $10 \mathrm{~m}$ in elevation from 90 to $80 \mathrm{MASL}^{40}$ in a horizontal run of approximately $420 \mathrm{~m}$ (Figure 20). ${ }^{41}$

b) Highest area: 93 MASL; southwest corner of site, along Merivale Rd.

c) Lowest area: 76 MASL; near southeast corner, where Prince of Wales Dr. first veers towards the northwest.

16) Site drainage: topographical data suggests that major drainage patterns are from west to east, with water shedding towards the Rideau Canal and River. There are two main outlet culverts passing under Prince of Wales Dr., which direct storm water into natural drainage ravines that empty into the canal. See Figure 21 for a three-dimensional study of site drainage.

\footnotetext{
${ }^{40}$ MASL is an acronym for "metres above sea level".

${ }^{41}$ Based on the City of Ottawa's digitized 1:2000 topographical data (AutoCAD ${ }^{\circ}$ files) obtained from MacOdrum Library's GIS server (Carleton University) [131].
} 
17) Possible pollution sources (immediate and direct):

a) Automotive activities: engine/movement noise, headlights, exhaust gases, fluid leaks, and road salt can cause pollution of air, soils, water on and around site. All perimeter roads are arterial; bisecting road (Fischer Ave.) is also arterial. The frequently-congested Highway 417 is only $1.8 \mathrm{~km}$ from the site's geographical centre and less than $1 \mathrm{~km}$ from the site's northwest corner.

b) Civic Hospital: waste incineration, sirens and lights.

c) CEF agriculture: soil and groundwater contamination from fertilizer and pesticide build up in farm fields, from all non-organic agricultural research.

d) Residential and commercial: heating fuels, power tool / small engine noise, lights, chemicals, lawn / garden pesticides and fertilizers

e) Airport: airplane exhaust and noise.

f) Atmospheric deposition: dustfall of wind-transported materials and particulates from rain or snow also referred to as "atmospheric fallout". Includes pollution from industry (heavy metals, volatile compounds, phosphates, toxic by-products, etc.) and from a wide range of other urban sources [123]. 
g) Roadside litter: garbage (metal and plastic products, etc.) ejected illegally from passing vehicles and garbage collection activities can end up in soils.

h) Sir John Carling Building demolition site: first reported on December 21 ${ }^{\text {st }}$ of 2016, in the Ottawa Citizen and Ottawa Sun [124] [125] [126]; after the Sir John Carling Building was demolished in 2014, the contractors buried contaminated rubble within the basement foundation of the demolished building. As a result, the surrounding soils and groundwater are contaminated with alkaline concrete dust (containing calcium hydroxide) and acidic phenols (presumably picric acid [2,4,6Trinitrophenol] or one of its salts, which is claimed to have been an ingredient in the main demolition explosives) [126]. The articles discussing the contamination do not give specifics on the types of phenols used in the explosives. Phenolic compounds are also used in agriculture as pesticides, herbicides and fungicides [127] [128]. The phenols used both in explosives and agriculture are toxic and harmful to aquatic life [129] [130]. Not only is the soil and groundwater of the northeastern corner of the CEF now contaminated, but the toxic chemicals were somehow being expelled from a storm drain into Dow's Lake [124] [125] [126]. AAFC says that storm sewers near the buried rubble of the Carling Building demolition site were picking up groundwater leachate. How this really happened remains unknown, with detailed reports not yet being offered to the public (as of January $\left.20^{\text {th }}, 2017\right)$. They are said to have since been closed off, but the NCC 
reported as late as December $21^{\text {st }}, 2016$, that the extent and levels of the contamination are still unknown pending further testing [126].

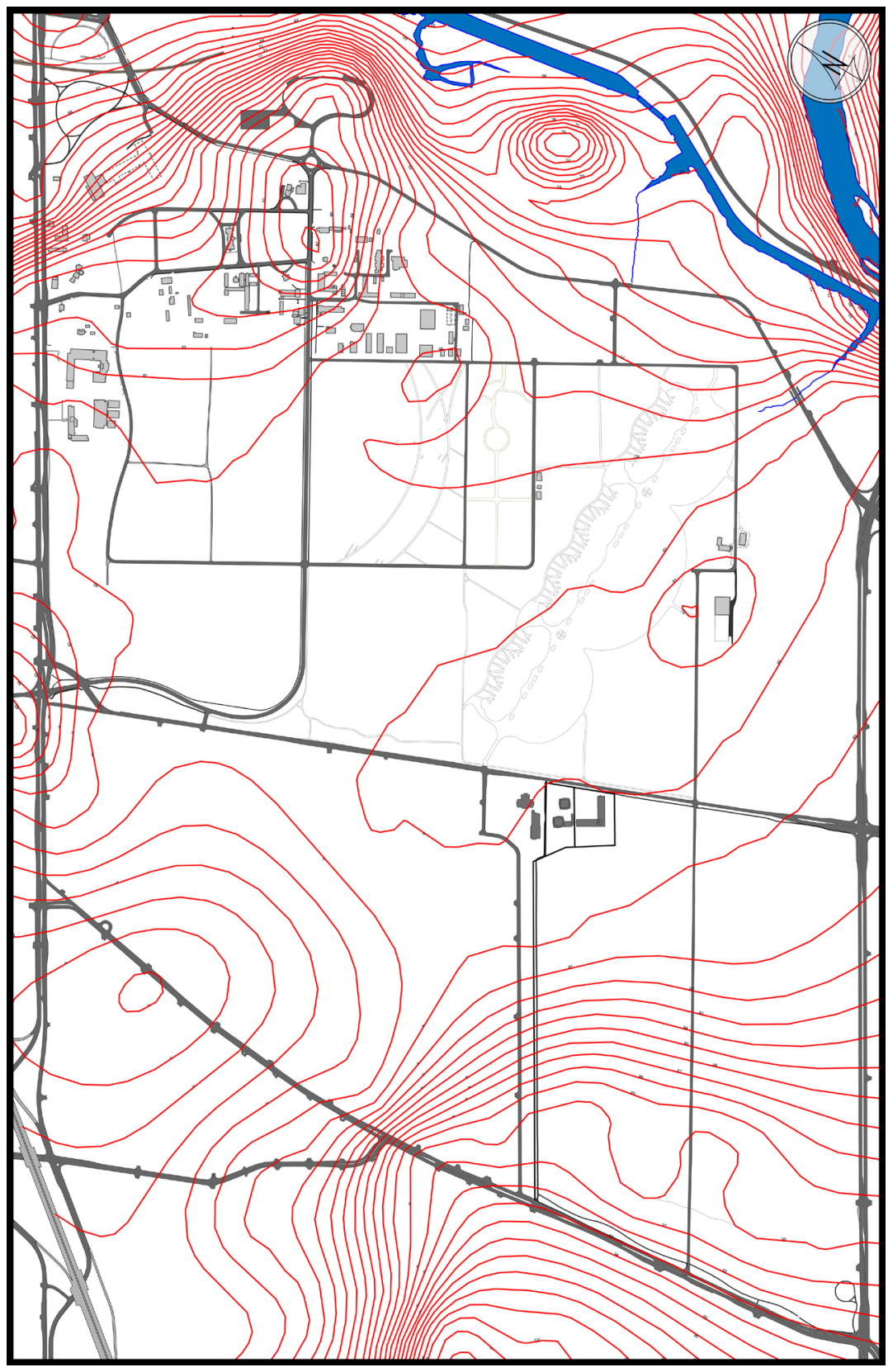

Figure 20: Topographical contours of the CEF and immediate surrounds [131]. 


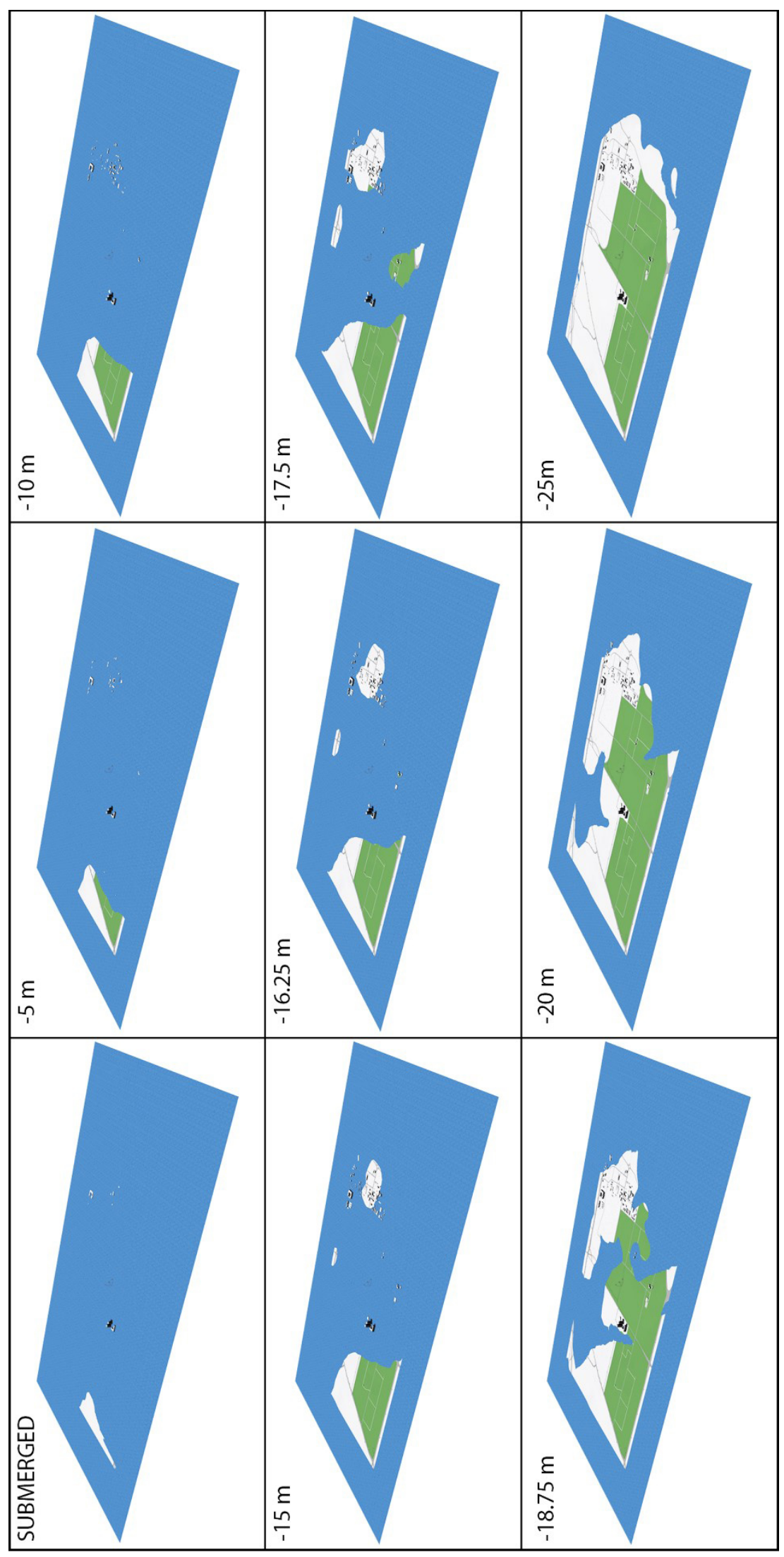

Figure 21: 3D drainage simulation; from Google Earth topography data. 


\section{CHAPTER: PLANNING THE OTTAWA PERMACULTURE INITIATIVE}

\subsection{PRAXIS DIAGRAM: NEW DIRECTIONS FOR THE CEF}

In master planning the farming community-some 260 hectares of the existing Central Experimental Farm property (Figure 22)-several goals coinciding with the principles and philosophy of permaculture were established. These objectives are intended to form the basis of an innovative experimental agro-social mission statement for the Ottawa Permaculture Initiative; they are enumerated in the following list.

1) First and foremost, is the reintroduction of a working ecosystem on the farm's property, thus providing added greenspace, parkland and wildlife habitat for the entire surrounding area, as well as creating a pollution buffer zone between the surrounding urban/suburban areas and the site. This ecosystem would be intended to integrate within the proposed human settlement and organic agricultural practices, with the intent of creating an active symbiosis between them, thereby promoting area biodiversity

2) The incorporation of agricultural and civil infrastructure into the site's natural landforms to benefit from the existing topography and drainage, with the objective of establishing a passive or near-passive aqueous exchange system 
3) The intelligent placement of all inhabited structures. Both the community and residential buildings must be oriented to enhance passive energy exchange between the Sun and the built environment, while providing ample daylighting to offset power consumption from artificial lighting.

4) Utilize a portion of the farm's acreage to harvest solar energy for the community's power demands with the aim of achieving net-negative electrical consumption.

5) Provide in excess of one-hundred percent food production for the farm's residential community by designating a maximum acreage for sustenance, market and forest gardens, without a significant impact on commercial/experimental yield-crop production potential. All surplus food production would be sold at affordable prices to the outlying communities via on-site outdoor farmer's markets.

6) Reserve at least one-third of the overall acreage (minimum of 80 hectares) for symbiotic intercropping research fields. The objective would be to simultaneously study the symbiosis of Cannabis sativa with other native yield crops and to harvest high-quality organic industrial hemp to serve in the research and development of novel biocomposite materials as viable and highly-sustainable replacements for wood and environmentally-harmful petroleum-based products. Intercropping would be employed as a strategy for avoiding the negative consequences of industrial monocultured crops, ensuring a low-impact on the existing soils and integrating yield 
crops within the overall ecosystem. Any excess revenues from hemp would be shared in common by the residents and employees of the farming community.

7) Generate an annual fair-trade revenue for the community by providing several million dollars' worth of high-grade organic medical and recreational marijuana to be sold to legally-sanctioned local, regional and national dispensaries. These proceeds would serve to cover operational costs for the entire farm and community. Any excess revenues from marijuana would be shared in common by the residents and employees of the farming community after a determined percentage is deposited in a trust fund for other local and national permaculture initiatives.

8) Operate two simultaneous living investigations into permacultural practices, the first and most prominent being a large communal settlement complex for upwards of seven hundred inhabitants or more and the second being a smaller-scale cluster of singlefamily and/or double-family residential units for thirty to seventy inhabitants. The goal here is to achieve an understanding of how permaculture is best applied in both simulated rural and urban environments, at different scales and organizations. This dichotomy of approaches would also offer working examples for those individuals or groups drawn to the site for inspiration and practical education purposes.

9) Discourage automobile dependency by erecting vehicle-access control barriers at all entrances to the site, while offering a network of walking/cycling paths throughout the 
property. With the exception of wheelchair-accessible parking spaces directly in front of the community complexes, accordingly-sized parking lots would only be provided in areas close to the site's perimeter.

10) Provide free educational programs in permaculture application strategies for citizens, designers, planners, educators and students of the greater Capital Region, or anyone willing to take up temporary residence at the site. Space would be allocated for said education courses/workshops and any related transient residency.

11) Organize educational group visits of the entire site in conjunction with tourist agencies during the tourist season in order to promote permaculture and sustainable lifestyles to the greater public, both nationally and internationally.

12) 'Permatecture': create a unique and beautiful landscape with harmonious architecture that can contribute to a sense of community and national pride in Canada's capital city. 


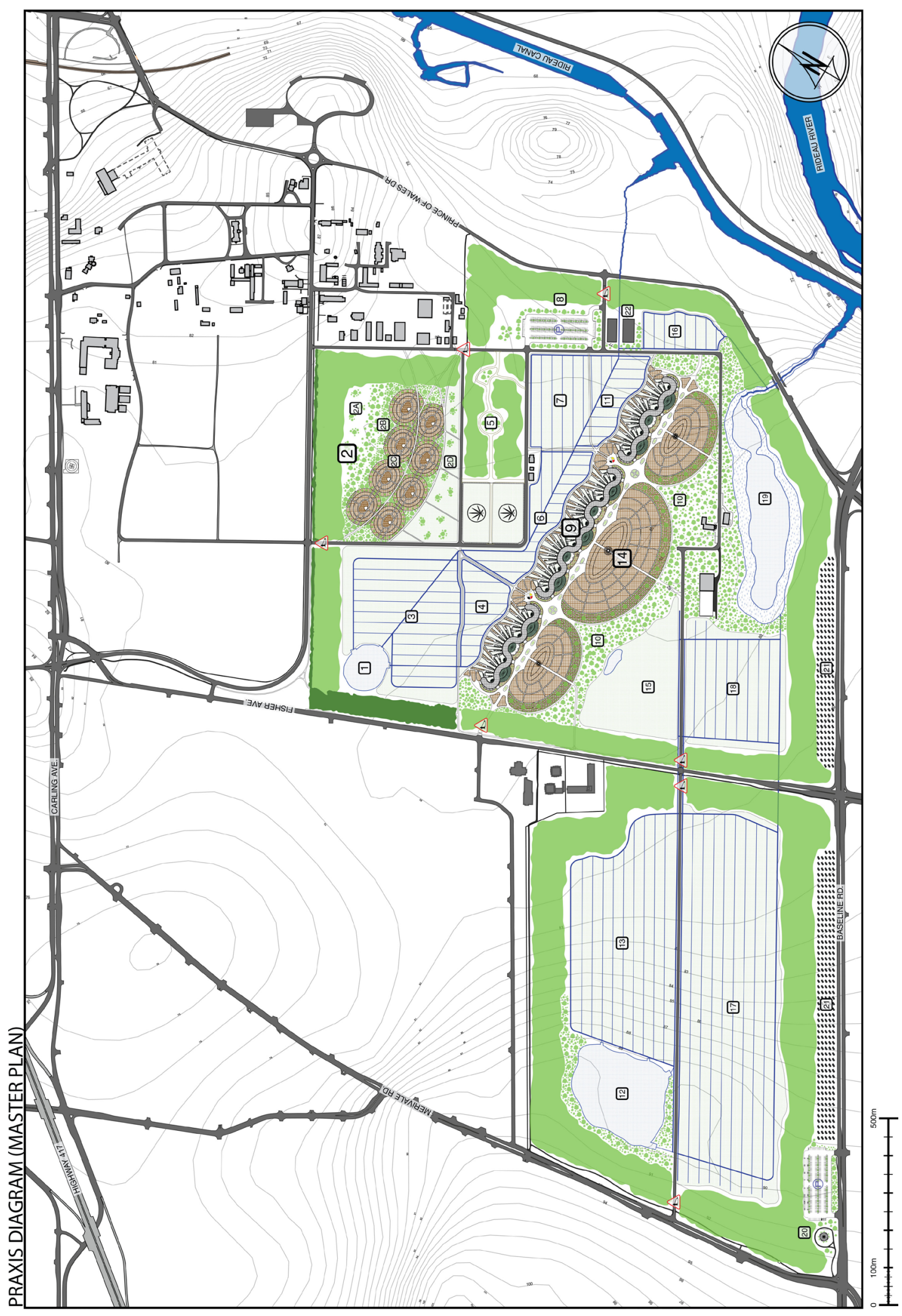

Figure 22: Praxis Drawing (Master Plan) of the Ottawa Permaculture Initiative (OPI); legend in Figure 23. 

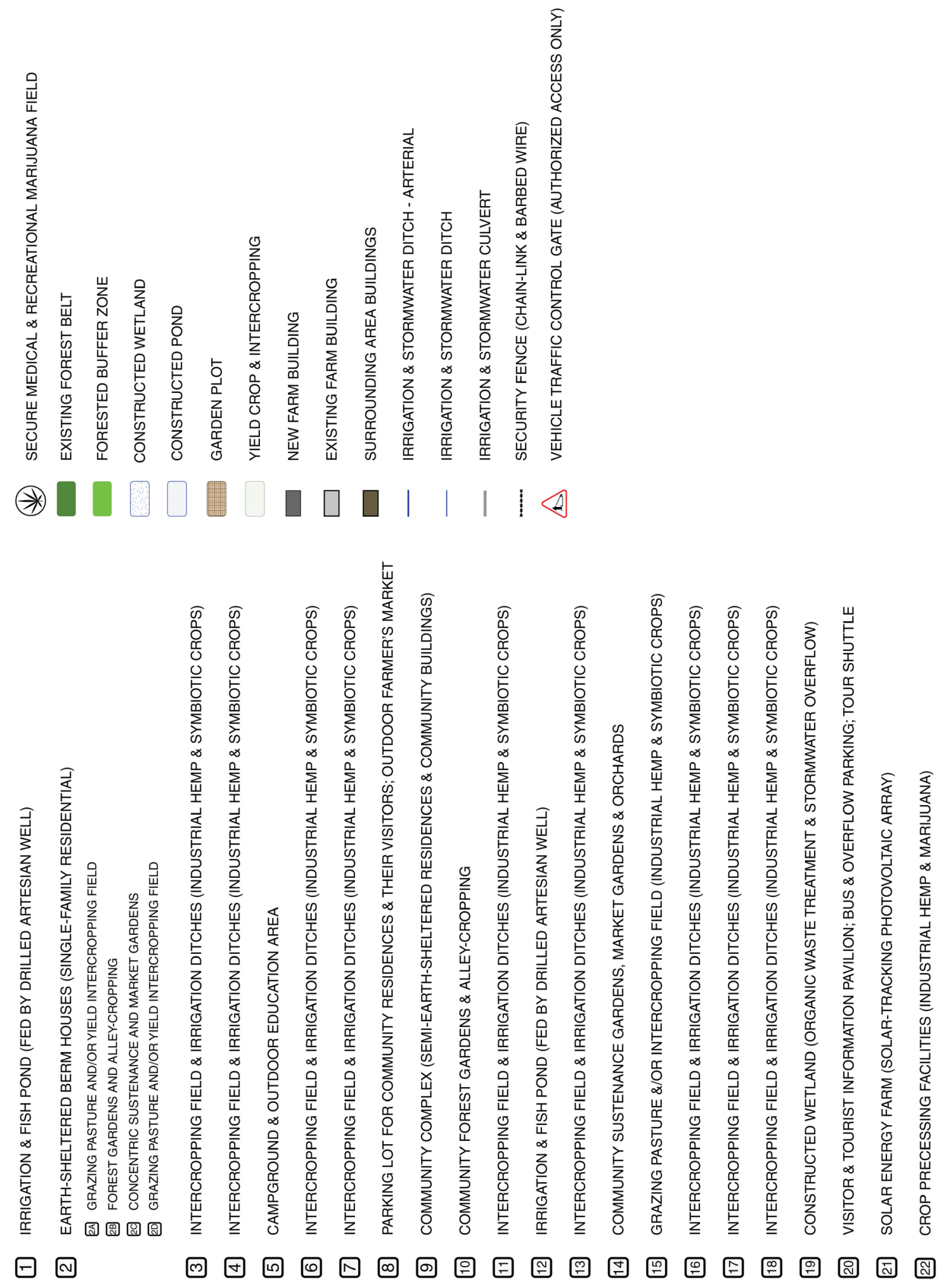

Figure 23: legend for Praxis Drawing (Figure 22). 


\subsubsection{URBAN ECOSYSTEM}

In Canada, most of our cities can be accurately described as deforested zones. According to Natural Resources Canada, a deforested area is defined as land which has permanently lost its original forestation, never to be replanted by humans or allowed to regenerate naturally, as happens following a wildfire or with some responsible logging techniques [132] [133]. Most, if not all Canadian cities and medium- to large-scale human settlements meet these criteria, with their natural habitats being razed, paved, developed and never again allowed to return to their original conditions. With this type of forest loss follows a decline in biodiversity, a degeneration in soil fertility, the loss of topsoil, the destruction of wildlife habitat, a decay in air and water quality, the loss of rainwater retention capacity and an increase in torrential stormwater runoff [132] [134]. Add to these the pollution from road salt, automobiles, industry, municipal waste, household chemicals, sewage, artificial light and urban noise, and one may see how the problems can compound themselves into menacing scenarios for the future. Cities, as we now know them, are deforested wastelands against the harmonics and symbioses of natural ecosystems.

In addition to the damage caused to the natural environment by unmitigated urban development (a.k.a. urban sprawl), an oft-overlooked consequence is the impact on the typical urbanite's psyche, whose connection to the natural world is thence all but severed. This alienation is perhaps, in turn, the main cause of human indifference toward the loss 
of vital ecosystems to industrialization and urban sprawl. Again, the compounding of an existential crisis is revealed. The urbanite inhabits an artificial and parasitical built environment and he is perhaps nearly oblivious to the harm that his world is doing to himself and the living systems beyond his myopic field of view.

\subsubsection{Reforestation}

If deforestation, as it has been shown, is a primary cause of ecosystem collapse [135] [136], then the only remedy, and perhaps cure, is to reforest as much of the human world as possible. Ideally, a permaculture project of this scope would be best situated in a forested rural area or a suburban neighbourhood bordering an established ecosystem with existing wildlife corridors. The challenges of establishing a symbiotic relationship between a human agrarian settlement and its natural surroundings under said ideal conditions would pale in comparison to the barriers likely to be encountered at the Central Experimental Farm.

Bordered on all but one of its sides by a mix of residential neighbourhoods with interspersed commercial and institutional land uses, the site is cut-off from any significant natural corridors. Native forest-dwelling mammals such as dear, fox, coyotes or wolves have no access without braving the perils of Ottawa's roadways and urban environment. Save the disjointed proximity to the Canal and Rideau River system, the farm is and will perhaps remain, in all practicality, an insulated pocket of urban greenspace. Unless the citizens of Ottawa engage themselves actively with local government to reestablish a 
network of veritable wildlife corridors throughout the city-an unlikely task beginning with the decolonization and demolition of many existing homes and buildings-city greenspace will continue to suffer from linear fragmentation. As such, any attempts to reestablish a thriving pristine ecosystem will be in vain considering the limitations imposed by its developed surrounds. Any hope for an urban ecosystem with any measurable degree of complexity and resiliency would thus begin as the earlier-discussed distributed ecovillage model.

It is with these limitations in mind that an approach to the "reforestation" of the project site was considered. For the purposes of this project, a total of 63 hectares of densely-planted regional species of trees and shrubs would adorn the site perimeter with 25 additional hectares of more sparsely-planted trees and shrubs placed strategically throughout the property and integrated symbiotically with agricultural crops.

\subsection{Zone Buffering}

One of the many advantages of the reintroduction of wooded thickets to open spaces in and around urban areas is the mitigation of four main types of pollution: sound, light, water and air pollution [137] [138] [139] [140]. With the perimeter of the OPI site being in excess of 8 kilometres, and nearly every metre thereof abutting roads that see considerable traffic congestion during peak commuting hours, the main strategy for combatting automobile pollution would be the introduction of densely-forested 
perimetrical buffer zones. In addition to moderating the effects of airborne pollutants and providing oxygen, the buffer zones will filter a percentage of nighttime light pollution, absorb and dissipate excess noise, help prevent topsoil erosion, retain ground moisture, regulate stormwater run-off (help reduce water pollution in watersheds), provide habitat for species of birds, insects and small mammals, promote biodiversity, provide windbreaks, moderate microclimate, reduce UHI effect and provide natural cover for walking/cycling paths.

In the Praxis Diagram (i.e. the Master Plan, Figure 22), the proposed forested perimeter is an average of 60 metres in width and would shield the site from all abutting roads. It would be composed of a mix of self-proliferating native species of hardwood (deciduous), softwood (coniferous), shrubs, wildflowers, ferns and other groundcover. Native species of deciduous trees include sugar maple, red maple, red oak, yellow birch, ironwood (Hop-hornbeam), American elm and many others; while coniferous varieties include the eastern species white pine, white cedar, and hemlock, as well as red pine, black spruce, white spruce, tamarack and several more [141] [142] [143].

\subsection{Wildlife Habitat}

As mentioned above, the limitations of reforestation on a fragment of greenspace amidst an expanse of urban development are not to be ignored. Consequently, it is understood that restoration of the original ecosystem's entire roster of flora and fauna- 
over 5,000 native species [99]—is, at this particular moment in history, entirely impossible; however, a low-intervention partially-managed ecosystem hosting a variety of nesting and migratory birds, insects, small reptiles and small mammals is indeed possible. Of the native species of wildlife, the reforested areas of the site could, for example, provide a home to squirrels, raccoons, songbirds, woodpeckers, snakes and other species that struggle to live in and around traditional urban human habitations.

\subsection{Forest Gardening \& Alley Cropping}

In keeping with the guiding principles of permaculture, the biodiversity of replanted forest zones would be utilized responsibly and practically to provide wild edibles and organic food for the community's inhabitants. While the outlying forested buffers would be reserved for the lowest level of human intervention, specific areas of lowerdensity reforestation are allocated in the Praxis Diagram for forest gardening and alley cropping (Figure 22, nos. 2B and 10). In relation to the human dwellings, the forest gardens would occupy the areas just beyond the higher-intervention concentric gardening plots (Figure 22, nos. 2C and 14).

Alley cropping, is a method of growing organically by utilizing natural symbiosis (codependency) that can exist between crops of different varieties, usually between a tree variety and an arable crop. It is a form of intercropping where the particular properties and 
chemical processes of one plant benefits the other and vice versa [144] [145]. It can be as simple as planting a nitrogen-fixing crop in alleys adjacent to a nitrogen-hungry crop, or as sophisticated as mixing several varieties of crops, each with its own peculiar contribution to an overall symbiotic system. For example, a natural pesticide-producing flowering species (e.g. chrysanthemums) can be planted strategically to ward off pests that feed on the yield species, while another flowering species that attracts bees or other pollinating insects can be introduced to provide fruit trees with the pollen they need for fruit-bearing. In turn, the fruit trees can provide partial shade for the yield crop, should it be required. The possibilities are literally endless and through careful research, planning and experimentation, a sustenance-providing ecosystem can be created that adds to the overall environmental health and biodiversity of the area.

The areas designated as nos. 2B and 10 in the Praxis Diagram (Figure 22), as well as any areas populated by scattered trees (including the outer rings of the garden plots designated as nos. $2 \mathrm{C}$ and 14 ), are thus referred to as forest gardens, which employ both the techniques of systematic alley cropping and more dispersed intercropping. These areas would be used to grow multiple varieties of fruit-bearing species, berry bushes, wildflowers, certain garden variety vegetables and even varieties of plants simply intended to feed local wildlife. As such, bee-keeping and organic honey production is well-suited for the forest gardens, where pollination is needed for flowering crops, plants and trees. 


\subsubsection{Infrastructure}

It was discussed in section 1.1.2.3 that, in any permaculture design process, master

planning is an ongoing holistic practice that must consider all aspects of a site, from its surroundings, topography, drainage and seasonal sun-exposure, to its intended land uses, infrastructure and human habitations. Any infrastructure and development projects need to be efficient, feasible and desirable, both from a human standpoint as well as from an environmental perspective. Human intervention should, ideally, be kept to a minimum in order to lessen impact on any established ecosystems and to maintain an economy of means. Unfortunately, when the site has already been subjected to extensive human intrusion (deforestation, industrial agriculture, development, pollution, etc.), as with the Central Experimental Farm and its surrounding lands, ecosystem rehabilitation becomes a primary focus, rather than integration alone.

It is therefore understood that the proposal for this particular site would require greater initial human intervention and many years of dedicated management-a multidecennial project for its residents, employees and volunteers. In recognition of OPI's core objective, namely that of promoting permaculture both nationally and internationally as a way of life, the significance of the Experimental Farm's historical purpose for achieving said goal should not be ignored. Despite the site's limitations and shortcomings, investment in its rehabilitation and restructuring as a world-class model for urban and extra-urban 
permaculture communities producing ultra-sustainable hemp for local, regional and national markets, is an enterprise with returns that could greatly outweigh its costs, perhaps immeasurably so.

\subsection{Constructed Water Features}

Equal to or perhaps even greater in scope than the construction of the 7.75-hectare community complex (Figure 22, no.9) is the proposed construction of four large water systems which, combined, would serve several vital functions for the farming operations and community as a whole. Since the site is envisioned as a sustainable agrarian community, the main function of the water systems would be to provide crop irrigation during periods of insufficient rainfall while in the "system establishment" stage of permaculture succession [17, pp. 66-67]. Conventionally, irrigation ditches are most often fed by rerouting creeks or streams; however, absent the possibility of drawing water to the site from any natural watercourse-which is also highly discouraged by environmentalists due to the many negative effects on dependent ecosystems-the only remaining option would be to excavate artificial spring-fed ponds. As with all permaculture systems and subsystems, the ponds would serve several concomitant functions: aquatic habitat, irrigation, aquaculture, natural fertilizer and potential microclimate moderation functions.

Proposed in the Praxis Diagram are three ponds of different sizes and depths, each placed advantageously to best exploit the site topography and generate passive gravity-flow 
in feeding a network of irrigation and drainage channels totaling over 35 kilometres in combined length (Figure 22, nos. 3,4, 6, 7, 11, 13, \& 16-18). The largest pond, measuring over 5 hectares in area, will be excavated in the area of highest elevation, the northwest corner on Merivale Rd. (Figure 22, no.12), and will be an average depth of at least 4 to 5 metres to allow for the winter survival of introduced fish stocks, frogs and other aquatic life. Adding fish, amphibians, other aquatic fauna, and species of aquatic plants to the ponds promotes the culture of beneficial nitrogen-fixing microorganisms, which can impart vital nitrates and other nutrients to the irrigation water, thereby acting as organic fertilizer for the crops and gardens [146]. Depending on the water quality and their health, the fish could also be raised as food for the residents (aquaculture). Being the largest of the three irrigation ponds, it will deliver water to the largest intercropping fields (Figure 22, nos. $13,17 \& 18$ ) and serve as the site's main reservoir and aquaculture pond.

At 2.5 hectares, the second-largest irrigation reservoir is roughly half the area of the first (Figure 22, no.1). It is planned for the northwestern corner of the site (on Fisher Ave.) and will feed the intercropping field ditches directly north of the community complex (Figure 22, nos. 3, 4, 6, 7, $11 \& 16$ ), as well as for the residential cluster's crops (Figure 22, no.2) and the 2.5 -hectare secure marijuana growing site. To promote aquatic biodiversity and provide natural fertilizer, it would also be stocked with fish and aquatic organisms, requiring its minimum average depth to be at least 4 metres. 
The third spring-fed irrigation pond is the smallest at only 0.5 hectares and will serve as drinking water for grazing livestock, as well as provide irrigation for the community complex gardens. Aquaculture is not considered for this small reservoir in order to safeguard against potential associated factors that could reduce its potability.

The final main water feature planned for the site is a constructed wetland in the southeast corner, which will not be fed by a drilled well or artesian spring (Figure 22, no.19). It is planned as a quasi-intermittent wastewater treatment and stormwater retention basin surrounded by a marsh ecosystem. Fed by a combination of freshwater from the 5-hectare irrigation/aquaculture pond, precipitation run-off and effluent from the community, its "quasi-intermittence" would be determined by the amount of stormwater, seasonal meltwater and wastewater diverted from the entire property during any given period of time. Initial excavated area for wetland will total nearly 8 hectares with at least 3.5 hectares being a planted marsh populated by a native mixture of submergent, emergent and riparian vegetation.

\subsection{Stormwater Management}

One of the many benefits of having the 35-kilometre network of gravity-fed irrigation channels is the potential for them to double as a stormwater catchment and management system. In such a hybrid setup, unwanted flooding of crops and soil erosion can be prevented, while rainwater can be diverted to the building complexes for storage in 
subterranean cisterns and later used to supply indoor gardens and other residential uses. Flow control could be achieved by engineering a series of flood gates throughout the network, with the final overflow gates located where the system's main lines tie into the existing gullies and ravines that now drain into the Rideau Canal. There are at least two such natural drainage landforms located at the southeastern and eastern sides of the farm and are well-situated, both geographically and topographically, to integrate into our proposed system.

In addition to the hybrid irrigation system, stormwater drainage from the leveled, paved and built areas of the site will be directed into biofiltration and/or bioretention basins (Figure 22, no.9) that tie into underground and/or basement catchment cisterns. The biofiltration systems use a combination of plants, sand, soil and gravel to passively filter and actively remove pollutants from collected stormwater, all while capturing and slowing run-off that can lead to soil/land erosion, overburdening of municipal storm sewers and pollution of natural watersheds [147].

\subsection{Wastewater Management}

The southeast location for the constructed wetland system was chosen mainly because of site topography, as it would occupy a low, yet relatively flat area of the site. This allows for a passive gravity-feed system for farm effluent, municipal wastewater and storm drainage. In addition to topography, proximity to an existing connection to the Rideau 
Canal system was considered to allow for easy drainage of overflow during extreme precipitation events.

As stated in 4.1.1.2.1, the primary function of the constructed wetland is wastewater treatment. The physical and organic processes involved in this type of ecosystem transform stormwater, greywater and effluent into purified water that is safe to use on crops, expel into natural waterways or use as drinking water for farm animals [148] [149]. A commercial system that can be incorporated into building systems is marketed under the brand name, Living Machine ${ }^{\varpi}$ [150] [151]. In some of the best-designed constructed wetland systems, this naturally-treated water can even be safe for direct human consumption [152] [153] [154].

The constructed wetland, in essence, is a microcosmic working model of what permaculture is on a larger scale. Many active organisms-including the human component-are utilized in concert with passive processes to produce a natural balance that benefits at once the living systems directly involved, the human beings who occupy the land and the wider-area ecology. Instead of being piped to central chemical treatment plants, then released into larger bodies of water-or, as in the case of some municipalities and cities, released raw, without any treatment at all [155] [156] [157] [158] [159]—sewage is instead treated at or very near its source, organically, effectively and sustainably. The purification mechanisms (from passive physical and chemical processes to active biological 
uptake, metabolism and decomposition processes) are many and take place in or on the root systems of aquatic vegetation, in the bottom sediment layers and in the saturated soils of submerged shallows. Much of the biological activity involves plant-microbe and microbe-microbe symbiotic relationships, making constructed wetlands archetypes of a self-sustaining anthropogenic ecosystem [160] [161].

\subsection{Building Placement}

After water, energy requirements are the next essential set of planning guidelines in any permaculture project. As stated in the list of goals (in section 4.1), net energy consumption should sum to a negative in order to ensure a minimum environmental footprint. With regard to building heating/cooling and lighting, intelligent design can minimize energy demands by making use of both established and novel green building technologies. At the planning stage, that is to say, pre-design, building placement and orientation must set the stage for a building's architecture to ensure that the benefits of intelligent design are maximized. That is to say, the design considerations should reflect in the design decisions; the planning decisions should reflect in the design considerations; and the architecture should be a product of all of the above.

Questions specific to the site itself arise and must considered: how does the site relate to the sun? From which direction do the prevailing winds originate? How well do the site's topography and geology lend themselves to building construction? How can the 
proposed structures be constructed with the least amount of earth-moving and landlevelling?

To begin with, the seasonal path of the sun represents the single most important concern for passive energy exchange. Solar gain can and must be considered such that, in all seasons, its radiative and convective potentials are utilized to promote passive heating and cooling. In our Master Plan, the decision was thus made to orient both the community complexes (Figure 22, no.9) and single-family residential cluster in congruence with the mean sun path, which is always its equinoctial route across the sky (see Figure 19). This would ensure that a maximum average south-facing building exposure is maintained in all seasons, which, in the heating season, equates to reduced heating, decreased dependence on artificial lighting and, in the cooling season, provides an increased potential for stackeffect cooling. Needless to say, these passive capacities must be reflected in the design of the building itself, but in the absence of sound planning, can never be realized to their fullest potentials.

Next, situating the building on site was considered. After examining the existing topography concurrently with the residential and communal requirements of the Master Plan, the decision was made to locate the largest building complexes centrally on the widest undeveloped expanse of flat to low-grade land that the OPI site has to offer (Figure 22, no.9). With a proposed community of some 500 to 700 residents and their permacultural 
prerequisites in mind, the chosen plot of land is well-suited for the kilometre-long complex, its concentric gardens, crop-integration and surrounding forest gardens. Conveniently, according to the provided topographical information (Figure 20, p. 132), the land's elevation drops only 3 metres over the entire kilometre, allowing for acceptable levels of energy consumption and costs for grading and earth-moving.

\subsection{Solar Energy Harvesting}

As mentioned previously, the ideal setting for any permaculture project is a rural environment with direct access to an established ecosystem. This usually refers to somewhere isolated and off-grid. Such a situation is ideal not only for its proximity to unspoiled landscapes and diverse ecologies, but also because the limitations of an energy self-sufficient human settlement forces its residents to conserve energy and restructure their lives to accept, if not enjoy, their lack of modern excesses. However, if we are to convince the world of its value for humanity, we must bring permaculture to the cities. When contemplating the value of an off-grid society, the question must be asked: if there exists an electrical grid, should it be utilized or not?

While the answer may be different for every project-based on size, location and espoused values of the individuals involved-in this case, the wisest decision would be to farm solar energy and sell any excess electrical production to Hydro Ottawa. Not only does 
it contribute to the area's clean power generation, but revenues can contribute to offsetting the community's operating and maintenance costs. Additionally, if power production is halted by technical malfunctions or low-efficiency due to prolonged inclement weather, electricity could still be drawn from the city's electrical grid, ensuring a continuance of electrical power to the residences and facilities.

Placement of the solar farm was a decision based equally on sun exposure, convenience (access for maintenance vehicles), ecology and aesthetics. For maximum solar irradiance, a south-facing rectilinear array bordering Baseline Road seems like a logical choice. Ease of access for any company technical crews and OPI maintenance staff also favoured its proximity to a major traffic artery, as opposed to a location accessed via the farm laneways and driveways. Finally, ecology and aesthetics form a joint argument: tracking solar panels may not integrate well into a diverse agroecology, as they can prevent certain types of vegetative growth in their immediate vicinity and, arguably, create an unattractive counterpoint to a natural context. Nevertheless, the possibility is not completely ruled out as a future investigation into agrivoltaics, which may in fact prove the possibility or even desirability of crop-integrated photovoltaic arrays [162]. In the context of permaculture, however, without data to suggest otherwise, the segregation of agrivoltaics and mutualistic polycultures may still be required.

To calculate the minimum number of solar panels that should be installed, we consulted the specifications published on one of the most efficient systems available on the 
market: SunPower E-Series Commercial (E20-327-COM) [163]. According to the manufacturer's metrics, each panel measures approximately 1.5 metres by 1 metre and produces 327 watts of nominal power. In the Praxis Diagram, a solar farm with 5,484 panels on 457 solar-tracking towers is planned, giving it a total of 1.8 megawatts of nominal power (Pnom). It is well understood that nominal power is never reproduced under real-world conditions, especially when the test standards that produce the company's numbers assume $1000 \mathrm{~W} / \mathrm{m}^{2}$ of solar irradiance, which is the maximum value given at sea level at the equator under optimal atmospheric conditions, i.e. full sun [164]. To account for a loss of efficiency from inversion of direct current (DC) to alternating current (AC), as well as from electrical resistance from other system components, the company recommends a 25 percent reduction in Pnom. This would bring the total system power down to 1.35 megawatts. And to produce a conservative estimate for real-world conditions at the forty-fifth parallel, it should be reduced by another 25 percent, bringing the system to around 1 megawatt under ideal summer sun conditions.

Based on averages published by Hydro Ottawa, the standard household (i.e. "customer") uses about $675 \mathrm{KWh}$ per month, or $22.5 \mathrm{KWh}$ per day (nearly $1 \mathrm{KW}$ per hour) [165]. In Ottawa, the average number of daylight hours is 5.25 per day ${ }^{42}$, which, when

\footnotetext{
${ }^{42}$ Values found on the internet vary from 3.7 hours to 5.7 hours, depending on the source. Many factors can influence these average numbers, such as solar hours per year, which is affected by climate data (cloudy days, precipitation and general atmospheric conditions) for the years surveyed. 5.25 hours is the value given on the ClimaTemps.com website [http://www.ottawa.climatemps.com/sunlight.php].
} 
divided into $22.5 \mathrm{KWh}$, requires a production of $4.3 \mathrm{KWh}$ per household. If SunPower's recommended math is applied, $4.3 \mathrm{KWh}$ is to be divided by $0.327 \mathrm{KW}$ (Pnom for their E20 panels) and a total number of 13.1 panels is required to generate the average power consumption of a typical Ottawa household. Since this number is based on their ideal test conditions, to compute an average number of panels needed, the calculation is repeated for a lower-efficiency brand and model, the Samsung ${ }^{\circledR}$ LPC250SM, for which the company provides more realistic nominal power values (nominal operating cell temperature, or NOCT, at $800 \mathrm{~W} / \mathrm{m}^{2}$ solar irradiance) in addition to the standard test condition metrics (STC) [166]. So, in dividing 4.3 KWh by the given NOCT value for the LPC250SM (0.2 $\mathrm{KW}$ ), a total of 21.5 panels per household deduced. This gives an average of 17.3 panels per residential unit to provide the electrical needs of the OPI community.

Being conscious and responsible eco-citizens living in high-performing green buildings, it can be assumed that the residents of OPI will use considerably less power than the Ottawa average. Again, to produce a real-world number and provide enough electrical overhead for periods of elevated consumption, we will use Hydro Ottawa's average value (4.3 KWh) will be used as the maximum per-dwelling consumption. With 230 residential units, each requiring 17.1 panels, a total number of 3,933 solar panels is calculated for OPI's household use, or $955 \mathrm{KWh}$ (nearly $1 \mathrm{MWh}$ ). This number falls well within the original conservative estimate of 5,484 panels producing an average real-world value of 1 megawatt and enough overhead for some other agricultural/industrial uses and sale to Ottawa Hydro. 
Admittedly, the solar farm of the Praxis Diagram is sized primarily for residential consumption, yet there still remains the light-industrial complex (hemp-processing facility; see Figure 22, no. 22) and the nighttime grow-lighting for the winter garden modules (Figure 36, p. 203). Electrical requirements for both these non-residential uses will require in-depth study that is beyond the scope of this thesis; however, ample expansion potential for an agrivoltaic farm exists in the southwest intercropping field (Figure 22, no.17) and the grazing pasture south of the community complex (Figure 22, no.15). The visitor centre parking lot could also see the addition of solar car ports, which could add upwards of 1,000 or more panels to the network (Figure 22, no.20).

In observance of stated goal number 9) of Section 4.1, automobile dependence will be further discouraged through the maintenance of an electric vehicle sharing program, owned and operated by the OPI, exclusively for the residents, employees and volunteers of the community. Charging of the vehicles will take place in the community parking lot (Figure 22, no. 8), with electricity provided mainly by solar car ports and/or garages with roof-mounted panels. ${ }^{43}$

\footnotetext{
${ }^{43}$ Depending on the vehicle manufacturer specifications and recommendations, insulated and temperaturemoderated garages may be required to maintain charge in the vehicle battery cells during the heating season.
} 


\subsubsection{Sustainable Sustenance: Crops and Market Gardens}

It is an oft-repeated dogma to justify centralized economics and perpetual urban

growth: The Earth is overpopulated and cannot otherwise sustain the exponential reproduction of its human inhabitants; yet, rarely are we presented with its most compelling refutation, that our problem is not necessarily how many humans live in the world, but how we humans live in the world. While it is not the intention to here dispute the inevitable crisis posed by exponential population growth, it can be argued that both the problems of population management and environmental instability generally share a common origin: centralization.

Cities, in their present form, represent the epitome of centralized human systems and rely wholly on an external and exploitive support network, which is termed, the economy. Food is not grown in cities. Resources are not extracted from urban metropolises. In essence, the bulk of their wealth is not generated from them either, despite the common misconception that cities create economy. Certainly, cities contain many of the secondary industries that transform raw materials into marketable products, but in the age of corporate globalization, where industry is most often relocated and outsourced to thirdworld slums for near-slave labour-sometimes for outright slavery-monopoly capitalism is rapidly dropping its mask. When the thin veil of dogma is stripped from centralizedurbanized capitalism and its apologetics, one is confronted with a system that does little 
more than centralize the vast wealth created for it elsewhere (i.e. outside of cities or most often in other countries with abysmal human rights and labour practices), deposits it in the bank accounts of powerful Western financial dynasties and then redistributes miserly sums to its bureaucrats, caretakers and service-employees-the wage-slaves we call typical urbanites.

Of course, this outlook on urbanity may be regarded as an oversimplification, but not if the discussion aims to create an overall depiction of how capitalism relates to both the human and natural worlds, from which it sources and centralizes the entirety of its financial power. In the process of "creating wealth" for a minority, it creates poverty for the vast majority; but not simply human poverty, for its incorrigible policy of perpetual growth also impoverishes and imperils the world's ecosystems. And this perpetual growth likewise translates to populations, with humanity's impoverishments creating increased human proliferation, then in turn creating more environmental pressures [167] [168]. Thus, if we humans are to, at once, reverse the vicious cycle of unmitigated population growth, as well as create a system of production and trade that benefits the whole of humanity and the Earth-rather than enriches an astonishingly narrow and gluttonous cross-section known as, The Elite, at the expense of everyone and everything else-the function and functioning of cities must be revolutionized. Of course, the verb, to revolutionize, itself has to be redefined and repurposed: a diametric reorientation, as opposed to its mainstream postmodern misappropriation as, a "drastic improvement". If cities are to become less of a 
blight on the natural world, they need to reinvent themselves within the natural environment. As such, their inhabitants would have to begin producing their own sustenance, transforming their own waste and sharing the common fruits of their labour. Reliance on capitalist middlemen in stocking supermarkets, setting prices and profit margins, disposing of ton after ton of perfect edibles in the effort to justify food prices, is a fallacious and wasteful system that cannot be sustained as populations increase around the world.

It is for these reasons, presumably, that permaculture stresses local food selfreliance, which is perhaps its fundamental motivation. A human settlement that not only produces, but shares communally, the toils and fruits of its labour and then gives back to the ecosystems it relies upon, is a population no longer in competition with itself and its environment. It is truly beyond sustainable; it is universally synergistic.

In the praxis diagram for OPI, a total of 17.4 hectares is allotted for sustenance and market gardening. 12.6 hectares for the large community complexes and 4.8 hectares for the residential berm-house cluster. Each of the large community gardening plots mirrors the building complex it is assigned to (Figure 22, no. 14). Following the fundamental principles of the permaculture zones (Figure 1, p. 32) and examples set by existing projects, the larger plots are subdivided into concentric semi-elliptical rings, which are again 
subdivided into smaller plots. Each consecutive ring represents one of six zones of human activity as it relates to the surrounding environment. (Figure 22, no. 14)

Beginning at the centre, Zone 0-the place of human dwelling-is the highest activity zone. Zone 1 is the first ring outside of the residence, which requires the most intervention and activity: food production requiring frequent inspection, maintenance and care. This includes raised beds, cold-frames and small greenhouses (if required in spring for germination, seedlings, cloning and early vegetative growth $)^{44}$, annual garden varieties, herbs, flowers, free-run chickens, hatcheries and coops. Zone 2 and Zone 3 would comprise native food varieties of the residents' choosing that require a successively-decreasing level of attention and intervention. Zone 4 will be planted with lower-scale intercrops of higheryielding varieties such as native maize, ancient grains, wheat, soybeans, and sunflowers. Zone 5 is an alley-cropping orchard for an assortment of fruit trees, nut trees, fruit-bearing shrubs and any plants that would benefit from the partial shade of the alleys. Zone 6 (the forest garden) is the largest zone beyond the concentric growing plots, which is described as a class of agroforestry. It will incorporate any native or wild varieties that thrive in

\footnotetext{
${ }^{44}$ Terms refer to the early stages of plant growth: germination is the period during which a seed is activated and sprouts; seedlings are the stage following germination when simple root systems are first established; clones are started from a single parent, or "mother" plant, as opposed to germinated seeds; clone rooting, or cloning, is the stage following the cutting of leafy stems, when the stems are activated to produce their own root sprouts and become individual plants; vegetative growth is the cycle following the above initial phases of growth, when root systems, stems and leaves proliferate in preparation for the flowering phase (when the plants finally yield flowers and/or fruit).
} 
forested ecosystems and require nearly no human intervention. See 4.1.1.1.3 for a more detailed description of forest gardening.

In spite of their well-ordered, concentric and compartmentalized appearance in the Praxis Diagram, the large sustenance and market garden plots for the community complexes are mainly intended to benefit from an ecosystem-inspired approach to agriculture. As such, planting would follow the permaculture zoning pattern merely as a general guide, with symbiotic interplanting as the primary objective in crop placement. The same model described above is applied to the concentric elliptical ring gardens of the residential cluster (Figure 22, no. 2).

\subsubsection{Intercropping Industrial Hemp and Medical Marijuana}

There are several different names used for the sustainable practice known as intercropping. Interplanting, companion planting, and multi-cropping are three of the most common alternates. Likewise, there are many techniques that that fall under its banner; all of which are forms of polyculture and are good examples of planned mutualistic symbiosis. Two such methods were covered briefly in the discussion on alley-cropping and forest gardening (4.1.1.1.3). Here, the concern is with higher-yield commercial crop production, as it pertains to OPI's original goal of providing sustainably-sourced hemp for building materials research, development and manufacturing. Incidentally, this aim would also provide a continuance of the Central Experimental Farm's historical purpose, as the 
intercropping areas will double as research fields, eventually supplying valuable data and findings on polycultured organic Cannabis. Therefore, the commercial intercropping fields designated in the Praxis Diagram (Figure 22, 3, 4, 6, 11, 13, and 16-18) can correctly be referred to as dual-purpose.

As research fields, various permaculture techniques would be practiced, studied, published and refined, all with the aim of developing crop-enhancement through mutualism. In other words, the OPI would study ways to increase productivity and raw material quality without sacrificing biodiversity. Both tradition and studies already agree that, generally, this can be accomplished with carefully-planned polycultures, all while rejuvenating and maintaining soil health, contributing to pest/weed control and stimulating a working ecosystem. It is important here to note that different varieties of hemp and marijuana (both members of the Cannabis sativa species) have been used successfully as companion crops to protect a range of different plants [27, p. $53 \& 71]$ [169]. What remains understudied are the species of plants that best combine with various strains of Cannabis to increase its yield and defend it from infestation. Traditionally, hemp and marijuana have been used as the protective crop because of its robustness, its observed pesticidal properties and its ability to rejuvenate compromised soils [169]. But, despite its hardy constitution, it still remains vulnerable to a handful of diseases, parasites and vermin, which, in monoculture operations, can devastate entire harvests and thus necessitate the use of chemical pesticides. With existing studies hard to find, the selection of suitable 
companion crops for OPI's industrial hemp and medical marijuana fields must rely on empirical evidence gathered on other studied polycultures, as well as the experiential knowledge of established practitioners, as points of departure for its own research.

Fertilizer for all agricultural activities at OPI would coincide with permaculture convention and would be sourced nearly entirely from plant mutualism, ecosystem services, composted waste (cover crops, green manure, animal manure, garden refuse, kitchen compost and aquaculture byproducts in the irrigation water $)^{45}$. It is even possible to employ a system that recycles human waste, so long as residents keep a fairly strict diet and limit-if not eliminate-pharmaceutical drug use by turning to holistic, natural nutraceuticals and other alternatives.

\subsubsection{Human Habitat AND ACtIVITY}

\subsubsection{Communal and Quasi-Atomic Communities}

The social structure of OPI is a consideration that guided, above all, the planning and design of the community. As a planning initiative, it is necessary to begin with a target number of residents and a general intuition of their demographics. Who would want to commit themselves OPI? How long would they stay? What could be the nature of their commitments? Would some contribute financially to the community? Would every

${ }^{45}$ If necessary during the system establishment phase, organic fertilizers would be purchased from nearby organic farms. 
member share the revenues of OPI's production equally or would profit-sharing be based on levels of commitment and investment?

Idealistically, a model decentralized community would divest in capitalism altogether; however, the reality of capitalist economics is still inescapable if a project of this nature is to receive initial funding and generate the necessary income to survive. As such, OPI would need a detailed economic plan and social contract, which are well beyond the grasp of this paper. Nevertheless, it is anticipated that the bulk of primary funding could originate from many separate sources: a pilot programme producing organic marijuana for licenced dispensaries; a loose conglomerate comprising all three levels of government (local, provincial and federal) and environmental non-governmental organizations (NGOs); donations from environmentally-responsible philanthropists, private individuals and internet-based crowdfunding programmes; and initial investment from prospective OPI residents. Uniting these untied affiliates is of course the understanding that possible returns on their investment transcend simple financial recuperation or profit: they are financing a future for humanity as a whole.

Of course, no one is to be exploited for their contribution, whether that investment is time, expert consulting, manual labour, or monetary contribution. Any profits would be split between resident workers (incomes based on individual contributions weighed against community overhead and commercial revenues) and a trust fund for financing national permaculture initiatives. A second, higher-level trust fund, would be held in common 
between all future Canadian permaculture initiatives, to help finance both national and international projects. The ultimate mission is to stimulate an organic growth of permaculture economies across Canada and throughout the world. In essence, what is proposed is a fully-transparent profit-sharing program on all its levels, with a goal of not enriching individual "stakeholders", but promoting eco-cultures and eco-economies ('economies') that give back to Nature what unrestrained industrial capitalism and rampant individualism have raided so callously from her over the past several centuries.

With this 'eco-nomy' in mind, OPI's community is planned for upwards of 750 full time residents who are fully committed to a decentralized communal lifestyle. They are attracted to OPI because of the example it can set for the surrounding communities, the city and the nation. Moreover, they seek to live the alternative and not simply pay it mouth service. These individuals and families would originate from a diversity of backgrounds and all may choose to live and work for a short time or a lifetime, provided that they contribute to the best of their abilities. In short, none would be drawn to OPI for a "free ride", as it is a community model that would stress universal responsibility. As mutualism is practiced as a form of agriculture, so too will it be espoused as a tenet of social organization: "From each according to his ability, to each according to his needs". The strengths of one cancel the weaknesses of the other; the talents of one become the assets of all; the power of all becomes the capacity of one. 
In the Praxis Diagram, two models for communal living are proposed. One is a medium-density residential complex (Figure 22, no. 9) that incorporates interior winter growing areas (winter garden nurseries) and community building modules whose use is to be determined by the needs of the community. Such uses may include education, daycare, medical clinics, performing arts, administration, research laboratories, or anything the residents of OPI consider necessitous. This complex is designed to house up to 750 inhabitants, will feature 222 units of varying sizes and configurations that share large communal kitchen areas, as well as the above-mentioned community services.

The second model is proposed to study a quasi-communal cluster of earth-sheltered berm-houses where residents may prefer to live somewhat more privately (single-family or double-family arrangement), while still remaining part of a larger community organization (Figure 22, no. 2). Superficially, the latter configuration appears more self-sustaining and economically viable, yet when one considers the external support network required for community services, it becomes clear that an overall comparison study is necessary. At OPI, the berm-house residents would share the community complex buildings for services. The inclusion of this second model is important also because it could stand as a working example for visitors seeking knowledge and inspiration for planning their own ecological homestead elsewhere. 


\subsubsection{Practice and Education}

As discussed in Chapter 1, permaculture is not a new concept. Most of its practices combine traditional knowledge with more recent advancements and technologies to create an ever-evolving system that can be applied anywhere food is grown. Since the 1970s, it has been gaining increasing attention along with the spread of environmental awareness worldwide. Nonetheless, it still remains largely undiscovered by the general public and generally ignored by official policymakers. Its value to humanity awaits the urgent international attention it so deserves. It thus becomes the responsibility of all its proponents and practitioners to educate the world. If education is a universal human right, then affordable or free instructional programmes become the duty of all medium and largescale permaculture projects. Accordingly, 5.7 hectares have been dedicated to an outdoor education area and campground in the Praxis Diagram (Figure 22, no. 5). There, students could live cheaply for the duration of their courses in ecological human settlement, sustainable building construction and urban permaculture. It would include campsite accommodation for tents, campers and larger recreational vehicles, as well as practice growing plots and a sizeable workshop tent for class instruction.

Community and institutional education workshops could also play a key role in furthering OPI's mission to engage the community at large, sustain a working relationship with government bodies and network with schools, colleges, universities and NGOs. Space 
for these periodic events would be provided in the community complex education and public assembly buildings (Figure 33, p.200).

\subsubsection{Eco-Tourism}

As an adjunct of the educational programmes, greater outreach could be achieved by establishing OPI as a popular destination for tourists. By liaising with tourist agencies and taking advantage of Ottawa's 1.79-billion-dollar annual tourist industry [170] the site could generate international interest. And with the Nation's Capital hosting more than 8 million visitors per year, over 4 million of whom are attracted by outdoor activities and events [171], word of OPI's truly-sustainable vision for humanity could well assist in spreading permaculture awareness across Canada and the world.

Due to the expanse of the site, with many potential attractions and curiosities for sightseers, a shuttle system to escort them about the property is proposed. As a zeroemission system, the shuttle service itself could add to the experience by either employing modern horse-drawn buses or rechargeable battery-electric buses. For this purpose, a visitors' centre and car park with tour-bus parking are assigned to the extreme southwest corner of the property (at the intersection of Merivale and Baseline roads) (Figure 22, no. 20). The 'eco-shuttle' would have its pick-up and drop-off in this parking lot. 


\section{CHAPTER: PERMATECTURE: PERMACULTURE MEETS}

\section{ARCHITECTURE}

\subsection{DESIGN CONSIDERATIONS}

In approaching the facilities' design for OPI, it seemed logical to follow a process parallel to that of the master planning: both landscape design and building design, as they relate to permaculture, share similar considerations and objectives. Since the Praxis Diagram (Master Plan) focuses on reintegrating human settlement into Nature and emulating biodiversity, any buildings introduced to the site must not interfere with this relationship. More importantly, wherever possible, built structures should play a principal role in the symbiotic interrelations established between human beings and their immediate environment. To achieve this end, the building complexes were designed with a set of goals that mirror the list of objectives set forth in the introduction to 4.1. These design criteria are described briefly in the following list.

1) 'Spatial symbiosis' (permatecture): create an organic harmony between programme and architecture, exterior domain and interior space, public realm and private residence, such that each part is reflected in the whole and vice versa. Occupants should experience a unity of architectonic expression, both spatially and materially, that substantiates a connection with the Earth. 
2) Bio-integration: desegregate the built environment from its green surroundings, the building's materiality from its earthly elements and the lived milieu from the worked landscape.

3) Precipitation catchment: incorporate design elements that capture rainwater runoff, including meltwater from snow and ice, which would be channeled into storage cisterns. The objective is to sustainably-source as much water as possible, with minimal to zero use of chlorinated municipal water.

4) Passive energy exchange: built forms should maximize solar gain during the heating season and, during the cooling months, transform passive thermal energy into convective cooling currents. Minimizing energy consumption from HVAC systems is a foremost concern.

5) Thermal performance: incorporate innovative and dynamic building systems to regulate heat transfer. A 'trifecta approach' would be employed, in which envelope materials, thermal mass and advanced building systems coordinate to maximize thermal efficiency.

6) Maximize daylighting: building skins and geometric shapes should complement cardinal orientation to produce comfortable levels of solar transmittance. Design 
elements that admit both direct sunlight and diffuse daylight would assist in offsetting the electrical demands of artificial lighting.

7) Prolong growing season: continue sustenance gardening throughout the coldest months with climate-controlled indoor winter gardens, which should stand as central design features.

8) Dissolve social alienation: create attractive communal spaces that encourage frequent social interaction, normalize community life and prevent societal atomization.

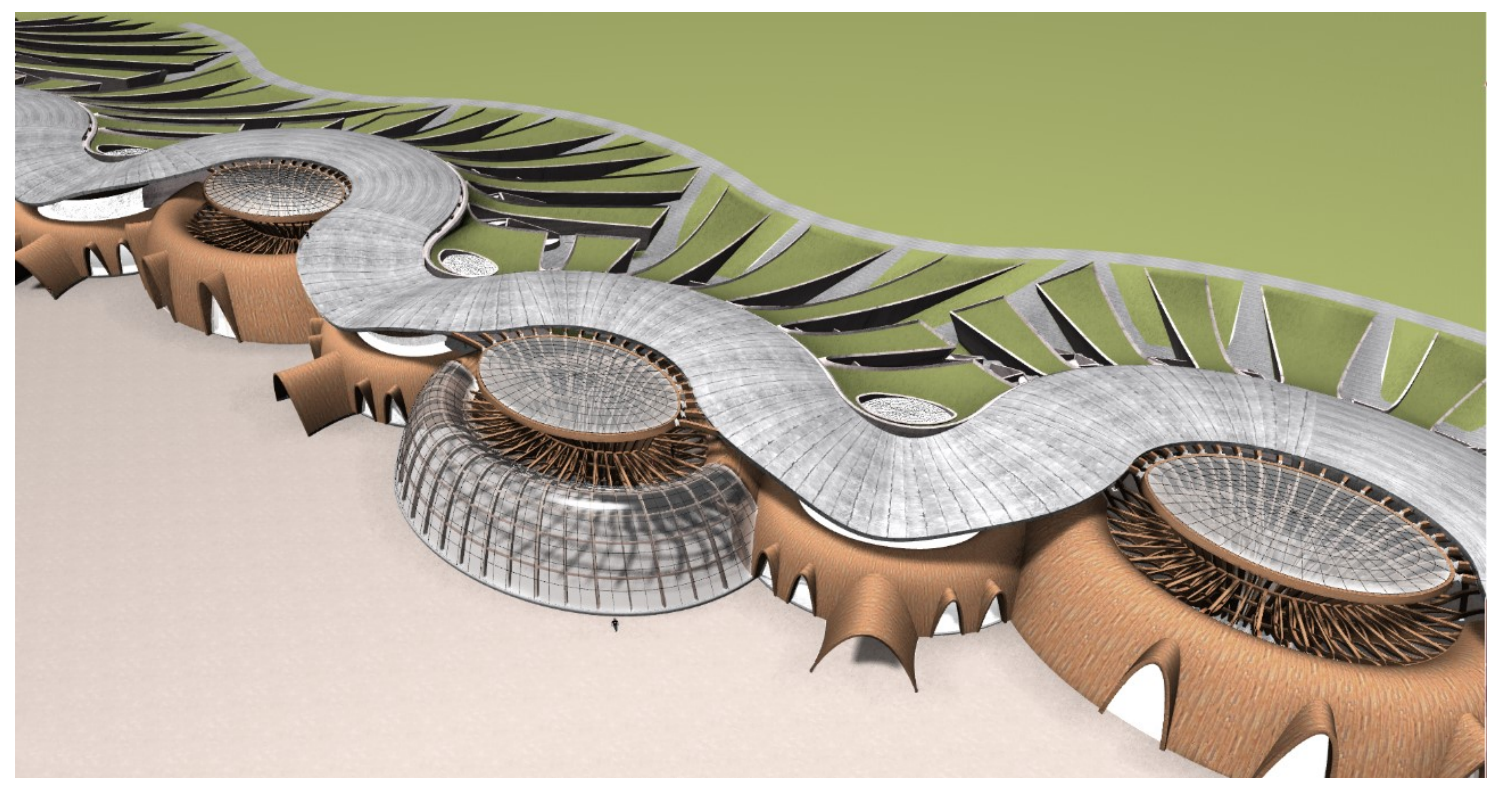

Figure 24: Perspective of Community Complex's south-facing side; presented here as "under-construction", with exterior roof walkout glazed flooring yet to be installed. 


\subsubsection{Natural Daylighting, SUn Path and Building Design}

The first major practical consideration for the community buildings was the incorporation of design features that unite to harness the free energy of the sun. As the universal power plant, it alone could provide most of the community's free-energy needs. With intelligently designed structures, the sun can simultaneously heat, cool and illuminate an interior space for a large portion of the daylight hours. With light wells, reflective surfaces and proper surface geometries, even earth-sheltered and subterranean buildings can benefit from natural daylight with little or no daytime artificial lighting. Likewise, with adequate thermal mass, placed strategically to maximize passive solar gain, free radiant heat can continue to offset heating demands beyond the sunset hour.

In order to take full advantage of these physical processes, first the community complex was oriented perpendicular to the sun path at solar midday on the equinoxes (Figure 19, p. 124). Secondly, spaces that necessitate the most sun exposure-i.e. the winter gardens-were given a compound-curved glazed façade with 'plan curvature' that approximates the quasi-elliptical equinoctial sun path. ${ }^{46}$

\footnotetext{
${ }^{46}$ With the building's geometry possessing complex curvature, the term 'plan curvature' is here used to describe the quasi-elliptical curvature in-plane with its plan view (two-dimensional horizontal projection); the term 'sectional curvature' is here applied to describe its parabolic curvature in-plane with any section view (two-dimensional vertical projection) taken at a normal angle to its "plan curvature".
} 
Additionally, the structure's frame members all possess 'sectional curvature' that is parabolic, which performs the dual-purpose of acting as structural arch and parabolic reflector. In addition to the building geometry, insulated glazing units (IGUs) of varying reflectivity and transmissivity would be used strategically to direct sunlight into the buildings. For this purpose, a unique structural glulam "timber bent" (frame) was designed, which began as a standard parabolic arch before being split in half, widened, offset vertically and bridged with an upward-facing parabolic truss, as shown in the north-south section (Figure 38, p. 212). There are forty such frames arranged in a quasi-elliptical array, together forming a giant oak-tree-like primary structure in a "hierarchic" structural glazing façade system (Figure 26). When the array's inner (rear) parabolic frame members are combined with reflective glazing, they form a surface that captures incident sunrays and reflects them down into the interior space. This hybrid 'truss-bent' design is used in both the winter garden modules and the community building modules, despite the latter not being fully glazed.

Another principal design feature formed by the truss-bent array is an "eye-shaped" glazed atrium roof that tops each of the community building and winter garden modules (Figure 25). As a "hierarchic structure", the main load carrying elements (glulam trussbents) are contained in the tree-like array, which are all tied together by glulam blocking and cable tensioners. The cables thus perform two functions: create rigidity in the central array and provide the secondary support structure for the IGUs across the entire span of 
the atrium roof. Tied to the main tension cables are tertiary structural elements, is a web of smaller cable tension trusses, which span in between the main cables and connect directly to point-fixed glazing support brackets (a.k.a. "spiders"). Altogether, the intricate hierarchy of the atrium creates a web-like pattern inspired by Native dreamcatcher designs. The principal function of this glazed web is to act as a large skylight for the communal spaces below. The interior space of this superstructural 'oak tree' provides the added capability of functioning as a "solar chimney" in the cooling season, with its solar-heated air creating a stack-effect potential that could be incorporated with air ducts running through the Southside berm structures and under the ground, acting as a passive air exchange and cooling system. This aspect will remain a design consideration for the future.

'Eye-shaped' skylights are repeated throughout the community complex, both in the residential units and above communal gathering areas referred to here as, 'drum circles' (see 5.2.1.2). In the earth-integrated residential units, smaller skylights cap light wells that pierce through all floors to bring added diffuse daylight to each unit. The interior walls of the wells are lined with reflective coatings to maximize their efficacy. 


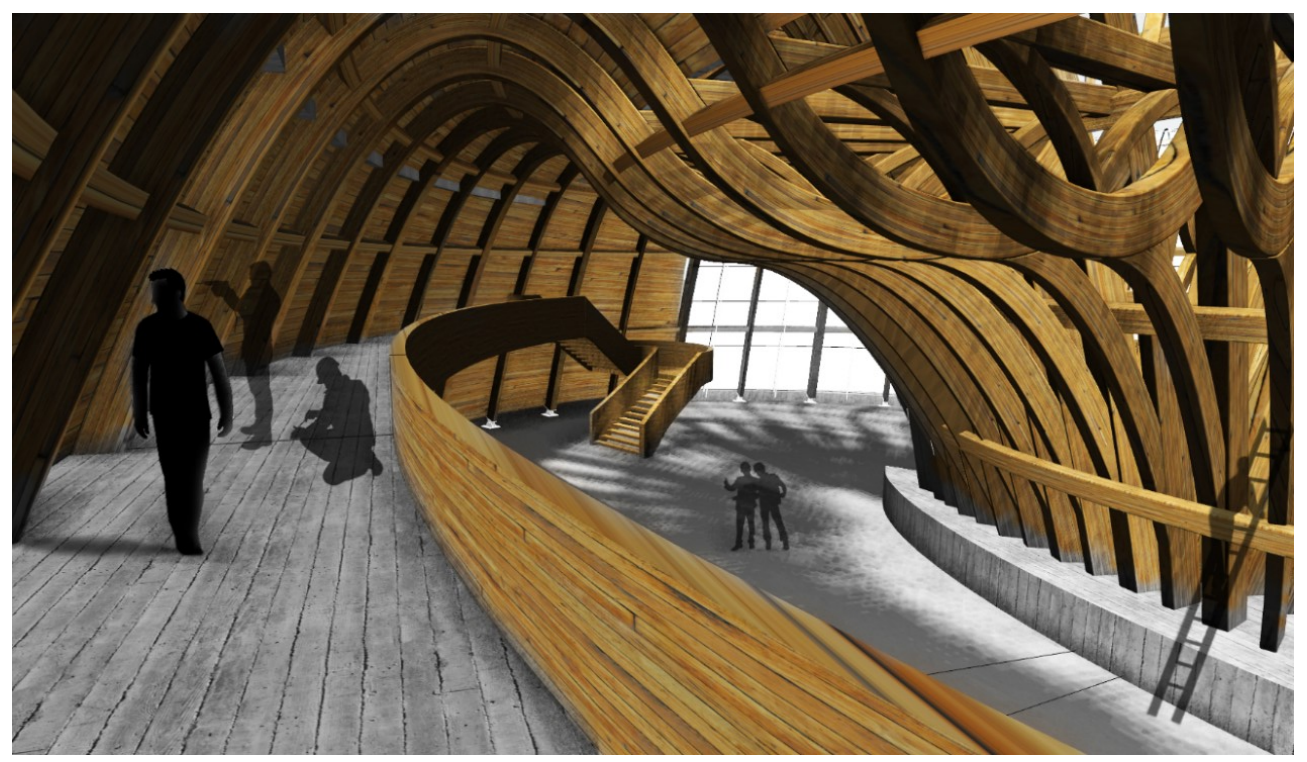

Figure 25: Walk above communal kitchen (under construction).

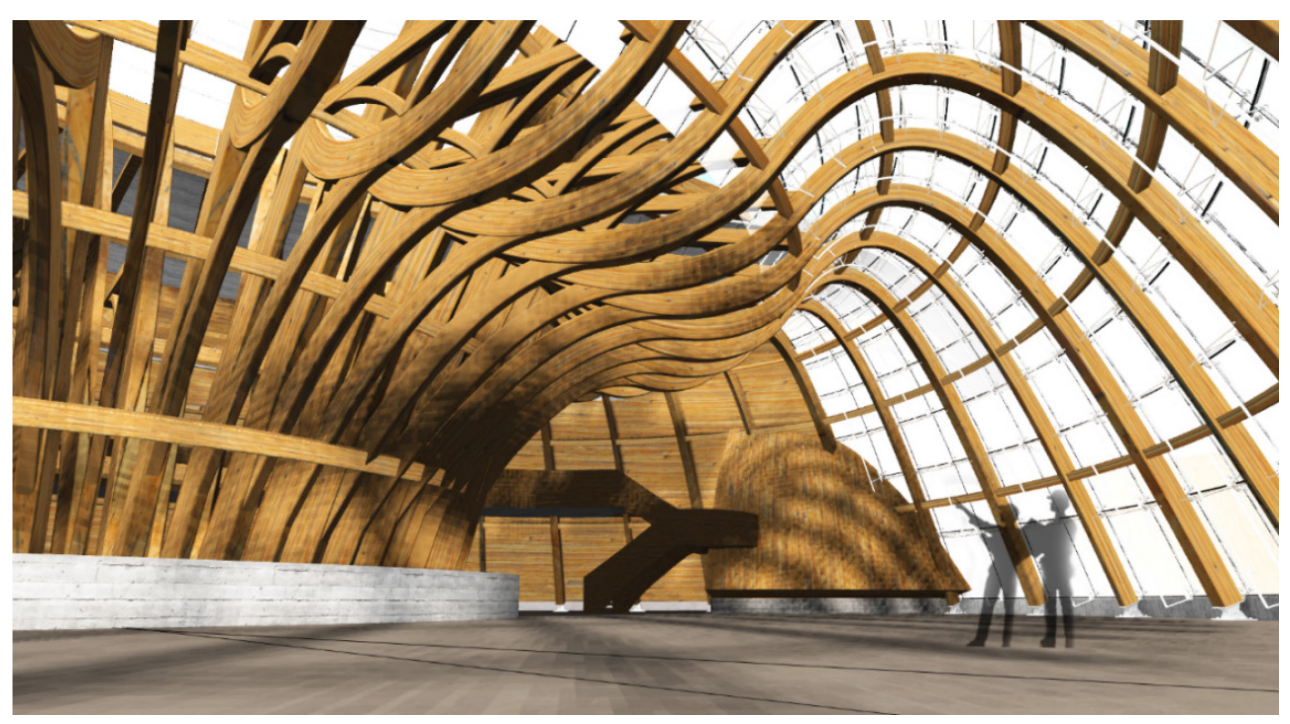

Figure 26: Glulam 'Giant Oak Tree' in Winter Gardens (under construction). 


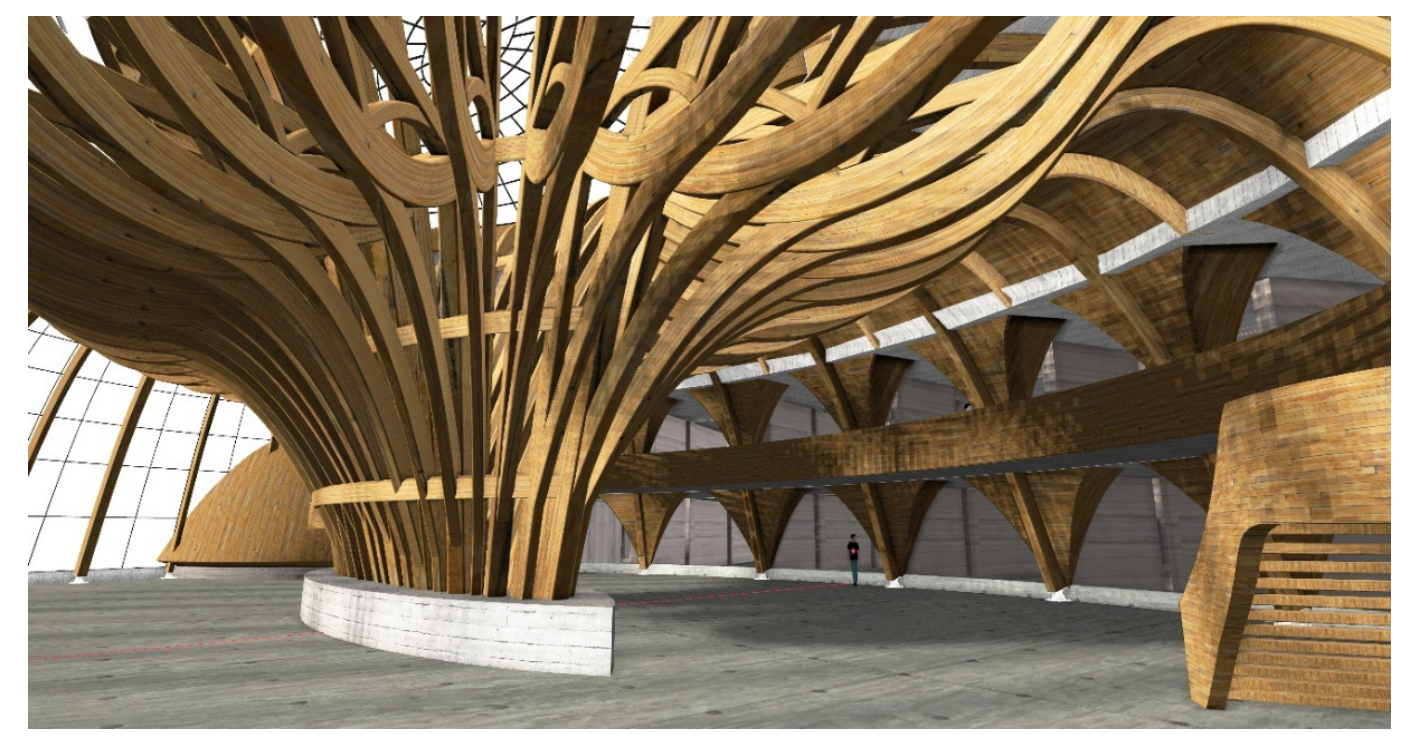

Figure 27: View of entrances to units in communal kitchen and on mezzanine, seen from Winter Garden.

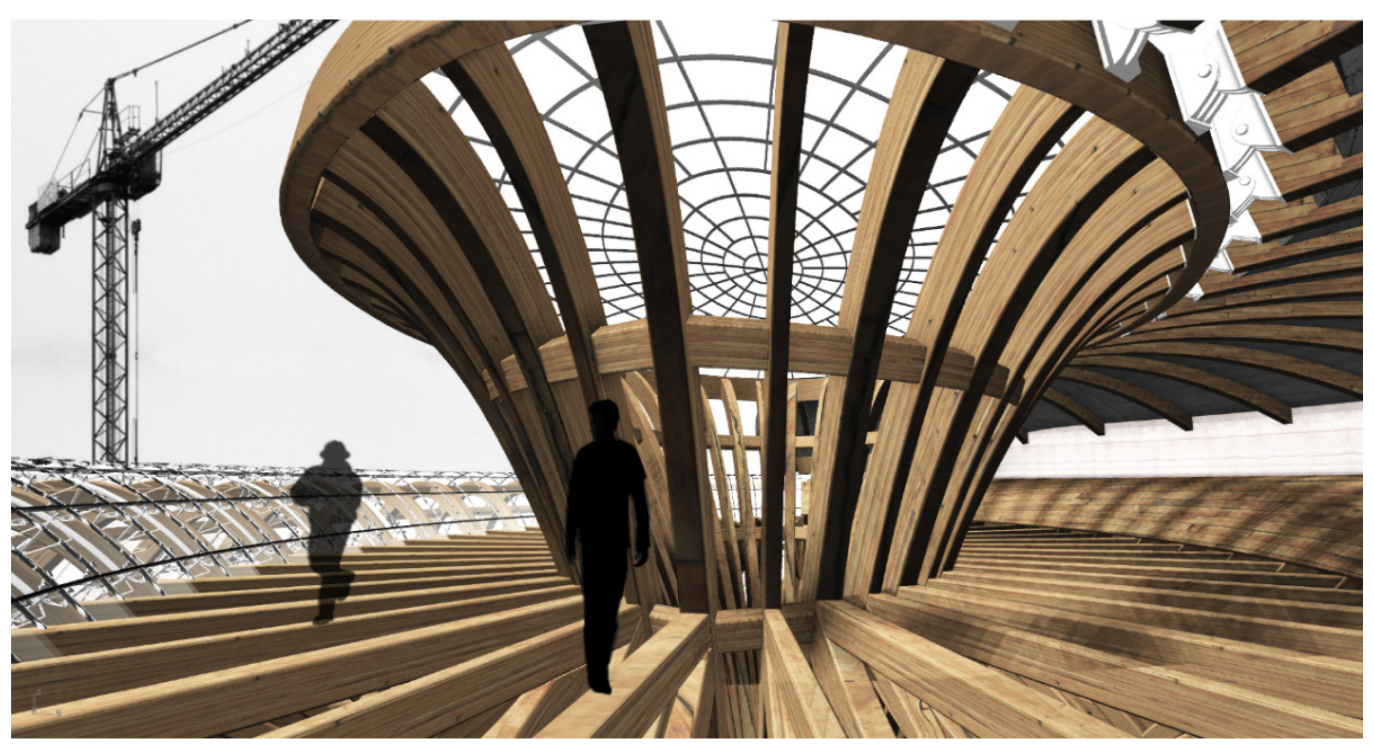

Figure 28: "Eye-shaped" atrium roof under construction. 


\subsubsection{Earth-InTEgrated ANd Crop-Integrated ARChitecture}

To achieve the objective for bio-integration, it was decided that creating a partially earth-sheltered community complex was a feasible strategy. Due to site topography, there were no substantial sloping grades to utilize for an elevational style earth-sheltered building, which left only one possibility that would prove economically-feasible: earthberm construction. As mentioned previously, this was also the style of home chosen for the residential cluster since it provides many of the insulative and mass properties of in-hill construction, it can be built on level terrains and is much less costly in terms of labour than recessed construction. ${ }^{47}$ By contrast, the community complex would be a higher-density residential structure, with many dwelling units that could end up completely covered by earth with typical berm-sheltering. Since residential units require natural daylight and emergency exits, it was decided that the residential development would be a neoteric expression of a three-storey condominium building, with the north-facing sides of the units being partially earth-sheltered. The originally-intended berm was thus carved into 'raylike' outcroppings extending outwards from the centre of the truss-bent array discussed in

5.1.1 (Figure 29). The earth would be contained by cement-stabilized rebar-reinforced rammed-earth retaining walls, forming open channels that partially-expose the units and

\footnotetext{
${ }^{47}$ Of the three main styles of earth-sheltered construction, berm-sheltered buildings are constructed on level, nearly-level and gently-sloping grades, whereas elevational (in-hill) construction are, as their name implies, built into the side of stronger/steeper slopes. The third method, the atrium (recessed or below-grade), requires the most excavation and earth-moving as the building is fully or mostly subterranean [172] [226].
} 
provide rear-access staircases, as well as terraced exterior spaces that overlook the north hemp fields.

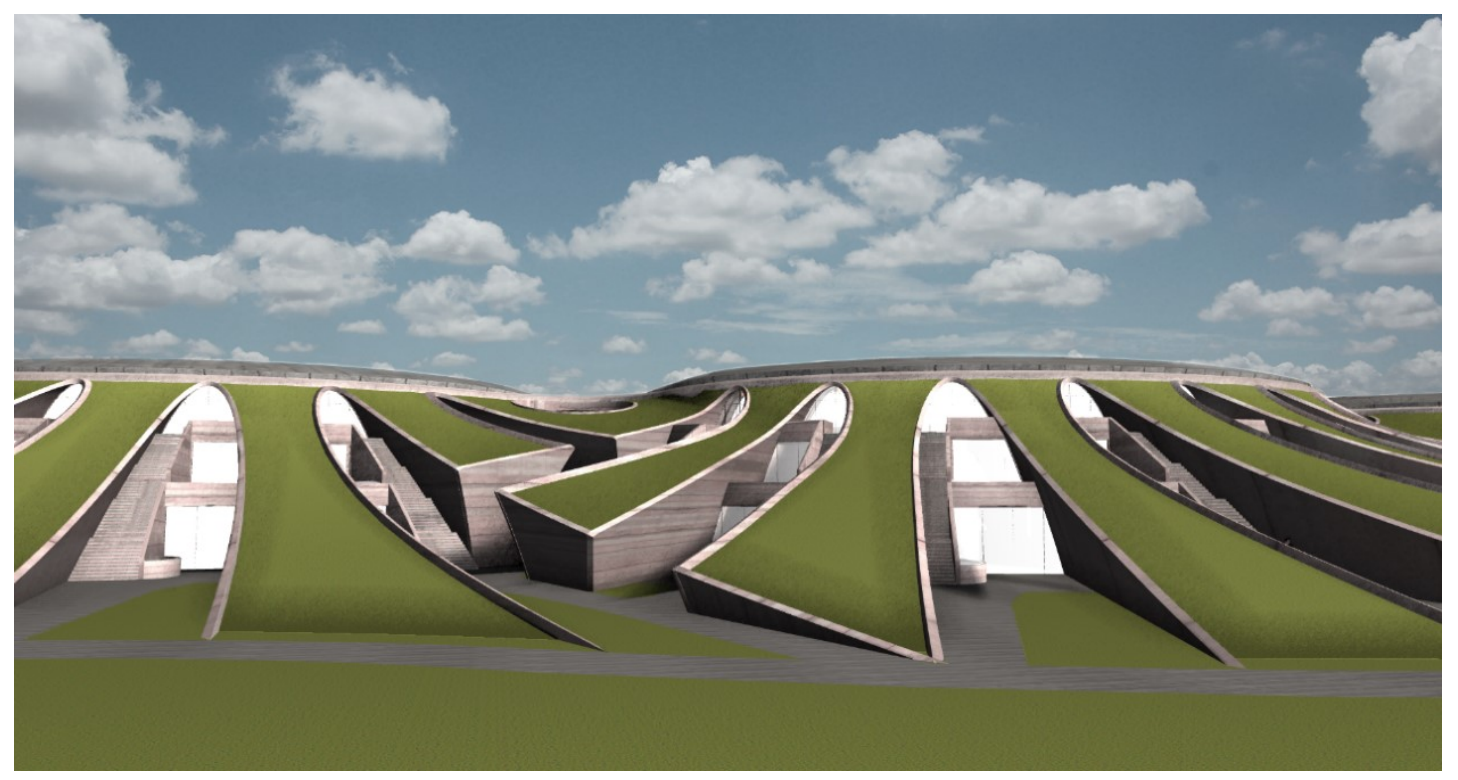

Figure 29: Perspective of the Community Complex's north-facing "quasi berm-sheltered” construction.

There are numerous benefits achieved by earth-sheltered construction. Principally, they revolve around thermal performance, utilizing the thermal mass of dense earthen matter to absorb lost heat and provide thermal lag (retardation of conductive and radiative heat transfer) as well as lowering the exposure of north-facing building envelopes to prevailing winds and reducing the amount of unwanted air exchange with the outside atmosphere [172] [173] [174] [175] [176]. Since the north-facing envelope is partiallyexposed, it would not receive the full benefits of earth-integration; however, given the design limitations of multi-residential development, this "hybrid" application is perhaps a 
best-case scenario that balances lighting and circulation requirements with energy conservation.

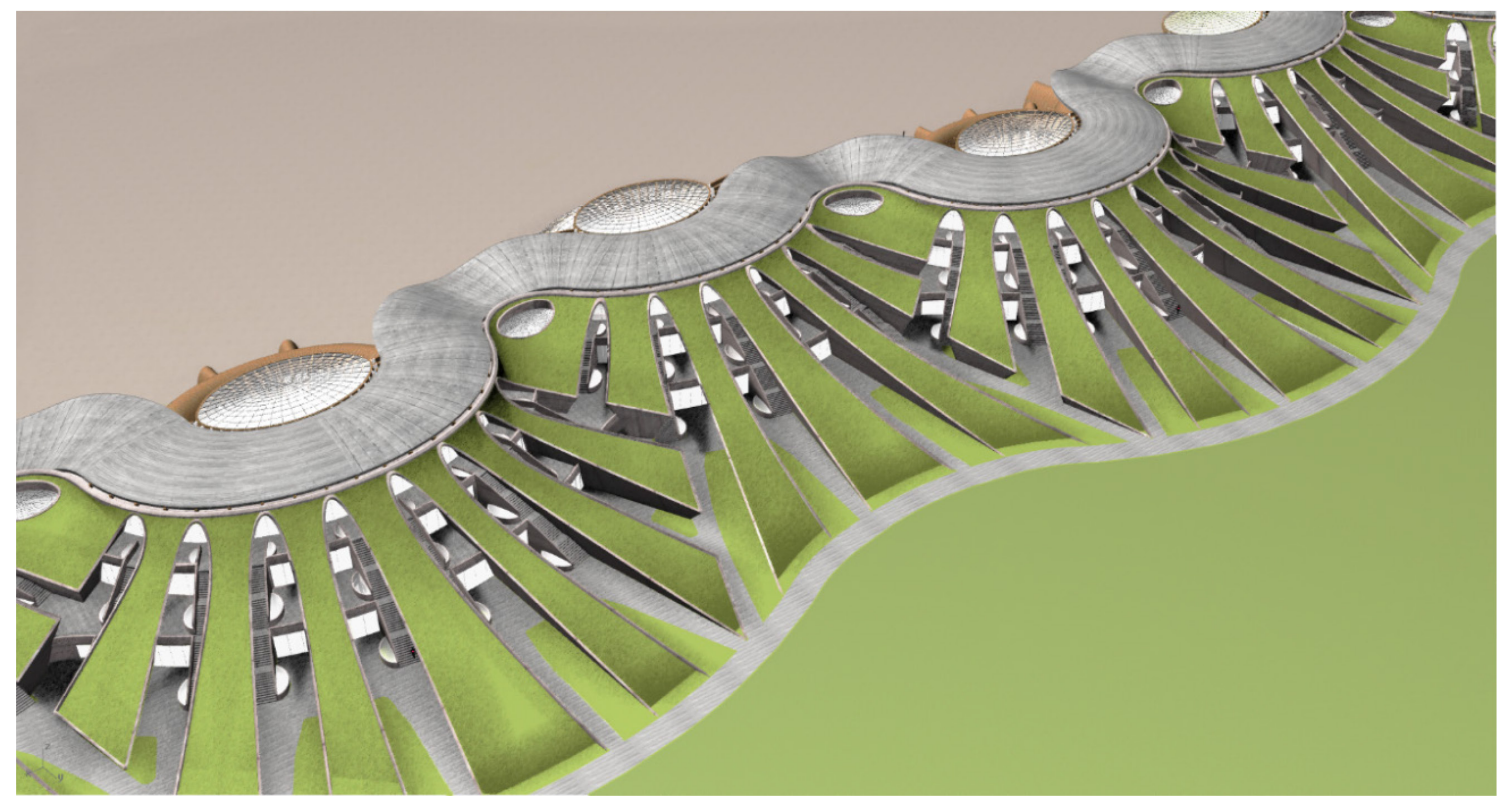

Figure 30: Top view of north side (or rear) of Community Complex.

In addition to partial earth-sheltering, the idea of 'crop-integration' as the second aspect of bio-integration is here introduced. The concept is here applied by extending the intercropping fields into the earth-filled outcroppings of the community complex. Theoretically, it can be imagined that this arrangement could impart to the residents of OPI a sense of belonging to their outside ecosystem, being "at one" with the living products of their labour-a vision based on the realization that the characteristic alienation experienced by labourers in relation to the products of their work, is not lost upon the 
typical farmer or farm-worker. ${ }^{48}$ Perhaps even more so on the modern industrial farm, with automation and mechanization mediating the relations of farmer and farmed, where the harvest is but a trade commodity stripped of its ecological value, its life. But in the context of permaculture, this alienation is to be defeated. If capitalism has, at once, alienated humanity from its work, from itself and from Nature, then society must endeavour to reestablish these interconnections. Every design intention, every gesture that expresses this reunification is thus another advance towards the rehabilitation of our species.

\subsubsection{RainWATER HARVESTING}

With much of OPI's agricultural water use planned to come from natural rainfall and groundwater sources, the community residential complexes would also take advantage of their combined 1.87-hectare serpentine concrete roof structures to gather run-off. Designed into the community complex roof system is a water catchment channel formed by the third-floor's exterior rammed-earth cavity wall (Figure 30). The cavity's ceiling is

\footnotetext{
48 "All these consequences are implied in the statement that the worker is related to the product of labour as to an alien object. For on this premise it is clear that the more the worker spends himself, the more powerful becomes the alien world of objects which he creates over and against himself, the poorer he himself - his inner world - becomes, the less belongs to him as his own. It is the same in religion. The more man puts into God, the less he retains in himself. The worker puts his life into the object; but now his life no longer belongs to him but to the object. Hence, the greater this activity, the more the worker lacks objects. Whatever the product of his labor is, he is not. Therefore, the greater this product, the less is he himself. The alienation of the worker in his product means not only that his labor becomes an object, an external existence, but that it exists outside him, independently, as something alien to him, and that it becomes a power on its own confronting him. It means that the life which he has conferred on the object confronts him as something hostile and alien." - Karl Marx, Estranged Labour in Economic and Philosophical Manuscripts of 1844 [227].
} 
open to allow run-off from the sloping curved roof to flow down inside. Its cavity-facing wall surfaces are lined with waterproof membranes and the cavity floor forms a channel drain punctuated by a vertical downpipe system, which are connected to basement rainwater cisterns. These same cisterns also gather pre-filtered stormwater from the bioretention/biofiltration basins discussed in 4.1.1.2.2. Additionally, connections to drilled wells and an emergency municipal water linkage would ensure a continuous supply should the cisterns ever run dry.

Uses for harvested precipitation include irrigation for the winter garden modules and outdoor sustenance gardens, use in toilets, indoor hydroponics/aquaponics (with a proper pre-filtration and treatment system), other household uses including showers/baths, laundry and even drinking water [177] [178].

\subsubsection{ENVELOPE SyStems AND MATERIALS}

The most essential building system for any sustainable project-perhaps for any building with interior climate control-is arguably the sum of its envelope components. Each singular layer, material and part must combine in unison to form a thermallyinsulating and impenetrable skin, impervious to both pressurized air and liquid water. The most effective systems combine this impermeability to external forces with a one-way permeability to internal water vapour (moving from interior to exterior). Unfortunately, some of the most impervious materials to wind and wind-driven rain are also unforgiving 
when it comes to moisture vapour transport (MVP) and can cause a build-up of interior condensation. One such material is glass. And considering the amount of south-facing glass that is designed into the community residence complexes-much of which would enclose the extremely humid environments of the winter garden modules-there arises the daunting challenge of retarding heat loss during frigid winter nights, all while preventing condensation, and then accelerating convective cooling during the hottest summer days. Any and all climactic conditions that fall in between these two extremes will also pose their own challenges, not to mention those singular and formidable weather events that can test the overall integrity of a structure. It was therefore understood that highly-dynamic environments require innovative and responsive building envelope technologies.

\subsubsection{Transforming Dual-Skin Façade}

To meet the challenges presented by Ottawa's wide-ranging climate, an original building system that the author had previously designed was readapted to the complex envelope curvature of OPI's winter garden module. Inspired by existing dual-skin structural glazing façade systems that incorporate automated "venetian" sun shutters, this system concept is intended to create a 'hybrid transforming dual skin', in which the shutters themselves become an airtight and translucent second skin when fully closed (Figure 31 and Figure 32). This can be achieved by using transparent polycarbonate shutter slats that are insulated with semi-transparent silica aerogel. When aligned to their vertical positions, 
the slats self-seal magnetically with adjacent slats and continue to transmit diffuse light. If applied to true dual skin glazed envelopes, these insulated shutters add a third barrier skin and can increase RSI-Value by upwards of 5.3 (R-Value by 30 ). This novel mechanical transforming building skin is named by the author as, 'Solar-Thermal Control Barrier System (STCBS)@' (see Appendix A for a more detailed explanation).

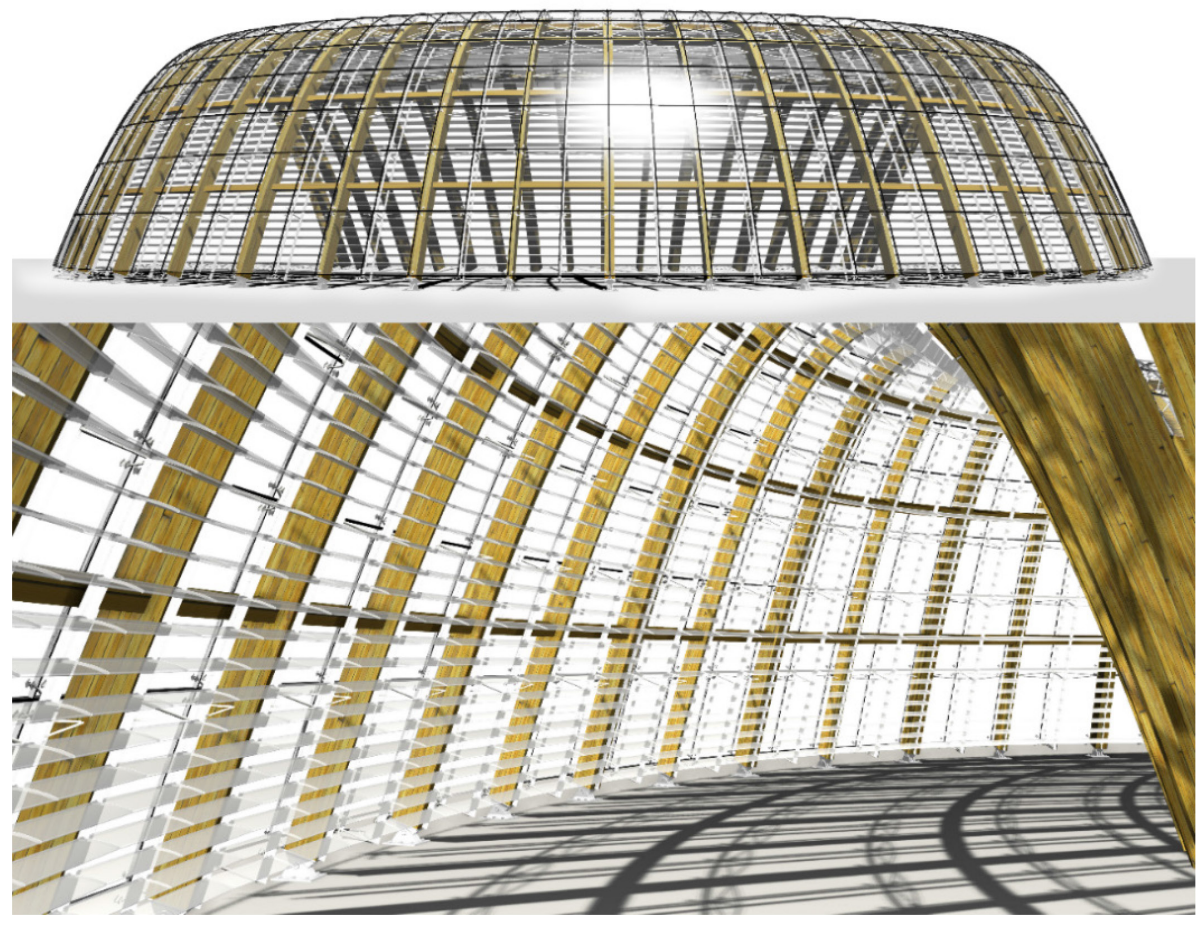

Figure 31: STCBS@ applied to parabolic compound curvature; shutters in open position. 


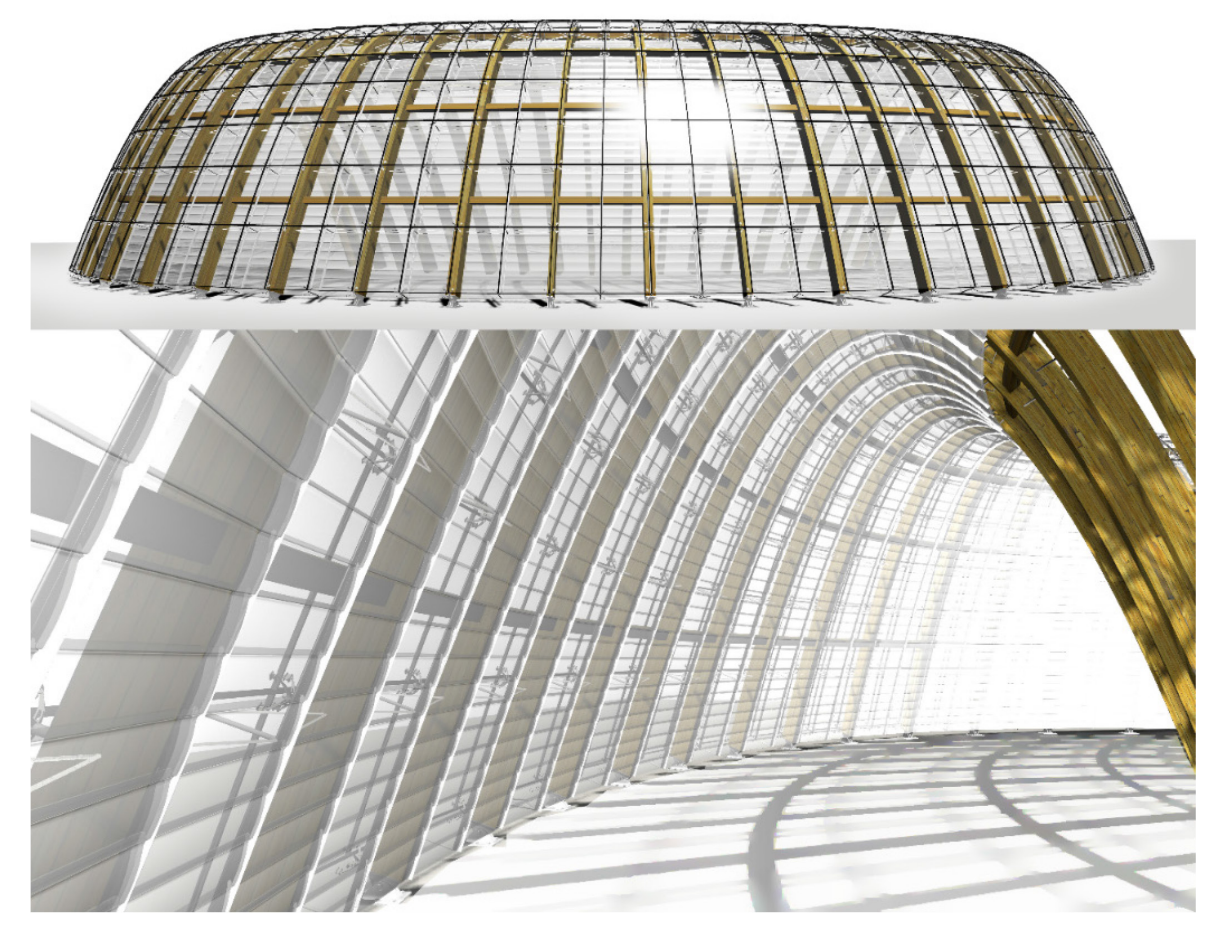

Figure 32: STCBS@ applied to parabolic compound curvature; shutters in closed position.

With its first iteration configured for a rectilinear double-wall assembly, the system was remodeled to conform to the winter garden's curved single-wall structural glazing façade. The adaptation first involved replacing its original cable and pulley actuation assembly with a concealed chain-drive system. With the first actuation design relying upon weighted counterbalances for its vertical alignment, it was imperative to redesign the system to operate against the influence of gravity, at any angle normal to the façade curvature. The devised solution was to have the louvers rotate about geared fulcrums contained within rails fitted to the inside of the exterior façade's primary glulam structural members, with intermediate rails integrated into the secondary cable truss assemblies. These crucial changes would allow the system to remain sealed and airtight when in its 
closed configuration, effectively creating a transforming single-to-double skin insulated glazing envelope with complex curvature. In combination with both active and passive ventilation, it could also address many of the common problems associated with insulated glass constructions, including condensation, unwanted glare, insufficient R-value and uncontrolled solar thermal gain.

\subsubsection{Engineered Glue-Laminated Lumber}

One of the greatest difficulties in choosing materials for the communal residential buildings was the design of advanced wall systems with low environmental impact values (manufacturing pollution, carbon emissions, embodied energy, etc.). Ideally, hemp-fibre reinforced polymer (HFRP) biocomposites would be commercially available as structural materials; however, further research and development are still required to make them a reality for the sustainable building industry. This leaves more traditional materials as the only choices for the building's structural systems. By consulting the existing literature, embodied energy and carbon emission values for materials can be compared and weighed against their respective benefits as construction materials. Despite being the cause of much deforestation and the loss of old-growth forests in many areas of the world, lumber is still considered a renewable and, hence, a "sustainable" building product. In general, solid sawn wood products also receive varying embodied energy values, all relatively low by comparison with materials like concrete and steel [179]. These values increase to nearly 
double for most engineered structural composite lumber (SCL) products, such as glued laminated timber (Glulam) and cross laminated timber (CLT), but are still considered lower-impact than most other traditional materials. Absent the present existence of engineered structural biocomposite hemp ('SBH') products, it for these reasons that glulam was chosen for the primary structure of the communal-residential buildings' south-facing envelope. Further motives for its use include significant loadbearing potential, availability of rot-resistant strains and customizable arch formation; all are required specifications for its application in the winter garden modules.

\subsubsection{Reinforced Concrete}

With generally unfavorable published values for its environmental footprint, reinforced concrete is a material that was avoided for much of OPI's main load-bearing structures. Of course, footings must all conform to buildings codes, making concrete indispensable in any large-scale building project. Foundation walls historically have been constructed of dense rigid materials other than concrete, but today are avoided due to inherent drawbacks, issues of quality-control, cost and labour-intensity. There still exist examples of houses using rammed earth for foundation walls, but they are difficult to find for the northern part of the United States and Canada. Building codes in most parts of Canada have yet to even mention rammed earth as a structural material, focusing still on concrete masonry units (CMUs), concrete and "permanent wood foundations" for exterior 
basement walls [180] [181] [182]. With more recent advances in rammed earth, there is hopefully little reason why this will continue to be the case. But, until the National Building Code is amended to include it, and unless sufficient evidence is found to petition for its use, OPI would conform to modern standards for foundation design and avoid subgrade stabilized rammed earth for load-bearing foundation walls. Despite its high embodied energy and carbon emission values, steel-reinforced concrete will be used in its place.

In addition to reinforced concrete being used for foundations and footings, the north-facing residential area of the community buildings would have to use it for all horizontal surfaces (roof structures and floors) because stabilized rammed earth has not yet been developed for such applications. At least, nothing is presently readily available in the literature to support this specific structural application. In order to lower the embodied energy of all concrete used at OPI, engineers would be consulted relating the potential use of hemp fibres to reinforce all structural concrete, thereby reducing coarse aggregate content, reducing its energy intensity, and increasing its flexural strength and hygrothermal properties (see 2.1.3, p. 58 for discussion on this particular use of hemp fibres).

\subsubsection{Stabilized, Reinforced and Insulated Rammed Earth}

Perhaps one of the most important material choices for OPI's buildings was the decision to specify site-sourced excavated soils in the construction of cement-stabilized and 
steel-reinforced rammed earth walls. The rammed earth is an integral design component for the communal-residential complexes, as it will form nearly the entire superstructure for the partially berm-sheltered residences. Visually, the layered compaction process produces a unique undulant stratification texture that reminds one of natural geological deposits, arguably of an exceptional aesthetic quality far beyond that of architectural concrete.

One important benefit of using stabilized rammed earth technology is the possibility of utilizing site-sourced soil for the earth mixture to reduce the project's carbon and energy-intensity footprints, especially since an excess of excavated dirt would be available during and after the pond excavations. If soil tests reveal it to be unsuitable for rammed-earth construction, local quarries and construction companies would then have to be examined as possible alternative sources.

Rammed-earth is an ancient building technology that can be found worldwide, from age-old ruins to modern-day rural dwellings. In general, its recent use has been restricted mainly to hot and dry climates [183] [182], which benefit most from its thermal mass and thermal lag capacities. Unfortunately, unstabilized rammed-earth-i.e. in its oldest, purest and most ecologically-sustainable form-possesses several weaknesses that preclude its effective use in colder and wetter climates. Firstly, it tends to degrade and erode in areas of high precipitation, which is of course a combined function of time, rainfall and constituent soil-quality. Secondly, in heating climates, it lacks the necessary thermal resistance to generate energy-efficiency and thus nullifies its initial low carbon emission 
and embodied energy values. Lastly, despite being code-compliant in a few localities in North America for residential load-bearing walls, its compressive strength range is in the order of only one-fifth of the lowest-strength poured concrete used in residential construction. ${ }^{49}$ Unstabilized and unreinforced rammed earth also exhibits relatively poor shear and tensile strengths, making it susceptible to catastrophic failure under seismic loads [184].

Recent advances in rammed-earth technology, however, have rendered it a genuine option for climates such as Ottawa's. The addition of Portland cement at 5-10 percent per unit weight—sometimes even as high as 15 percent—has created a harder, increased loadbearing (compressive strength) and more impermeable cement-bound material (CBM) referred to as, cement-stabilized rammed earth. With steel-reinforcing rods, cementstabilized mixes offer higher tensile strengths and shear resistance, and research is now being conducted into its prestressing and post-tensioning to further enhance its tensile properties [185] [184]. Gradually, it is approaching the service characteristics of normalstrength concretes, while still offering lower energy intensities and carbon footprints.

A further advance for colder climate applications was the creation of an insulated sandwich-panel-like system that utilizes a core of rigid polyisocyanurate foam (PIR or

\footnotetext{
49 A typical compressive strength of $2 \mathrm{MPa}(300 \mathrm{psi})$ is given for unstabilized rammed-earth versus a minimum of $15 \mathrm{MPa}$ (2200 psi) for typical residential poured concrete. Normally, load-bearing concrete used in foundations is suggested to produce a minimum of 20-25 MPa (3000-3600 psi) [230] [228].
} 
polyiso), typically 4 inches $(100 \mathrm{~mm})$ with an R-Value of 26 , together with a proprietary permeability-reducing admixture to achieve even better thermal performance, efflorescence control and freeze-thaw resistance $[186] .{ }^{50}$ In general, this enhancement comes as a blessing to the rammed earth construction trades-perhaps to the field of green architecture as a whole. However, an inherent flaw in the system is here recognized, as it relates to the future of the ecologically-friendly building industry: the standard use of plastic foam insulation. Despite their high R-values, petroleum-based foams are part and parcel of the oil industry, and are non-biodegradable plastics that produce toxic fumes during fires-including deadly hydrogen cyanide gas, carbon monoxide and toxic isocyanates-with PIR being the most dangerous of the plastic foams [187]. PIR also outgasses harmful isocyanates during its curing processes, which poses a notable health and cancer risk to its manufacturing employees [188] [189]. As such, they are by no means ideal building products for sustainable projects.

The rammed earth system best suited to OPI's requirements and core principles is therefore a modified version of the typical SIREWALL ${ }^{\bullet}$ envelope assembly. Rather than using 4-inch rigid PIR insulation, 6-inch rigid mineral wool (basalt fibre) board insulation

\footnotetext{
${ }^{50}$ This higher-performing rammed earth technology belongs to a Canadian company, called SIREWALL', based out of Salt Spring Island, British Columbia. A precedent for their system applied in a heating climate similar to Ottawa's is the Edmonton Valley Zoo. Being two degrees in latitude higher than Ottawa, Edmonton has the same climate classification (Köppen-Geiger classification of Dfb: "humid continental climate with severe winters, no dry season, warm summers and strong seasonality"), but a lower annual temperature average of about 2.4 degrees Celsius and often experiences more extremes in cold [231] [232].
} 
will be used if a suitable hemp-based technology is unavailable. Mineral rock fibre is shown to have much lower embodied carbon emissions and energies than plastic foams. Its initial $\mathrm{R}$-Value is appreciably lower than PIR's, but it maintains a more stable thermal resistivity over time and at lower temperatures. ${ }^{51}$ For the cement-stabilized rebar-reinforced rammed earth walls of the residential complex, Roxul ${ }^{\circ}$ ConRock 60 is the insulation of choice due to its excellent moisture resistance, fireproof properties, longevity and recommended use in concrete sandwich panel fabrication [190]. The original intent was to use hemp fibre insulation but a suitable rigid board type, with adequate compressive and shear strengths to fill the core of loadbearing "sandwich" panels, is not yet commercially available. To date, hemp insulation is only sold in a flexible and compressible batt form. However, given the promising physical properties of hemp-lime biocomposites like hempcrete, it would be chosen for the stabilized rammed earth cores instead of Roxul if engineers deem it appropriate.

With the earth-berm outcropping retaining walls being specified as SIREWALL technology or a similar insulated, low-permeability, stabilized and reinforced rammed earth system, approximately half of their surface areas would be in contact with soil (organic growth media) and backfill. This would require the use of appropriate membrane

\footnotetext{
${ }^{51}$ As an example, Roxul ${ }^{\circ}$ Top Rock DD stone wool products (rigid roofing board insulation) have been shown to even increase in R-value as the temperature drops below zero centigrade, reaching a test peak of R4.6 per inch at -4 degrees Celsius [233].
} 
materials and adequate drainage systems, which would also be designed in accordance with expert specification. Only consultation with stabilized/reinforced rammed earth engineers would determine how to best detail any subgrade and earth-berm applications, if indeed such applications are deemed possible. No North American precedents for subgrade stabilized rammed earrth type systems were found during the course of this study, but examples of polymer-stabilized rammed earth being used in South Africa for load-bearing foundation walls do exist [191].

\subsubsection{Stainless Steel Roofing}

Originally, the material of choice for sealing the long undulating serpentine roof assemblies was prestressed architecturally-exposed high-performance cellular lightweight concrete; however, due to Ottawa's varied climate, which can range from 30 degrees Celsius in the summer to -30 degrees in the winter, with considerable freeze-thaw cycling, it was ruled out as a viable option. An exposed lightweight concrete roofing system to withstand the harsh Canadian climate, yet still guarantee permanent waterproofness and enduring structural integrity, to date has no known precedent. Therefore, the next likely choice is a roofing technology with a verified performance record for overlaying curved roof assemblies: standing seam sheet metal.

The choice of metal was the subsequent major consideration. Four main roofing metals were weighed against three main sustainability criteria. Copper, aluminum, pre- 
finished mild steel and stainless steel were compared for their overall durability, energy intensities and aesthetics ${ }^{52}$. Of the four, austenitic stainless steel (type 316L) was chosen because it excels for all criteria relative to the other options. Stainless steel, in general, is stronger than both copper and aluminum and is therefore more dent and scratch resistant; under most atmospheric conditions, it will not discolour like copper; its chromium oxide surface is self-healing, which gives it lasting corrosion resistance; it can be made completely waterproof by continuous seam welding, even made submersible; it can be applied to nearly any curvature or slope; it is available in numerous alloy grades, for almost any chemical environment or climate; it is extremely low-maintenance and can be repaired relatively easily; its life cycle costs are less than regular mild steel, which has only a fraction of its lifespan. Case studies also report that a stainless steel roof can easily outlast the service life of the building [192].

In terms of environmental impact, stainless steel is more energy-intensive than materials such as wood, glass or even concrete, but relative to copper and aluminum, it takes the lead [179] [193] [194] [195]. The same holds true for its total carbon emissions. Additionally, if given a "bright" mill finish, it can considerably lower a building's cooling

\footnotetext{
${ }^{52}$ Durability, as it pertains to metals, is here applied as a combined function of corrosion-resistance, toughness and hardness. Corrosion-resistance refers directly to a metal's ability to resist oxidation (rust formation), which is often its first mode of failure in exterior environments. Toughness here refers to its ability to both deform plastically before cracking and resist fracture under fatigue cycling (fracture toughness). Hardness, or its strength of material, relates generally to its resistance to denting, scratching and bending (plastic deformation) [234] [235] [236] [237].
} 
requirements by reflecting much of the summer sun's incident radiation. For its application on the community complexes, it appears to be the ideal choice, despite its initial costs in material and labour.

\subsection{COMMUNITY COMPLEX PLANS}

Where bourgeois urbanism fails equally the individual and society at large is in its undying obsession for reproducing microcosms of capitalism's elitist superstructure. Cities are historically segregated into socioeconomic groupings, euphemistically branded, "neighbourhoods", with the lower classes frequently crammed into polluted industrial areas and other urban regions where the affluent rarely set foot; the latter of course tend to occupy the highest ground, where they take shelter from every form of calamity, be it "act of God", or folly of man. Between these extremities of caste lies the vast buffer of commercial suburbia reserved for the "ascending" classes, without which, the naked disparity of the Western countries could well prove too distasteful to behold and to swallow. Everywhere throughout this great barrier that is the middle-class, can be found the absurd expression of the "American dream": quadrant upon quadrant of rectilinear cellules segregating each individual or family-unit from the other. The individual inhabitants of each atom call it "home", and their quadrant, "the community". But when this organization of atoms is examined in greater detail, it becomes undeniable that this societal arrangement is scarcely communal and can rarely justify its designation as a 
community. Admittedly, the greater land areas are carved into smaller properties and thus may be described as "shared" or held in common; however, the mere act of purchasing said property is a gesture of segregation. Irrespective of the socio-economic stratum or its population density-be it 75-square-metre condominium or manor and 5-hectare estatethe solid walls and imaginary property lines that divide our material world manifest socially as barriers to genuine community. To produce alternatives that correspond with the mutualistic values of permaculture, is to contribute to the desegregation of the human world, from not only Nature, but also from itself.

Whether permaculture may be more aptly described as the practical application of green communism, ecological communalism, sustainable socialism, or some other prohibitive amalgam is a semantic triviality. Its reality remains one of collective unification. Expressing this worldview architecturally thus becomes a problem of merging the practical and the theoretical. In the case of OPI's communal-residential development, this expression is best defined as, a 'spatially-symbiotic fusion of private dwelling and public co-habitation'. As such, the conventional North American condominium lifestyle is rejected, along with its alienated paradigm of social disengagement, and replaced by a 'hybrid collectivism'.

The plans for the OPI communal-residential buildings, including two representative dwelling unit plans, are presented in Figure 33 to Figure 40 and are, in 
regard to their specific features, sufficiently detailed to speak for themselves. Accordingly, the following discussion will focus on their spatial relationships, design intentions and permacultural principles.

In terms of the style of architecture, proposed for the Community Complex is an upscaled (literally, larger in scale) and neoteric expression of indigenous architecture that combines with modern forms and sustainable building technologies to pay homage to the original land stewards of the region. The entire length of the complex is inspired by Algonquin and Iroquois longhouses, while its domed and curvilinear shapes are derived from Algonquin wigwams [196, pp. 61-110]. Further inspiration is derived from other North American indigenous architectural expressions: the igloo of the Inuit and the earthlodges of the Akira, the Pawnee and the Hidatsa [196, pp. 151-171]. The intention was not mimic or appropriate, but to pay homage and draw inspiration from First Nations' culture, in recognition of the fact that permaculture has derived much of its inspiration, spirit and practical knowledge from aboriginal sources. Furthermore, the intent is to speak of the diversification of the Canadian cultural landscape to include the cultures of all peoples. As such, OPI's doors will be open to people of any background, as the medicine wheel acknowledges the value of all races and peoples. 


\subsubsection{COMMUNITY SPACE}

With the spirit of collectivism in mind, the design of the communal-residential complexes began with their social, or "public" areas. Being an agro-social community, this first involved the consideration of its agrarian requirements, which include both the production of fresh foods outside of the growing season, the indoor preparation for spring planting and any controlled environments for hydroponic or aquaponic set-ups. The result was the creation of key repeating design features referred to previously as the 'winter garden modules' (Figure 36).

Again, the permaculture zoning model is applied as a design guide for 'social symbiosis', where the private dwelling units are treated as "ground zero" for human activity, with an immediate circulation and social gathering ring just beyond the units. Here, in this 'intermediate ring', we find perhaps the greatest level of regular group interaction: the communal kitchens and dining halls. The outermost ring of the complexes is occupied by either a winter garden or a community service module, the latter a being zone of shared labour, public education or group recreation. Punctuating this outermost ring are intercessional spaces containing the public entrance lobbies and circular collective gathering pits, called drum circles, reserved for group dynamics, decision-making or spontaneous social activity (Figure 33). 


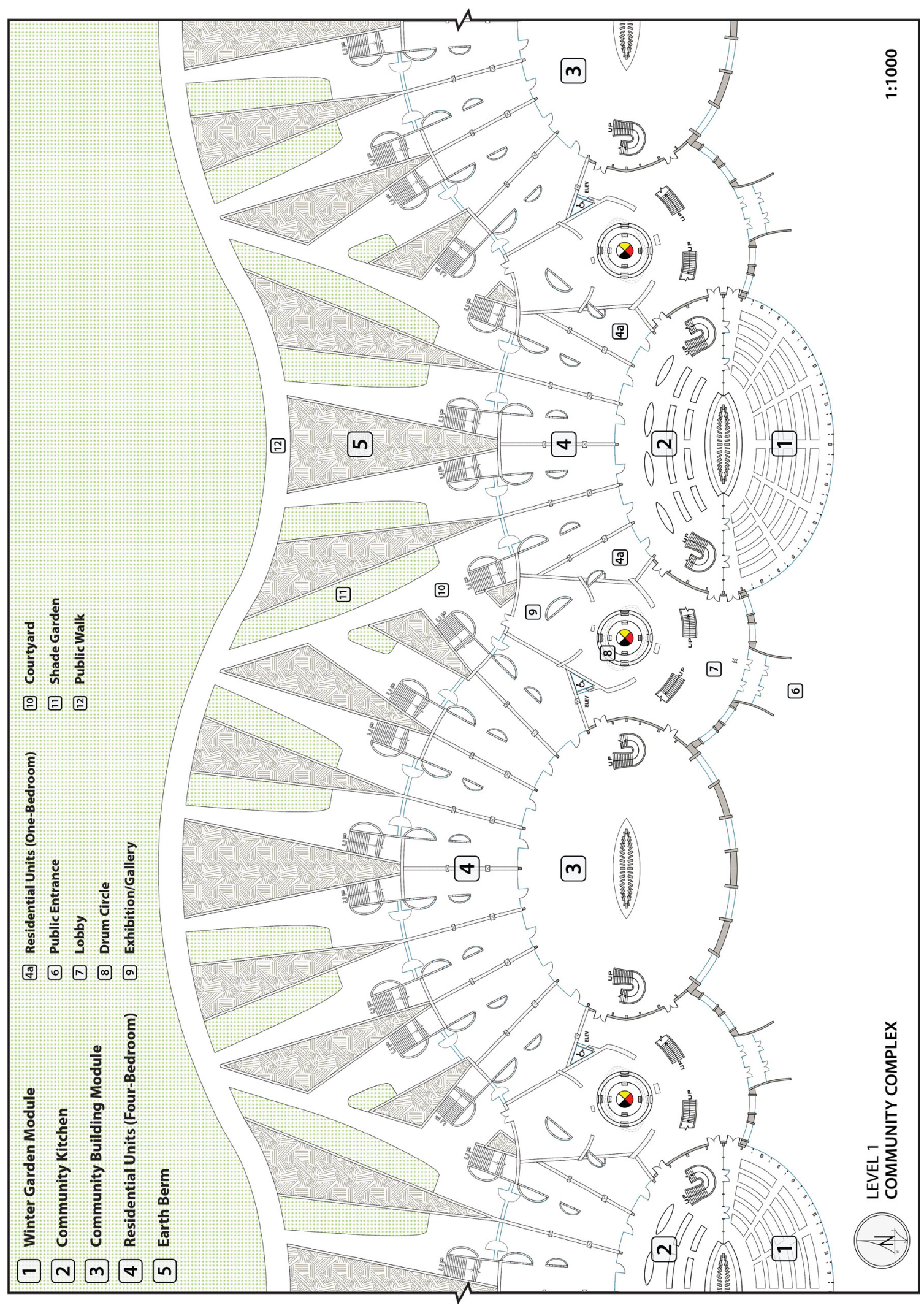

Figure 33: Plan for Level 1 of the Community Complex. 


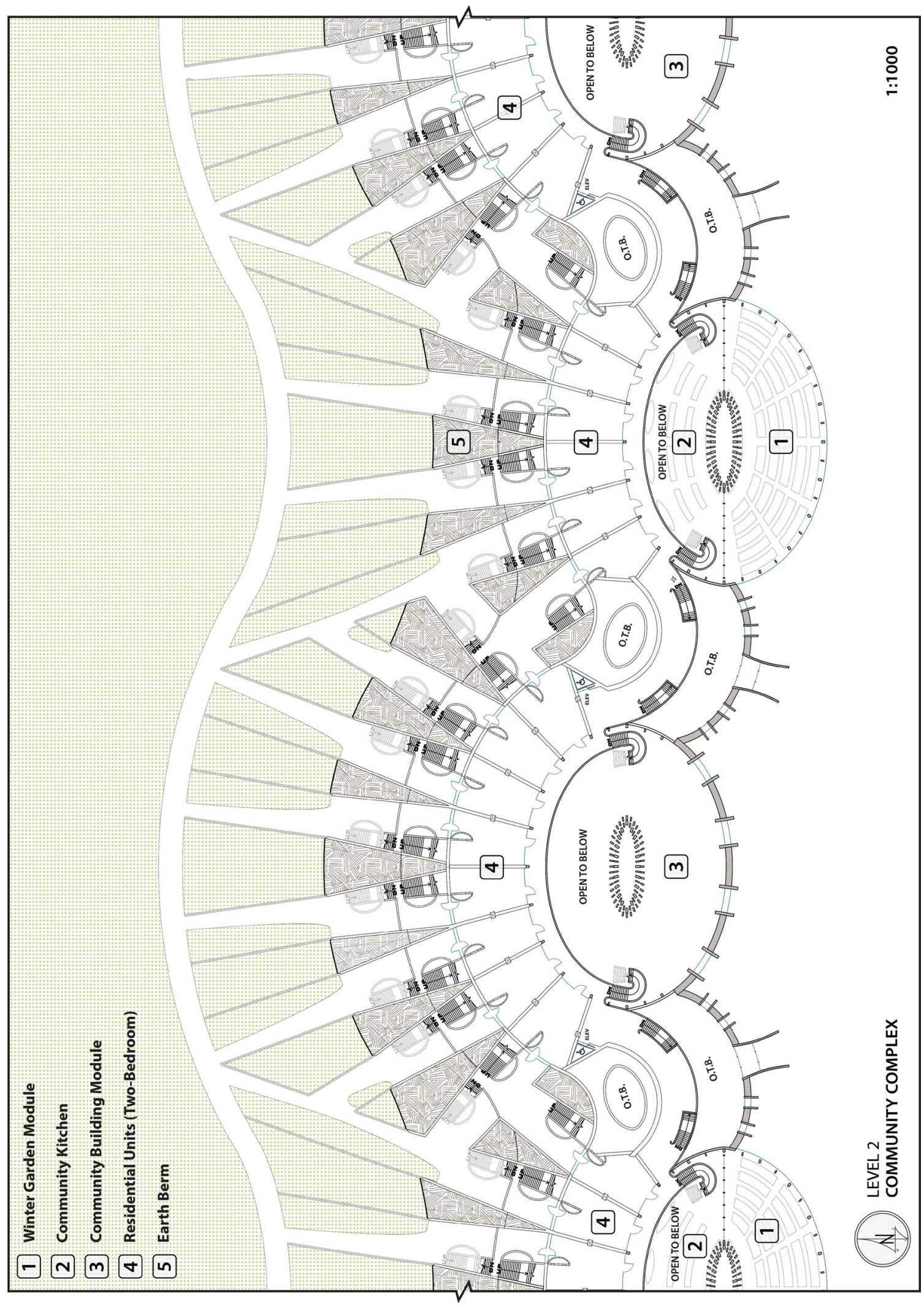

Figure 34: Plan for Level 2 of the Community Complex. 


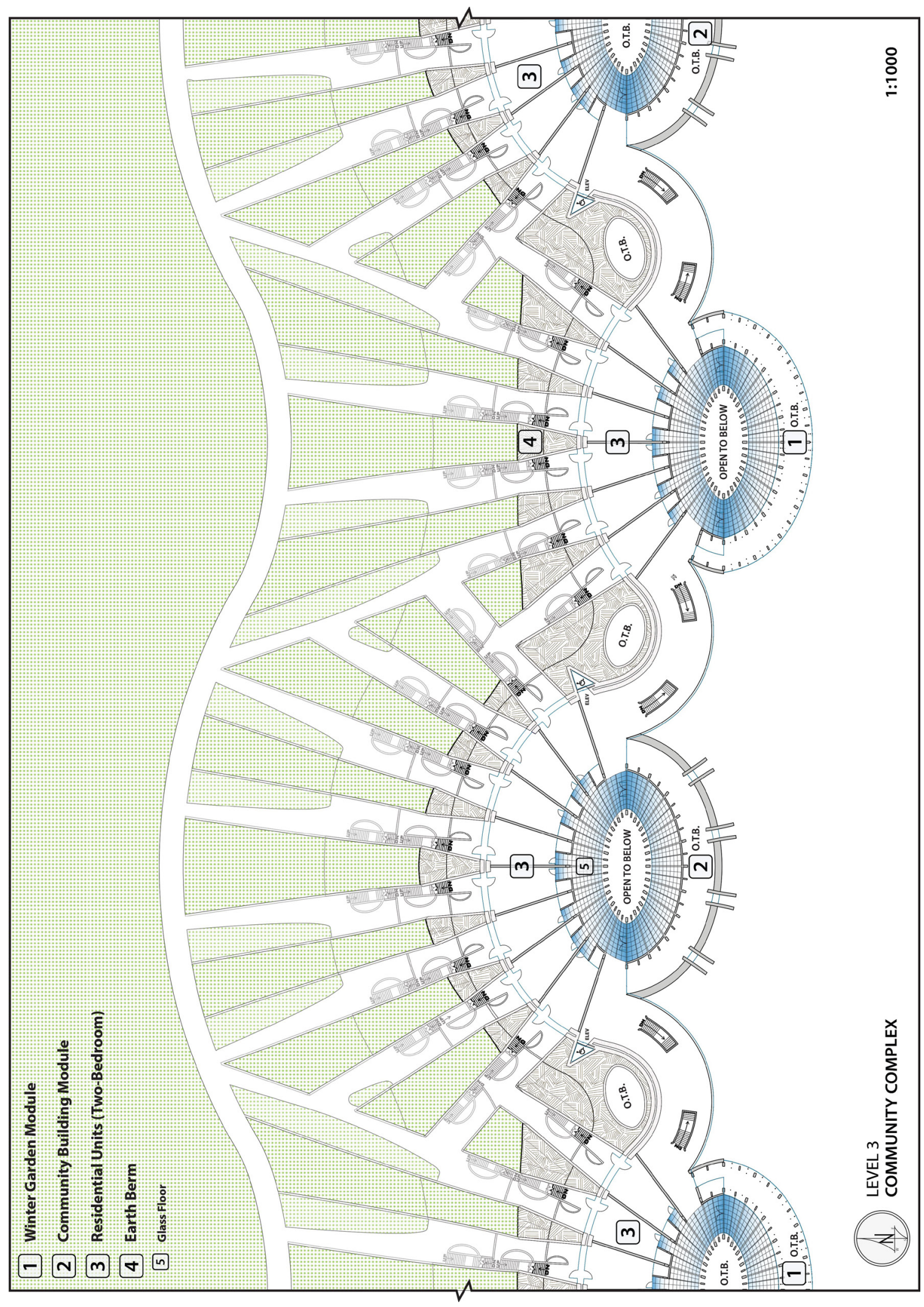

Figure 35: Plan for Level 3 of the Community Complex. 


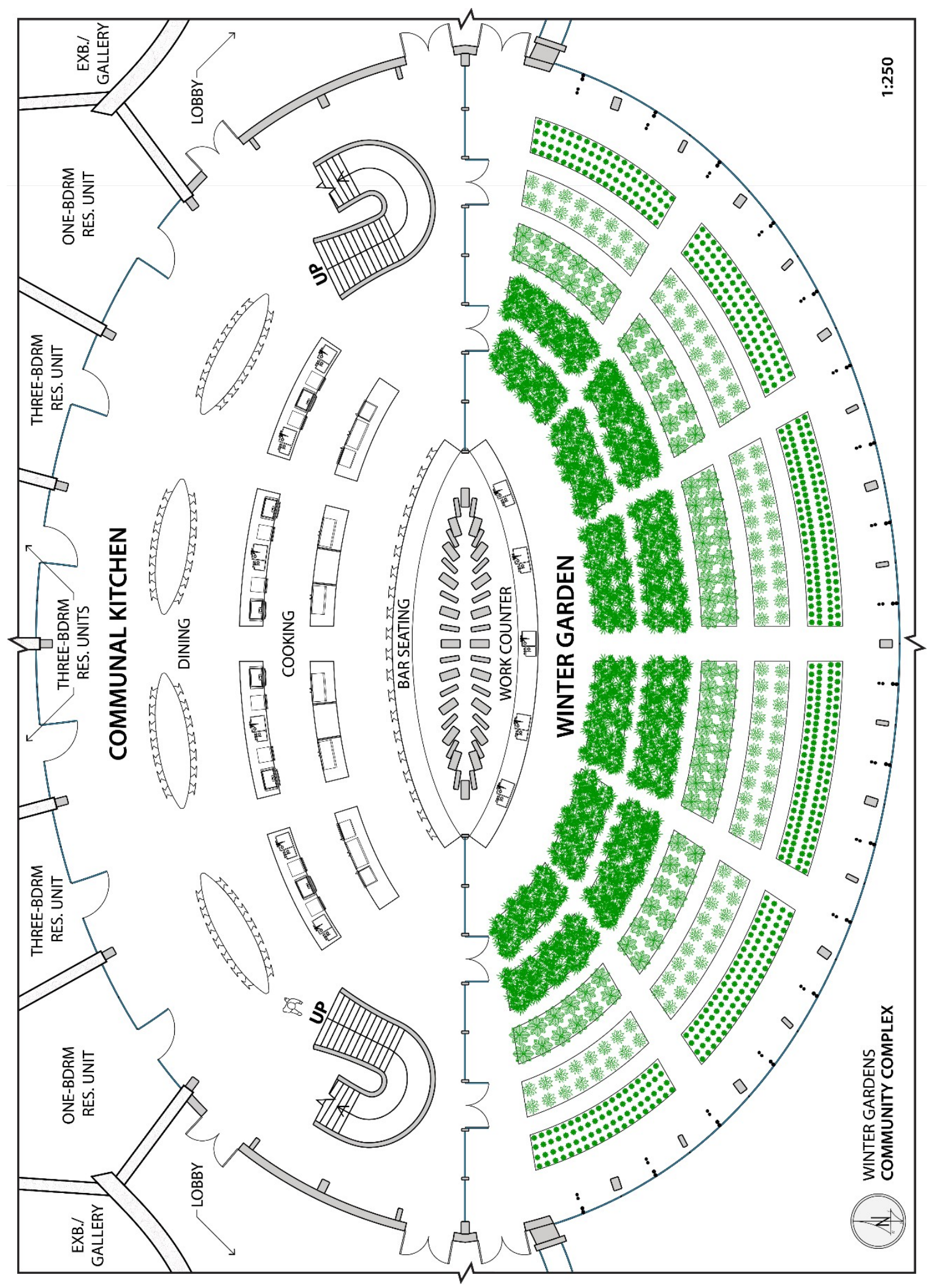

Figure 36: Plan for Winter Garden Modules and Communal Kitchens. 


\subsubsection{Community Kitchens}

The sharing of food is a group activity that transcends time, place and culture. Social

food preparation and ceremonial feasting are likely as primordial and universal as hunting and gathering. Indeed, it seems that, in any given private get-together, the kitchen generates the most social accretion of any domestic space in the home. Its importance for group cohesion therefore should not be underestimated, particularly where communalism is articulated as the primary design intent.

Being part of the circulatory 'intermediate ring', the communal kitchens form a transitional space between the residential units and the winter gardens, between the enclosed private setting and the social work environment. Looking at its spatial organization, it becomes evident that this ring is subdivided into concentric component spaces that also reproduce the permaculture activity zones, albeit in reverse. Moving from centre to extremity, the inner ring is the area of lowest activity, reserved for food storage (refrigerators, freezers, pantries and cabinets); the next zone is a higher activity ring, where food is prepared and dishes are cleaned (counters, cooktops, ovens, sinks and dishwashers); the penultimate ring being for higher-level social activity, such as eating, celebrating, group studying and planning meetings (dining/conference tables); with the extreme-most zone being for circulation and residential unit access (Figure 36). 
Sustainability concerns for the communal kitchens are addressed by the specification of only the most energy-efficient and hard-wearing commercial appliances on the market. For example, all cooktops should be of the commercial magnetic induction kind, save for at least one natural gas range per kitchen, for use with non-magnetic cookware. Additionally, all solid food waste will be composted and recycled as organic garden fertilizer.

\subsubsection{Drum Circles}

Every community building and winter garden module-each with their distal grouping of residential units-is separated by a grand entrance corridor that begins outside as a large arched timber portico and glass vestibule. The entrance opens up to a sizeable lobby, succeeded by a gathering depression and exhibition space. The circular terraced depression is surrounds an Algonquin medicine wheel laid into the bamboo flooring, which is a traditional aboriginal symbol associated with the eternal circle of life (Figure 33, 8). The medicine wheel is also a comprehensive emblem signifying the interconnectedness of all things under Sun and Moon: the cardinal directions, their associated seasons, the four major races of people, the stages of life, the elements and many other sacred associations. As such, it speaks directly to OPI's philosophy of universalism, mutualism and diversity. Specific meanings of the colours vary somewhat from tribe to tribe, but in general they outline the following pattern. Facing north is the white quadrant, which symbolizes the 
white race, winter, wind, reflection, spiritual health, grandparenthood and elders. The East quadrant is signified by yellow, representing the oriental race, spring, fire, mental health, childhood and birth. The South quadrant is red for the aboriginal peoples, summer, earth, physical health and adolescence. The West quadrant is either black or blue, depending on the tribal tradition. It symbolizes the black race, autumn, water, emotional health, adulthood and parenthood [197] [198] [199]. Here it is black, which seems to be its most common depiction. Analogous in many ways to the permaculture rings, the medicine wheel demonstrates and promotes collective synergism.

Being spaces for group decision making and social planning, the drum circles are both symbolic and practical. They pay homage to Native American governance models, which, in addition to being exemplary communal social structures, can rightly be interpreted as pre-colonial forms of direct democracy. The circle also encourages egalitarian dynamics by equally distributing members about its circumference and facilitating eyecontact between individual speakers and the entire group.

\subsubsection{Needs-Based Space Allocation}

The complexity of community dynamics in a project like OPI requires flexibility in the allocation of its programme elements. A human settlement of upwards of 700 or more people from diverse backgrounds will generate its own population demographics. Each grouping would come with its own particular needs, which would have to be met by this 
community, by the existing services of the surrounding area or by some reasonable combination of both. As an aspiring model for self-sustaining collectivism, the ideal would be to have all needs and services provided by a network of such settlements, with the most vital and immediate of these needs provided by the community itself. Some of these high priority social services include health and dental services, daycare, education, administration and recreation. Each entails its own set of specific building and programme requirements, which would be best determined by the actual community members. In lieu of this consideration, the areas marked as "community building module" in the floorplans are reserved for such further planning and design (Figure 33 to Figure 35).

\subsubsection{INDOOR WINTER GARDENS}

Much regarding the winter garden modules has already been described above. This is due to the fact that they are multifaceted and staple programme elements that meet all eight of our design considerations, as well as several of the master plan objectives. By bringing permaculture indoors and allowing for its practice outside of the growing season, bio-integration would become an uninterrupted reality for the live-in participants of OPI. The structure of each winter garden itself combines spatial symbiosis, precipitation catchment, passive-energy exchange and daylight transmissivity into one organic totality.

The modules can be best described as 'advanced high-performance greenhouses' that incorporate indoor nurseries, raised beds, and growing stands. Some would also 
accommodate hydroponic and aquaponic systems for research into energy-efficient soilless-organic agriculture techniques. Above all, they would provide a space for the residents to visit, alone or in groups, and experience a continued connection with the cultured organisms that support their ecological lifestyle, a life amidst the living, breathing products of their endeavors. It has been shown that natural daylight and plants have direct and substantial impacts on the psychological health of building occupants [200] [201] [202]. If so, then the indoor gardens would also contribute to emotional well-being and anti-depression, providing an invaluable greenspace amidst the cold white landscapes of Ottawa's long winters.

Plant varieties for the winter gardens would include any legumes, vegetables and fruits suited to an indoor environment that receives lower levels and reduced-quality of incident sunlight in comparison to the outdoor summer sun. Shortened days mean artificial grow lamps (energy-efficient L.E.D. units) would be required to approximate growing season conditions. Marijuana is a suitable choice of species to include since it is known to do well indoors under artificial lights, within a relatively-wide range of atmospheric conditions, in both soil and soilless growth media.

Practically, a fully-glazed indoor garden nearly speaks for itself; but, architecturally, both its exterior and interior insulated glass walls serve the added function of at once illuminating the communal kitchens and residential units. Truth be told, direct sunlight to the residences would be minimal in comparison to the growing spaces and kitchen areas, 
but every freely-sourced wave of light that reaches the dwellings is one less that will be generated electrically and artificially (see 5.1.1 for more in-depth daylighting considerations). With traditional greenhouses being difficult to climate-control in colder regions, energy expenditure can likewise become a prohibitive concern. To increase thermal performance in the winter gardens, curved low-e insulated glass panels will form their outer skins. Precise climate-control and a potential threefold efficiency gain could be achieved by the addition of an automated 'hybrid transforming dual skin' that operates in conjunction with an advanced "intelligent" HVAC system (see 5.1.4.1 for an introductory description and Appendix A for greater detail).

\subsubsection{RESIDENTIAL UnITS}

Design considerations for OPI's living quarters primarily revolved around balancing privacy with social engagement. Care was taken to ensure direct access to social gathering areas, while allowing for complete or near-complete isolation when required by the occupants.

To begin with, the 222 apartments occupy the quasi-earth-sheltered north-facing terraced spaces of the communal-residential buildings (Figure 30, p.181). The total number is split into three design categories, ranked in order of size from largest to smallest: large families, couples or small families, and students or singles. The large family apartments total 60 in number and have an average floor area of 160 square metres, which 
is appropriate for a family of 4 or 5 members. The medium-sized residences, for couples or small families, sum to 74 units of approximately 95 square metres each. The smallest units, are intended for students, singles or young couples; there are 88 in total with an average living space of 70 square metres. With the rear of the buildings being terraced into levels, the largest dwellings therefore occupy the ground level, with the mid-size units on the second level and the third floor reserved for the smallest (Figure 38 - North-South section).

The grouping of dwellings is achieved via association with their respective community buildings or winter garden modules. Each unit group inhabits a fan-like arrangement, flaring out from its communal space towards the rear exterior of the complex. With a glazed wall facing the communal kitchen, every ground floor apartment receives a transitional area, a foyer with seating area, where the private domain meets the social sphere. On the upper levels, these transitional spaces do not provide a direct view onto the kitchen, instead, they look upon the kitchen's atrium and its large sun-lit oak-tree-like structure. Privacy in the intermediate areas is achieved by simply closing their blinds, with sound dampening provided by the specialized noise-reducing double-glazed IGUs that form the unit's glass walls [203]. The exterior north-facing envelope system is treated with a dual-skin insulated glass façade to provide added thermal and acoustic performance. Noise reduction between units is accomplished by material density and sound-deadening insulation: insulated rammed-earth walls and insulated concrete slab ceilings and floors. In effect, not only does each dwelling receive its own isolated pocket of soundproof air, but 
also allows for a zone-controlled microclimate, where the occupants would decide their own comfort range.

For the purpose of this study, and to provide an impression how their areas will be utilized, two examples of the residential apartments were planned and designed. First, the largest ground-floor unit was partitioned and furnished with all the necessities for a family of four (parents, adolescent and child) (Figure 39). Secondly, a similar layout was readapted to the smallest third-floor apartment and modified for a single or young couple (Figure 40). With the floorplans sufficiently detailed to illustrate their utility of space, full descriptions will here be excluded.

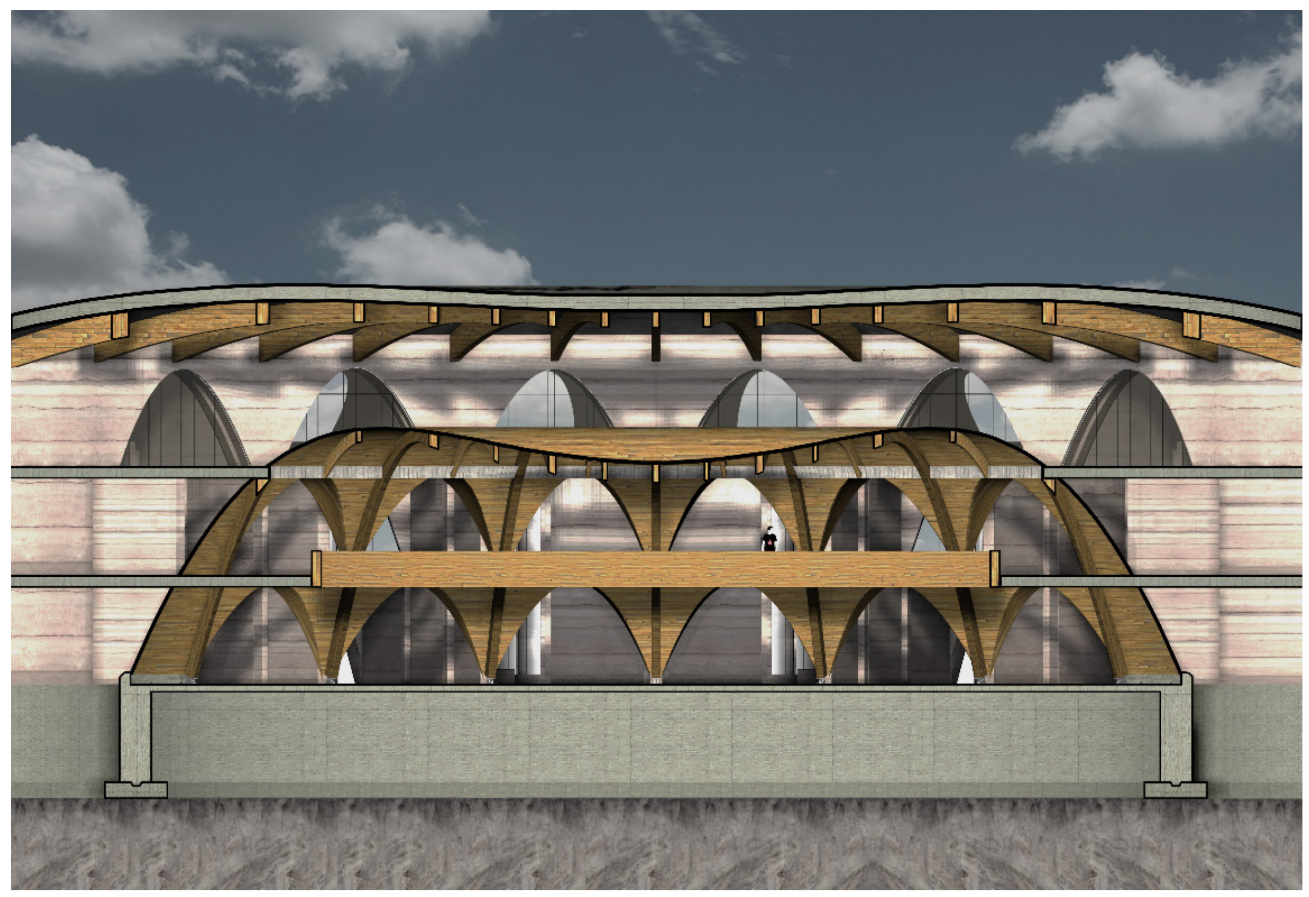

Figure 37: East-west section (from right to left); showing spatial relationship between rear SIREWALLS and glulam-structure of winter garden/communal kitchen modules. 


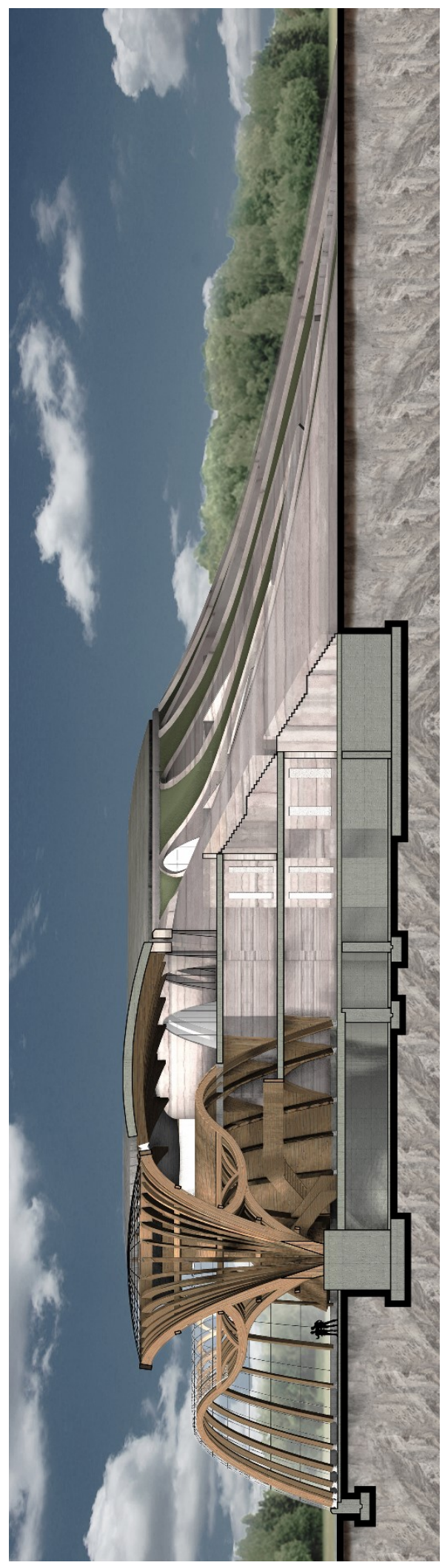

Figure 38: North-south section (from right to left). 


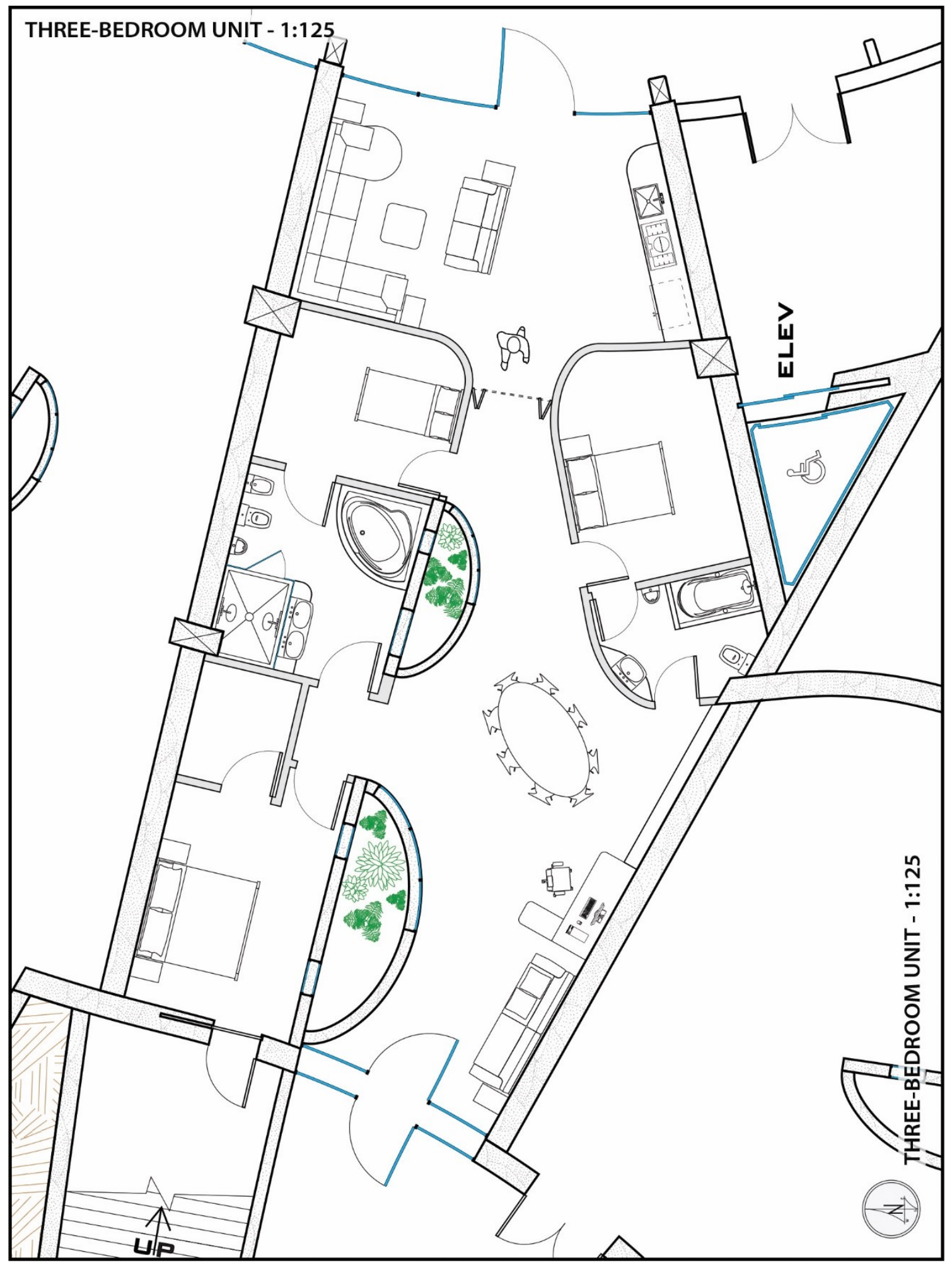

Figure 39: Model large family dwelling unit; total living space is $165 \mathrm{~m}^{2}\left(1776 \mathrm{ft}^{2}\right)$. 


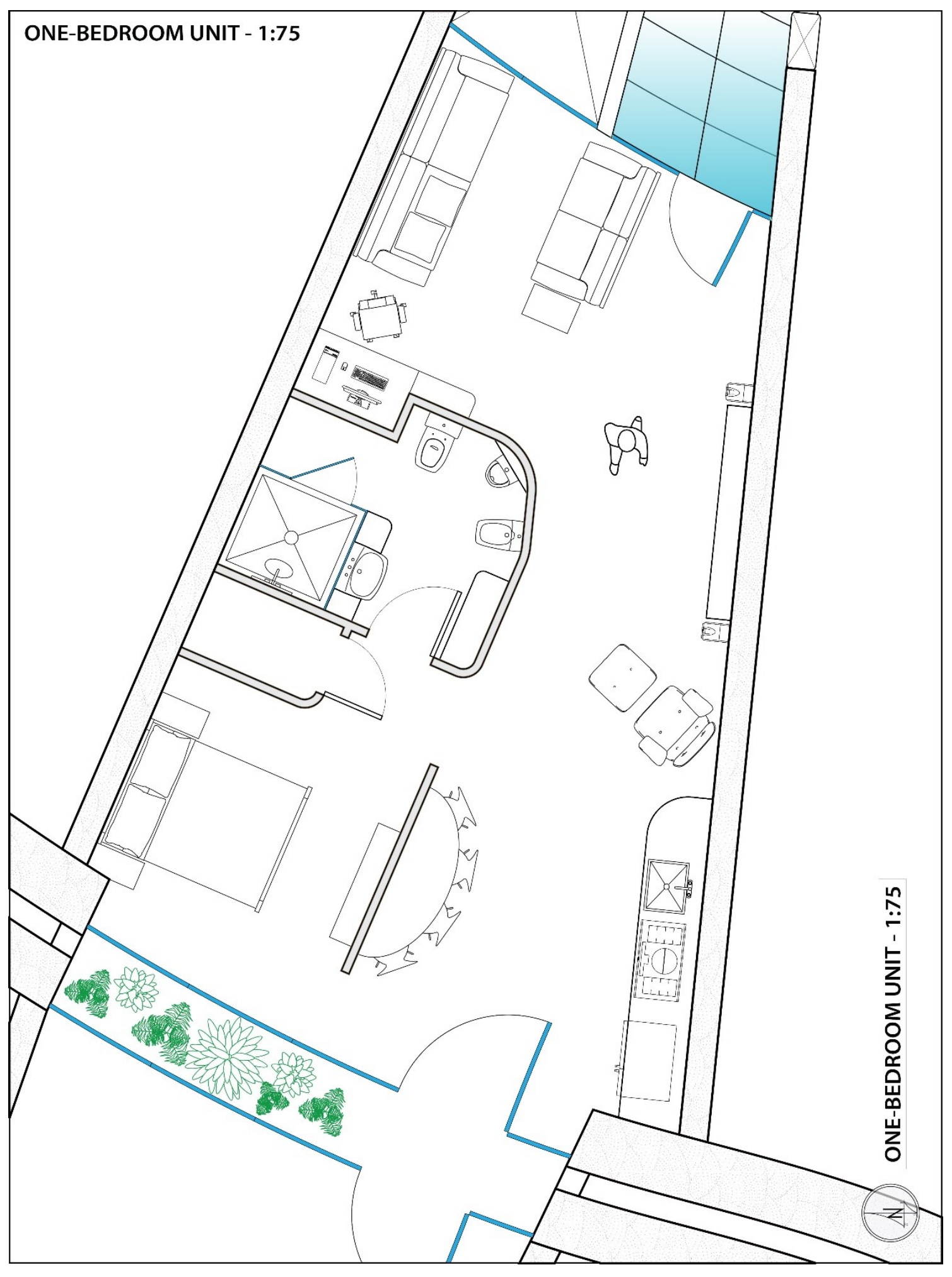

Figure 40: Model small bachelor/student dwelling unit. 


\subsection{SINGLE-FAMILY RESIDENTIAL: EARTH-SHELTERED BERM HOUSING}

The necessity of including a second residential model for OPI is discussed in 4.1.2.1. Simply the idea is proposed in the Praxis Diagram, while the planning, design and detailing of the berm-houses could remain a viable project for the future. As such, drawings and further discussion will not be included in this project. 


\section{DISCUSSION AND CONCLUSIONS}

1) On the concept of 'socio-ecomorphism': Employing a philosophical approach to identify and confront the ultimate crisis of human civilization-that of probable eventual self-destruction-means envisioning totalizing methods of response. The crisis is real. Gone are the days when dismissing social and environmental activists as "alarmists" was a typical, socially-acceptable and an academically-sanctioned reaction. The alarms bells are resonating with a growing number of people internationally. The marginalized voices of yesterday are becoming the voices of reason for tomorrow. The crisis they have been warning of for decades is wholesale environmental collapse and the evidence for localized, even regional, ecosystem simplification and ecosystem services failure is compiling from around the world. A potential "dominos effect" is in the making and it is industrial civilization's gamble that has initiated this chain of frightening events. The burden of proof has shifted from the environmentalists and scientists who are sounding the alarms to those who find false comfort in the status quo: their arguments for perpetual growth and global capitalism have been exhausted on all fronts, by the verifiable and devastating results of the systems they self-identify with. Finally, they are beginning to lose the information war, but unfortunately, their dogmatic voices continue to dominate and resonate with the power structures they serve so uncritically and apathetically. It is the duty of all people of conscience to continue to reach out to those around them and calmly try to wake them. When 
conciliatory approaches fail, more confrontational strategies are required. Subversion becomes a negation of a negation, towards the affirmation of an alternative dialectical totalization.

This thesis brought together some of the most positive negations of the dominant paradigm available to synergize as a singular hypothetical narrative that attempts to negate a crisis. In the process, a synergy was truly discovered: permaculture as a holistic remediator that combines traditional wisdom, scientific knowledge, ecological integration and socio-economic decentralization into an opposing model to corporate agribusiness, environmental exploitation and centralized urbanism. The theoretical expression of this synergetic praxis is what is herein articulated as 'socio-ecomorphism', where the image of humanity is consciously remade, or remodeled, in a collective ecocentric social project, to re-conform with Nature's complex system of equilibriumin-diversity. The practical expression of this praxis was realized in a proposal for a central agroecological settlement in the heart of an inner-city suburb, called The Ottawa Permaculture Initiative, which is imagined as an instigative prototype for a "distributed ecovillage" throughout the city.

Every human can set an example to all of humanity-every single individual can be moral. The definition of morality is perhaps as difficult to express in words as is the concept of evil; yet they are understood, tacitly and intrinsically, perhaps even 
primordially, such that their respective actions upon the world are revealed to us as polar opposites: we see, or intuit, that the former results in mutualistic symbiosis, diversification, intricate complexity, the affirmation of the positive — what may be called Beauty - the evolving dynamic totality of which is perhaps what has been called Creation. The latter opposes Creation and results in anthropocentric monism, sadism, egoism, deception, destruction: the negative dialectic, or the negation of the positive. When the individual chooses to be moral and, in turn, influences another, it is experienced as solidarity and together they affirm a positive. As this process is repeated, a group is fused around a moral obligation to oppose the negative. The group's solidarity is amplified like a sympathetic resonance within a social sphere: more individuals are initiated and other groups are formed. By this process, a movement is accreted and solidarity evolves into mass consciousness. From here, the movement begins its exponential accumulation of groups and individuals. At a certain juncture, the movement climaxes, reaches a peak in its diversity, complexity, resilience and energetic expression: Revolution.

The term "revolution" has gained a plethora of historical associations and philosophical definitions. It is employed both theoretically and practicably in this study: in theory, it is here used to describe the 'diametrical reorientation' of the urban paradigm, away from one of anthropocentric class hierarchy and capitalist socioeconomics towards an ecocentric communitarian mass consciousness; in practice, it 
was employed to present a potential real-world scheme for realizing this aforementioned praxis. Theory and practice are presented as an evolving dynamic whole. Like the very process of ecological succession, revolution begins with a disturbance in a barren soil-at some point, some lifeform acts upon its world energetically and instigates a "butterfly effect" that evolves into the dynamic equilibrium that is called Nature. Whether that succession is primary, secondary, tertiary or some incalculable expression of the great infinite Cycle of Life, it matters not. All that matters is: we must act as if succession is always possible. Each and every one of us simply needs to understand that we are all capable of this initial disturbance. And when a moral obligation is intuited, the time to make a disturbance occurs right at the very moment of intuition.

This study is a result of an ongoing intuition, which has succeeded in creating an understanding. What has been understood is that this era of crisis and uncertainty creates a universal moral obligation. The obligation can be called "moral" because it at once involves the future of our species and the fate of all species. One can laugh at the idea that a life system as complex as Earth could be destroyed by a simple organism such as Man. However, when one considers the complexity of the human body in comparison to the bacterium-and then realizes that when homeostasis is disrupted and the body is weakened, a simple virulent bacterium can divide into billions upon billions of pathogenic bacteria, eventually destroying the complexity of the human 
body, resulting in death-then the idea of planetary death as a result of human activity becomes much less laughable. In fact, it becomes a real scenario that is evidenced by the increasing virulence of human activity. Human consciousness of itself and the consequences of its actions upon the world can and must intervene to reverse this pathogenic totalization.

If this is interpreted as a "moralizing" narrative then this particular form of moralization should be reinterpreted in the context of our species survival. The moral individual should likewise be understood as an expression of Marx's species-being or Sartre's universal-singular. As a being-for-species, the singular pursuits of whom are universalized within a complex and biodiverse natural environment, the individual evolves into a being-for-Nature, whose conscious acts are geared towards synergizing with all other living species. In the context of this being-for-Nature, revolution becomes a force of Nature, in a greater project of global homeostasis. Since this is never a static or inert equilibrium, it may be rightly renamed homeodynamics. The concept here introduced as socio-ecomorphism is thence the conscious and collective pursuit of humans struggling for this homeodynamic equilibrium.

2) On the cultivation of cannabis: The concept of "the moral fibre" hence transcends the mere practice of cannabis cultivation and incorporates the plant species into a philosophical paradigm: a product of Nature that can at once mediate our relations to 
Nature and our relations of production. Grown in polycultures, it can help remedy the biologically-simplified and contaminated soils of industrial agriculture, as well as provide humanity with the raw products for medicines, food, clothing and shelter. The pressures on forest ecosystems can be relieved, perhaps even eliminated, by allowing trees to survive, thrive and success. Old growth forests could be unhindered in their natural cycles of growth; succeeding forests could be allowed to flourish, increase in complexity and recreate mature growth once again. As the elders of their landscapes, trees carry within their fibres the natural histories of the Earth. When a hyper-complex rainforest is destroyed for its raw materials and agricultural land, not only is biodiversity and wildlife habitat destroyed, but an entire natural cultural landscape is extinguished. Deforestation is the consummate form of genocide: ecocide-entire species become extinct. And the greatest crime of all is the impact on the great cycles of energy and elements-entropy is increased in our closed system we call Earth.

This thesis proposes that hemp and marijuana be utilized in plant guilds on permacultured landscapes to replace many of the products humanity now robs from forests. Moreover, if produced in intensive forest garden type systems, cannabis could be integrated into perennial ecosystems that contribute substantially to biodiversity. Permaculture has the potential for universalizing the importance of cannabis and, in turn, cannabis possesses the capacity for establishing the universal significance of permaculture. To these ends, it was proposed that OPI incorporate a cannabis research 
regime to develop novel methods of agroecological cultivation, as well as to stimulate new research into hemp-reinforced structural biocomposites to replace solid-sawn and structural composite lumber products in the building industry, among many other architectural uses. The time is ripe for such proposals: cannabis is rapidly being vindicated in the public's eye, after nearly a century of unwarranted persecution, and governments finally appear to be catching up with public opinion.

3) On the proposed use of Central Experimental Farm land: The proposed site for this project's permacultural landscape is already recognized as its own self-contained sociocultural landscape. It presently sits as an undeveloped island of agricultural research land in the centre of an urban environment-a "farm-within-a-city". But this island is not an ideal expression of the idea of cultural landscapes and it leaves much to be desired in the realm of progressive agronomics. Firstly, while it is acknowledged that the CEF has both tangible and associative connections to its history and the greater Ottawa community, its research potential arguably holds the greatest value for Canadians and humanity as a whole, not its physical heritage associations. With climate instability and declining biodiversity worldwide, it is proposed that its present research pursuits be better contemporized and enhanced in order to pursue research into largerscale solutions to the global detriment caused by energy-intensive farming. To these ends, a change in its physical landscape is proposed such that its present rectilinear field structure be replaced with an eco-physical model. This new agroecology approach 
would retain all structures with architectural heritage value, but transform 260 hectares of compartmentalized and rectilinearly-fragmented fields into an ecologicallysuccessive evolving permacultural landscape with 500-700 dedicated live-in researchers, students, activists and their families. This socio-ecomorphic settlement would thereby retain many of the associations with the CEF's historical function: an eco-farm-within-a-city that is committed to advancing the science and practice of sustainable agriculture.

4) On Indigenous-inspired permaculture: With the spirit of biological and cultural diversification at the core of the OPI proposal, homage would be paid to the original inhabitants and stewards of the CEF lands and the entire Kichi sipi Valley: First Nation peoples. In addition to acknowledging their contributions to holistic knowledge systems worldwide, such as to permaculture and ecology, members of the Algonquin First Nation and others from all 500 Nations of North America would be consulted on the planning/design and invited to participate directly in OPI's function. The goal would be to synergize indigenous knowledge with science to revive as much of the precolonial cultural and biological landscape as would be possible for CEF's present and particular urban context. Even though the indigenous cultural landscape is now the most obscure, invisible and associative layer of the urban setting-after several hundred years of colonialism, cultural imperialism, environmental destruction and urban sprawl have washed away almost all of its physical and immediate psychological 
linkages to its history at the CEF site-legal, biological and cultural associations still exist and cannot be ignored. And if History has a voice, it is crying out for us to listen to the iniquities of our past, such that we may avoid the downfalls of our future. If this project were indeed realized at any scale, on any site, one main priority would be to incorporate their ancient wisdom in the creation and function of OPI's intentional socio-ecomorphic landscape of agroecological systems, scientific research infrastructure, cultural affairs and social interrelations.

5) On the concept of the 'praxis diagram': The idea of the "master plan" should not be applied to a permaculture project such as OPI. A designed and finalized landscape, where the original intentions of the designer(s) are frozen in time (i.e. the supreme dictates of a "master"), is not suited to an agronomic plan modelled after natural systems and ecological succession. This is because the intentions themselves are intrinsically-bound to a continually-evolving landscape developing towards its climax in biodiversity. Permaculture is an iterative design process that takes place over generations. Its infrastructure and systems must adapt to the changing conditions of macroclimate, microclimate, species succession and human settlement requirements. As discussed in 1.1.2.3, the designers' original planning requirements and site layout should represent the second iteration of schematic design-a planned disturbancesecond to the original site's condition and left open for its evolving relationship with Nature. As these design intentions are guided by an overall ecocentric philosophy, this 
second iteration and all that follow are expressions of a praxis totalization. The praxis diagram is thus both a historical record of a project's evolution and a planning diagram for its future direction. This process could not be adequately described or demonstrated in this thesis as it would require a real project, demonstrated over time, which could also be one of the research pursuits of OPI: to study the development of an experimental model of a working permaculture ecovillage initiative over time.

The best outcome this thesis could hope for, with regards to the demonstration of such a model, was to create a hypothetical illustrated second iteration (Figure 22) that provides an example of how this holistic systems approach could be incorporated into an existing property. An example of a resilient food-producing environment with its initial infrastructure and constructed systems, along with discussions on its preliminary logic were provided. The success of this particular proposal may never be demonstrable or measurable since its actual implementation would face a multitude of political, financial and civic roadblocks. Nevertheless, the proposal for OPI now exists and it cannot be rejected as an impossibility. As an industrious species, we now build entire islands in the sea, at a great cost to marine ecosystems and established ocean currents, for the sole purpose of colonizing them with condominiums, shopping malls and military bases; it would thus seem that civilization is presently only capable of creating that which destroys-megastructures that defy Creation. When it comes to proposals to bring together even modest funds, resources and manpower to give back to Nature, 
the will is rarely, if ever, to be found in government or the private sector. We can only hope for the reversal of this blind mass-suicidal tendency and that it comes sooner rather than later.

On the practical level, however, it may be of interest to include here a short discussion on potential pilot projects for OPI at the CEF or at any other comparable site in Ottawa's greenbelt or quasi-rural outlying areas. Ironically, the one component of this project that was included in the Praxis Diagram, but was excluded in the facilities design section, could make for a significant smaller-scale preliminary trial experiment. This would be the 'quasi-atomic' residential berm-house cluster (Figure 22, no. 2) on the 20-hectare plot bordered by the NCC Driveway to its north, Ash Lane to its west, Cow Lane to its south and Morningside Lane to its east. Of course, changes would have to be made considering that the original intent was to have this "quasi-atomic" model operating in conjunction with greater landscape design elements and utilizing the community services provided by the large residential complex (Figure 22, no. 9). For example, catchment, water features, energy requirements would have to be planned and designed, as well as the houses themselves. One concern arising out of the segregation and separate execution of this pilot would be its proximity to existing research being carried out on chemically-treated and genetically-modified crops, with a real possibility for transgenic drift and the diffusion of agricultural pollution across any constructed barriers. These factors could significantly reduce the pilot's potential for 
biodiversification, climax or organic certification, setting it up for potential failure and public cynicism. Of course, these are also factors to be confronted in other permaculture projects in the real world, which, in itself could provide an opportunity to study external pollution mitigation strategies. Another cause for concern are the likely limitations for expansion on the CEF property. If AAFC, the NCC and other federal agencies would ultimately consider such a pilot a token gesture towards sustainable ecological agriculture, with no intentions to expand the project over time, then the original intent (the praxis) of universalizing agroecology in Canada could be lost from its outset and, objectively, could be more damaging to the permaculture movement in the long run. Nevertheless, it should not be discounted as a viable option for getting permaculture's foot in the AAFC's door.

Another possible pilot study could be the use of cannabis, other phytoremediators and microbes to recuperate the contaminated soils at the CEF. The two current identified sites are the fields directly south of Carling Ave. polluted with accumulated road salts and the demolition site of the Sir John Carling Building in the northern corner near the intersection of Carling Ave. and Prince of Wales Drive, which is now shown to be contaminated with phenols and alkaline concrete dust. The difficulty for both these sites being that salt and alkalinity, depending on their soil concentrations, can prevent the growth of most plant species. Cannabis itself prefers slightly acidic soils, making it difficult to know whether it could be used to clean the soil of the aromatic 
phenols in the presence of high concentrations of alkaline calcium hydroxide. However, minus the alkalinity, hemp has been used to successfully remove aromatic compounds from soils, such as DNT (2,4-dinitrotoluene; see Section 2.4 ). Thus, biological remediation using various techniques could certainly form the basis of a crucial study for both these particular contamination conditions.

6) On the concept of "permatecture": Designing a built system that integrates into a holistic permacultural landscape differs from traditional architecture in a fundamental manner: the design is not simply part of a human-centred system (i.e. an anthropocentric construct); it must synergize with an evolving designed landscape. The design process inherently engages a feedback loop between the ecosystem, the human system, landscape architecture and building architecture. This is perhaps why it was necessary to adopt an existing concept referred to as "permatecture", since the standard definition of "architecture" alone presently fails to address this holism. Permatecture represents this dynamic totality, in which the principles of symbiosis, activity/intensity zoning, natural forces (macroclimate pressures), site thermodynamics (microclimate regulation), bio-integration, energy passivity and efficiency, catchment, energy embodiment, carbon footprint, waste recycling, sustenance independence, and site selfsufficiency are all brought together in a holistic scheme towards permanent sustainability. 
Of course, no one can claim that any design is ever for "permanence". Nothing is permanent; however, when it involves the specification and use of limited natural resources, combined with renewable raw materials, architects should design for multigenerational building occupation to limit the strain placed on natural habitats by human industry. The longer buildings last, the more sustainable they become. This can be accomplished by carefully balancing at once the longevity and energy intensity of materials with their physical properties to create resiliency in building assemblies that react to, adapt with and engage the pressures of the external environment to diminish the constant struggle against natural forces. The ideal sustainable building, on the other hand, is never simply the sum total of its components and technologies. Permatecture represents a revolution of the built environment to enhance its contextualization within the natural environment, to at once provide for human needs and ecosystem requirements. With growing awareness of sustainability issues beginning to take hold in architecture, permaculture presents itself as the next great leap in environmental consciousness that can transform not only building design, but more importantly, urban and rural landscape design to synergize all three in a harmonic totalization of humanity and Nature.

The design component of this thesis attempts to demonstrate and describe this process. In designing the community complex for OPI, the ethics and practices of permaculture gave rise to concepts such as 'spatial-symbiosis' and crop-integration. 
The former exemplifies the application of permaculture zoning analysis (illustrated by the ring diagram, see Figure 1, p. 32) to create a diversity of spatial dynamics: interiorexterior, public-private, social-work, cultural-practical and circulation-residential, all organized with respect to human activity intensity. The latter (crop-integration), is an expression of the project for reunification of humans and the products of their industry, where the alienation between labourer, work and the products of labour is dissolved. The lived environment becomes intrinsically-bound to the work environment, the cultivation of crops is synonymous with the cultivation of human relations. The living products of living producers, living together within a living ecosystem.

\section{FINAL THOUGHTS}

The overall praxis developed here is therefore none other than to mend the Circle of Life that centralized urbanism has renounced in exchange for a vortex of increasing turbulence-a downward spiral of perpetual cancerous growth. The great cycle of living energy is encoded in every cell of every living organism. The expression of their genetics works in mutual symbiosis with every other cell in their body. This collection of cells creates the life-support systems that are collectively called, homeostasis. When this dynamic equilibrium is upset, the body compensates by expressing genes encoded for the very purpose of maintaining that balance. Not only is every organism a collection of these genetically-encoded cells, but also of other organisms (bodies of cells) working within that 
balance. When hostile organisms invade and produce toxic substances that intervene in these mutualistic-symbiotic functions, the body's cells can begin a process of unregulated multiplication (perpetual growth). This mutagenic cellular division (growth) can continue until the body of healthy cells can no longer sustain the life of the organism. If Earth is understood as this body, comprised of a collection of component organisms that together maintain its homeostasis, or homeodynamics, then perpetual human growth and our constant rearrangement of the natural world can be interpreted as a cancer onto Nature. The cities we create in opposition to the living forests that spontaneously generate life, can be seen as artificial tumors versus the vital organs of the natural world. The longer humanity remains unconscious of this sum totalization of its action upon the Earth, the greater the cancer spreads and the closer we bring this great organism of Creation to its death. If human beings are indeed endowed with the gift of logic, reason and creativity, then it is time to engage all at once, collectively, to put an end to any cancerous systems that we have created. As individual cells in a greater collectivity of life systems, each and every one of us contains the genetic potential to act toward the conscious expression of Earth's homeodynamics. Permaculture is perhaps only one of these expressions, but one that amalgamates a diversity of strategies into a singular practical philosophy for planetary healthcare. If ever there was hope for a Universal Mithridate, this could be it. 


\section{REFERENCES}

[1] J. Lockyer and J. R. Veteto, "Environmental Anthropology Engaging Ecotopia: An Introduction," in Environmental Anthropology Engaging Ecotopia: Bioregionalism, Permaculture and Ecovillages, J. Lockyer and J. R. Veteto, Eds., New York, Berghahn, 2013, pp. 1-31.

[2] B. Mollison and D. Holmgren, Permaculture One: A Perennial Agriculture System for Human Settlements, Melbourne: Corgi Books (Transworld Publishers), 1978.

[3] K. Padmavathy and G. Poyyamoli, "Alternative Farming Techniques for Sustainable Food Production," in Genetics, Biofuels and Local Farming Systems, 1 ed., vol. 7, E. Lichtfouse, Ed., Dordrecht, Springer Netherlands, 2011.

[4] United Nations, "World Urbanization Prospects (2014 Revision)," Department of Economic and Social Affairs, Population Division, New York, 2015.

[5] J. M. Smith, "Genetically Engineered Crops Damage Wildlife," March 2005. [Online]. Available: http://responsibletechnology.org/irtnew/docs/60.pdf. [Accessed 2 January 2017].

[6] M.-W. Ho, "Report on horizontal gene transfer - Department of Public Prosecution versus Gavin Harte and Others, New Ross, Ireland," [Online]. Available: http://www.i-sis.org.uk/ireaff99.php. [Accessed 2 January 2017].

[7] Institute for Responsible Technology, "State-of-the-Science on the Health Risks of GM Foods (v2.15.10)," [Online]. Available: http://www.responsibletechnology.org/docs/145.pdf. [Accessed 2 September 2017].

[8] T. Baker, "Ecovillages and Capitalism," in Environmental Anthropology Engaging Ecotopia: Bioregionalism, Permaculture and Ecovillages, vol. 17, J. Lockyer and J. R. Veteto, Eds., New York, Berghahn Books, 2013, pp. 285-300.

[9] D. Holmgren, Permaculture: Principles and Pathways Beyond Sustainability, Hepburn, Victoria: Holmgren Design Services, 2002.

[10] P. Bane, The Permaculture Handbook, Gabriola Island, British Columbia: New Society Publishers, 2012.

[11] D. Zuchowski, "Native Americans Played Crucial Role in Settler's Survival," Pittsburgh PostGazette, 24 November 2010.

[12] B. A. Black and C. Ruffner, "Native American Influences on the Forest Composition of the Allegheny Plateau, Northwest Pennsylvania," Canadian Journal of Forest Research, no. 36, pp. 1266-1275, May 2006.

[13] United States Department of Agriculture, "Native American Contributions," [Online]. Available: http://www.nrcs.usda.gov/Internet/FSE_DOCUMENTS/nrcs141p2_024206.pdf. [Accessed November 2016].

[14] N. J. Turner, D. Deur and D. Lepfsky, "Plant Management Systems of British Columbia's First Peoples," BC Studies: The British Columbia Quarterly, no. 179, pp. 107-133, Autumn 2013.

[15] D. J. Tenebaum, "Farming, Native American Style," 5 April 2012. [Online]. Available: http://whyfiles.org/2012/farming-native-american-style/. [Accessed December 2016].

[16] B. Falk, The Resilient Farm and Homestead: An Innovative Permaculture and Whole Systems Design Approach, White River Junction, Vermont: Chelsea Green Publishing, 2013. 
[17] B. Mollison, Permaculture: A Designer's Manual, Tyalgum, New South Wales: Tagari Publications, 1988.

[18] W. Weiseman, D. Halsey and B. Ruddock, Integrated Forest Gardening: The Complete Guide to Polycultures and Plant Guilds in Permaculture Systems, White River Junction, Vermont: Chealsea Green Publishing, 2014.

[19] R. Haluza-Delay and R. Berezan, "Permaculture in the City: Ecological Habitus and the Distributed Ecovillage," in Environmental Anthropology Engaging Ecotopia: Bioregionalism, Permaculture and Ecovillages, vol. 17, J. Lockyer and J. R. Veteto, Eds., New York, New York: Berghan Books, 2013, pp. 130-145.

[20] J. Dawson, "From Islands to Networks: The History and Future of the Ecovillage Movement," in Environmental Anthropology Engaging Ecotopia: Bioregionalism, Permaculture and Ecovillages, J. Lockyer and J. R. Veteto, Eds., New York, Berghahn, 2013, pp. 218-234.

[21] B. McKechnie, "Global News," 16 June 2015. [Online]. Available: http://globalnews.ca/news/2054762/what-you-need-to-know-about-backyard-chickens/. [Accessed January 2017].

[22] City of Ottawa, [Online]. Available: http://ottawa.ca/en/residents/animals-and-pets/other-animals. [Accessed January 2017].

[23] T. Hemenway, The Permaculture City: Regenerative Design for Urban, Suburban and Town Resilience, White River Junction, Vermont: Chelsea Green Publishing, 2015.

[24] T. Tomlik, "The Integration of Permaculture into a Land Use Plan for the City of Guelph, ON," M.L.A. thesis, Sch. of Env. Des.., Univ. Guelph, Guelph, ON, 2009.

[25] H. Yundt, "When Truth is Stranger than Fiction: the Capital that Sits on Another Nation's Land," 19 December 2010. [Online]. Available: http://spacing.ca/ottawa/2010/12/19/when-truth-isstranger-than-fiction-the-capital-that-sits-on-another-nations-land/. [Accessed December 2016].

[26] A. Thygeson, "Properties of Hemp Fibre Polymer Composites: An Optimisation of Fibre Properties Using Novel Defibration Methods and Detailed Fibre Characterisation," PhD thesis, Roy. Vet. Agr. Univ., Denmark, 2005.

[27] C. S. Duvall, Cannabis (author's manuscript), London: Reaktion Books, 2015.

[28] M. A. Greene, "Cannabis in Native American's Culture and Religion," Cannabis Digest, April 2012. [Online]. Available: http://cannabisdigest.ca/cannabis-native-americans-culture-religion/. [Accessed December 2016].

[29] J. A. Hartsel et al., "Cannabis sativa and Hemp," in Neutraceuticals: Efficacy, Safety and Toxicity, 1 ed., R. C. Gupta, Ed., Boston, Academic Press , 2016, pp. 735-754.

[30] M. Gallo, "Industrial Hemp, Phytoremediation, Biofuel, and Other Purposes," University of Hawai'i, Mānoa, Hawai'i, 2015.

[31] F. A. Roth II, "Thinning to Improve Pine Lumber," [Online]. Available: http://forestry.arkansas.gov/directorysearches/documents/thinning_to_improve.pdf. [Accessed December 2016].

[32] C. R. Nitschke, "Does Forest Harvesting Emulate Fire Disturbance? A Comparison of Effects on Selected Attributes in Coniferous-Dominated Headwater Systems," Forest Ecology and Management, vol. 214, p. 305-319, 2005.

[33] N. Lecomte et al., "Similarities and Differences between Harvesting- and Wildfire-Induced Disturbances in Fire-Mediated Canadian Landscapes," National Council for Air and Stream Improvement (NCASI), vol. Technical Bulletin No. 924, October 2006. 
[34] Y. Hu et al., "Lizard Responses to Forest Fire and Timber Harvesting: Complementary Insights from Species and Community Approaches," Forest Ecology and Management, vol. 379, p. 206-215, 2016.

[35] Q. Zhao et al., "Landscape-Scale Disturbances Modified Bird Community Dynamics in Successional Forest Environment," PLoS ONE, vol. 8, no. 11, 2013.

[36] U. Kezik and H. H. Acar, "The Potential Ecological Effects of Forest Harvesting on Forest Soil," European Journal of Forest Engineering, vol. 2, no. 2, pp. 87-95, 2016.

[37] D. Luoma et. al, "Relationships among Fungi and Small Mammals in Forested Ecosystems," [Online]. Available: http://www.fsl.orst.edu/mycology/LuomaEtal2003.pdf. [Accessed December 2016].

[38] K. Aubry et al., "The Ecological Role of Tree-Dwelling Mammals in Western Coniferous Forests," [Online]. Available:

http://www.plexusowls.com/PDFs/ecological_role_treedwelling_mammals.pdf. [Accessed January 2016].

[39] D. McRae et al., "Comparisons Between Wildfire and Forest Harvesting and their Implications in Forest Management," Environmental Research, vol. 9, pp. 223-260, 2001.

[40] Sensi Seeds, "Equatorial Cannabis Varieties," Sensi Seeds, 2014. [Online]. Available: https://sensiseeds.com/en/blog/equatorial-cannabis-varieties/. [Accessed December 2016].

[41] T. R. Fortenbery, "Industrial Hemp: Opportunities and Challenges for Washington," Washington State University, Pullman, Washington, 2014.

[42] N. Stevulova et al., "Properties Characterization of Chemically Modified Hemp Hurds," Materials, vol. 7, pp. 8131-8150, 2014.

[43] South Africa Hemphouse. [Film]. Cape Town, South Africa: AP Television (Associated Press), 2011.

[44] L. Kidalova et al., "Effective Utilization of Alternative Materials in Lightweight Composites," Journal of Cleaner Production, October 2012.

[45] U. Berardi, "Hygrothermal Performance of Hempcrete for Ontario (Canada) Buildings," Journal of Cleaner Production, vol. 142, pp. 3655-3664, January 2017.

[46] S. Moisette et al., "Hysteresis Phenomenon in Hemp Concrete," in First International Conference on Boi-Based Materials, Clermont-Ferrand, France, 2015.

[47] Woodbridge Associates, "Hemp Insulation and Hemp Board: Business Case (Final Report)," Prepared for Alberta Agriculture and Rural Development et al., Vancouver, 2009.

[48] Roxul, "ROXUL COMFORTBATT: Product Description \& Application," April 2016. [Online]. Available: http://www.roxul.com/files/RX-NA_EN/pdf/Technical Data Sheetsupdated/Residential/COMFORTBATTCANADA_TECHDATASHEET_EN.pdf. [Accessed December 2016].

[49] Owens Corning, "EcoTouch Pink Fiberglas: Product Data Sheet," February 2014. [Online]. Available: http://insulation.owenscorning.ca/assets/0/188/78472516-d5df-4f5b-8cad782318611001.pdf. [Accessed December 2016].

[50] Black Mountain Natural Insulation, "NatuHemp: Technical Data Sheet," [Online]. Available: http://www.blackmountaininsulation.com/NatuHemp_Technical_Sheet.pdf. [Accessed December 2016]. 
[51] Roxul, "CavityRock: Cavity and Rain Screen Wall Application," [Online]. Available: http://www.roxul.com/files/RX-NA_EN/pdf/tech data/TB- Rainscreen Systems.pdf. [Accessed December 2016].

[52] E. Papadopoulou et al., "Value-Added Inudstrial Products from Bast Fiber Crops," Industrial Crops and Products, vol. 68, pp. 116-125, June 2015.

[53] J. Fajrin et al., "Flexural Behaviour of Hybrid Sandwich Panel with Natural Fiber Composites as the Intermediate Layer," Journal of Mechanical Engineering and Sciences (JMES), vol. 10, no. 2, pp. 1968-1983, 2016.

[54] THC: The Hemp Connoisseur, "Hemp Fiberboard Poised To Replace Plywood," April 2014. [Online]. Available: http://www.thcmag.com/hemp-fiberboard-poised-to-replace-plywood/. [Accessed December 2016].

[55] Bothbest Bamboo Flooring (online retailer), "Hemp Board - New Green Option For Cabinet Board," [Online]. Available: http://www.bambooindustry.com/blog/hemp-board.html. [Accessed December 2016].

[56] N. Nikvash et al., "Comparative Properties of Bagasse Canola and Hemp Particle Boards," European Journal of Wood and Wood Products, vol. 68, no. 3, pp. 323-327, 2010.

[57] R. Robinson, The Great Book of Hemp: The Complete Guide to the Environmental, Commercial, and Medicinal Uses of the World's Most Extraordinary Plant, Rochester, Vermont: Park Street Press, 1996.

[58] L. Osburn and J. Osburn, "Hemp Plywood Becomes a Reality," North Coast XPress, February/March 1994. [Online]. Available: https://ratical.org/renewables/plywood.html. [Accessed December 2006].

[59] House of Representatives, State of Hawaii, "Industrial Hemp [Cannabis sativa] - Economic Viability and Political," House of Representatives, State of Hawaii, Honolulu, 1996.

[60] H. Fischer, "Sandwich Boards Made from Bio-Polyurethane Foam and Natural Fibre Cover Layers: New Approach for Sustainable Lightweight Construction," in 10th International Conference on Composite Science and Technology, Lisboa, 2015.

[61] E. A. Awwad et al., "Sustainable concrete using hemp fibres," Construction Materials, 2011.

[62] E. Awwad et al., "Sustainable Construction Material Using Hemp Fibers - Preliminary Study," Conference Paper - Sustainable Materials, Civil and Environmental Engineering, American University, 2010.

[63] E. Russo, "Hemp for Headache: An In-Depth Historical and Scientific Review of Cannabis in Migraine Treatment," Journal of Cannabis Therapeutics, vol. 1, no. 2, pp. 21-92, 2001.

[64] A. Ligresti et al., "Antitumor Activity of Plant Cannabinoids with Emphasis on the Effect of Cannabidiol on Human Breast Carcinoma," Journal of Pharmacology and Experimental Therapeutics, vol. 318, no. 3, pp. 1375-1387, 2006.

[65] S. A. Page and M. J. Verhoef, "Medicinal Marijuana Use: Experiences of People with Multiple Sclerosis," Canadian Family Physician, vol. 52, pp. 64-65, January 2006.

[66] M. Kowal et al., "Review on Clinical Studies with Cannabis and Cannabinoids 2010-2014," Cannabinoids, vol. 11, no. (special issue), pp. 1-18, 2016.

[67] R. Mechoulam and L. A. Parker, "The Endocannabinoid System and the Brain," Annual Review of Psychology, vol. 64, pp. 21-47, 2013. 
[68] P. A. Clark et al., "Medical marijuana: Medical Necessity Versus Political Agenda," Medical Science Monitor: International Medical Journal of Experimental and Clinical Research, vol. 17, no. 12, pp. 249-21, 2011.

[69] ProCon.org, "60 Peer-Reviewed Studies on Medical Marijuana: Medical Studies Involving Cannabis and Cannabis Extracts (1990 - 2014)," 2 October 2016. [Online]. Available: http://medicalmarijuana.procon.org/view.resource.php?resourceID=000884. [Accessed December 2016].

[70] G. Di Iorio et al., "The Endocannabinoid System: A Putative Role in Neurodegenerative Diseases," International Journal of High Risk Behavious and Addiction, vol. 2, no. 3, pp. 100-106, December 2013.

[71] Government of Canada, "A Framework for the Legalization and Regulation of Cannabis in Canada: The Final Report of the Task Force on Cannabis Legalization and Regulation," Health Canada, Ottawa, 2016.

[72] S. T. Wilkinson et al., "Marijuana Legalization: Impact on Physicians and Public Health," Annual Review of Medicine, vol. 67, p. 10.1-10.14, 2015.

[73] NORML Foundation, "NORML.org," 2016. [Online]. Available: http://norml.org/laws. [Accessed December 2016].

[74] V. Angelova et al., "Bio-accumulation and Distribution of Heavy Metals in Fibre Crops (Flax, Cotton and Hemp)," Industrial Crops and Products, vol. 19, pp. 197-205, 2004.

[75] G. Shi and Q. Cai, "Cadmium tolerance and accumulation in eight potential energy crops," Biotechnology Advances, vol. 27, p. 555-561, 2009.

[76] R. Podlipná, "Biodegradation of 2,4-dinitrotoluene by different plant species," Ecotoxicology and Environmental Safety, vol. 112, pp. 54-59, 2015.

[77] McGraw Hill, "Phytoremediation: Using Plants to Clean Soil," 2000. [Online]. Available: http://www.mhhe.com/biosci/pae/botany/botany_map/articles/article_10.html. [Accessed December 2016].

[78] Agriculture and Agri-Food Canada (AAFC), "Central Experimental Farm National Historic Site Management Plan (1 of 20)," 23 November 2012. [Online]. Available:

http://www.agr.gc.ca/eng/central-experimental-farm-national-historic-site-management-plan-1of-20/?id=1170695386778. [Accessed December 2016].

[79] I. M. Stewart, "SAUNDERS, WILLIAM," University of Toronto/Université Laval, 2003. [Online]. Available: http://www.biographi.ca/en/bio/saunders_william_14E.html. [Accessed December 2016].

[80] Minister of Agriculture, The Dominion Experimental Farms, Ottawa: Hon. W. R. Motherwell, Minister of Agriculture (1925), 1925.

[81] Alberta Agriculture and Rural Development, "Industrial Hemp Production in Canada," 29 June 2012. [Online]. Available: http://www1.agric.gov.ab.ca/\$department/deptdocs.nsf/all/econ9631. [Accessed January 2017].

[82] Wikipedia (via Google Images), "Central Experimental Farm (Wikipedia)," [Online]. Available: https://upload.wikimedia.org/wikipedia/commons/6/6f/CEF_map.jpg. [Accessed December 2016].

[83] CBC News, "Hospital Expansion Sows Concern Among Scientists Testing Drought-Resistant Crops," CBC News, 24 May 2016. [Online]. Available:

http://www.cbc.ca/news/canada/ottawa/hospital-expansion-sows-doubt-scientists-testingdrought-resistant-soybeans-1.3597748. [Accessed December 2016]. 
[84] CBAN: Canadian Biotechnology Action Network, "Genetically Modified Goats on Display at Ottawa Experimental Farm," 27 March 2012. [Online]. Available: http://www.cban.ca/Press/PressReleases/Genetically-Modified-Goats-on-Display-at-Ottawa-Experimental-Farm. [Accessed December 2006].

[85] T. Spears, "Access-to-information roadblocks: What's in that wheat field?," Ottawa Citizen, 22 July 2014. [Online]. Available: http://ottawacitizen.com/news/local-news/access-to-informationstruggles-whats-in-that-wheat-field. [Accessed December 2016].

[86] Ottawa Citizen, "Agriculture Canada made repeated mistakes when testing out genetically modified crops at the Experimental Farm," 21 July 2014. [Online]. Available: http://ottawacitizen.com/storyline/agriculture-canada-made-repeated-mistakes-when-testing-outgenetically-modified-crops-at-the-experimental-farm. [Accessed December 2016].

[87] Agriculture and Agri-Food Canada (AAFC), "Central Experimental Farm National Historic Site Management Plan (2 of 20)," 25 April 2013. [Online]. Available: http://www.agr.gc.ca/eng/centralexperimental-farm-national-historic-site-management-plan-2-of-20/?id=1170357621080. [Accessed January 2017].

[88] Agriculture and Agri-Food Canada (AAFC), "Central Experimental Farm National Historic Site Management Plan (9 of 20)," 05 August 2015. [Online]. Available:

http://www.agr.gc.ca/eng/experimental-farm-national-historic-site-management-plan-9-of20/?id=1170436212725. [Accessed January 2017].

[89] Agriculture and Agri-Food Canada (AAFC), "Central Experimental Farm National Historic Site Management Plan (8 of 20)," 21 June 2013. [Online]. Available: http://www.agr.gc.ca/eng/centralexperimental-farm-national-historic-site-management-plan-8-of-20/?id=1170431125051. [Accessed 2017 January ].

[90] Agriculture and Agri-Food Canada (AAFC), "Central Experimental Farm National Historic Site Management Plan (14 of 20)," 21 June 2013. [Online]. Available: http://www.agr.gc.ca/eng/centralexperimental-farm-national-historic-site-management-plan-14-of-20/?id=1170679162854. [Accessed 2017 January].

[91] Agriculture and Agri-Food Canada (AAFC), "Central Experimental Farm National Historic Site Management Plan (16 of 20)," 25 July 2013. [Online]. Available: http://www.agr.gc.ca/eng/centralexperimental-farm-national-historic-site-management-plan-16-of-20/?id=1170681236359. [Accessed January 2017].

[92] Agriculture and Agri-Food Canada (AAFC), "Central Experimental Farm National Historic Site Management Plan (5 of 20)," 13 March 2013. [Online]. Available: http://www.agr.gc.ca/eng/central-experimental-farm-national-historic-site-management-plan-5of-20/?id=1170425145846. [Accessed January 2017].

[93] Agriculture and Agri-Food Canada (AAFC), "Central Experimental Farm National Historic Site Management Plan (3 of 20)," 25 July 2013. [Online]. Available: http://www.agr.gc.ca/eng/centralexperimental-farm-national-historic-site-management-plan-3-of-20/?id=1170420541894. [Accessed January 2017].

[94] B. Qian et al., "Observed Soil Temperature Trends Associated with Climate Change in Canada," Journal of Geophysical Research, vol. 116, 2011.

[95] E. G. Gregorich et al., "Using a Sequential Density and Particle-Size Fractionation to Evaluate Carbon and Nitrogen Storage in the Profile of Tilled and No-Till Soils in Eastern Canada," Canadian Journal of Soil Science, vol. 89, pp. 255-267, 2009. 
[96] BBC World Radio, "The Globally Important Research at Ottawa's Central Experimental Farm (transcript)," 19 August 2016. [Online]. Available:

https://heritageottawa.org/sites/default/files/BBC_Globally Important Research_Central Experimental Farm_1.pdf. [Accessed January 2017].

[97] UNESCO World Heritage Committee, "Report on the Proposed World Heritage Indigenous Peoples Council of Experts (WHIPCOE)," UNESCO Bureau of the World Heritage Committee, Paris, 2001.

[98] Agriculture and Agri-Food Canada (AAFC), "Central Experimental Farm National Historic Site Management Plan (11 of 20)," Agriculture and Agri-Food Canada (AAFC), 21 June 2013. [Online]. Available: http://www.agr.gc.ca/eng/central-experimental-farm-national-historic-sitemanagement-plan-11-of-20/?id=1170444714340. [Accessed January 2017].

[99] National Capital Commission (NCC), "Report on Gatineau Park Ecosystems," Government of Canada, Ottawa, 2016.

[100] A. Tenasco and R. Nelson, "Aboriginal Educational Council: Annual Report 2013/2014," Carleton University, Ottawa, 2015.

[101] A. Pfeffer, "Experimental Farm Land Deal Kept Under Wraps Before Announcement, Documents Show," CBC News, 11 February 2016. [Online]. Available: http://www.cbc.ca/news/canada/ottawa/ottawa-hospital-experimental-farm-deal-stakeholdersnot-informed-1.3440775. [Accessed December 2016].

[102] United Nations Office of the High Commissioner for Human Rights (UNOHCHR), "International Decades of the World's Indigenous People," [Online]. Available: http://www.ohchr.org/EN/Issues/IPeoples/Pages/InternationalDecade.aspx. [Accessed January 2017].

[103] J. Harris, "Central Experimental Farm's Management Plan Should be Respected," Heritage Ottawa, 5 November 2014. [Online]. Available: https://heritageottawa.org/news/central-experimentalfarms-management-plan-should-be-respected. [Accessed January 2017].

[104] Algonquin National Secretariat, "The Ottawa River Valley Watershed and Aboriginal Communities, Showing the Height of the Land (map)," Timiskaming First Nation, Notre-Damedu-Nord, QC, January 2013. [Online]. Available: http://new-wordpress.algonquinnation.ca/wpcontent/uploads/2013/01/RN-51836-TFN-WLFN-EVFN-claim-area-finalX.pdf. [Accessed December 2016].

[105] N. Mitchell et al., "World Heritage Cultural Landscapes: A Handbook for Conservation and Management (World Heritage Papers, No. 26)," UNESCO World Heritage Centre, Paris, 2009.

[106] Intergovernmental Platform on Biodiversity and Ecosystem Services with United Nations University, "The Contribution of Indigenous and Local Knowledge Systems to IPBES: Building Synergies with Science," UNESCO, Tokyo, 2013.

[107] City of Ottawa, "Transportation Master Plan," November 2013. [Online]. Available: http://documents.ottawa.ca/sites/documents.ottawa.ca/files/documents/tmp_en.pdf. [Accessed Augusst 2016].

[108] K. Porter, "Road Salt Renders 5 Hectares of Farm Site Rnsuitable for Research," CBC News, 1 December 2016. [Online]. Available: http://www.cbc.ca/news/canada/ottawa/road-saltexperimental-farm-1.3875766. [Accessed December 2016]. 
[109] City of Ottawa, "Zoning By-law, Part 8 - Open Space and Leisure Zones (Sections 173-180)," 2008. [Online]. Available: http://ottawa.ca/en/part-8-open-space-and-leisure-zones-sections-173180\#13-central-experimental-farm-sec-177 . [Accessed December 2016].

[110] M. C. Peel et al., "Updated World Map of the Koppen-Geiger Climate Classification," Hydrology and Earth System Sciences Discussions, European Geosciences Union, vol. 11, no. 5, pp. 1633-1644, 2007.

[111] Environment Canada, "Canadian Climate Normals 1981-2010 Station Data," [Online]. Available: http://climate.weather.gc.ca/climate_normals/. [Accessed December 2016].

[112] Natural Resources Canada (NRCAN), "Plant Hardiness Zone Maps," 2014. [Online]. Available: http://planthardiness.gc.ca/?m=1. [Accessed December 2016].

[113] Windfinder, "Ottawa Airport: Wind and Weather Statistics," [Online]. Available: https://www.windfinder.com/windstatistics/ottawa_airport. [Accessed December 2016].

[114] R. Klock et al., "The Weather of Canada and Quebec: Graphic Area Forecast 33," NAV CANADA, Ottawa, 2002.

[115] C.-R. Chang, "A Preliminary Study on the Cool-Island Intensity of Taipei City Parks," Landscape and Urban Planning, vol. 80, pp. 386-95, May 2007.

[116] Ontario Ministry of Natural Resources (MNR), "The Ecosystems of Ontario, Part 1: Ecozones and Ecoregions," 2009. [Online]. Available: https://dr6j45jk9xcmk.cloudfront.net/documents/2712/stdprod-101587.pdf. [Accessed December 2016].

[117] Geological Survey of Canada, "Generalized Bedrock Geology, Ottawa-Hull, Ontario and Quebec (map)," 1979. [Online]. Available: http://geoscan.nrcan.gc.ca/starweb/geoscan/servlet.starweb?path=geoscan/fulle.web\&search1=R=1 09223. [Accessed November 2016].

[118] Ontario Ministry of Agriculture and Food, "Soils, Capability and Land Use in the Ottawa Urban Fringe - Report No. 47 of Ontario Soils Survey," 1979. [Online]. Available: http://sis.agr.gc.ca/cansis/publications/surveys/on/on47/on47_report.pdf. [Accessed December 2016].

[119] D. F. Hewitt, "Geological Notes for Map 2117: Paleozoic Geology of Southern Ontario," Ontario Department of Mines, 1966. [Online]. Available: http://www.geologyontario.mndmf.gov.on.ca/mndmfiles/pub/data/imaging/S015/S015.pdf. [Accessed December 2016].

[120] City of Ottawa, "City of Ottawa Surfical Geology (map)," [Online]. Available: http://ottawa.ca/cs/groups/content/@webottawa/documents/pdf/mdaw/mte4/ edisp/cap118601.p df. [Accessed December 2016].

[121] Ontario Groundwater, "Ontario Groundwater," [Online]. Available: http://ontariogroundwater.com/10030715. [Accessed August 2016].

[122] Natural Resources Canada, "Plant Hardiness of Canada," [Online]. Available: http://www.planthardiness.gc.ca/index.pl?m=11. [Accessed December 2016].

[123] R. Pitt et al., "Sources of Pollutants in Urban Areas (Part 1) - Older Monitoring Projects," Journal of Water Management Modeling, vol. 223, no. 23, pp. 465-483, February 2005.

[124] D. Reeveley, "Series of Screwups Let Toxins into Dow's Lake," Ottawa Citizen, 24 December 2016. [Online]. Available: https://www.pressreader.com/canada/ottawacitizen/20161224/281522225746208. [Accessed 2017 January]. 
[125] D. Reevely, "Reevely: Parks Canada Shrugged Off Leak Into Canal from Sir John Carling Site - at First," Ottawa Sun, 23 December 2016. [Online]. Available: http://ottawacitizen.com/news/localnews/reevely-parks-canada-shrugged-off-leak-into-canal-from-sir-john-carling-site-at-first. [Accessed January 2017].

[126] D. Reeveley, "Reevely: Toxins Leaked Into Dow's Lake from New Hospital Site, Feds Say," Ottawa Citizen, 21 December 2016. [Online]. Available: http://ottawacitizen.com/news/localnews/reevely-toxins-leaked-into-dows-lake-from-new-hospital-site-feds-say.

[127] J. R. Kox, "Sampling for Pesticide Residue Analysis," in Ecological Monitoring Methods: For the Assessment of Pesticide Impact in the Tropics, I. F. Grant and C. C. D. Tingle, Eds., Chatham , Natural Resources Institute, University of Greenwich, 2002, pp. 125-149.

[128] Z.-H. Li et al., "Phenolics and Plant Allelopathy," Molecules, vol. 15, pp. 8933-8952, 2010.

[129] E. D. Ongley, "Chapter 4: Pesticides as Water Pollutants (Control of Water Pollution from Agriculture - FAO Irrigation and Drainage Paper 55)," Food and Agriculture Organization of the United Nations (FAOUN), 1996. [Online]. Available: http://www.fao.org/docrep/w2598e/w2598e07.htm. [Accessed January 2017].

[130] New Jersey Departement of Health, "Hazardous Substance Fact Sheet - 2,4,6-Trinitrophenol," August 2002. [Online]. Available: http://nj.gov/health/eoh/rtkweb/documents/fs/1946.pdf. [Accessed January 2017].

[131] City of Ottawa, "CAD Topographic Mapping Data," [Online]. Available: http://data.ottawa.ca/dataset/cad-topographic-data. [Accessed March 2016].

[132] A. Bradford, "Deforestation: Facts, Causes \& Effects," LiveScience, 4 March 2015. [Online]. Available: http://www.livescience.com/27692-deforestation.html. [Accessed December 2016].

[133] Intergovernmental Panel on Climate Change (IPCC) , "Land Use, Land Change and Forestry: Special Report of the Intergovernmental Panel on Climate Change," IPCC, Montreal, 2000.

[134] J. Bartens et al., "Can Urban Tree Roots Improve Infiltration through Compacted Subsoils for Stormwater Management," Journal of Environmental Quality, vol. 37, pp. 2048-2057, 2008.

[135] World Wildlife Fund (WWF), "Living Planet Report 2016: Risk and Resilience in a New Era," 2016. [Online]. Available: http://awsassets.panda.org/downloads/lpr_living_planet_report_2016.pdf. [Accessed November 2016].

[136] R. J. Morris, "Anthropogenic Impacts on Tropical Forest Biodiversity: a Network Structure and Ecosystem Functioning Perspective," Philosophical Transactions of the Royal Society, vol. 365, pp. 3709-3718, 2010.

[137] D. J. Nowak et al., "Tree and Forest Effects on Air Quality and Human Health in the United States," Environmental Pollution, vol. 193, pp. 119-129, 2014.

[138] United States Environmental Protection Agency (EPA), "EnviroAtlas - Portland, OR - Near Road Tree Buffer," 31 December 2016. [Online]. Available: https://developer.epa.gov/forums/topic/enviroatlas-portland-or-near-road-tree-buffer/. [Accessed January 2017].

[139] J. H. J. Cushman, "Planting Trees and Not Crops to Fight Water Pollution," New York Times , 21 October 1997. [Online]. Available: http://www.nytimes.com/1997/10/21/us/planting-trees-andnot-crops-to-fight-water-pollution.html. [Accessed December 2016].

[140] C. Catanese, "Plant a Tree, Save a River!," United States Environmental Protection Agency (EPA), 13 January 2011. [Online]. Available: https://blog.epa.gov/blog/2011/01/plant-a-tree-save-a-river/. [Accessed December 2016]. 
[141] A. Keller-Herzog, "Native Trees," [Online]. Available: https://treeottawa.org/promote/nativetrees/. [Accessed December 2016].

[142] C. Hanrahan, "Trees and shrubs of the FWG," Fletcher Wildlife Gardens, 6 April 2013. [Online]. Available: http://www.ofnc.ca/fletcher/flora-fauna/trees-shrubs/index_e.php. [Accessed December 2016].

[143] Government of Ontario, "The Tree Atlas: Southeast region 6E-12," Queen's Printer for Ontario, 2012-2017. [Online]. Available: https://www.ontario.ca/environment-and-energy/tree-atlas. [Accessed December 2016].

[144] The Center for Agroforestry, University of Missouri, "Chapter 3: Alley Cropping in Training Manual for Applied Agroforestry Practices - 2015 Edition," 2015. [Online]. Available: http://www.centerforagroforestry.org/pubs/training/chap3_2015.pdf. [Accessed December 2016].

[145] B. T. Kang and R. Gutteridge, "5.2 Forage Tree Legumes in Alley Cropping Systems in Forage Tree Legumes in Tropical Agriculture," Tropical Grassland Society of Australia Inc., 1998. [Online]. Available: http://www.fao.org/ag/agp/agpc/doc/publicat/gutt-shel/x5556e0q.htm\#introduction. [Accessed December 2016].

[146] R. Mizanur et al., "Agricultural Use of Fishpond Sediment for Environmental Amelioration," Thammasat International Journal of Science and Technology, vol. 9, no. 4, 2004.

[147] D. Jurries, "Biofilters (Bioswales, Vegetative Buffers, \& Constructed Wetlands) for Storm Water Discharge Pollution Removal," State of Oregon Department of Environmental Quality, Portland, 2003.

[148] M. L. Robinson and A. O'Callaghan, "Constructed Wetlands a Natural Water Filtering for Conservation," University of Nevada Cooperative Extension .

[149] M. Miller, "Building Wetlands for Clean Drinking Water," Cool Green Science, 30 January 2013. [Online]. Available: http://blog.nature.org/science/2013/01/30/feature-building-wetlands-forclean-water/. [Accessed December 2016].

[150] United States Environmental Protection Agency (EPA), "Wastewater Technology Fact Sheet - The Living Machine (R)," Washington, D.C., 2002.

[151] Living Machine, "Reuse Explained," Living Machine, 2012. [Online]. Available: http://www.livingmachines.com/About-Living-Machine/Water-Reuse/Reuse-Explained.aspx. [Accessed January 2017].

[152] A. N. Angelakis et al., "The Status of Wastewater Reuse Practice in the Mediterranean Basin: Need for Guidlines," Water Research, vol. 33, no. 10, pp. 2201-2217, 1999.

[153] S. Lyu et al., "Wastewater reclamation and reuse in China: Opportunities and Challenges," Journal of Environmental Sciences, vol. 39, pp. 86-96, 2016.

[154] Y. Zhang, "Design of a Constructed Wetland for Wastewater Treatment and Reuse in Mount Pleasant, Utah," Utah State University, Logan, Utah, 2012.

[155] CBC News, "St. Lawrence Not Only Canadian Waterway sullied by Raw Sewage: Cities from Coast to Coast Continue to Dump Untreated Wastewater into Oceans, Lakes, Rivers," 15 October 2015. [Online]. Available: http://www.cbc.ca/news/canada/montreal/raw-sewage-common-problemexamples-1.3258594. [Accessed December 2016].

[156] Maclean's, "Canada Dumping Raw Sewage into Its Waterways," Maclean's, 17 October 2005. [Online]. Available: http://www.thecanadianencyclopedia.ca/en/article/canada-dumping-rawsewage-into-its-waterways/. [Accessed December 2016]. 
[157] "Many Cities Still Dump Raw Sewage: Halifax is Dumping Raw Waste Again, After a New Plant Failed," Maclean's, 30 April 2009. [Online]. Available:

http://www.macleans.ca/news/canada/many-cities-still-dump-raw-sewage/. [Accessed December 2016].

[158] A. Kelly, "Montreal isn't the only city dumping raw sewage - Toronto does it, too," CityNews, 12 November 2015. [Online]. Available: http://www.citynews.ca/2015/11/12/montreal-isnt-the-onlycity-dumping-raw-sewage-toronto-does-it-too/. [Accessed 2016 November].

[159] E. Thomson, "Billions of Litres of Raw Sewage, Untreated Waste Water Pouring into Canadian Waterways," CBC News, 12 December 2016. [Online]. Available: http://www.cbc.ca/news/politics/sewage-pollution-wastewater-cities-1.3889072. [Accessed Deccember 2016].

[160] United States Environmental Protection Agency (EPA), "A Handbook of Constructed Wetlands," USDA-Natural Resources Conservation Service and the US Environmental Protection AgencyRegion III, October 2015. [Online]. Available: https://www.epa.gov/sites/production/files/201510/documents/constructed-wetlands-handbook.pdf. [Accessed December 2016].

[161] Wastewater Gardens, "Constructed Wetlands to Treat Wastewater (Wastewater Gardens Information Sheet - IS20120105)," 05 January 2012. [Online]. Available: http://www.wastewatergardens.com/pdf/WWG_AboutConstructedWetlands.pdf. [Accessed December 2016].

[162] C. Dupraz et al., "Combining Solar Photovoltaic Panels and Food Crops for Optimising Land Use: Towards New Agrivoltaic Schemes," Renewable Energy, vol. 36 , pp. 2725-2732, 2011.

[163] SunPower Corporation, "SunPower E-Series Commercial Solar Panels - E20-327-COM (data sheet)," September 2015. [Online]. Available: https://us.sunpower.com/sites/sunpower/files/medialibrary/data-sheets/ds-e20-series-327-commercial-solar-panels.pdf. [Accessed November 2016].

[164] P. Burgess, "Variation in Light Intensity at Different Latitudes and Seasons, Effects of Cloud Cover, and the Amounts of Direct and Diffused Light," School of Applied Sciences, Cranfield University, Cranfield, Bedfordshire, 29 September 2009. [Online]. Available: http://www.ccfg.org.uk/conferences/downloads/P_Burgess.pdf. [Accessed September 2016].

[165] Hydro Ottawa, "Electricity Bill Comparisons," [Online]. Available: https://static.hydroottawa.com/documents/publications/factbook/backgrounders/13-billcomparisons.pdf. [Accessed December 2016].

[166] Samsung Electronics, "Samsung Takes On the Solar Challenge," May 2010. [Online]. Available: http://www.samsung.com/us/business/solarmodules/images/data/Catalog(Korea).pdf. [Accessed Deccember 2016].

[167] K. Zaman et al., "Exploring the Link between Poverty-Pollution-Population (3Ps) in Pakistan: Time Series Evidence," Journal of Economics and Sustainable Development, vol. 2, no. 11 \& 12, 2011.

[168] S. Mallick and N. Ghani, "A Review of the Relationship between Poverty, Population Growth, and Environment," The Pakistan Development Review, vol. 44, no. 4 Part II (Winter 2005) , pp. 597614, 2005.

[169] J. M. McPartland, "Cannabis as Repellent and Pesticide," Journal of the International Hemp Association, vol. 4, no. 2, pp. 87-92, 1997. 
[170] Ottawa Tourism, "Ottawa Tourism 2014 Annual Report," June 2015. [Online]. Available: https://www.ottawatourism.ca/wp-content/uploads/2015/06/Annual-Report-2014.pdf. [Accessed December 2016].

[171] Algonquin College and Ottawa Tourism, "Ottawa’s Premier-Ranked Tourist Destination Project Final Report," September 2009. [Online]. Available: http://www.mtc.gov.on.ca/en/publications/PR_OTTAWA_Report.pdf. [Accessed December 2016].

[172] U.S. Department of Energy (DOE), "Efficient Earth-Sheltered Homes," DOE Energy Saver, [Online]. Available: https://energy.gov/energysaver/efficient-earth-sheltered-homes. [Accessed March 2016].

[173] M. Staniec and H. Nowak, "Analysis of Energy Consumption in Earth-Sheltered Building with Southern Elevation Exposed," Technical Transactions, Construction, Civil Engineering, vol. 106, no. 5, pp. 217-224, 2009.

[174] M. Freney et al., "Earthship Monitoring and Thermal Simulation," Architectural Science Review, 2013.

[175] Wikipedia, "Earth sheltering," 2 January 2017 . [Online]. Available: https://en.wikipedia.org/wiki/Earth_sheltering\#Benefits. [Accessed January 2017].

[176] University of Alaska Fairbanks, Cooperative Extension Service, "Earth-Sheltered Houses: An Energy Factsheet (EEM-01359)," Cooperative Extension Service, April 2006. [Online]. Available: http://www.uaf.edu/files/ces/publications-db/catalog/eeh/EEM-01359.pdf. [Accessed January 2017].

[177] P. S. H. Macomber, "Guidelines on Rainwater Catchment Systems for Hawaii," College of Tropical Agriculture and Human Resources, University of Hawai'i at Mānoa, 2010.

[178] C. Hart and D. White, "Best Management Practices for Rainwater Catchment Systems in Alaska," Cold Climate Housing Research Center, Fairbanks, Alaska, 2003.

[179] G. Hammond and C. Jones, Inventory of Carbon and Energy (ICE) Database - Version 2.0, Bath: Sustainable Energy Research Team (SERT), University of Bath, 2011.

[180] K. J. Dick and T. J. Krahn, "Regulatory Challenges for Building with Rammed Earth in Canada," in Submission to the 16th International Non-Conventional Materials Conference (NOCMAT), Winnepeg, Manitoba, 2015.

[181] B. Windstorm and A. Schmidt, "A Report of Contemporary Rammed Earth Construction and Research in North America," Sustainability, vol. 5, pp. 400-416, 2013.

[182] A. J. Swan et al., "Sustainable Earthen and Straw Bale Construction in North American Buildings: Codes and Practice," Journal of Materials in Civil Engineering, vol. 23, no. 6, pp. 866-872.

[183] C. Rust, "Ontario’s First Rammed Earth House," BEC Green, 26 October 2010. [Online]. Available: http://becgreen.ca/2010/10/ontarios-first-rammed-earth-house. [Accessed December 2016].

[184] D. Zangmo and T. Tsubaki, "Seismic Retrofitting of Rammed Earth Walls witrh Prestressing," Yokohama National University, 2008.

[185] W. e. al., "Post-Tensioned Rammed Earth Construction". U.S. Patent 7,033,116 B1, 25 April 2006.

[186] SIREWALL, "SIREWALL System," SIREWALL, 2016. [Online]. Available: http://sirewall.com/sirewall-system/. [Accessed 2016 August ].

[187] A. A. Stec and T. R. Hull, "Assessment of the Fire Toxicity of Building Insulation Materials," Energy and Buildings, vol. 43, no. 2-3, pp. 498-506, 2011. 
[188] Z. Mikoczy et al., "Cancer Incidence and Mortality of Isocyanate Exposed Workers from the Swedish Polyurethane Foam Industry: Updated Findings 1959-98," Occupational and Environmental Medicine, vol. 61, pp. 432-437, 2004.

[189] The National Institute for Occupational Safety and Health (NIOSH), "https://www.cdc.gov/niosh/topics/isocyanates/," Centers for Disease Control and Prevention, 23 April 2014. [Online]. Available: https://www.cdc.gov/niosh/topics/isocyanates/. [Accessed January 2017].

[190] Roxul, "Roxul Conrock and Conrock 60: The Benefits of Better Engineering," [Online]. Available: http://www.roxul.com/files/RX-NA_EN/pdf/Brochures and Sell Sheets/Core Solutions/CONROCK_BROCHURE-EN.pdf. [Accessed December 2016].

[191] P. Marais et al., "The Use of Polymer Stabilised Earth Foundations for Rammed Earth Construction," Energy Procedia, vol. 83, pp. 464-473, 2015.

[192] Euro Inox, "Technical Guide to Stainless Steel Roofing (2nd Edition)," Euro-Inox, Brussels, 2004.

[193] G. P. Hammond and C. I. Jones, "Embodied Energy and Carbon in Construction Materials," Proceedings of the Institution of Civil Engineers - Energy, vol. 161, no. 2, pp. 87-98, 2008.

[194] A. Alcorn, "Embodied Energy and CO2 Coefficeients for NZ Building Materials," Centre for Building Performance Research, Wellilngton, NZ, 2003.

[195] M. Lawson, "Material Life: Embodied Energy of Building Materials," Canon Design, 2013.

[196] P. Nabokov and R. Easton, Native American Architecture, New York: Oxford University Press, 1989.

[197] S. Laframboise and K. Sherbina, "The Medicine Wheel," Dancing to Eagle Spirit Society, 2008. [Online]. Available: http://www.dancingtoeaglespiritsociety.org/medwheel.php. [Accessed December 2016].

[198] "Medicine Wheel," Anishnaabeg Bimaadiziwin: An Objibwe Peoples Resource, [Online]. Available: http://ojibweresources.weebly.com/medicine-wheel.html. [Accessed December 2016].

[199] D. Warne, "The Medecine Wheel: Beyond the Tradition (film)," [Online]. Available: https://youtu.be/tgO7kop1ZME. [Accessed January 2017].

[200] V. R. M. Lo Verso et al., "Daylighting as the Driving Force of the Design Process: from the Results of a Survey to the Implementation into an Advanced Daylighting Project," Journal of Daylighting, vol. 1, p. 36-55, 2014.

[201] N. E. Rosenthal, "Antidepressant Effects of Lightin Seasonal Affective Disorder," American Journal of Psychiatry, vol. 142, pp. 163-170, 1985.

[202] S. Rockcastle and M. Anderson, "Human Perceptions of Daylight Composition in Architecture: A Preliminary Study to Compare Quantitative Contrast Measures with Subjective User Assessments in HDR Renderings," Ecole Polytechnique Fédérale de Lausanne (EPFL), 2015.

[203] Pilkington - NSG Group, "Noise Control with Glass - Technical Bulletin," Autumn 2008. [Online]. Available: http://assetmanager-ws.pilkington.com/fileserver.aspx? $\mathrm{cmd}=$ get_file\&ref $=8221 \& \mathrm{~cd}=\mathrm{cd}$. [Accessed December 2016].

[204] J.-P. Sartre, "Existentialism Is a Humanism," 1956. [Online]. Available: https://www.marxists.org/reference/archive/sartre/works/exist/sartre.htm. [Accessed February 2016].

[205] E. Fromm, "Marx's Philosophy of Man," 1961. [Online]. Available: https://www.marxists.org/archive/fromm/works/1961/man/ch05.htm. [Accessed December 2016]. 
[206] J.-P. Sartre, "Search for a Method (2nd part)," 1960. [Online]. Available: https://www.marxists.org/reference/archive/sartre/works/critic/sartre3.htm. [Accessed December 2016].

[207] Trapese Popular Education Collective, "Do It Yourself: A Handbook for Changing Our World," 2007. [Online]. Available:

http://trapese.clearerchannel.org/chapters/HandbookForChangingOurWorld_chap1.pdf. [Accessed November 2016].

[208] California Indian Education (CALIE), "Inspirational Quotes: Traditional Knowledge and Education," [Online]. Available: http://www.californiaindianeducation.org/inspire/traditional/. [Accessed December 2016].

[209] L. Lawless, Director, Unrepentant: Kevin Annett and Canada's Genocide. [Film]. Canada.2006.

[210] K. Annett, Hidden from History: The Canadian Holocaust, Online: CreateSpace Independent Publishing Platform, 2001.

[211] J. Lockyer and J. R. Veteto, "Environmental Anthropology Engaging Permaculture: Moving Theory and Practice Toward Sustainability," in Environmental Anthropology Engaging Ecotopia: Bioregionalism, Permaculture and Ecovillages, J. Lockyer and J. R. Veteto, Eds., New York, Berghahn, 2013, pp. 95-112.

[212] Ottawa River Heritage Designation Committee, "A Background for Nomination of the Ottawa River Under the Canadian Heritage Rivers System," 2005. [Online]. Available: http://ottawariver.org/pdf/0-ORHDC.pdf. [Accessed December 2016].

[213] NRCAN, "Origin of the Names Canada and its Provinces and Territories," Government of Candaa, 12 October 2016. [Online]. Available: http://www.nrcan.gc.ca/earth-sciences/place-names/originsgeographical-names/9224. [Accessed December 2016].

[214] Dow Chemical Company Inc., "Styrofoam (TM) Highload 40, 60 and 100 Extruded Polystyrene Insulation," [Online]. Available: http://www.dow.com/webapps/lit/litorder.asp?filepath=styrofoam/pdfs/noreg/179-02548.pdf. [Accessed December 2016].

[215] M. Sinka, "Sustainable Thermal Insulation Biocomposites from Locally Available Hemp," in Environment. Technology. Resources: Proceedings of the Ninth International Scientific and Practical Conference. 2013. , Rezekne, 2015.

[216] A. Pfeffer, "Ottawa Hospital to Review Controversial Site for New Civic Campus," CBC News, 10 February 2016. [Online]. Available: http://www.cbc.ca/news/canada/ottawa/ottawa-hospitalexperimental-farm-review-1.3440941. [Accessed November 2016].

[217] United States Geological Survey, "Landsat-Earth Observation Satellites: 2015-3081, ver. 1.1," August 2016. [Online]. Available: https://pubs.usgs.gov/fs/2015/3081/fs20153081.pdf. [Accessed December 2016].

[218] S. Zareie et al., "Using Landsat Thematic Mapper (TM) Sensor to Detect Change in Land Surface Temperature in Relation to Land Use Change in Yazd, Iran," Solid Earth, vol. 7, p. 1551-1564, 2016.

[219] AAFC, "Ottawa Research and Development Centre," February 2016. [Online]. Available: http://www.agr.gc.ca/eng/science-and-innovation/research-centres/ontario/ottawa-research-anddevelopment-centre/?id=1180546650582. [Accessed December 2016].

[220] J. Spiroux et al., "A Comparison of the Effects of Three GM Corn Varieties on Mammalian," International Journal of Biological Sciences, vol. 5, no. 7, pp. 706-726, 2009. 
[221] C. H. Cummings, "Risking Corn, Risking Culture," World Watch Institute Magazine, November/December 2002.

[222] Greenpeace International, "Maize Under Threat: GE Maize Contamination in Mexico," August 2003. [Online]. Available:

http://www.greenpeace.org/international/PageFiles/24249/maizeunderthreat.pdf. [Accessed December 2016].

[223] P. Reddy, "Impacts of Gene Pollution due to Transgenic Organisms," International Journal of Life Sciences Research, vol. 2, no. special issue, pp. 25-29, 2015.

[224] O’Shaughnessy's Online, "O’Shaughnessy's Online," 4 January 2015. [Online]. Available: http://www.beyondthc.com/mcpartlands-corrected-vernacular-nomenclature/. [Accessed December 2016].

[225] J. M. McPartland and G. W. Guy, "A Question of Rank: Using DNA Barcodes to Classify Cannabis Sative and Cannabis Indica," in 24th Annual Symposium of the International Cannabinoid Society, Baveno, Italy, 2014.

[226] Conrad's Castles Construction Inc., "Styles Of Earth Sheltered Homes," 2013. [Online]. Available: http://earthshelteredhome.com/building-styles.htm. [Accessed December 2106].

[227] K. Marx, "Estranged Labour from Economic and Philosophical Manuscripts of 1844," 1844. [Online]. Available: https://www.marxists.org/archive/marx/works/1844/manuscripts/labour.htm. [Accessed December 2016].

[228] Canadian Mortgage and Housing Corporation (CMHC), "Concrete Foundations (NHA 5892)," Government of Canada, Ottawa, 1988.

[229] T. T. Bui et al., "Failure of Rammed Earth Walls: from Observations to Quantifications," Construction and Building Materials, pp. 295-302, 2104.

[230] T. T. Bui et al., "Failure of Rammed Earth Walls: From Observations to Quantifications," Construction and Building Materials, pp. 295-302, 2014.

[231] SIREWALL, "Edmonton Valley Zoo," SIREWALL, [Online]. Available: http://sirewall.com/project/edmonton-valley-zoo/. [Accessed December 2016].

[232] ClimaTemps, "Edmonton, Alberta Climate \& Temperature," ClimaTemps, [Online]. Available: http://www.edmonton.climatemps.com/. [Accessed December 2016].

[233] Roxul, "Stone Wool Delivers Stable R-Values at Extreme Temperatures (Technical Bulletin)," 28 June 2010. [Online]. Available: http://www.roxul.com/files/RX-NA_EN/pdf/tech data/TB- extreme temps.pdf. [Accessed December 2016].

[234] Center for Advanced Life Cycle Engineering (CALCE), "Material Hardness," Center for Advanced Life Cycle Engineering, University of Maryland , 2001. [Online]. Available: http://www.calce.umd.edu/TSFA/Hardness_ad_htm. [Accessed January 2017].

[235] ASM International, "Fatigue," in Elements of Metallurgy and Engineering Alloys (\#05224G), Materials Park, Ohio, American Technical Publishers Ltd., 2008, pp. 243-264.

[236] NDT Resource Center, "Toughness," NDT Resource Center, [Online]. Available: https://www.ndeed.org/EducationResources/CommunityCollege/Materials/Mechanical/Toughness.htm. [Accessed 2016 December ].

[237] Outokumpu, "Corrosion Resistance," Outokumpu, [Online]. Available: http://www.outokumpu.com/en/products-properties/more-stainless/corrosionresistance/pages/default.aspx. [Accessed January 2017]. 
[238] J. Kalkhof, "Permatecture," Permatecture, [Online]. Available: http://permatecture.at/component/content/article/2-permatecture/26. [Accessed January 2017].

[239] S. R. M. Wilson, "Permatecture: Combining Permaculture \& Architecture," Permatecture, [Online]. Available: http://www.designforhumanity.org.au/. [Accessed January 2017].

[240] Norwegian Institute of Permatecture, "The Norwegian Institute of Permatecture," [Online]. Available: http://permatecture.blogspot.ca/. [Accessed January 2017].

[241] Ø. Holmstad, "A New Permatecture Toolbox! (From Nikos A. Salingaros)," Resilience, [Online]. Available: http://www.resilience.org/stories/2011-06-27/new-permatecture-toolbox-nikossalingaros/. [Accessed January 2017].

[242] J.-P. Sartre, Critique of Dialectical Reason, Volume 1 (1960), New York: Verso, 2004. 


\section{APPENDICES}

\section{Appendix A. Solar-Thermal Control Barrier System $\odot$}

The following figures (details and project slides) are, for the most part, explained illustratively. They are taken from the author's prior project work for an advanced buildings systems (ABS) course at the Azrieli School of Architecture, Carleton University, in the Fall of 2015. Everything included in this appendix is original work: an invention based on standard dual-skin façade (DSF) sunshading systems-taken to the next level-with the theoretical potential for producing solid wall thermal performance in glazed assemblies, perhaps even improving performance over most insulated solid walls. It represents a workin-progress that was adapted to this project in 5.1.4.1. Transforming Dual-Skin Façade (page 184).

A brief summary of the STCBS@ project: it began with a dual-skin glazed envelope system with and integration of the author's Solar-Thermal Control Barrier System $\odot$ within the cavity in conjunction with a hybrid passive-active heating/air-conditioning (HVAC) system. The standard sunshade louver system now being used in vented DSF assemblies was redesigned with aerogel/nano-carbon insulated polycarbonate louvers instead of the standard aluminum shutters. These new high-performing louvers were also designed to magnetically seal while in their closed positions to create an air-barrier and therefore maximize their thermal performance. 
SYSTEM DESIGN: DUAL-SKIN STRUCTURAL GLAZING FACADE WITH HYBRID ACTIVE-PASSIVE MECHANICAL INTEGRATION AND AUTOMATIC THERMAL-SOLAR CONTROL BARRIER SYSTEM ${ }^{\circ}$

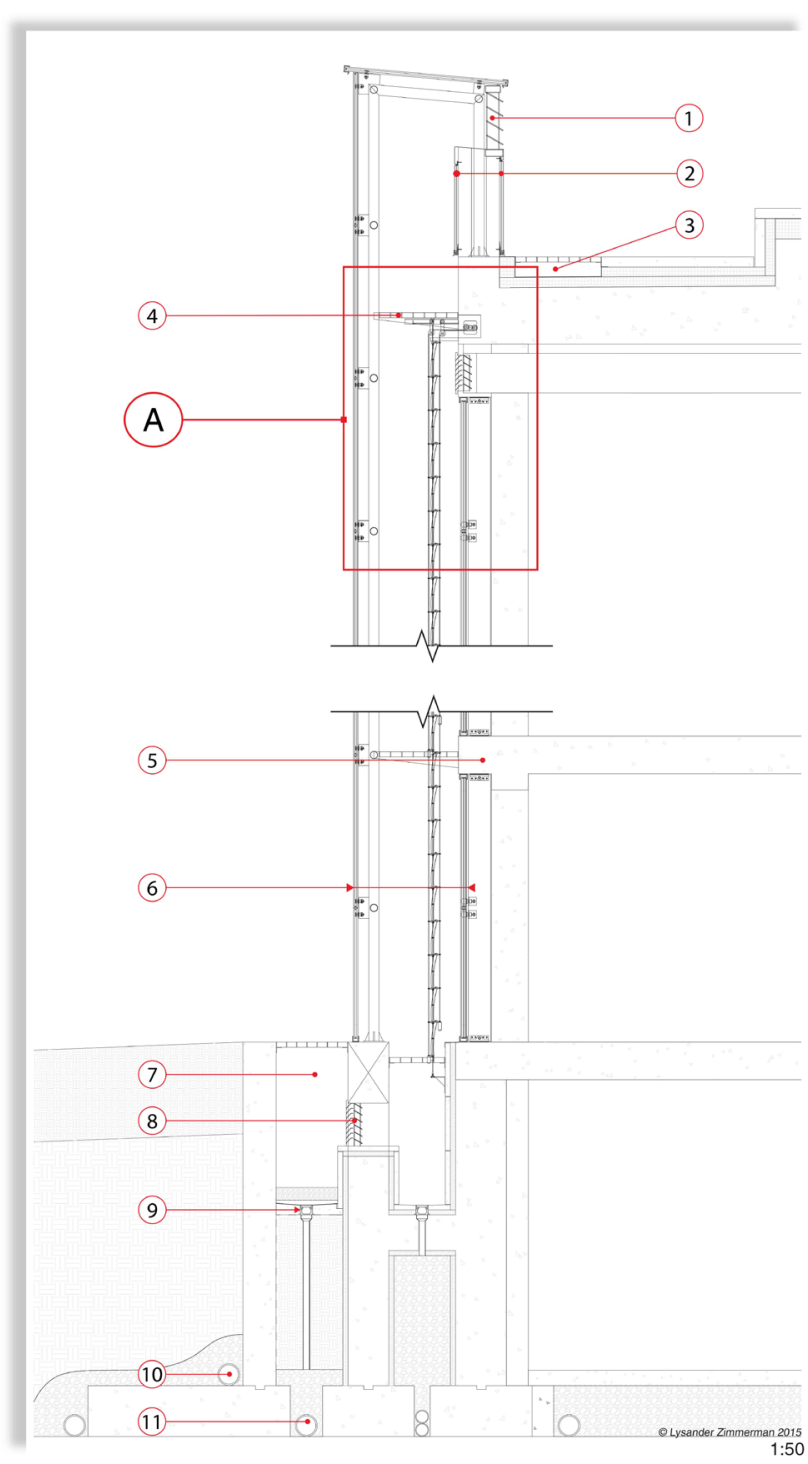

1. Louvered operable automatic exhaust ven

2. DriDesign aluminum facade panels

3. Parapet drainage channel

4. Steel maintenance catwalk with galvanized steel grill

5. Concrete floor structure exposed to air cavity absorbs passive solar heat

6. $1000 \mathrm{~mm}$ dual skin I.G.U. assembly (with hybrid Thermal Sunshade Barrier)

7. Plenum supply trench

8. Louvered operable automatic intake vent

9. NDS Spee-D drainage channels and downspouts (sediment-filtered)

10. Foundation drainage (to irrigation ditch, dry well or geothermal retention

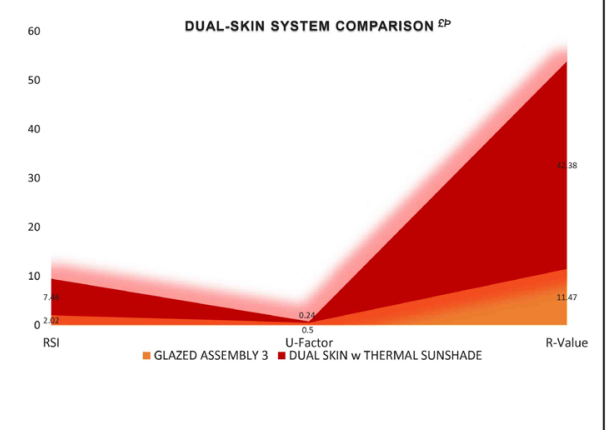

11. Foundation drainage (to rainwater collection system or retention basin)

Figure 41: Solar-Thermal Control Barrier System (STCBS@), preliminary design. 


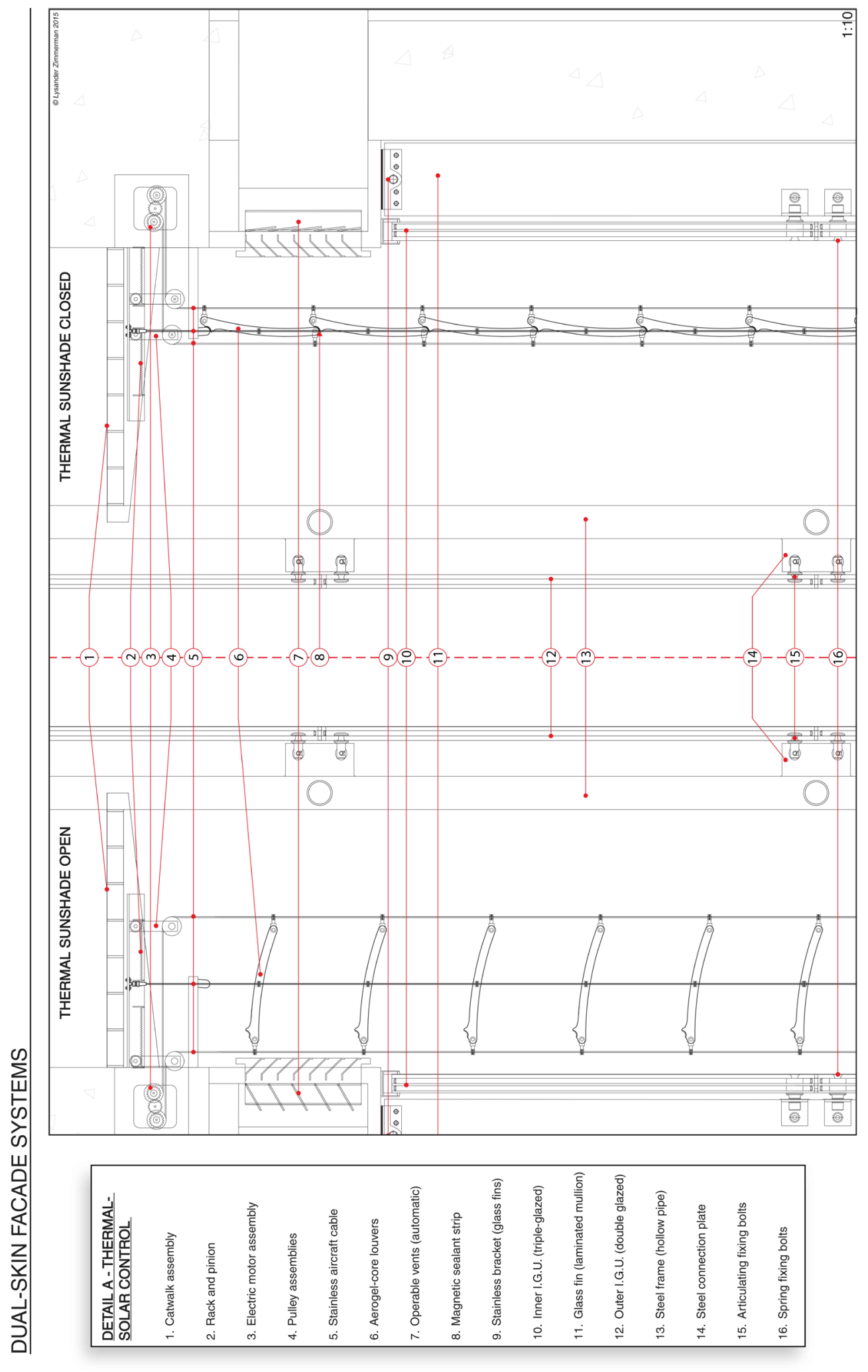

Figure 42: 'DETAIL A' (from Figure 41 ) - STCBS@ in both open and closed positions. 


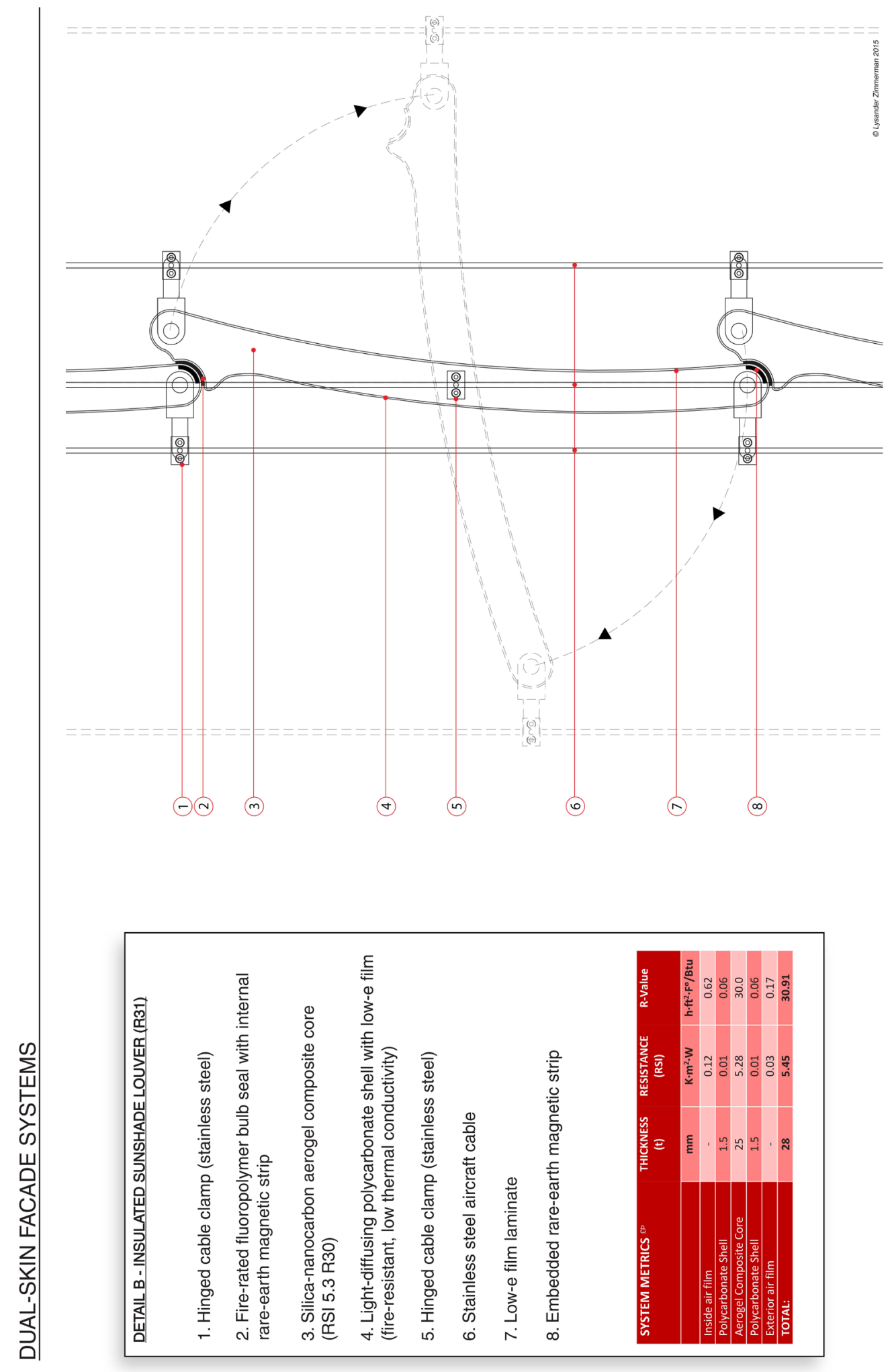

Figure 43: SCTBS@ close up detail of insulated louver. 


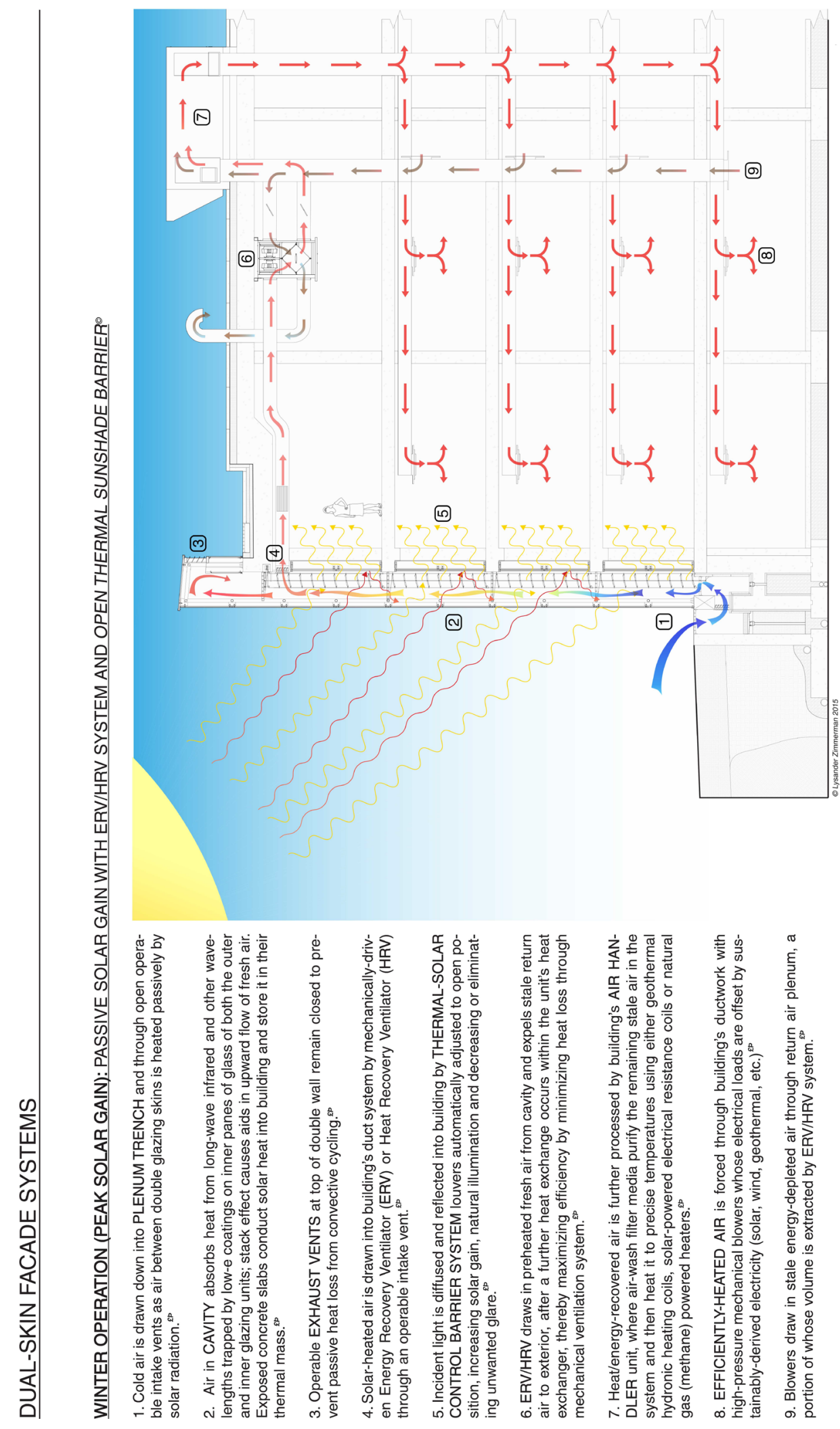

Figure 44: STCBS@ in winter operation with peak solar gain; partial glare control (open louvers). 


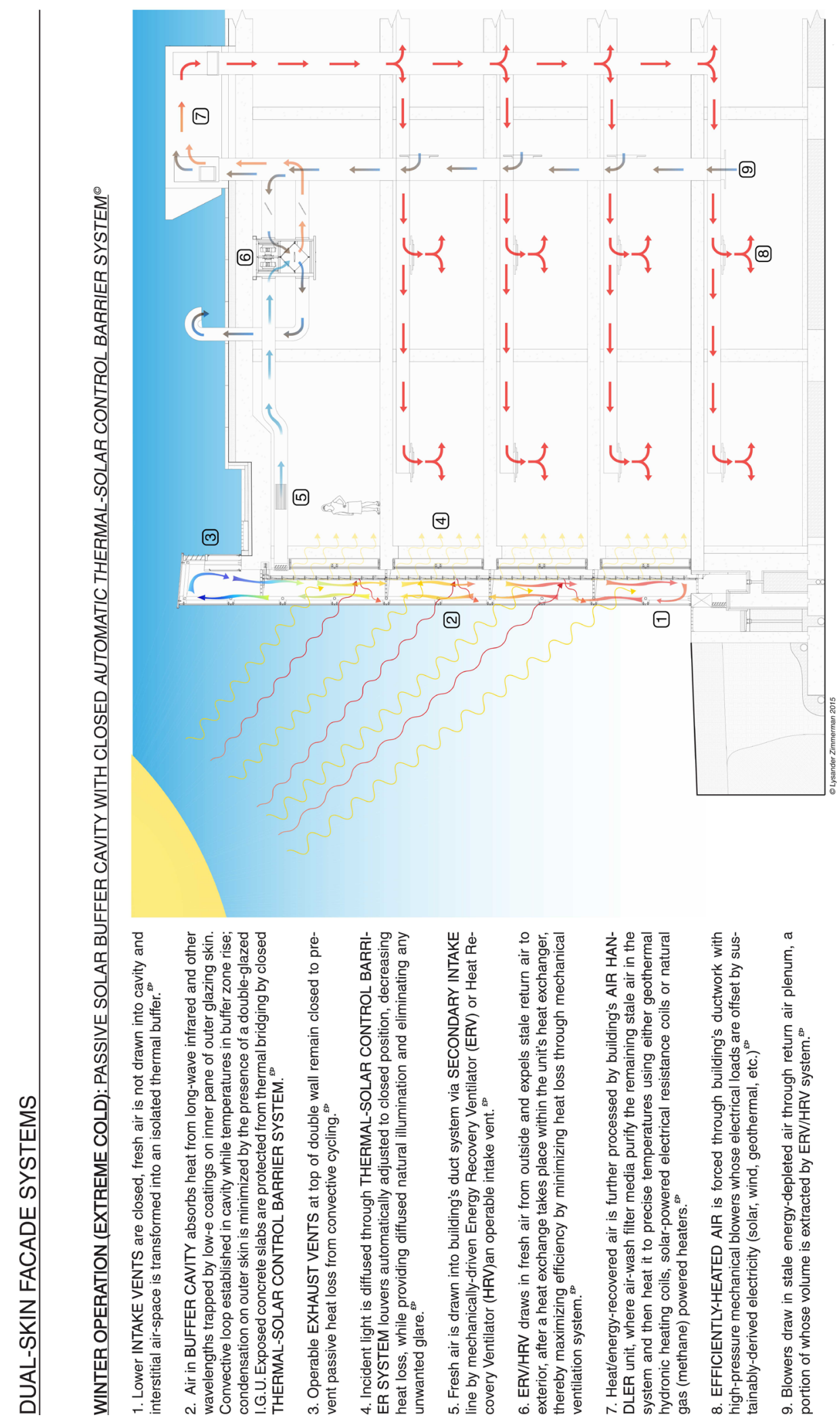

Figure 45: STCBS@ in winter operation for extreme cold outside; total glare control (louvers closed). 


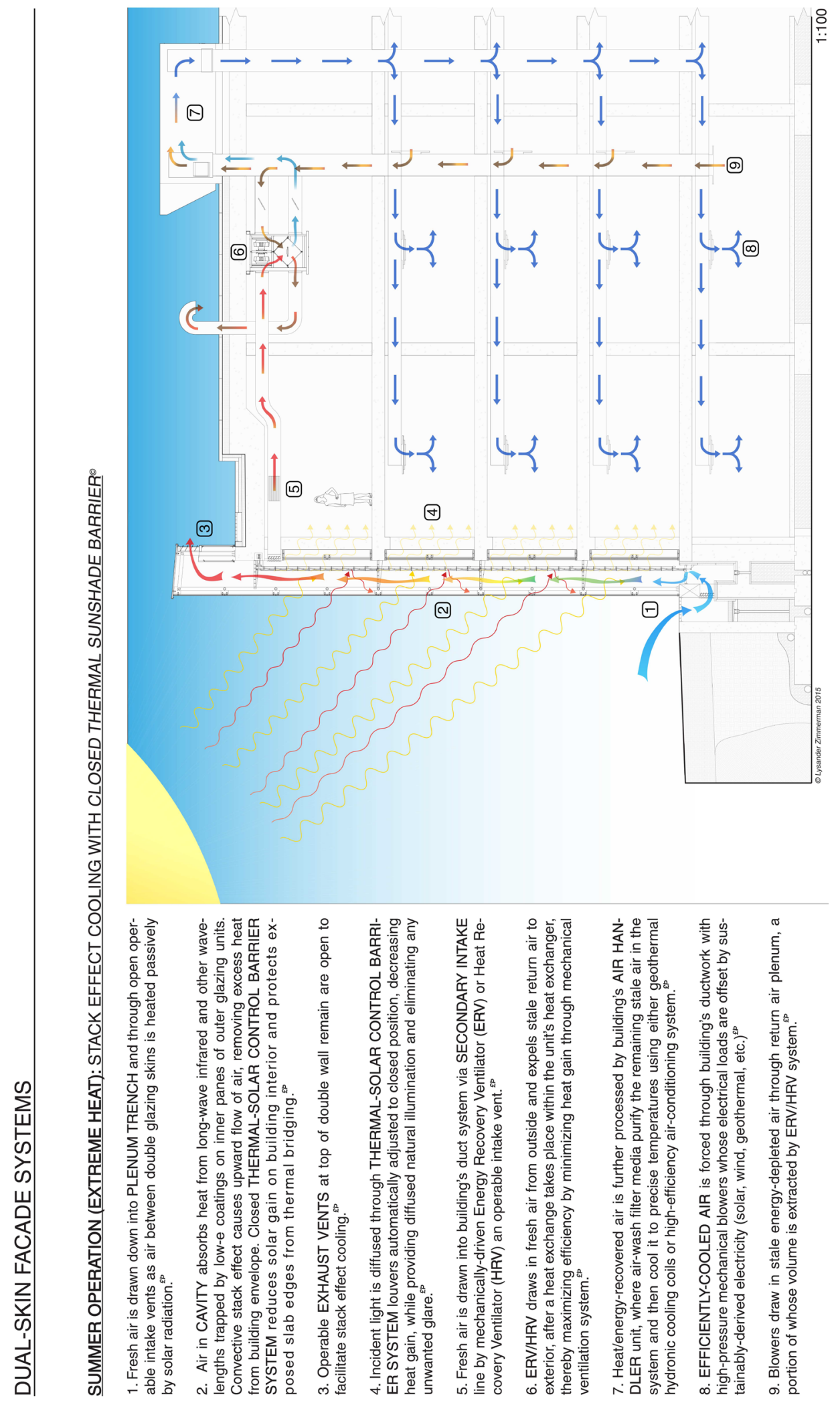

Figure 46: STCBS@ in summer operation, stack effect cooling; total glare control (louvers closed). 


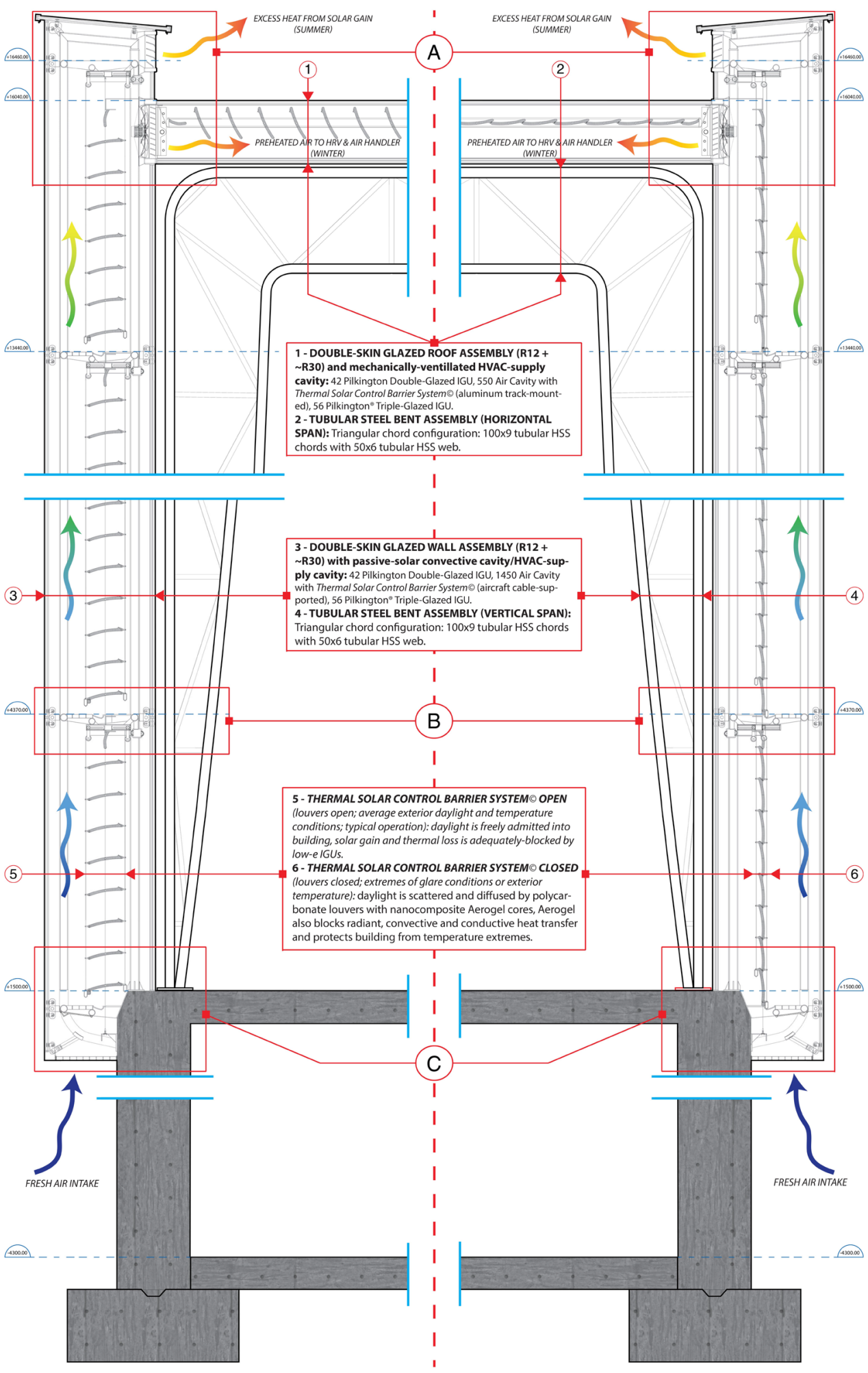

Figure 47: STCBS@ applied to dual-skin glazed facade and dual-skin glazed roof concept. 
(A)

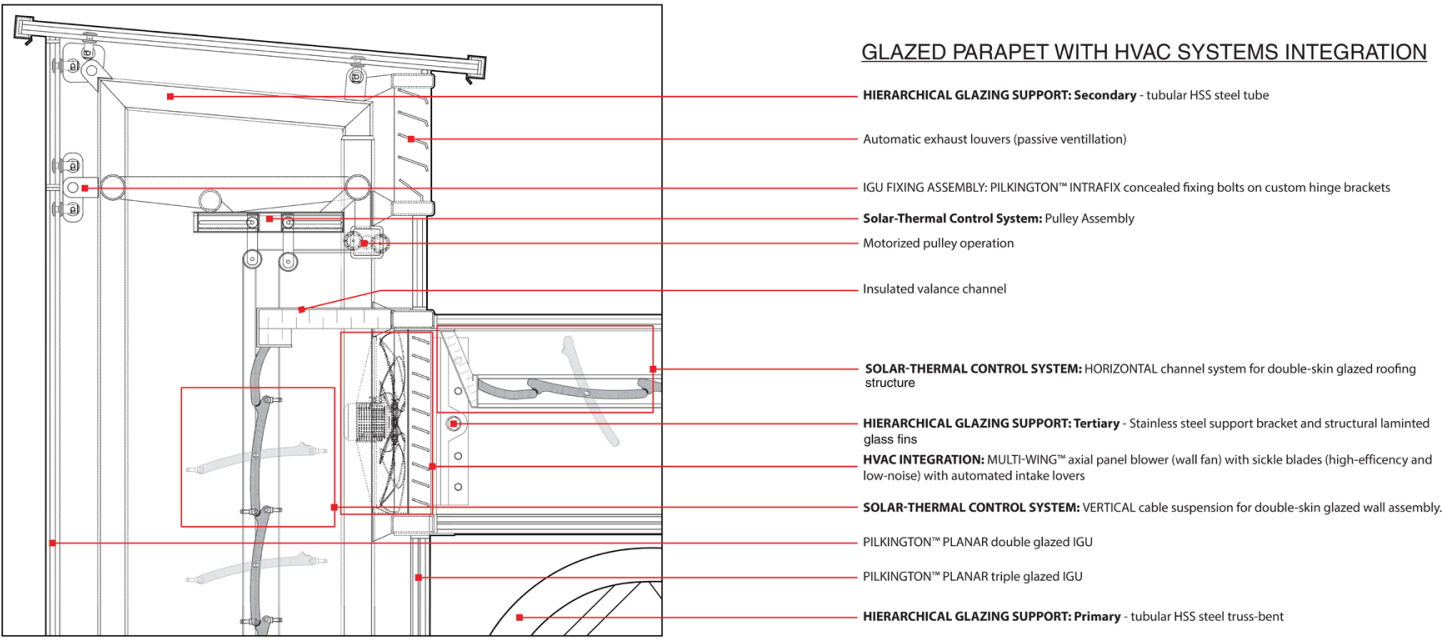

(B)

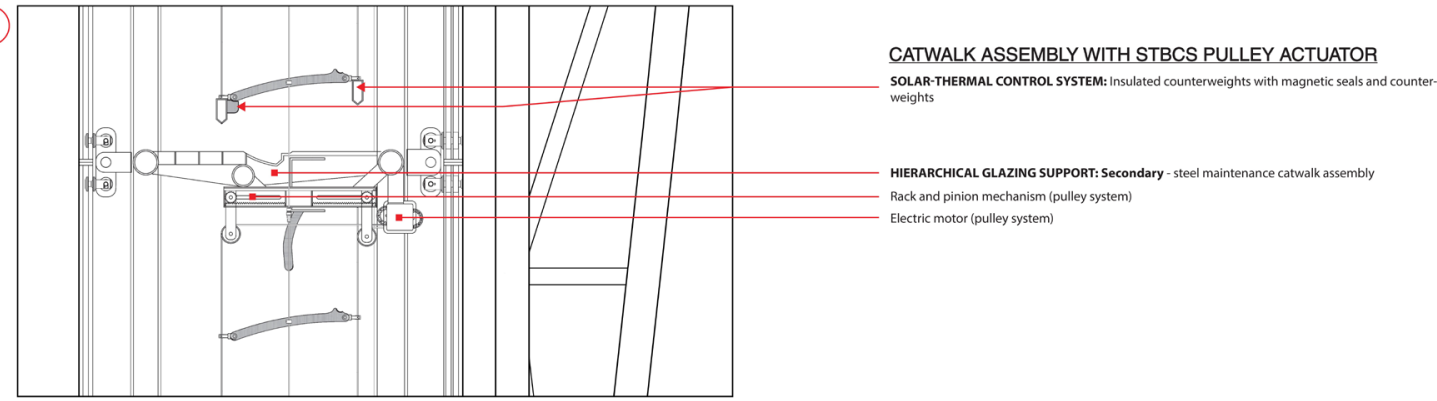

(c)

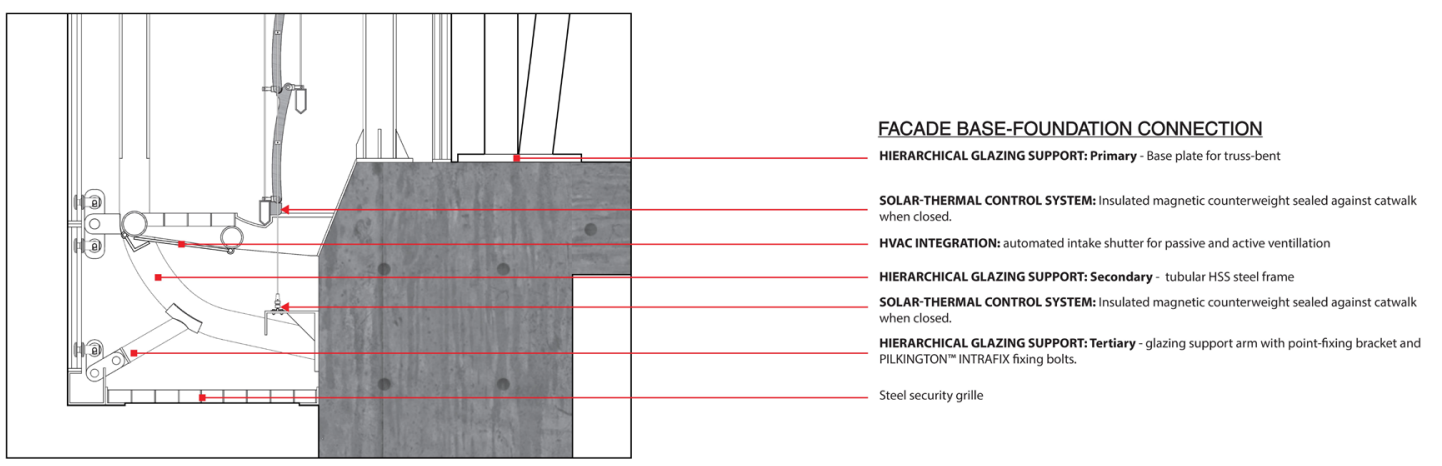

Figure 48: 'DETAILS A, B, \& C' from Figure 47. 


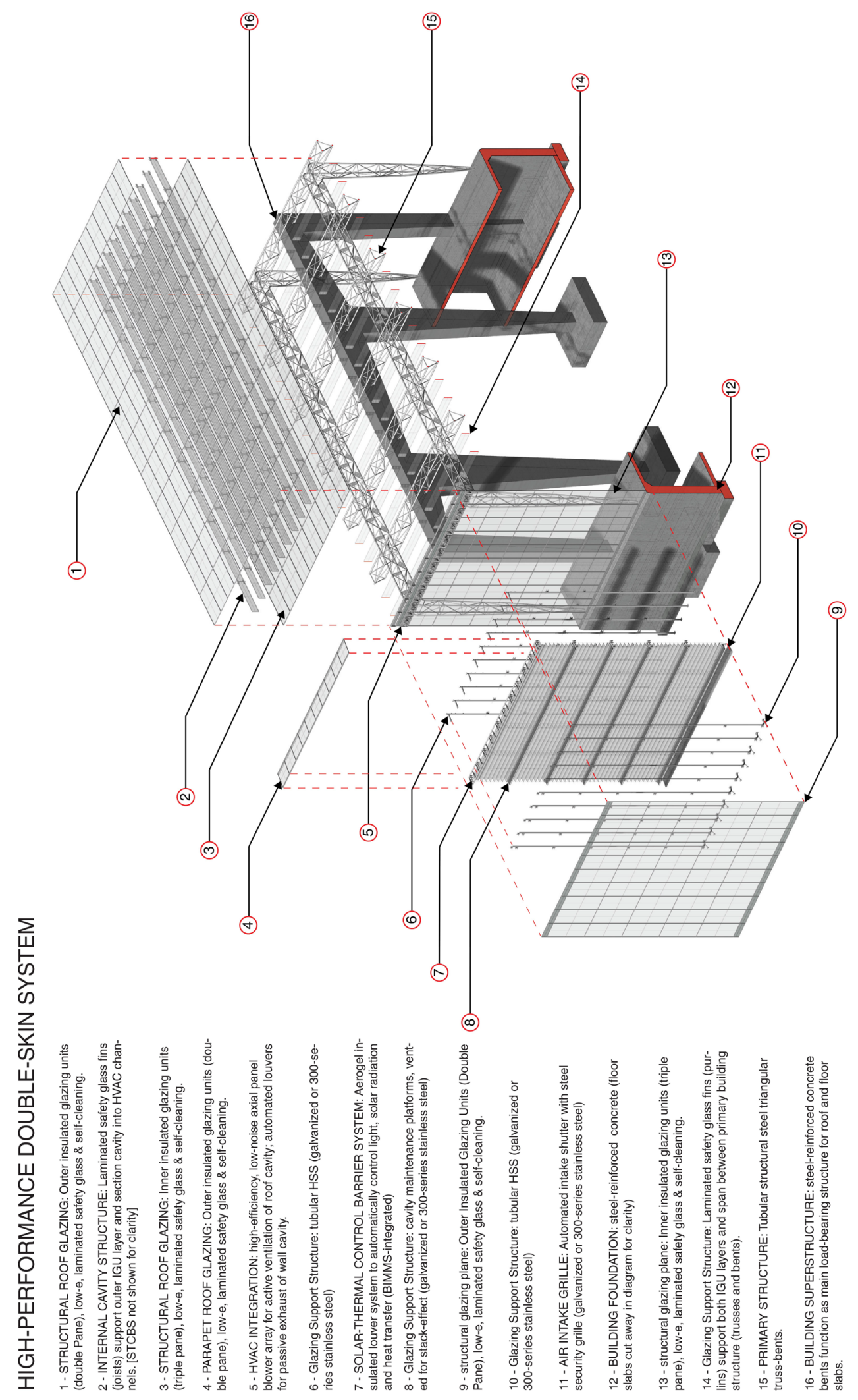

Figure 49: A 'typical' application of STCBS@ in a high-performance dual-skin envelope system. 
STCBS AT A GLANCE

1 - IGU FIXING ASSEMBLIES: Concealed fixing bolts (Pilkington Intrafix) mounted to custom brackets (316 stainless
steel)

2- STCBS PULLEY ASSEMBLY: Electric drive, guide and pulley system for automated louver control and operation

3- STCBS - OPEN POSITION: Aerogel + nanocarbon black .

4- PARAPET ROOF GLAZING: Outer insulated glazing units
(double pane), low-e, laminated satety glass \& self-cleaning.

5 - STCBS - CLOSED POSITION: Aerogel + nanocarbon black composite louvers in closed position to block direct
sunlight, diffuse light evenly into building eliminate glare, sigsunlight, diffuse light evenly into building, eliminate glare
nificantly reduce solar gain and/or retard heat loss.

6 - Glazing Support Structure: tubular HSS (galvanized or 300-series stainless steel)

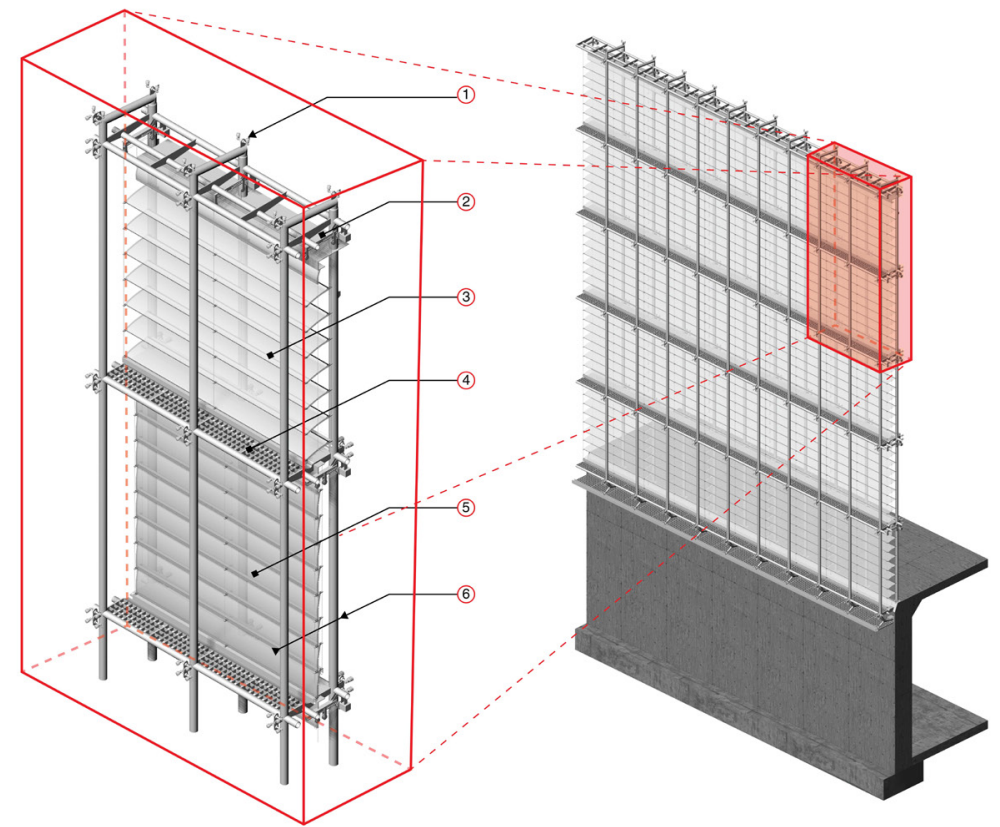

Figure 50: STCBS insulated louver system (cavity components) shown without glazing skins.

STCBS AND DOUBLE-SKIN FACADE - KEY COMPONENTS
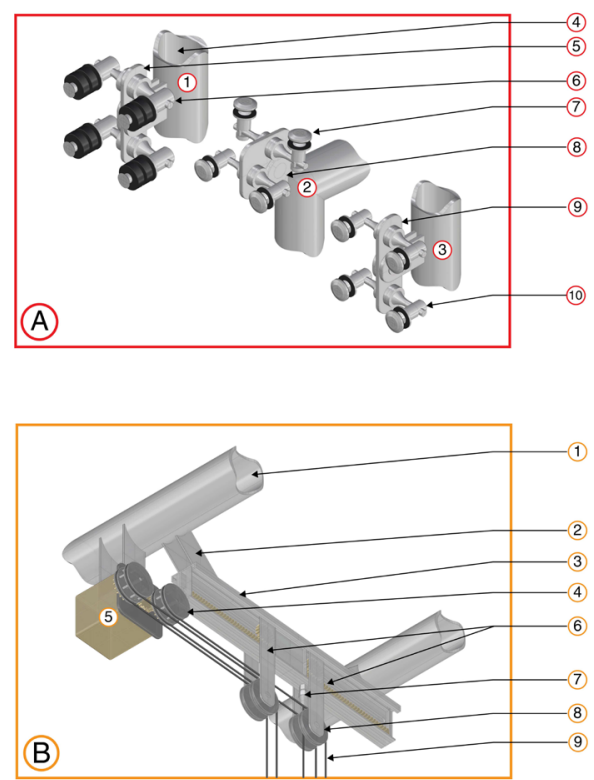

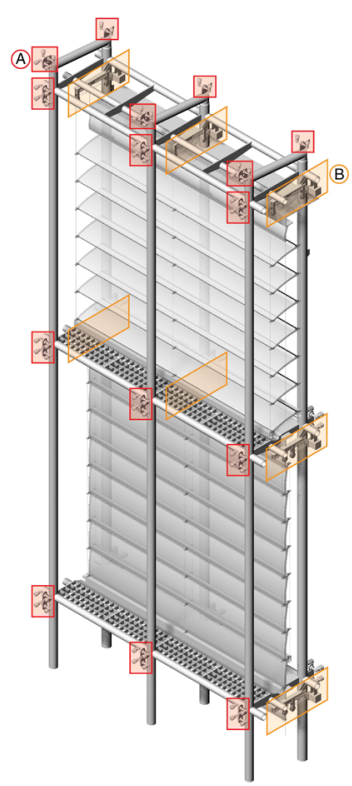

(A) IGU FIXING ASSEMBLIES

1- IGU FIIING ASSEMBLY - TRIPLE PANE (INNER LAYER)

2 - IGU FIXING ASSEMBLY - DOUBLE PANE (OUTER LAYER)

3 - IGU FIXING ASSEMBLY - DOUBLE PANE (PARAPET ROOF)

4 - GLAZING SUPPORT COLUMN (TUBULAR HSS COLUMN)

5 - CUSTOM STAINLESS STEEL FIXING ASSEMBLY BRACKET

6 - ARTICULATING FIXING BOLT - FOR TRIPLE PANE IGU

7 - ARTICULATING FIXING BOLT - FOR DOUBLE PANE IGU

8 - CUSTOM STAINLESS STEEL FIXING ASSEMBLY BRACKET

9 - CUSTOM STAINLESS STEEL FIXING ASSEMBLY BRACKET

10 - ARTICULATING FIXING BOLT - FOR DOUBLE PANE IGU

(B) STCBS PULLEY ASSEMBLY

1 - MAINTENANCE PLATFORM - TUBULAR HSS BEAM

2- ASSEMBLY BRACKET - FASTENED OR WELDED TO BEAM

3- CUSTOM I-BEAM AND PULLEY TRACK

4 - MOTOR ASSEMBLY DRIVE SPINDLES (GEAR-DRIVEN)

5 - ELECTRIC MOTOR ASSEMBLY

6 - GUIDE PULLEY ARM ON RACK AND PINION

7 - TENSION CABLE TURNBUCKLE

8 - GUIDE PULLEY WHEEL

9 - STAINLESS STEEL AIRCRAFT CABLE

Figure 51: STCBS@ mechanical components and 'typical' IGU-fixing system. 


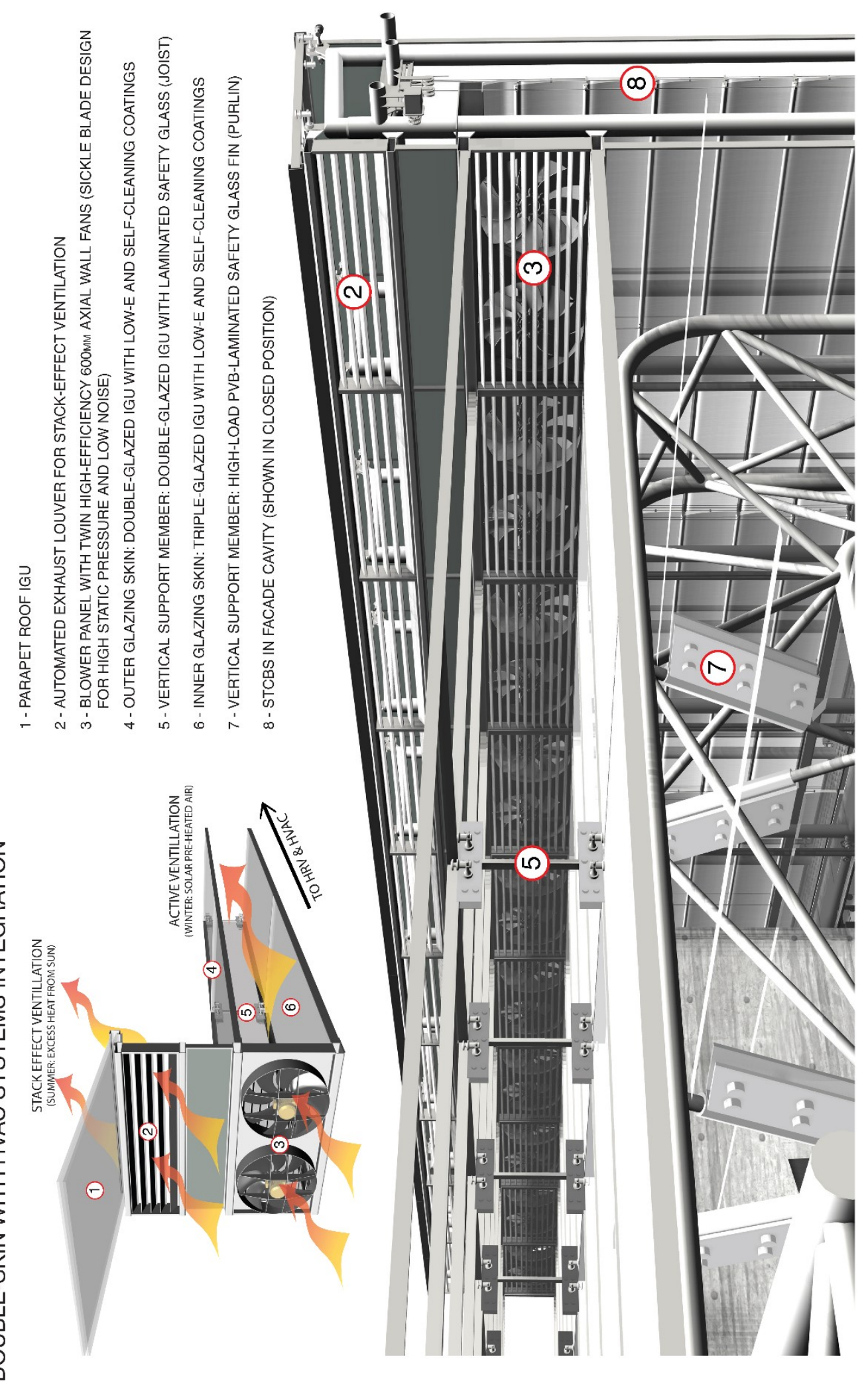

Figure 52: STCBS@ with original dual-skin ventilated roof and wall envelope system. 


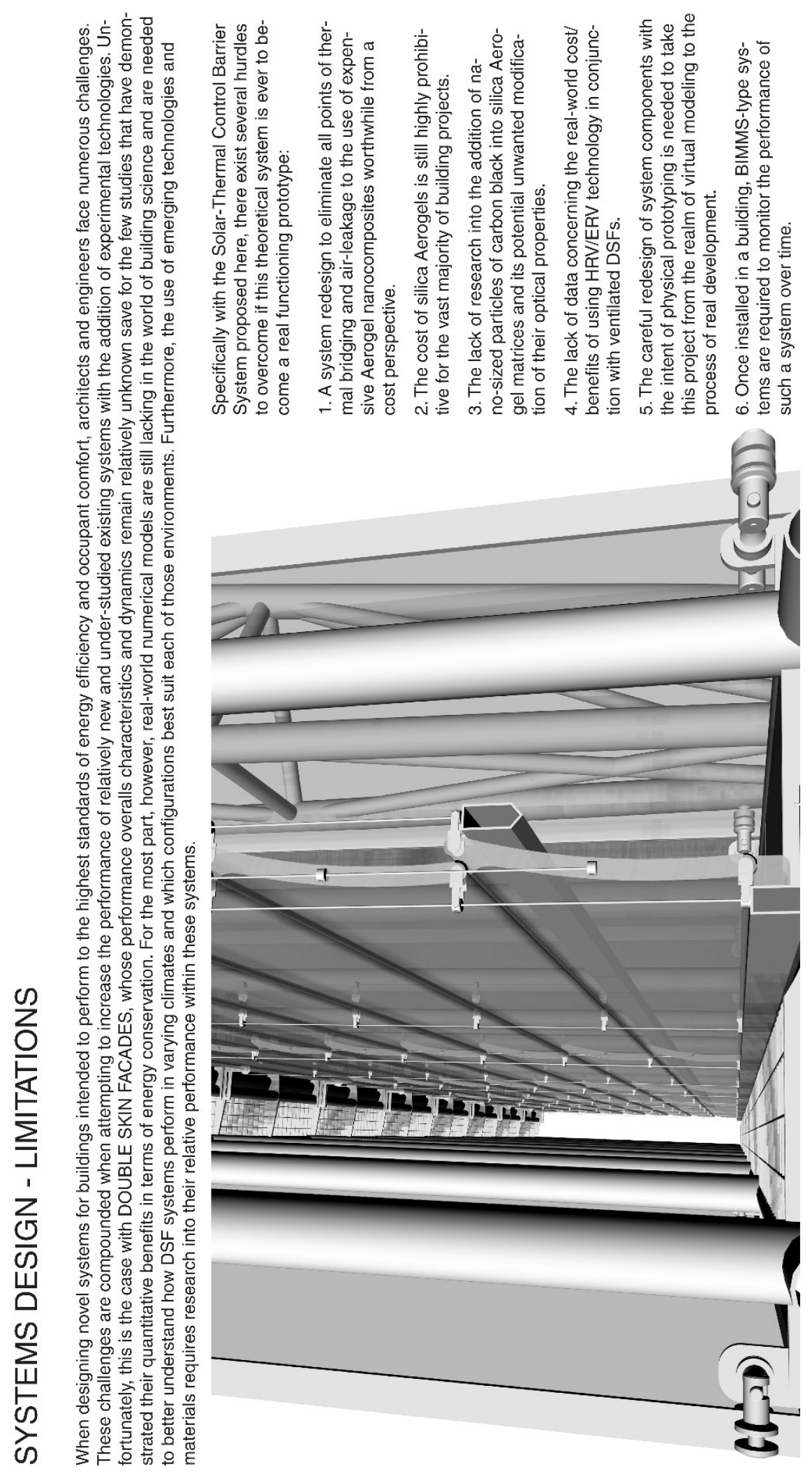

Figure 53: STCBS@ limitations discussion and system perspective. 